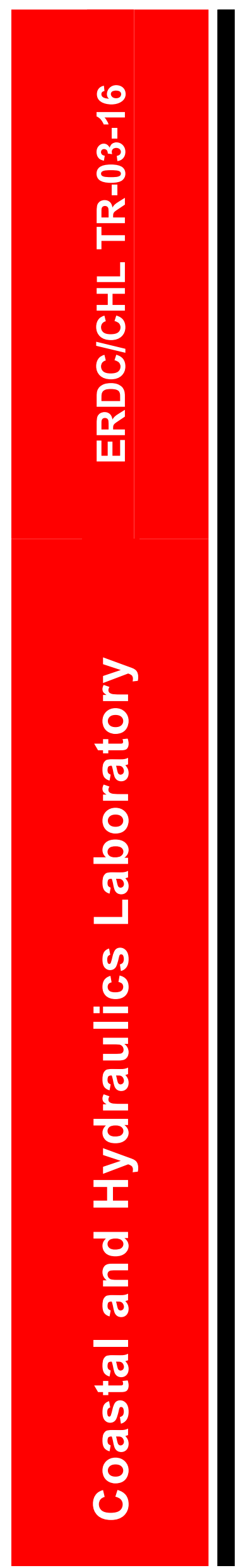

\title{
Assessment of Changes in Channel Morphology and Bed Elevation in Mad River, California, 1971-2000
}

Kevin Knuuti and Dinah McComas

September 2003

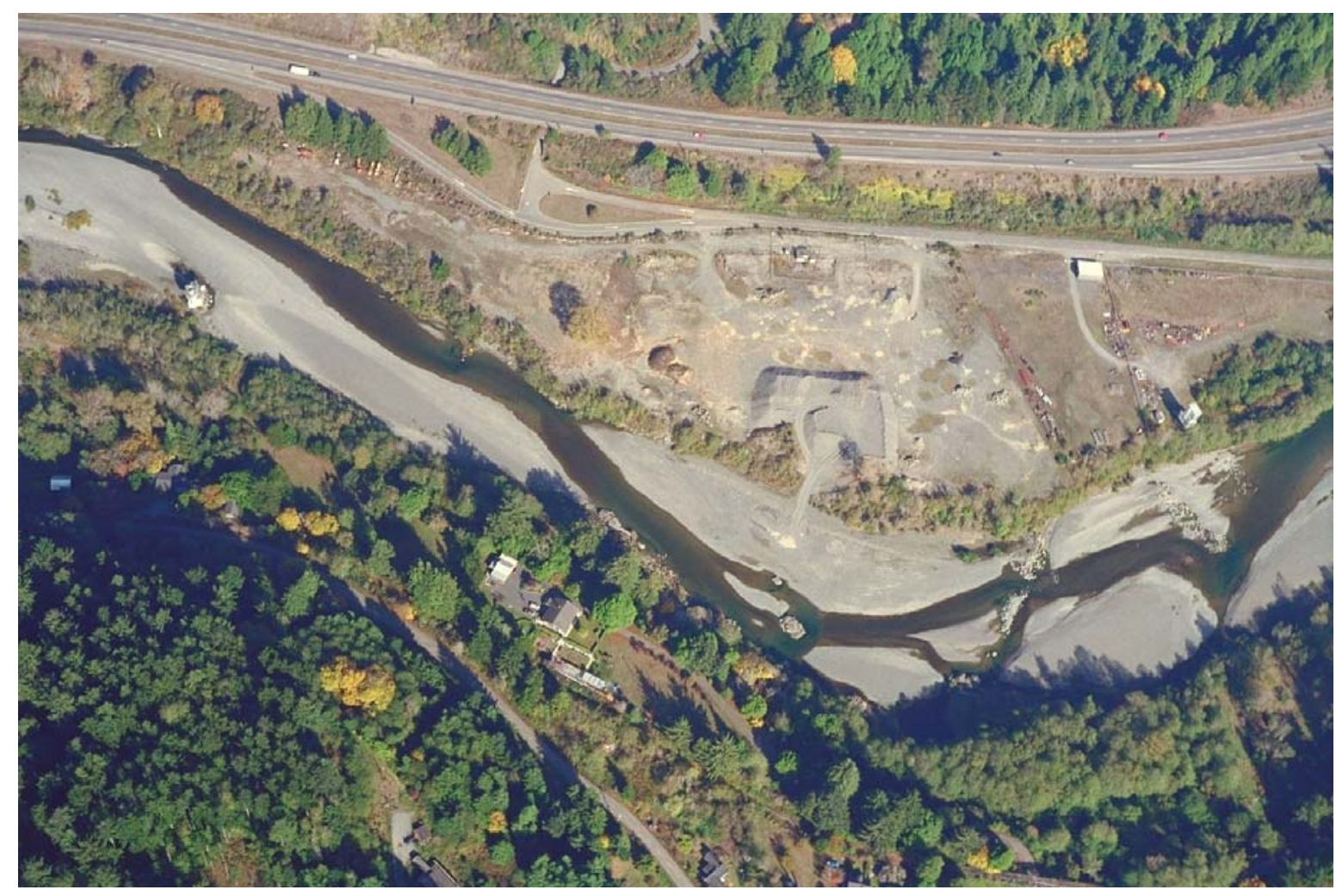




\section{Assessment of Changes in Channel Morphology and Bed Elevation in Mad River, California, 1971-2000}

Kevin Knuuti and Dinah McComas

Coastal and Hydraulics Laboratory

U.S. Army Engineer Research and Development Center

3909 Halls Ferry Road

Vicksburg, MS 39180-6199

Final report

Approved for public release; distribution is unlimited 


\begin{abstract}
The U.S. Army Corps of Engineers currently regulates gravel-mining activities in Humboldt County, CA, under the authority described in Sec. 404 of the Clean Water Act. In order to better understand the effects gravel mining has had on the Mad River, the U.S. Army Engineer District, San Francisco, initiated this study to examine changes in channel morphology and bed elevation between 1971 and 2000.

This study focused on existing cross-section data and historic aerial photography from a variety of sources, and river sediment (bed-load and bed-material) data collected by the USGS. It also used new cross-section data collected in 2000 and gravel extraction records. This information was used to quantify geomorphic changes in the river, to establish a sediment budget, and to determine a sustainable yield for gravel extraction based on maintaining the river in an equilibrium condition.
\end{abstract}

DISCLAIMER: The contents of this report are not to be used for advertising, publication, or promotional purposes. Citation of trade names does not constitute an official endorsement or approval of the use of such commercial products. All product names and trademarks cited are the property of their respective owners. The findings of this report are not to be construed as an official Department of the Army position unless so designated by other authorized documents. 


\section{Contents}

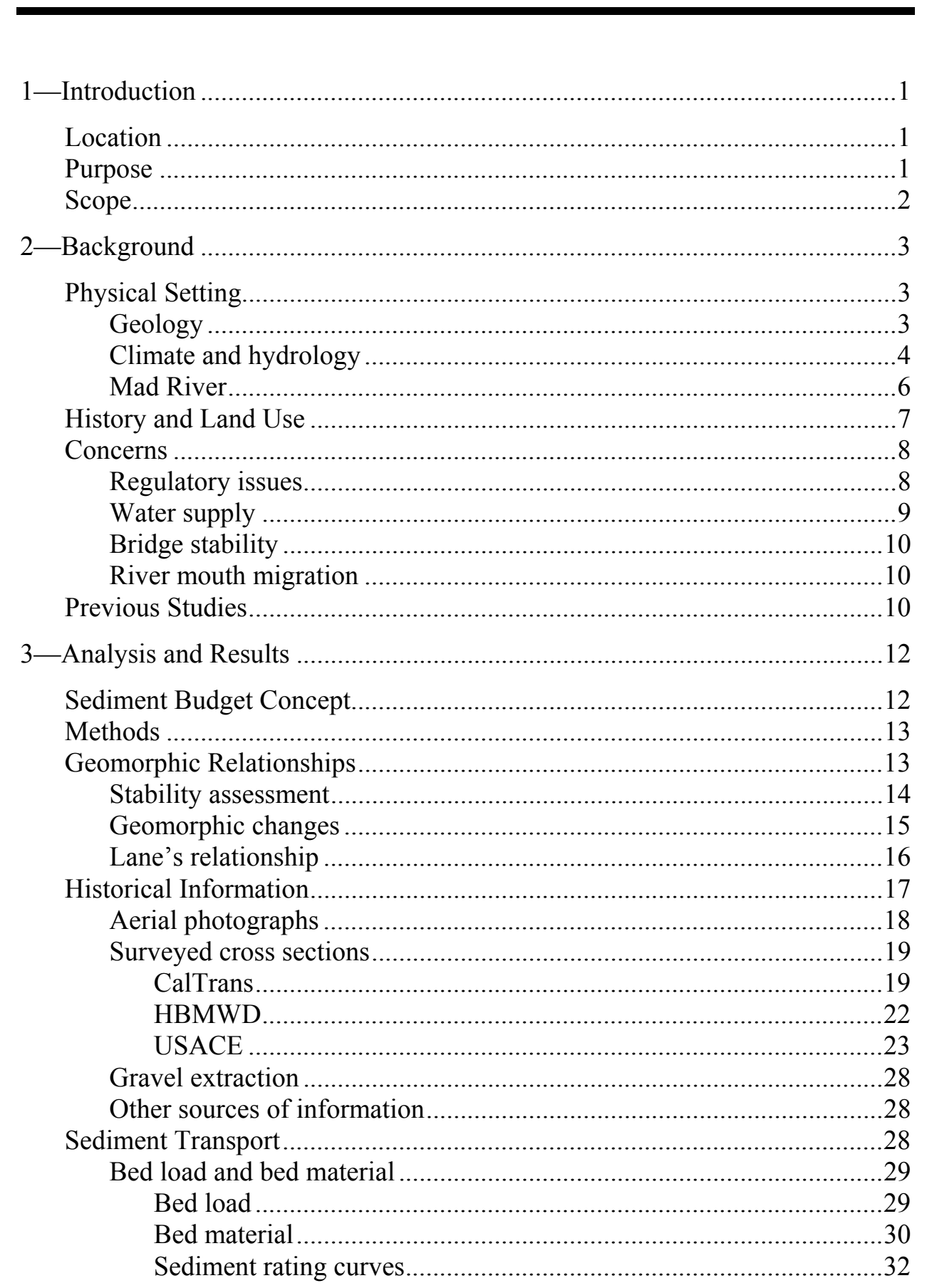




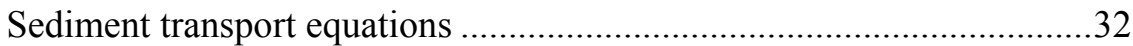

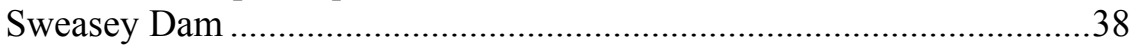

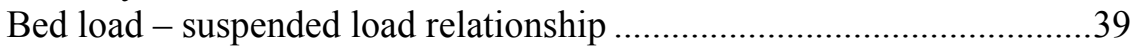

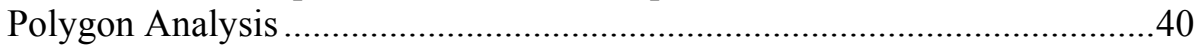

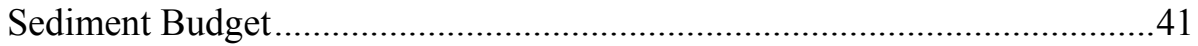

Highway 299 bridge to Blue Lake hatchery .........................................4

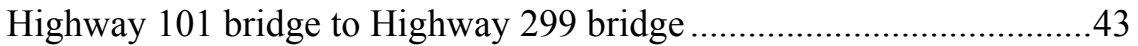

Highway 101 bridge to mouth of river .....................................................45

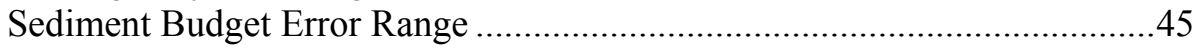

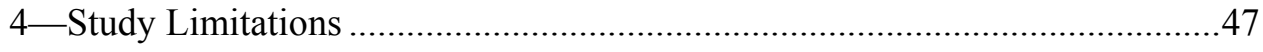

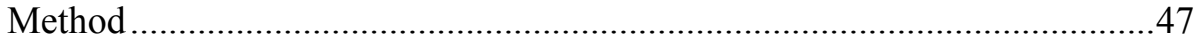

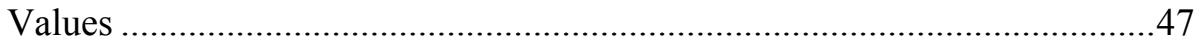

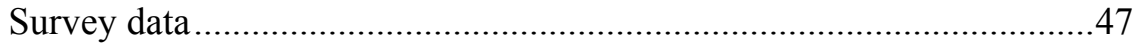

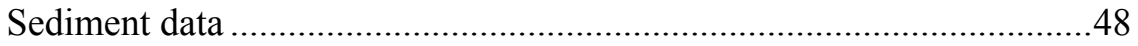

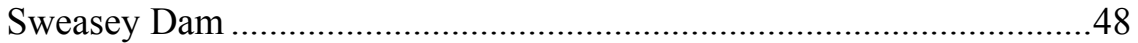

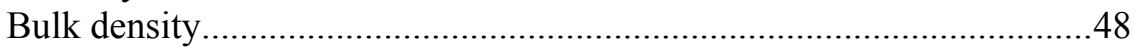

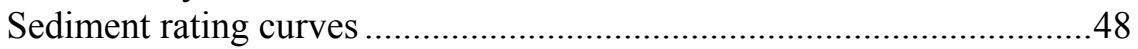

Changes in Gravel Mining Practices.............................................................48

5-Comparison with Previous Studies..............................................................50

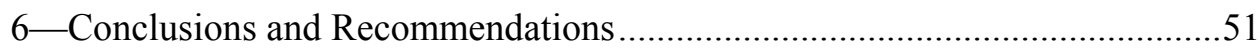

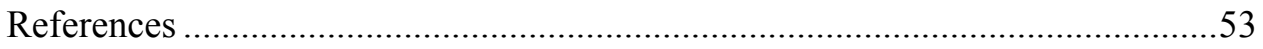

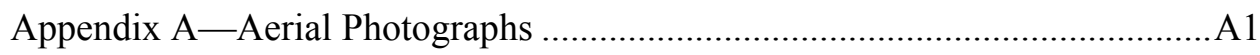

Appendix B_-USACE Surveyed Cross Sections ................................................ B1

Appendix C—Photographs of USACE Cross-Section Locations ........................ 1

Appendix D_Additional Photographs of Mad River and North Fork of Mad

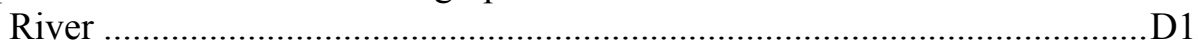

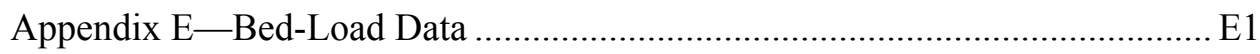

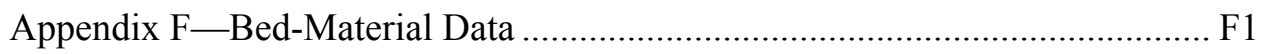

Appendix G-Historic Gravel Extraction Volumes...........................................G1

Appendix H-Polygon Analysis Method Results ..............................................H1

Appendix I-NMFS - Partial List of Basic Biological Concerns....................... I1

Appendix J-Response to Comments .............................................................. J1

SF 298

\section{List of Figures}

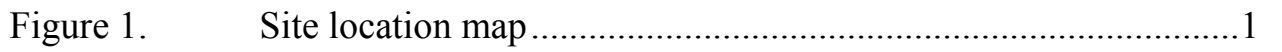

Figure 2. Average annual precipitation in Mad River basin ........................ 
Figure 3. Average daily flows, Mad River at Arcata.................................

Figure 4. Downstream width hydraulic geometry for North American gravel-bed rivers, and U.K. gravel-bed rivers

Figure 5. Hydraulic geometry relationship for meander wavelength with confidence intervals, based on composite data set of 438 sites

Figure 6. Graphical depiction of channel response to external activity

Figure 7. Channel boundaries digitized from rubber-sheeted composite aerial photographs

Figure 8. CalTrans surveyed cross sections, downstream side of Hwy 101 bridge

Figure 9. CalTrans surveyed cross sections, upstream side of Hwy 101 bridge.

Figure 10. CalTrans surveyed cross sections, downstream side of Hwy 299 bridge .22

Figure 11. CalTrans surveyed cross sections, upstream side of Hwy 299 bridge. 22

Figure 12. USACE cross section locations, 1971 and 2000 .25

Figure 13. Longitudinal profile showing average (across cross sections) bed elevation changes from 1971 to 2000 .27

Figure 14. Bed material at surface in mining area, cross section 27 (right side)

Figure 15. Bed material 1-ft below ground surface, cross section 27 (right side) .31

Figure 16. Bed material at surface, not in mining area, cross section 27 (right side) 32

Figure 17. Bed-load data and sediment rating curves................................33

Figure 18. Bed-load equations and data for Arcata gauge...........................35

Figure 19. Bed-load equations and data for Blue Lake gauge......................36

Figure 20. Bed-load equations and data for Kneeland gauge ......................37

Figure 21. Shields parameter analysis to estimate flows required to move various sized particles at Arcata gauge.... .38

Figure 22. Bed-load transport versus suspended load transport .39

Figure 23. Flow correlation between USGS gauging stations at Arcata and Blue Lake .42 
Figure 24. Flow correlation between USGS gauging stations at Arcata and Kneeland

\section{List of Tables}

Table 1. Recorded Extreme and Annual Precipitation at Selected Stations In or Near Mad River Basin .........................................5

Table 2. Stream Gauges in Mad River Basin ...........................................5

Table 3. Predicted Effects of Land Use Practices on a Stable

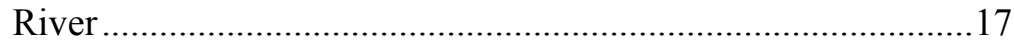

Table 4. Volumetric Change in River from Average-End-Area

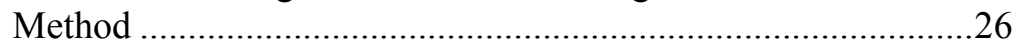

Table 5. Sediment Transport Equations Evaluated for Lower Mad

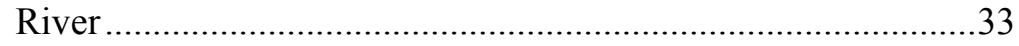

Table 6. Volumetric Polygon Analysis Results......................................40

Table 7. Sediment Budget Values for Lower Mad River Between Hwy 299 and Blue Lake Hatchery .............................................44

Table 8. Sediment Budget Values for Region Between Hwy 101 and Hwy 299 Bridges............................................................45

Table 9. Comparison of Sediment Budgets for Lower Mad River from Hwy 299 Bridge to Blue Lake Hatchery .50 


\section{Preface}

This study was conducted for the Regulatory Branch, U.S. Army Engineer District, San Francisco, by Mr. Kevin Knuuti, of the U.S. Army Engineer Research and Development Center (ERDC), Coastal and Hydraulics Laboratory (CHL). It was begun while Mr. Knuuti was an employee of the San Francisco District and completed by him after he transferred to CHL. Work was performed under the general direction of Ms. Jane Hicks, northern region manager for the San Francisco District's Regulatory Branch, and under the direct supervision of Dr. Yen-hsi Chu, Chief, Coastal Engineering Branch, CHL.

Technical review of this report was completed internally at ERDC by Ms. Maureen Corcoran. Technical review and comments were also provided by various interested parties, including Dr. Brian Cluer, National Marine Fisheries Service; Professor G. Mathias Kondolf, Ph.D., University of California, Berkeley; Mr. Paul Kraus, Eureka Readymix; and Professor Andre Lehre, Ph.D., Humboldt State University. The following people provided additional technical assistance or guidance in the completion of this report: Bill Firth, San Francisco District; Carlos Hernandez, San Francisco District; Ken Thompson, San Francisco District; Michael Lamprecht, Seattle District; Dr. Ronald Copeland, retired, CHL; Cristina Poindexter, Stanford University; Randy Klein, County of Humboldt Extraction Review Team (CHERT); Margaret Tauzer, NMFS; Rob McLaughlin, Eureka Readymix; Mike Webster, USGS; Greg Sisich, USGS; Cathy Avila, CALTRANS; Carol Reish, Humboldt Bay Municipal Water District; Bill Davis, Esq.; John Winzler, Winzler and Kelly Consulting Engineers; Richard Stein, Humboldt County Natural Resources Department; Mike Sandecki, California Office of Mine Reclamation; and Dr. Tom Lisle, USFS.

This work was completed under the administrative supervision of Mr. Thomas W. Richardson and Dr. William D. Martin, Director and Deputy Director, respectively, CHL.

Dr. James R. Houston was Director of ERDC and COL James R. Rowan, EN, was Commander and Executive Director. 


\section{Conversion Factors, Non-SI to SI Units of Measurement}

\begin{tabular}{||l|l|l||}
\hline \hline Multiply & By & To Obtain \\
\hline \hline acre feet & $1,233.489$ & cubic meters \\
\hline cubic feet & 0.02831685 & cubic meters \\
\hline cubic yards & 0.7645549 & cubic meters \\
\hline degrees Fahrenheit & $5 / 9$ & degrees Celsius ${ }^{1}$ or kelvin ${ }^{1}$ \\
\hline feet & 0.3048 & meters \\
\hline inches & 0.0254 & meters \\
\hline inches & 25.4 & millimeters \\
\hline miles (U.S. statute) & 1.609347 & kilometers \\
\hline square miles & $2,589,998$ & square meters \\
\hline tons (2,000 pounds, mass) & 907.1847 & kilograms \\
\hline yards & 0.9144 & meters \\
\hline \hline $\begin{array}{l}1 \\
\text { To obtain Celsius (C) temperature readings from Fahrenheit (F) readings, use the following } \\
\text { formula: } \\
\text { C = (5/9)(F-32). To obtain Kelvin (K) readings, use: K }=(5 / 9)(F-32)\end{array}$ & 273.15. \\
\hline
\end{tabular}




\section{Introduction}

\section{Location}

The Mad River basin is located in Trinity and Humboldt Counties, approximately 300 miles $^{1}$ northwest of San Francisco. The river flows through the towns of Forest Glen, Kneeland, Blue Lake, and Arcata before emptying into the Pacific Ocean immediately north of Humboldt Bay (see Figure 1). Gravel mining operations are primarily located on the lower 13 miles of the river, in the region between the Highway 101 bridge, in Arcata, and the fish hatchery near Blue Lake.

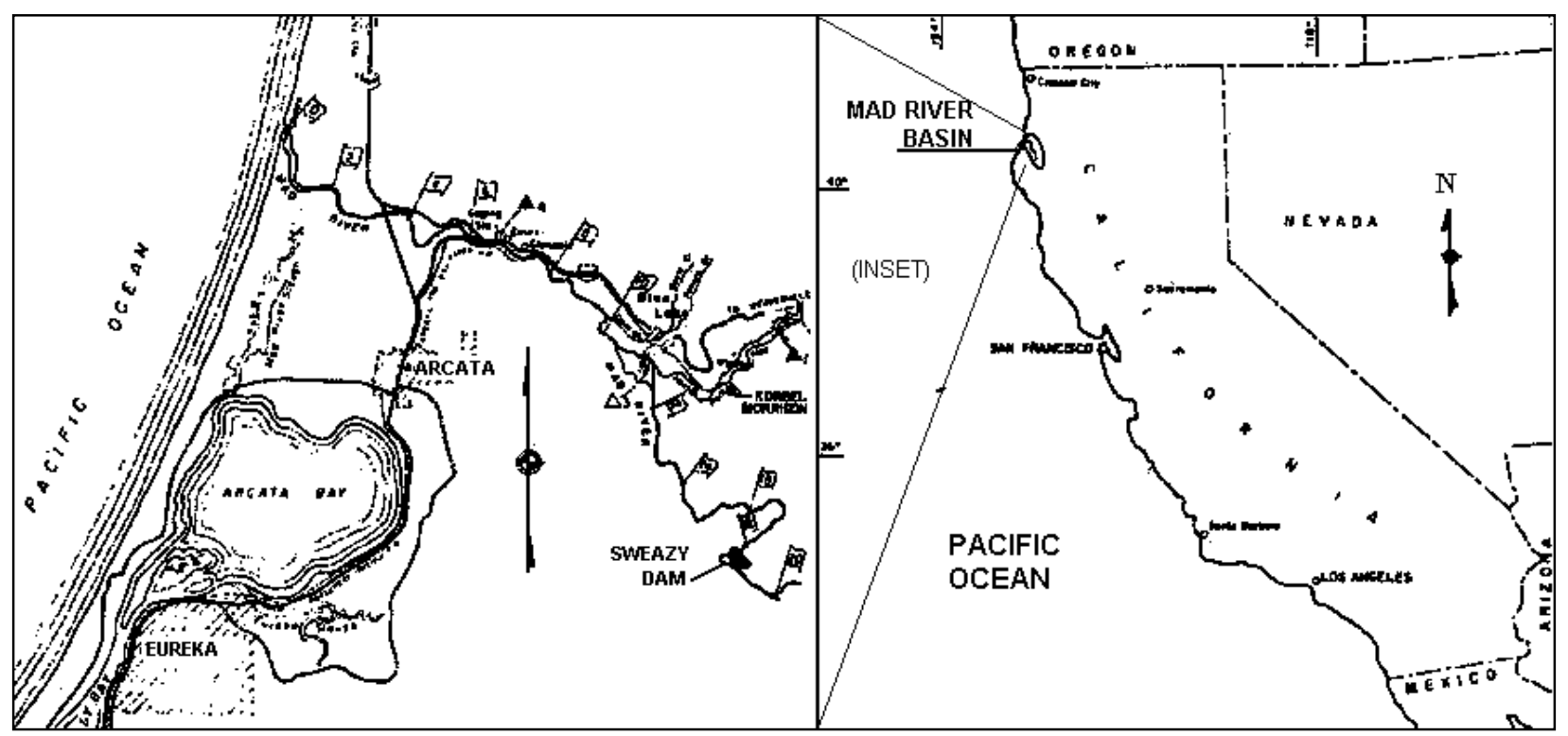

Figure 1. Site location map

\section{Purpose}

The purpose of this study was to compile and evaluate available information related to sediment transport, hydraulics, fluvial geomorphology, and gravel

\footnotetext{
${ }^{1}$ All units of measurement in this report are in non-SI units. A table of factors for converting non-SI to SI units of measurement is presented on page viii.
} 
mining on the Mad River and to use that information to determine whether the current gravel mining strategy on the river is acceptable or should be modified. If the available information was insufficient to accomplish this purpose, this study was to recommend what additional work would be necessary to accomplish the original goal. This work was done for and under the guidance of the Regulatory Branch of the U.S. Army Engineer District, San Francisco.

\section{Scope}

This study was limited almost solely to the evaluation of previously existing information. That information included U.S. Geological Survey (USGS) stream flow, bed load, bed material, and suspended load data; historic aerial photographs; maps; and river cross-section surveys. New information obtained for this study was limited to a new set of USACE cross-section surveys (completed in 2001), and photographs showing conditions of tributaries, banks, and bed material. Older survey data that were referenced to the NGVD-29 fixed vertical datum was converted to the NAVD-88 fixed vertical datum in accordance with Federal guidelines (Federal Register 1993). The adjustment from NGVD-29 to NAVD-88 was determined by high-accuracy global positioning system (GPS) surveying techniques. 


\section{Background}

\section{Physical Setting}

The topography of the Mad River basin is characterized by a succession of large tectonic folds oriented along a northwest-southeast axis. The Mad River and its tributaries are located in the valleys of these folds, except where steep canyons have been cut across the folds along geologic weak points. The Mad River follows a northwesterly course, amidst these valleys and folds, for approximately 80 miles to its mouth at the Pacific Ocean. Its drainage basin is approximately 495 square miles, has an average width of approximately 6 miles, and is bound on the west by the Van Duzen River basin and on the east by the Trinity River basin. After flowing through a steep (average slope varies between 1.1 percent and 5.7 percent), narrow, $\mathrm{V}$-shaped canyon for most of its length, the Mad River enters a different setting. Fourteen miles from the river mouth and just above the town of Blue Lake, the valley floor around the Mad River widens considerably and the channel slope decreases. The average slope in this area becomes approximately 0.3 percent, forming a natural depositional area on the river. The entire basin area is heavily wooded with dense stands of Douglas Fir (Pseudotsuga menziecii) and California Coastal Redwood (Sequoia sempervirens) except for the flatter, wider area between Blue Lake and the mouth which has been developed for dairy farming, lumber processing, and gravel mining and processing. Silviculture throughout the area has resulted in clearcutting certain areas, which has, in turn, led to increased erosion.

\section{Geology}

Most of the Mad River basin is underlaid by late-Jurassic to late-Cretaceous rock of the Franciscan assemblage, and is dominated by graywacke with significant occurrences of siltstone, shale, chert, limestone, conglomerate, altered mafic volcanic rocks (greenstone), ultramafic rock (mostly serpentine), and metamorphic rocks with zeolite, blueschist and eclogite facies (Bailey et al. 1964). Severe folding and faulting in this area has contributed to the highly weathered state of the bedrock and has resulted in many areas being covered with a deep overburden layer of soil. The combination of weathered bedrock, a thick overburden layer, and steep canyon slopes has left the entire area highly susceptible to erosion and landslides. 
The youngest (Pliocene Epoch) geologic deposit in the Mad River basin is the Falor formation, which is composed largely of unconsolidated marine deposits. This formation is located in the north-central part of the basin around the delta and river mouth region.

Surficial geology throughout the study reach is dominated by fluvial terraces of the late Quaternary period that are located adjacent to several stretches of the river. These terraces consist of a poorly sorted mixture of cobbles, gravel, sand, silt, and clay that accumulated in previous river and stream channels and floodplains (California Department of Water Resources 1982).

Seismic activity is common in the area, due in large part to the high tectonic activity of the region. Numerous faults cross the lower Mad River. In the steeper, hill-slope areas of the river basin, landslides are also a common occurrence.

Though the landslides sometimes coincide with periods of seismic activity, their primary cause is periods of heavy rainfall that lead to excessive soil moisture, pore pressure, and instability in the finer-grained sedimentary soils and highly weathered metamorphic rocks.

\section{Climate and hydrology}

Humboldt County has a Mediterranean climate with moderate temperatures and considerable precipitation. The climate along the coast is cool and moist with considerable summer diurnal fog. From summer to winter the average temperatures along the coast vary only $10^{\circ} \mathrm{F}$. Maximum temperatures for the year rarely exceed $80^{\circ} \mathrm{F}$ on the coast, though inland temperatures often reach $100^{\circ} \mathrm{F}$ in the summer. Temperatures below freezing occur periodically throughout the winter.

Rainfall occurs mostly during the wet winter season, from October to April, but is common throughout the year. Average annual rainfall ranges from 40 in. near the mouth of the Mad River to 70 in. in the central part of the basin (see Figure 2). Approximately 90 percent of the average annual rainfall occurs in the seven months from October through April. The estimated basin average is 63 in. The areal distribution of the storm rainfall generally follows a pattern similar to that of the normal annual rainfall. Records are available for three active precipitation gauges located within the Mad River basin. Maximum and minimum recorded seasonal precipitation and estimates of average seasonal precipitation at selected stations are shown in Table 1.

Recorded river discharge data are available from six USGS stations in the basin. Two are presently in operation. Pertinent gauge information is presented in Table 2. 


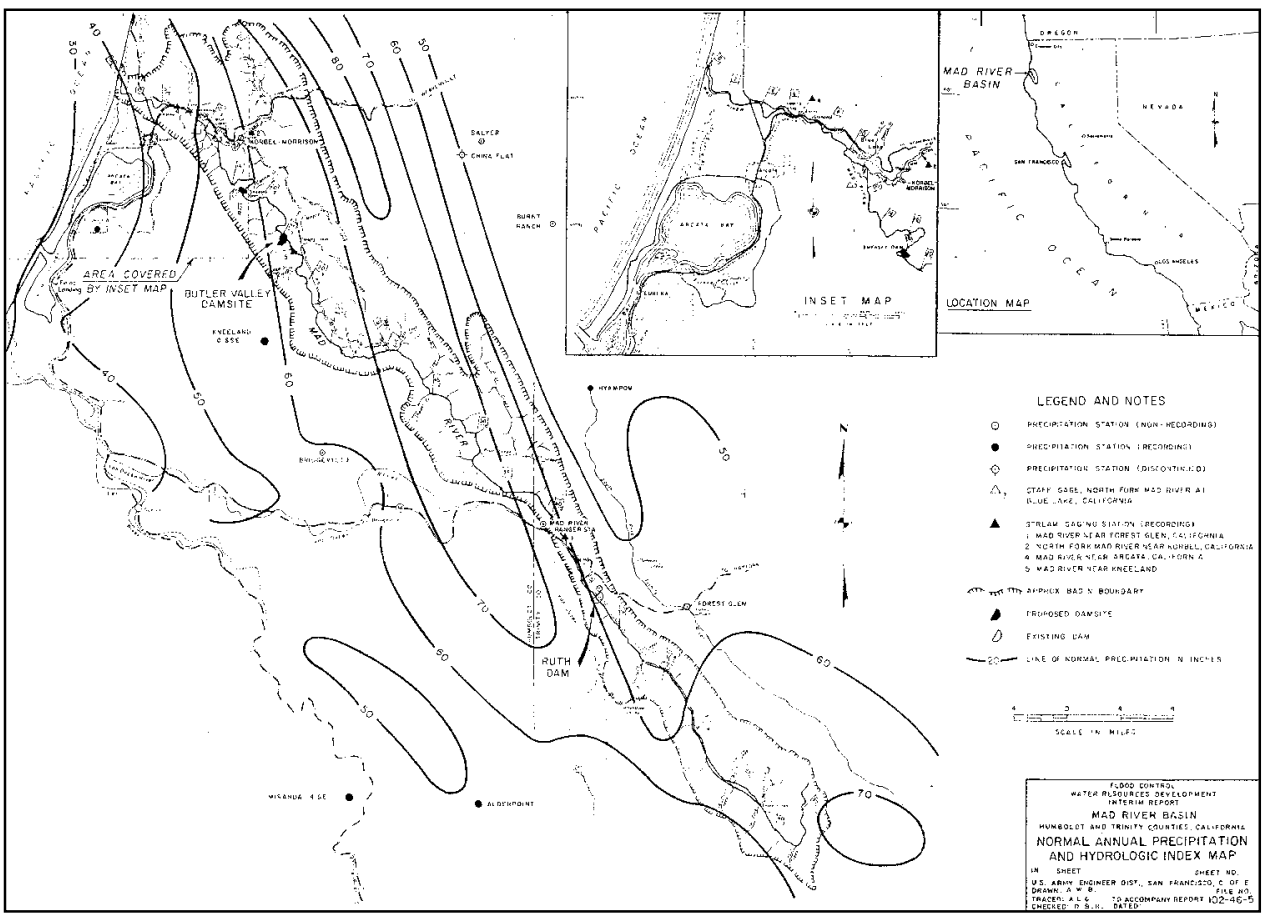

Figure 2. Average annual precipitation in Mad River basin

\begin{tabular}{|c|c|c|c|c|c|}
\hline Station & $\begin{array}{l}\text { Elevation, } \\
\mathrm{ft}\end{array}$ & $\begin{array}{l}\text { Annual } \\
\text { Precipitation } \\
\text { Maximum, in. }\end{array}$ & $\begin{array}{l}\text { Annual } \\
\text { Precipitation } \\
\text { Minimum, in. }\end{array}$ & $\begin{array}{l}\text { Annual } \\
\text { Precipitation } \\
\text { Average, in. }\end{array}$ & $\begin{array}{l}\text { Years of } \\
\text { Record }\end{array}$ \\
\hline Eureka & 43 & 74.10 & 17.56 & 39.11 & $1887-1999$ \\
\hline Eureka NW & 43 & 67.12 & 18.12 & 37.67 & 1904-1999 \\
\hline Mad River & 2775 & 115.61 & 24.33 & 60.88 & $1945-1990$ \\
\hline
\end{tabular}

\begin{tabular}{|c|c|c|c|c|}
\hline $\begin{array}{l}\text { Station (USGS station } \\
\text { number) }\end{array}$ & $\begin{array}{l}\text { Drainage Area } \\
\text { (square miles) }\end{array}$ & $\begin{array}{l}\text { Period of } \\
\text { Record }\end{array}$ & $\begin{array}{l}\text { Maximum } \\
\text { Discharge, cfs }\end{array}$ & $\begin{array}{l}\text { Date } \\
\text { Occurred }\end{array}$ \\
\hline $\begin{array}{l}\text { Mad River Above Ruth } \\
\text { Reservoir Near Forest } \\
\text { Glenn (11480390) }\end{array}$ & 93.8 & 1981-present & 15,000 & $\begin{array}{l}\text { February 17, } \\
1986\end{array}$ \\
\hline $\begin{array}{l}\text { Mad River Near Forest } \\
\text { Glenn }(11480500)^{1}\end{array}$ & 143 & 1954-1997 & 39,000 & $\begin{array}{l}\text { December } \\
22,1955\end{array}$ \\
\hline $\begin{array}{l}\text { Mad River Near Blue Lake } \\
(11480780)^{1}\end{array}$ & 393 & 1973-1976 & 31,700 & $\begin{array}{l}\text { March 18, } \\
1975\end{array}$ \\
\hline $\begin{array}{l}\text { Mad River Near Kneeland } \\
(11480750)^{1}\end{array}$ & 329.66 & 1965-1974 & 55,000 & $\begin{array}{l}\text { December } \\
22,1964\end{array}$ \\
\hline $\begin{array}{l}\text { Mad River Near Korbel } \\
(11480800)^{1}\end{array}$ & 40 & 1958-1974 & 10,100 & $\begin{array}{l}\text { January 16, } \\
1974\end{array}$ \\
\hline $\begin{array}{l}\text { Mad River Near Arcata } \\
(11481000)^{1}\end{array}$ & 485 & 1911-present & $81,0001 /$ & $\begin{array}{l}\text { December } \\
22,1964\end{array}$ \\
\hline
\end{tabular}




\section{Mad River}

The headwaters of the Mad River start in the southern portion of Trinity County at an elevation above 5,500 ft. Ruth Dam, which is located east of Forest Glen, regulates flows from the upper 119 square miles of the basin. The largest tributary of the Mad River is the North Fork, with a drainage area of approximately 50 square miles. Other tributaries in the project study area include Lindsay Creek and Hall Creek, among others, though these are all relatively small. Throughout most of its course, the Mad River flows through a steep, narrow, V-shaped canyon. Near the confluence with the North Fork of the Mad River, above the town of Blue Lake, the channel slope decreases and the canyon opens into a broad alluvial plain. The valley floor is covered with alluvial bars, floodplain deposits and terrace deposits, and the river alternates between meandering, anabranching, and braided forms. The river enters another narrow canyon for the short distance between the Arcata and Mad River Railroad (AMRR) Bridge and the Highway 299 bridge and then opens up again into a historic delta region known as Arcata Bottoms. The lowest 3 miles of the Mad River, from the Highway 101 bridge to the mouth, are tidally influenced with the mouth being extremely dynamic. A Federal flood-control levee extends along the right (northern) bank of the lower portion of the North Fork and continues along the main stem of the river near the town of Blue Lake.

Flows in the Mad River vary seasonally, with the heaviest flows occurring during the winter months and low flows occurring throughout the summer (see Figure 3). With its elongated drainage pattern, the Mad River is somewhat flashy and peak flows can quickly rise and fall. The highest measured average daily flow (at the Arcata gauge) in the river was 63,100 cfs in December 1955. Runoff from the Mad River sometimes spills over into Arcata Bay during major floods.

Water diversions on the Mad River occur at Ruth Lake and in the area controlled by the Humboldt Bay Municipal Water District (HBMWD), immediately above the bridge where Highway 299 crosses the river. The HBMWD's primary means of extracting water is with a series of Ranney collectors, which are above-ground towers with below-ground perforated laterals (pipes laid horizontally above the bedrock and below the gravel bed of the river). Additionally, the HBMWD has a surface-water diversion and extraction point (in this same area) that it operates throughout the year. The average total annual diversion of water by the HBMWD is approximately 20,000 acre-ft/year (28 cfs).

An abandoned water diversion was previously located approximately 19 miles from the river mouth, upstream of the USGS Blue Lake gauge, at the former Sweasey Dam. Sweasey Dam was constructed in 1938 as a water supply for the city of Eureka and impounded approximately 2,000 acre-ft of water. Though the dam was constructed with a sediment-flushing valve, this valve was inoperable by 1941. By 1964, sediment had completely filled the impoundment area behind the dam and the dam was no longer able to serve its purpose of water supply. The dam was removed in 1970 and the impounded sediment was allowed to flush downriver. In the period after its removal, the USGS noted no significant increase in the suspended sediment concentration in the river at its Arcata gauge and only a short period of channel aggradation and widening in the area from the dam to a point 1.5 miles downstream (USGS 1975). 


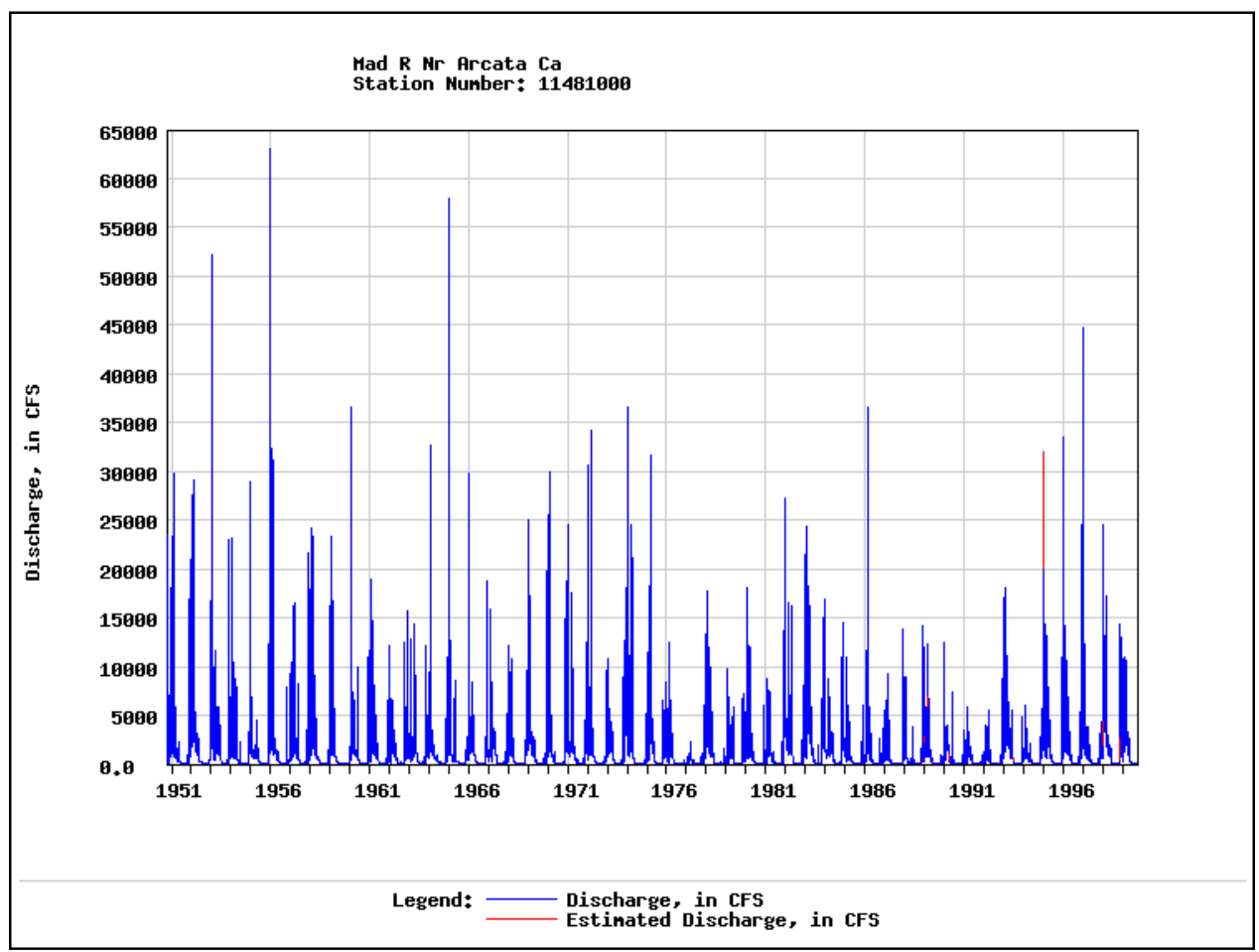

Figure 3. Average daily flows, Mad River at Arcata (source: USGS)

As part of a study in 1970, the U.S. Army Corps of Engineers surveyed 30 cross sections on the river between the mouth and the Blue Lake hatchery. The Corps cooperated with the USGS to collect bed-material, bed-load, and suspended-load sediment samples over a range of flows at the gauge locations in Arcata, Blue Lake, and Kneeland on the Mad River, and at Korbel on the North Fork Mad River. Sediment-load sampling results are discussed in more detail in Chapter 3.

\section{History and Land Use}

Prior to European settlement of California, the Wiyot Indians inhabited this area and used the Mad River as a source of salmon and sturgeon. In the nineteenth century, European settlers established roads and a railroad in the area and began heavy logging activity. By the mid- to late-1800s, logging and local lumber mills were producing enough lumber to export it throughout the northwestern United States. During this time, rough roads were built, trees were cut by hand, logs were dragged by oxen and mules, and timber was exported by rail and ship. The logging, road building, and railroad building operations likely resulted in significant erosion and increased the sediment load in the Mad River and its tributaries.

As roads and railroads were being built, the need for base materials (gravel) increased. This increased need led to the development of the local gravel mining industry. As more roads were built and more trees were harvested, increased erosion led to higher sediment loads in the Mad River and more gravel for mining. This, in turn, led to more road development, more logging, and more 
erosion. This cycle continued until road building declined and the timber industry began to modify its harvesting methods in the latter half of the twentieth century.

Though the methods have changed over the past 150 years, logging and timber harvesting are still active industries in the Mad River basin. Gravel mining has been an important and active industry in the area since at least 1952, with most mining operations occurring in the area between the Blue Lake hatchery and the Highway 101 bridge (see Appendix G).

Agricultural activities and cattle ranching have also been significant in the lower portions of the Mad River basin since the 1850s. Though they have also led to additional erosion in the area, their influence on the sediment load in the Mad River was probably much less than that of the timber and road building industries.

\section{Concerns}

Several different agencies and groups have expressed concerns over how gravel-mining activities in the Mad River may be affecting the existing conditions around the river. The California Department of Transportation is concerned that gravel mining has led to bed degradation that could affect the structural stability of the Highway 101 and Highway 299 bridges. The HBMWD is concerned that continued gravel mining operations could negatively affect its ability to supply water to the people, businesses, and industries of the Humboldt Bay area. Various agencies and special interest groups are concerned that gravel mining is adversely affecting fish and wildlife in the river and its surrounding areas. Concerns peaked in 1992 when a local environmentalist filed a lawsuit against one of the gravel operators and an employee of one of the gravel operators was arrested. In response to an appeal for assistance from Humboldt County Supervisor Bonnie Neely, California Secretary of Resources Doug Wheeler met with gravel operators during a visit to Eureka. Secretary Wheeler then had his staff gather representatives from the appropriate agencies and prepare a memorandum to address the situation.

\section{Regulatory issues}

In 1992, several parties signed a memorandum of agreement (MOA) concerning instream gravel mining operations on the lower Mad River. ${ }^{1}$ The signatories included the Humboldt County Board of Supervisors, several California agencies (Resources Agency, Board of Mining and Geology, Department of Conservation, Department of Fish and Game, and State Lands Commission), and three gravel operators (Eureka Sand and Gravel, Mad River Sand and Gravel, and Redwood Empire Aggregates). Although Arcata Readimix did not sign the agreement, it agreed to its conditions.

\footnotetext{
${ }^{1}$ Personal Communication, 2 September 1999, Michael Lamprecht, Regulatory Field Office, U.S. Army Engineer District, San Francisco.
} 
The MOA directed Humboldt County to take the lead in preparing a programmatic environmental impact report (PEIR) to evaluate the effects of instream gravel mining operations on the morphology and habitat of the Mad River. Humboldt County hired a consultant to complete the PEIR and a draft was issued in 1993. The final PEIR was completed and approved in May 1994. ${ }^{1}$ The MOA also created a scientific advisory committee that was to evaluate the river and its natural resources and recommend methods, locations, and volumes for safe gravel mining in the river. In 1996, the scientific advisory committee was formalized in a group called the County of Humboldt Extraction Review Team (CHERT). CHERT is composed of two geomorphologists, one hydrologist, and one aquatic ecologist. CHERT reviews annual data on cross sections and site conditions for the purpose of recommending site-specific gravel extraction methods and maximum volumes.

Currently, the National Marine Fisheries Service (NMFS) and the Corps are both involved in regulating gravel mining operations on the lower Mad River at the Federal level. NMFS is primarily concerned with habitat and populations of anadromous fish that use the Mad River. The Corps is responsible for issuing a letter of permission (LOP) to the gravel operators.

\section{Water supply}

The HBMWD is concerned that continued gravel mining operations could lead to additional bed degradation that could adversely affect the groundwater phreatic surface and thus the ability of the HBMWD to supply water to the people, businesses, and industries of the Humboldt Bay area. Recent photographs of the Ranney well towers along the river indicate significant bed degradation when compared with older photographs and design and construction drawings. This is supported by surveys across the river in the HBMWD area by Bechtel Engineering Corporation, ${ }^{2}$ Winzler and Kelley (Winzler and Kelley 1966, ${ }^{3}$ $1998^{4}$ ), and Andre Lehre ${ }^{5}$ that document significant bed degradation between 1960 and 1995.

\footnotetext{
${ }^{1}$ Personal Communication, op cit., p. 8.

${ }^{2}$ Bechtel Engineering Corporation. (1961). "Mad River Project." Engineering drawing set prepared for Humboldt Bay Municipal Water District.

${ }^{3}$ Winzler and Kelly. (1966). "Construction of pump stations, pipe lines, reservoir and controls," Engineering drawing set prepared for Humboldt Bay Municipal Water District.

${ }^{4}$ Winzler and Kelly. (1998). "Mad River cross sections," Engineering drawing set prepared for Humboldt Bay Municipal Water District.

${ }^{5}$ Lehre, A., Klein, R., and Trush, W. (1993). “Appendix F, River Institute Consultants

Report," A technical supplement to draft environmental impact report for surface mining of sand and gravel on Mad River, Humboldt County, California. Prepared for the Humboldt County Board of Supervisors, Eureka, California.
} 


\section{Bridge stability}

The California Department of Transportation (CalTrans) is concerned that gravel mining has led to bed degradation that could affect the structural stability of the Highway 101 and Highway 299 bridges. CalTrans has been surveying channel cross sections at these bridges since 1928, and its surveys show significant bed degradation at the bridge locations. A recent report completed for Eureka Readymix indicates that there is some discrepancy associated with the CalTrans bridge cross section surveys and concludes that while degradation has occurred it has not been as significant as CalTrans claimed. ${ }^{1}$ This issue will be addressed in more detail in Chapter 3.

\section{River mouth migration}

Geologic information, historic maps and aerial photographs indicate that the mouth of the Mad River has actively migrated over time. Though the river mouth was migrating north for several years during the 1980s and 1990s, in 1999 it suddenly changed course and reopened a previous mouth several miles to the south, near the town of McKinleyville. Although changes in the sediment load in a river can sometimes result in river mouth migration, it is a complicated process having to do with fluvial hydraulics and sediment transport as well as with nearshore coastal processes and wave mechanics. The periodic migration of the Mad River's mouth was not investigated as part of this study.

\section{Previous Studies}

Several studies have been conducted on issues related to sediment transport and river morphology on the lower Mad River. These studies include the following:

a. USGS.

(1) Streamflow Sediment and Turbidity in the Mad River Basin Humboldt and Trinity Counties, California. Water-Resources Investigations 36-73. U.S. Geological Survey, December 1973. Prepared for the U.S. Army Engineer District, San Francisco.

(2) Sediment Transport Turbidity, Channel Configuration and Possible Effects of Impoundment of the Mad River, Humboldt County, California. Water Resources Investigations 26-75. U.S. Geological Survey, December 1975. Prepared for the U.S. Army Engineer District, San Francisco.

\footnotetext{
${ }^{1}$ Pacific Affiliates. (1999). "Evaluation of California Department of Transportation Mad River Bridge cross sections, Highway 299 and Highway 101," Prepared for Mad River gravel operators.
} 
b. USACE.

(1) Interim Review Report for Water Resources Development on Mad River, California. U.S. Army Corps of Engineers, September 20, 1967.

(2) Mad River, Humboldt and Trinity Counties, California, Letter from the Secretary of the Army. U.S. Army Corps of Engineers, July 16, 1968.

c. California Department of Water Resources (DWR).

(1) Bulletin No. 94-7 Land and Water Use in Mad River-Redwood Creek Hydrographic Unit. California Department of Water Resources, April 1965.

(2) Mad River Watershed Erosion Investigation. California Department of Water Resources, June 1982.

d. Others.

(1) Analysis of the Effects of Historic Gravel Extraction on the Geomorphic Character and Fisheries Habitat of the Lower Mad River, Humboldt County, California. A Technical Supplement to the Draft Environmental Impact Report for the Surface Mining of Sand and Gravel on the Mad River, Humboldt County, California. Andre Lehre et al, April 1993.

(2) Changes in Bed Elevation and Sediment Storage in the Mad River, 1970-1999. G. Mathias Kondolf and Erin Lutrick, March 2001. Prepared for Eureka Readimix.

(3) Historical Analysis of Geomorphic Channel Changes, Lower Mad River, Humboldt County, California. Jeffrey W. Tolhurst, August 1995. Master of Science thesis, Department of Geology, Humboldt State University. 


\section{Analysis and Results}

\section{Sediment Budget Concept}

To accurately assess the effects that gravel mining has had on the morphology of the lower Mad River and to recommend a strategy for gravel extraction, a detailed sediment budget is needed for the region in question. A sediment budget analysis is based on a simple conservation of mass approach in which the difference between the rates at which sediment enters and leaves the study area yields the rate at which gravel is stored in the study area. This relationship can be written as

$$
Q_{\text {s-in }}-Q_{\text {s-out }}=Q_{\text {s-stored }}
$$

where $Q_{s}$ represents the rate of sediment transport in the river (often expressed in tons/year). If $Q_{s-\text { in }}$ is greater than $Q_{s-o u t}$ then the rate at which sediment is stored in the study area, $Q_{s-s t o r e d}$, is positive and sediment accumulates. If $Q_{s-s t o r e d}$ is a negative number, then more sediment is leaving the study area than entering it and channel degradation or bank erosion occurs. For this study, the area of interest is bounded by the Mad River hatchery, just above Blue Lake, on the upstream end and the Pacific Ocean on the downstream end. Sediment input, $Q_{s-i n}$, is a combination of bank erosion within the study area and sediment that naturally flows into the study reach via fluvial processes as bed-material load. Sediment output, $Q_{s-o u t}$, is a combination of gravel extraction and sediment that naturally flows out of the study reach via fluvial processes as bed-material load. The change in storage, $\Delta S$, within the study reach can be seen as the total degradation (bed lowering), channel widening, or aggradation (bar development, floodplain deposition, etc.) that occurs. Because sediment transport varies considerably with flood events and wet or dry years, the sediment budget should represent an average condition, which may or may not accurately represent the actual conditions in any given year.

For the lower Mad River, the general attitude of the parties involved is that long-term gravel extraction should be managed in a manner that keeps the river in a stable condition, with no net aggradation, degradation, or channel widening (bank erosion). For this to occur, storage of sediment in the study reach should be zero (0) and $Q_{s-i n}$ should equal $Q_{s-o u t}$. This can be represented as

$$
Q_{\text {s-in }}-Q_{\text {s-out }}=0 \text { or } Q_{\text {s-in }}=Q_{\text {s-out }}
$$


With the various sources of sediment input and output in the study area, this equation can be expanded to

$$
\begin{aligned}
& Q_{s-\text { in, fluvial }}-\left(Q_{s-\text { out }, \text { fluvial }}+Q_{s-o u t, \text { gravel extraction }}\right)=0 \\
& \text { or } \\
& Q_{s-\text { in, fluvial }}-Q_{s-\text { out }, \text { fluvial }}=Q_{s-\text { out, gravel extraction }}
\end{aligned}
$$

This relationship does not include a component for the sediment contributed from bank erosion due to the geomorphic processes associated with natural bank erosion and channel migration. If bank erosion was considered a sediment input source for the purpose of managing gravel extraction, then the river channel could be subjected to an unstable condition where there is no net aggradation or degradation of the bed but there is significant channel widening. Excluding channel erosion within the study reach allows for the natural process of channel migration, bank erosion, and point bar development. This is not to imply that bank erosion is not an important contributing factor to the sediment budget of the lower Mad River. It simply means that bank erosion should not be included in sediment budget estimates if one is attempting to calculate the safe gravel mining extraction rate for an equilibrium condition.

It is important to note that while long-term management goals for the Mad River assume the maintenance of an equilibrium condition, the PEIR agreement is that extraction should be managed in a way that allows a slow rate of recovery in the degraded channel. This results in the following modification to the equations previously described.

$$
Q_{s-i n, \text { fluvial }}-Q_{s-o u t, \text { fluvial }}>Q_{s-o u t, \text { gravel extraction }}
$$

\section{Methods}

With the exception of one new set of channel cross-section surveys, this study did not include the collection of any new data related to sediment transport on the lower Mad River. Analysis methods included considering various geomorphic relationships; examining historic information such as maps, aerial photographs, and gravel mining records; comparing various sets of surveyed channel cross sections; and evaluating potential sediment transport using collected bed material, bed-load and suspended-load data along with various common sediment transport relationships.

\section{Geomorphic Relationships}

Geomorphologists have been studying stable and unstable channels for decades and have developed relationships that describe channel hydraulic 
geometry, planform, slope, and discharge. Commonly referenced sources of geomorphic relationships for gravel-bed rivers include Emmett (1975); Wolman (1955); Williams (1978); Leopold et al. (1964); Hey and Thorne (1986); Thorne et al. (1997); and Copeland et al. (2001), among others.

\section{Stability assessment}

Although evaluating common geomorphic relationships, such as bank-full width to bank-full discharge, meander wavelength to bank-full discharge, and meander bend radius of curvature to meander wavelength was considered, it was decided not to evaluate them to any significant degree. While these relationships may be useful for design purposes, they are less useful for determining the stability of an existing river system, such as the lower Mad River, due to the scatter and wide confidence intervals associated with the data used to establish the relationships. Figures 4 and 5 show the scatter and wide confidence intervals associated with two common geomorphic relationships, bank-full width to bankfull discharge and meander wavelength to bank-full discharge. After examining these figures, and noting that they are plotted on logarithmic scales, it becomes apparent that the dependent variable that corresponds with any given independent variable can often vary by an order of magnitude or more. An existing river system that does not fit the specific equations that were derived from these figures can therefore still fall well within the range of data that were used to derive the equations and could thus represent a stable river system, regardless of its failure to match the specific equations.

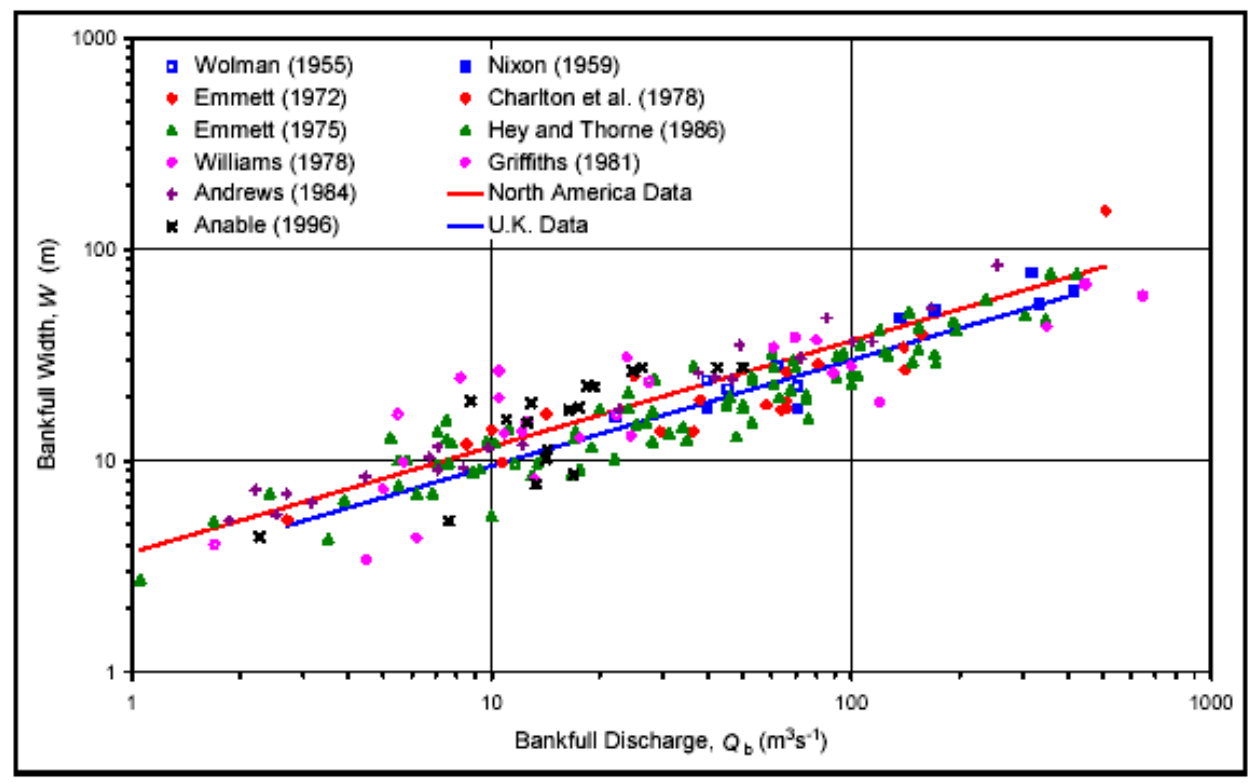

Figure 4. Downstream width hydraulic geometry for North American gravel-bed rivers, $\mathrm{W}=3.68 \mathrm{Q}_{\mathrm{b}}{ }^{0.5}$, and $\mathrm{U} . \mathrm{K}$. gravel-bed rivers, $\mathrm{W}=2.99 \mathrm{Q}_{\mathrm{b}}{ }^{0.5}$ (Copeland et al. 2001) 


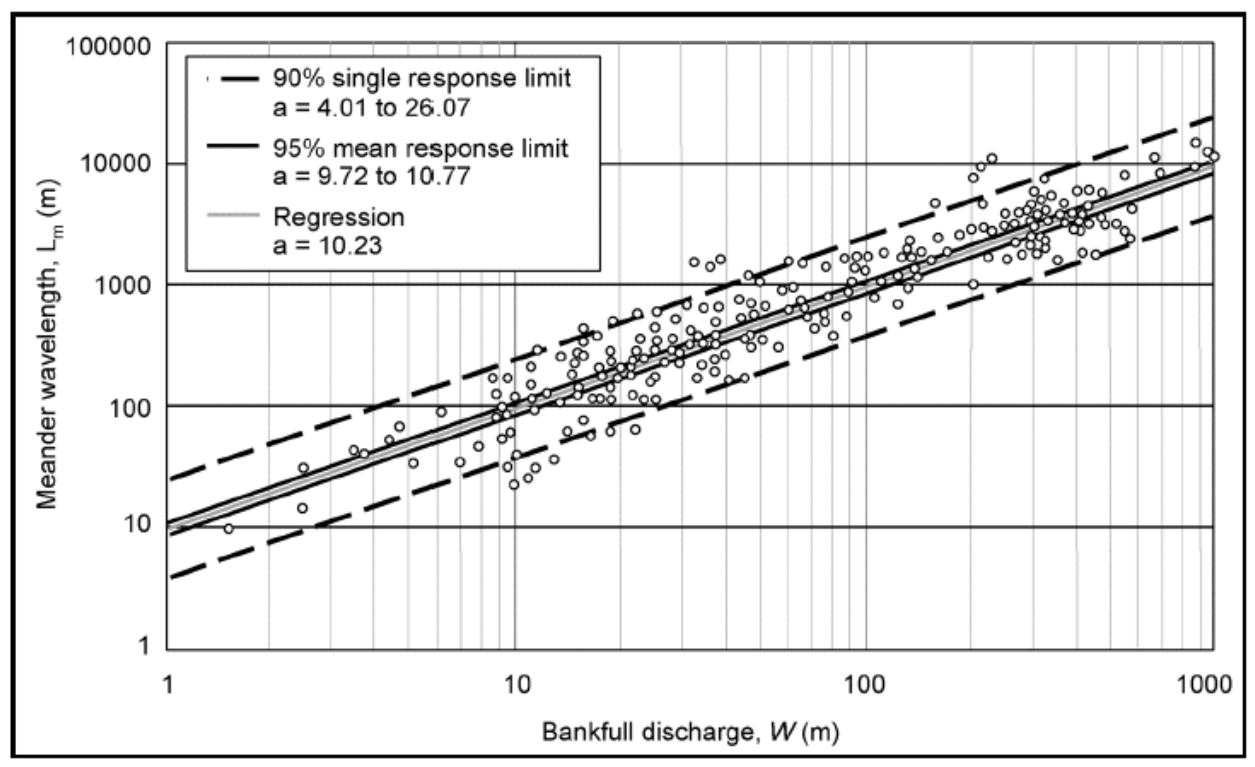

Figure 5. Hydraulic geometry relationship for meander wavelength with confidence intervals, $\lambda=10.23 \mathrm{~W}$, based on composite data set of 438 sites (Soar and Thorne 2001)

\section{Geomorphic changes}

Despite not using them to determine the stability of the Mad River system, a few common geomorphic relationships were still examined. Using historic aerial photographs and topographic maps, radii of curvature were measured for meander bends, meander wavelengths, and channel sinuosity. Hydraulic geometry relationships at the three gauging stations were calculated using USGS data as presented in USGS 9-207 forms for the different stations. Effective discharge at two of the stations (Arcata and Kneeland) was estimated by integrating the bed-load transport curves with the discharge-frequency curves for those stations. The effective discharge was used, along with the hydraulic geometry relationships, to determine the channel depth, width, and crosssectional area for the effective discharge. The relationships were also used in the sediment transport equations listed in Table 5, later in this report.

Channel geometry (depth, width, and area) values were compared at effective discharge to the relationships at various cross-section locations throughout the study reach and also to the relationships between channel dimensions and meander bend radii described by Williams (1986). The comparison indicated that the river is much wider and shallower in areas where the gravel miners operate than it is throughout the rest of the river. This could be caused by gravel mining, or it could be that those locations are naturally wider and shallower and attract gravel mining because of their sediment trapping capacities. Most likely, it is a combination of these two explanations. The gravel miners probably began operating in these areas because they were effective sediment traps and the areas probably continue to act as sediment traps due to the gravel mining activities.

While the "Stability Assessment" section in this chapter explains why relationships such as Williams' should often not be used to assess the stability of 
a natural channel, several areas of the river are so much wider and shallower than Williams' relationship suggests for stable systems that they could be significant, in this case. The fact that the river has been slowly increasing its sinuosity over the past several decades was also noticed. An increase in sinuosity (decrease in bed slope) can be caused by an extended sediment deficit. Though the lower Mad River's increase in sinuosity has been fairly small, it has been steady and is therefore worthy of mention.

\section{Lane's relationship}

Geomorphic relationships were not used to determine the stability of the lower Mad River, but were used to predict the effects of certain land-use practices and external influences on the river's morphology. A simple relationship describing natural river systems was initially presented by Lane (1955). Lane found that the product of sediment discharge and sediment size was proportional to the product of water discharge and channel slope and expressed his proportionality relationship as

$$
Q_{s} D \sim Q_{w} S
$$

where $Q_{s}$ is the bed-material load, $D$ is the sediment size, $Q_{w}$ is the water discharge, and $S$ is the channel slope. Using this relationship, the effects on a stable river of change in one variable can be predicted (see Figure 6 and Table 3). The effects can differ for the areas immediately near, upstream, and downstream from the change.

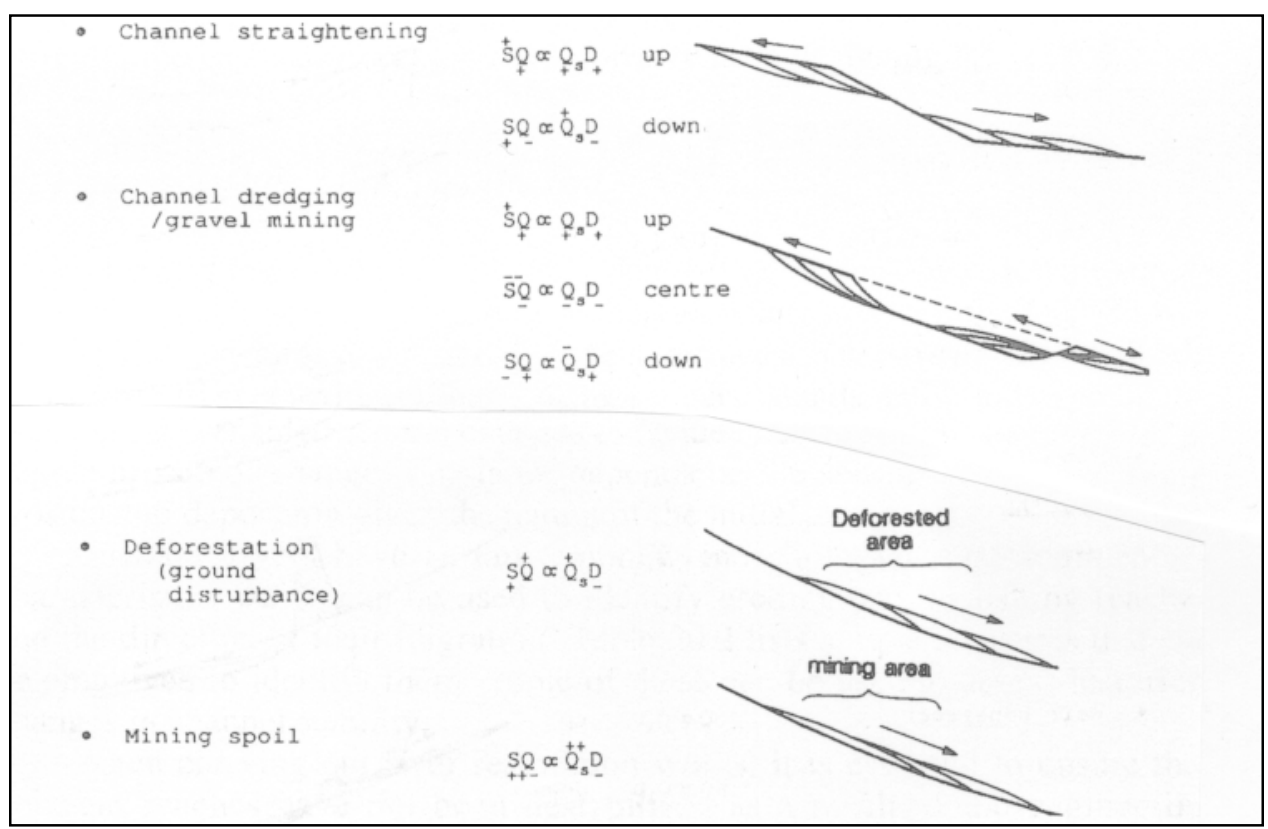

Figure 6. Graphic depiction of channel response to external actions (Hey 1986) 


\begin{tabular}{|c|c|c|c|}
\hline \multicolumn{4}{|c|}{$\begin{array}{l}\text { Table } 3 \\
\text { Predicted Effects of Land Use Practices On a Stable River }\end{array}$} \\
\hline Action & Immediate Result & Downstream Effect & Upstream Effect \\
\hline $\begin{array}{l}\text { Increased } \\
\text { upland erosion } \\
\text { (due to } \\
\text { logging and } \\
\text { other land use } \\
\text { practices) }\end{array}$ & $\begin{array}{l}\text { Increased } \\
\text { sediment load in } \\
\text { river causes } \\
\text { aggradation in area } \\
\text { of increased } \\
\text { erosion }\end{array}$ & $\begin{array}{l}\text { Increased sediment load } \\
\text { causes channel } \\
\text { aggradation to progress } \\
\text { downstream from } \\
\text { deposition area }\end{array}$ & $\begin{array}{l}\text { Decreased slope may } \\
\text { result in channel } \\
\text { aggradation progressing } \\
\text { upstream from deposition } \\
\text { area }\end{array}$ \\
\hline $\begin{array}{l}\text { Gravel mining } \\
\text { (level } \\
\text { skimming of } \\
\text { bars) }\end{array}$ & $\begin{array}{l}\text { Channel is over- } \\
\text { widened and slope } \\
\text { may be decreased, } \\
\text { area becomes } \\
\text { sediment trap } \\
\text { (increased } \\
\text { deposition) }\end{array}$ & $\begin{array}{l}\text { Decreased sediment load } \\
\text { in river causes channel } \\
\text { degradation to progress } \\
\text { downstream from mining } \\
\text { area, increased bank } \\
\text { height could lead to } \\
\text { instability and increased } \\
\text { erosion }\end{array}$ & $\begin{array}{l}\text { Increased slope at } \\
\text { upstream end of mining } \\
\text { area may cause channel } \\
\text { degradation to progress } \\
\text { upstream (headcutting), } \\
\text { increased bank height } \\
\text { could lead to instability and } \\
\text { increased erosion }\end{array}$ \\
\hline
\end{tabular}

Typically, however, a change in the bed-material load will have an effect that migrates downstream while a change in the channel bed level or slope will have an effect that migrates upstream. With these relationships in mind, available data and information on the Mad River were examined to determine what effects gravel mining might have on the morphology of the river. For a case of negative sediment storage in the study area (gravel extraction greater than area storage), Table 3 indicates that the river should respond and exhibit a degraded bed upstream and downstream of the mined area with probable evidence of headcutting in area tributaries.

To evaluate the possibility of channel degradation in the Mad River and headcutting in area tributaries, Mad River channel cross-section surveys and physical features of the tributaries were examined. The length of the Mad River and its tributaries in the study area were walked to look for signs of erosion, bed lowering, headcutting, and aggradation. Channel cross-section surveys are discussed in detail later in the "Surveyed Cross Sections" section in this chapter. Physical examination of the river and its tributaries indicated that significant bed degradation has occurred in the time since bridges and other structures were built and that bed degradation is progressing upstream and into neighboring tributaries. Photographs in Appendices $\mathrm{C}$ and $\mathrm{D}$ show incision and headcutting in Warren Creek, Lindsay Creek, Hall Creek and the North Fork of the Mad River. Figures 8-10, C-41 (XC21), C-64 (XC29), D-10, and D-11 show channel degradation at the Highway 101 bridge, the Highway 299 bridge, the AMRR bridge, the Blue Lake (hatchery) bridge, and the Raney collector towers in the HBMWD area. Though all of these indicate that there has been a sediment deficit in the study area, they are not quantitative enough to be able to recommend a gravel mining strategy for the area.

\section{Historical Information}

The historical information reviewed included maps, aerial photographs, engineering drawings (CalTrans and HBMWD), and surveyed channel cross sections. The maps reviewed were primarily historic USGS and Department of 
Defense maps that showed traces of former channel locations. Unfortunately, these maps were not detailed enough to allow for any significant analysis. As a result, the analysis of historic information was focused on aerial photographs and surveyed cross sections.

\section{Aerial photographs}

For this study, complete sets of aerial photographs dating back to 1941 were reviewed. Also reviewed were other aerial photographs from earlier dates but they were not included in the analysis due to incomplete sets, poor quality, and concerns about the angles at which the photographs were taken. Photographs were selected that were spaced out enough temporally to allow noticeable changes in the river system and that also corresponded to the dates of channel cross-section surveys. The sets chosen for analysis were from 1941, 1954, 1970, 1981, and 1999. The photographs were obtained from a variety of sources, including Humboldt County Department of Natural Resources, Humboldt State University, Pacific Affiliates, and Corps files.

In analyzing the aerial photographs, two types of analyses were performed. In the first, the aerial photograph sets were scanned and then digitally connected to make composite photographs of the study area for the years selected. The composite images were georeferenced by "rubber-sheeting" them with AutoCAD. While this is generally not an advisable method of georeferencing aerial photographs for detailed technical analysis, it was all that was feasible due to limited resources and funding. After rubber-sheeting the composite images, the channel boundaries were digitized and superimposed atop one another. By placing the different years' channel boundaries in their own AutoCAD layers, it was possible to combine any year's of channel boundaries with any base map, thus showing how channel boundaries had changed over time (see Figure 7).

In evaluating the effectiveness of this method, it was determined that there were too many errors in the georeferencing to allow an accurate analysis. Because the composite images were fairly linear, representing approximately 13 miles of the Mad River, the georeferencing points available were also fairly linear. The lack of good two-dimensional (2-D) separation between the georeferencing points, combined with the distortion around the edges in the aerial photographs, resulted in significant scaling errors throughout the georeferenced composite images. With more time, this method would probably lead to a useful addition to the analysis. In its present condition, however, it was not suitable for inclusion with the results in the analysis. See the "Other sources of information" section in this chapter for mention of similar work done by Tolhurst (1995) as part of his Master of Science research at Humboldt State University.

In the second type of aerial photograph analysis, the work by Professor G. Mathias Kondolf, in his analysis of sediment transport on the lower Mad River 
(Kondolf and Lutrick 2001), ${ }^{1}$ was extended. This work is discussed in "Polygon Analysis" later in this chapter.

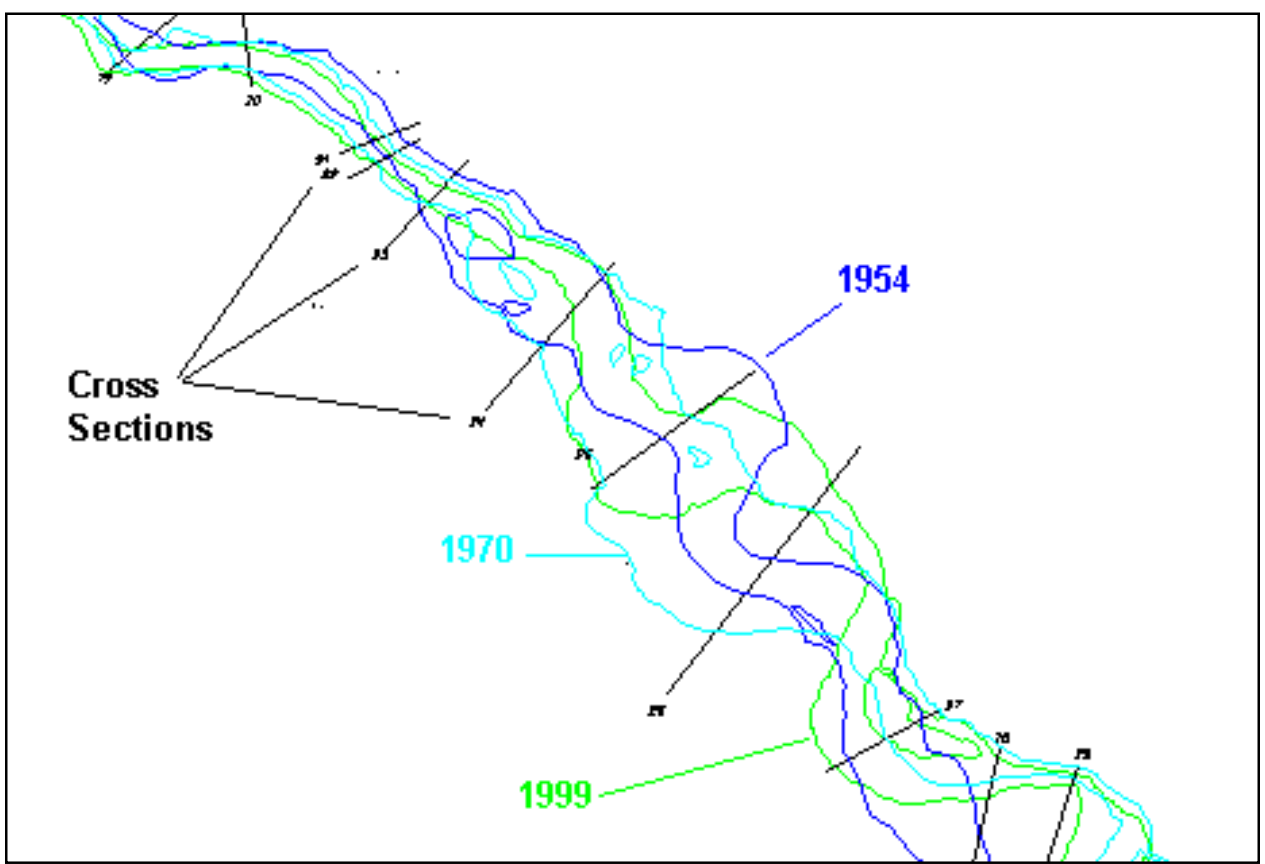

Figure 7. Channel boundaries digitized from rubber-sheeted composite aerial photographs

\section{Surveyed cross sections}

A significant portion of this study was the evaluation of historic and current surveyed channel cross sections. Cross sections were available from CalTrans, at the Highway 101 and 299 bridges, from Lehre et al. (1993), ${ }^{2}$ the HBMWD, and from the Corps.

CalTrans. CalTrans measures channel cross sections in the study area at the Highway 101 and Highway 299 bridges, at a frequency of approximately once every 10 years, and has survey information for these two bridges dating back approximately 50 years. Though CalTrans has expressed concern over the possible effects of gravel mining on bed degradation near these bridges, and has used its cross sections to illustrate its concerns, the gravel operators on the Mad River have questioned those concerns. An analysis completed by Pacific Affiliates in 1999 for the Mad River gravel operators describes why the gravel operators feel the CalTrans cross sections may be in error and why they believe the cross sections exaggerate the amount of bed degradation around the bridges. This analysis lists perceived problems with a lack of data points within the wetted channel, discrepancies with cross section end point elevations, and

\footnotetext{
${ }^{1}$ Kondolf, G. M., and Lutrick, E. (2001). "Changes in bed elevation and sediment storage in the Mad River, 1970-1999," Prepared for Eureka Ready Mix.

${ }^{2}$ Lehre, A., Klein, R., and Trush, W. (1993), op. cit, p. 9.
} 
concerns with vertical datums for the different years' surveys (Pacific Affiliates 1999). ${ }^{1}$

After reviewing the concerns of the gravel operators, CalTrans stated that they still believe their cross sections are accurate and provide a good history of bed change around the bridges. CalTrans made its bridge cross-section survey data and bridge construction drawings available to the Corps for an independent analysis.

For the Highway 101 bridge, CalTrans measured upstream and downstream channel cross sections in 1928, 1929, 1957, 1972, 1989, and 1992. The 1928 (downstream) and 1929 (upstream) channel cross sections are based on data that were collected during or immediately after construction and represent the as-built condition.

For the downstream side of the bridge, the 1928 cross section shows a flat bottom for the channel, with a thalwag elevation of $11.4 \mathrm{ft} \mathrm{NGVD}(14.75 \mathrm{ft}$ NAVD). This elevation, however, represents the edges of water on both sides of the channel leading to the conclusion that the actual thalwag was below $11.4 \mathrm{ft}$ NGVD (see Figure 8). While a similar situation may initially appear to exist for the 1957 cross section, examination of the upstream side of the bridge's 1957 cross section indicates that the elevations shown for the downstream cross section are probably representative of the actual bed elevation at that time (see Figure 9).

Accounting for the uncertainty associated with the methods CalTrans used in measuring the Highway 101 bridge cross sections, the cross sections still indicate approximately $6 \mathrm{ft}$ of bed degradation between 1957 and 1992. They also indicate approximately $1 \mathrm{ft}$ of degradation between 1972 and 1992.

For the Highway 299 bridge, CalTrans measured upstream channel cross sections in 1941, 1960, 1972, 1974, and 1991 and downstream channel cross sections in 1960, 1974, and 1991. Accounting for the uncertainty associated with the cross section measurement methods, and the discrepancies with the vertical datums mentioned previously, the channel cross sections still indicate a minimum of $7 \mathrm{ft}$ of channel bottom degradation between 1960 and 1991 and a minimum of $5 \mathrm{ft}$ of channel bottom degradation between 1972 and 1991 (see Figure 10 and Figure 11).

The 1999 report by Pacific Affiliates for the Mad River gravel operators raises several concerns with the data previously presented by CalTrans with respect to channel cross sections at the Highway 101 and 299 bridges. Upon reviewing and analyzing CalTrans' raw cross section data and bridge construction drawings, it was clear that the information can be confusing and is easy to misinterpret. Adjusting CalTrans' raw data to account for vertical datum changes results in cross sections that do not appear to overlie each other very well in some instances (see Figures 8-11). Visually adjusting these cross sections in a manner that would appear to be logical, given common physical features that are captured in each cross section, however, results in similar amounts of bed

\footnotetext{
${ }^{1}$ Pacific Affiliates. (1999), op. cit, p. 10.
} 
degradation (greater in some cases and less in others). Regardless of this, the cross section information makes it clear that the riverbed in the vicinity of the two bridges has lowered significantly since at least 1960 and perhaps back as far as 1928 (101 bridge) and 1941 (299 bridge).

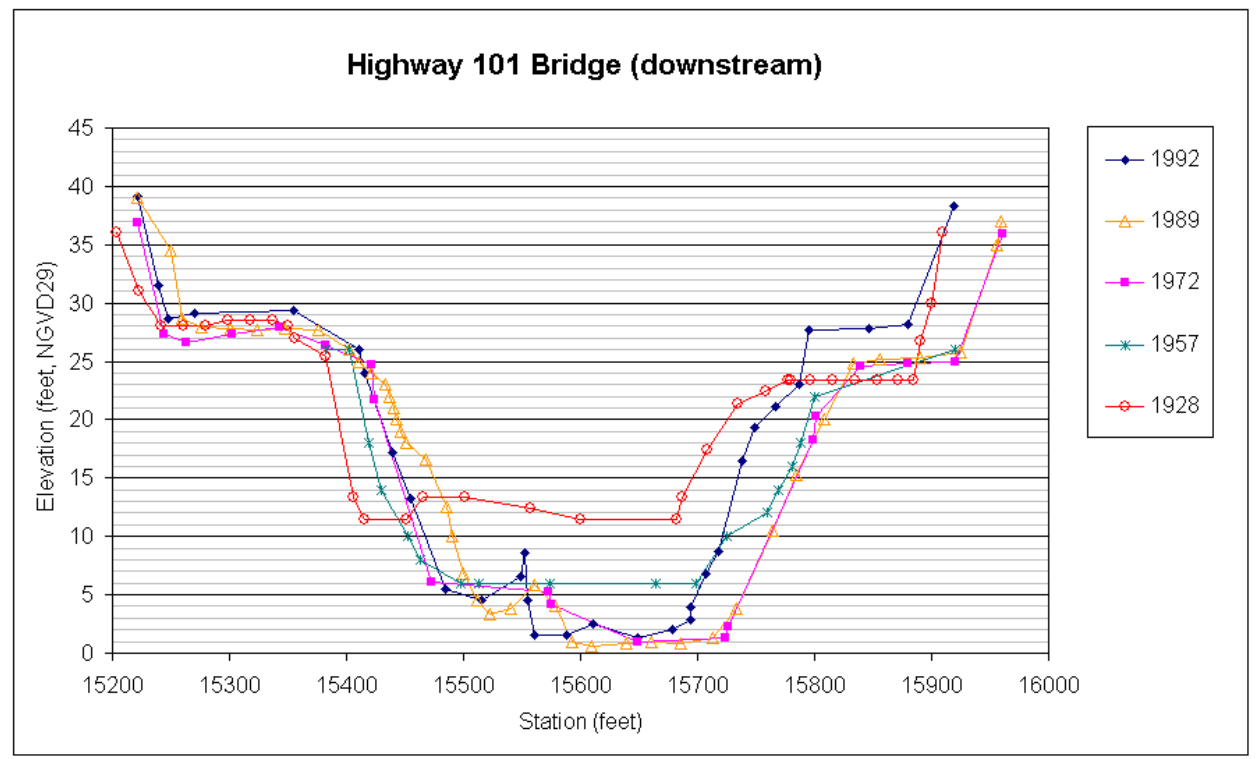

Figure 8. CalTrans surveyed cross section, downstream side of Highway 101 bridge

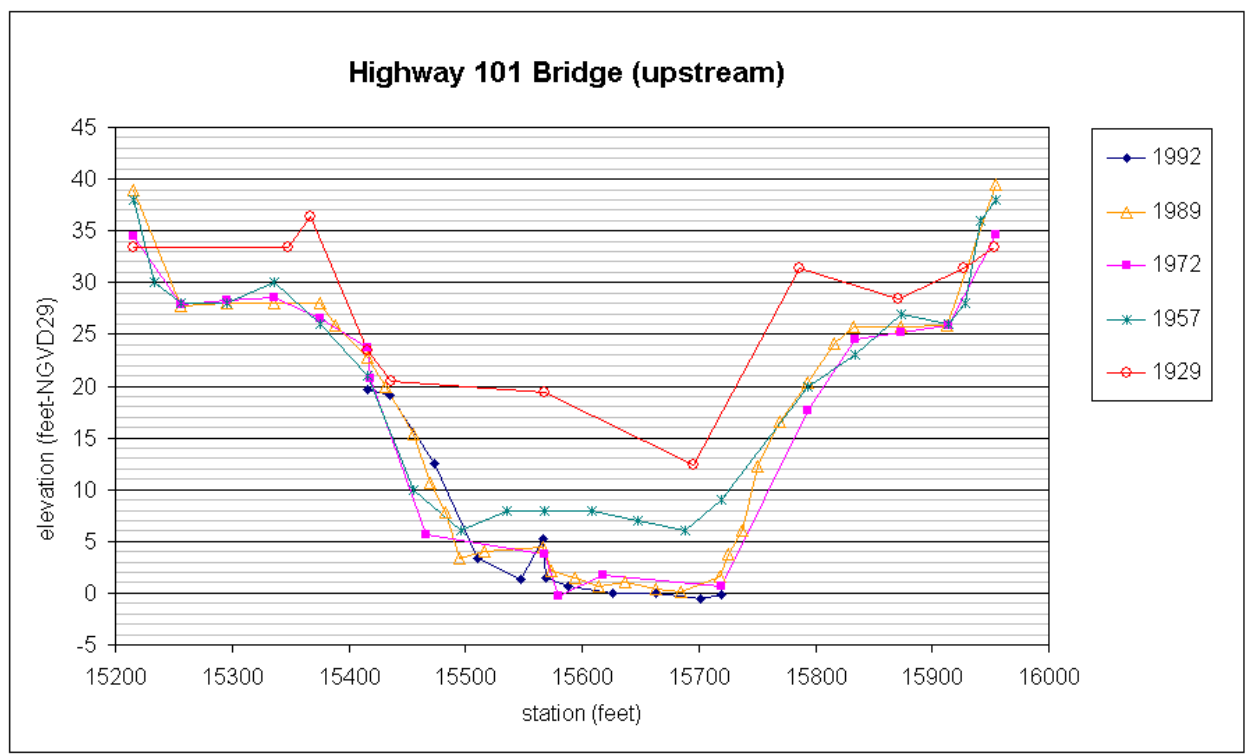

Figure 9. CalTrans surveyed cross section, upstream side of Highway 101 bridge 


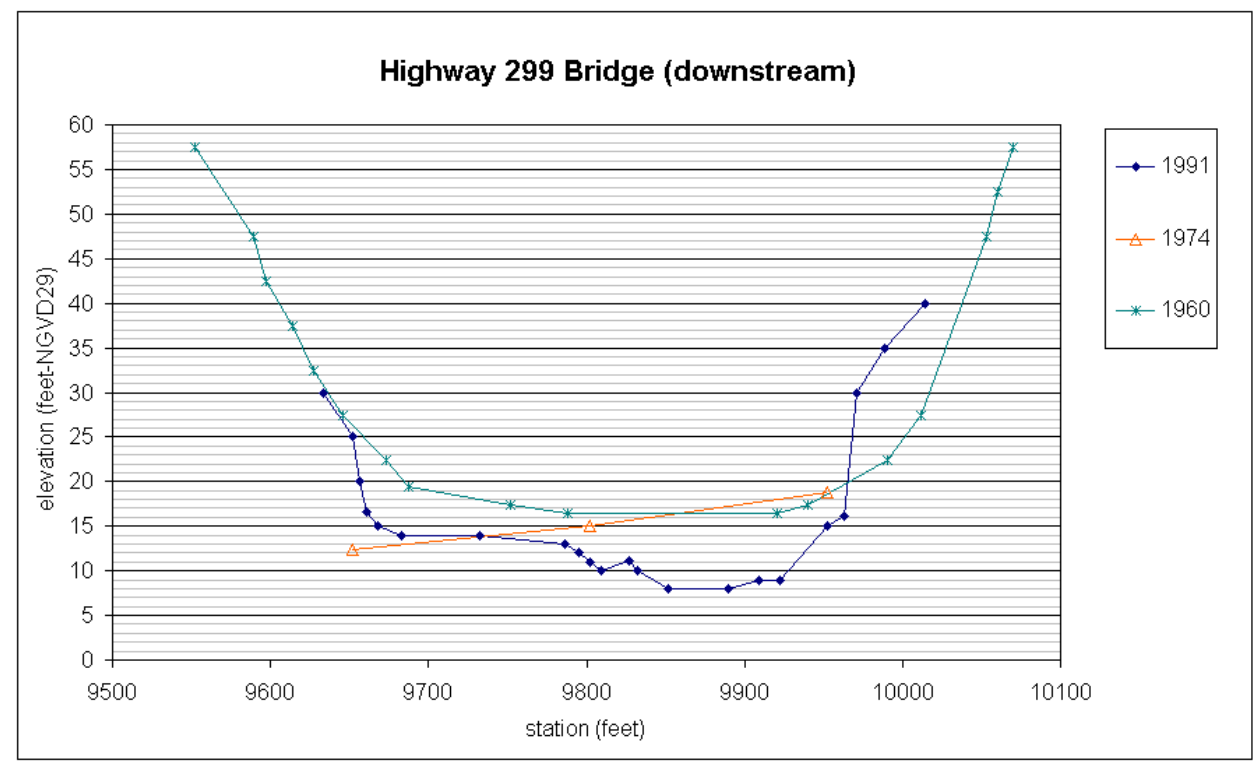

Figure 10. CalTrans surveyed cross section, downstream side of Highway 299 bridge

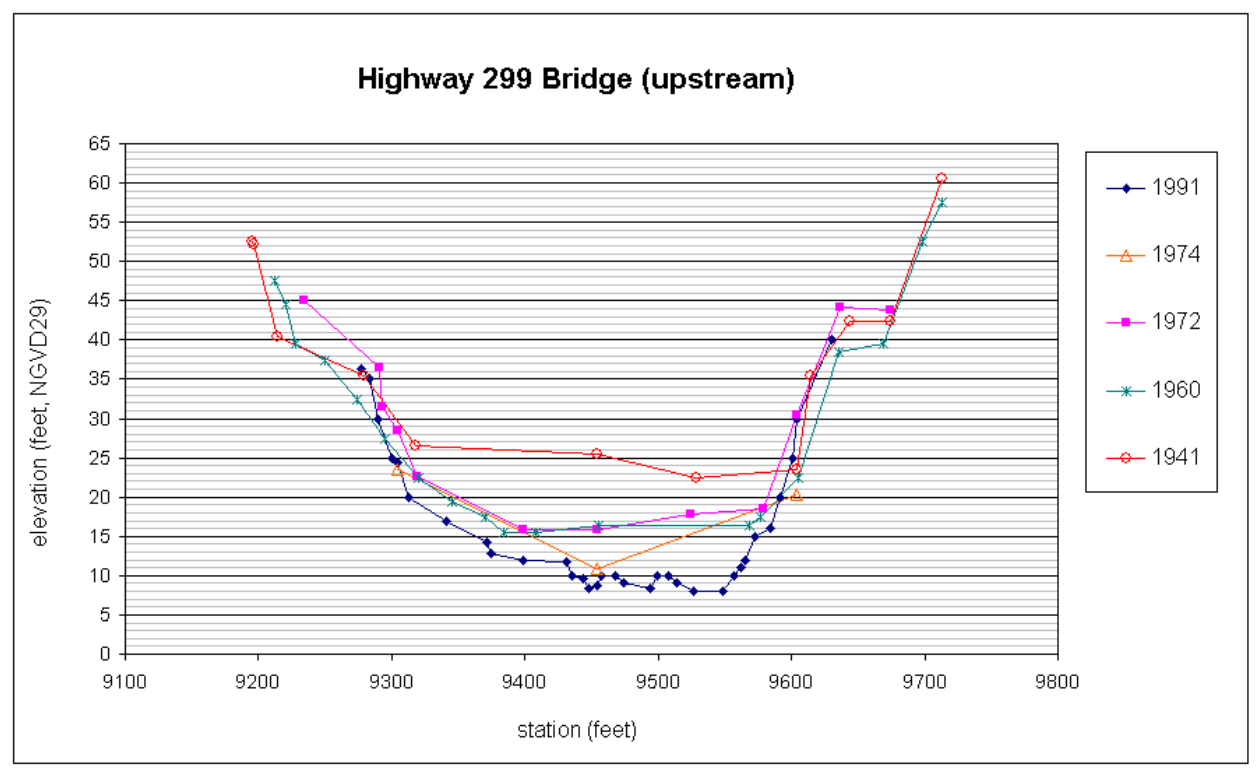

Figure 11. CalTrans surveyed cross section, upstream side of Highway 299 bridge

HBMWD. The Humboldt Bay Municipal Water District has construction drawings and cross section survey information for the region of the Mad River between the Highway 299 bridge and the AMRR bridge. Construction drawings from 1966 (Winzler and Kelly) ${ }^{1}$ show the riverbed elevation at pump stations 2, 3 , and 5 and above the pipelines associated with those pump stations for that year. River cross-section surveys show changes in bed elevation and channel

\footnotetext{
${ }^{1}$ Winzler and Kelly. (1966), op. cit., p. 9.
} 
geometry between 1992 and 1998 (Winzler and Kelly 1998), ${ }^{1}$ with some cross sections being in the immediate vicinity of the pump stations (2,3, and 5) shown in the 1966 drawings and some crossing or being close to Corps cross sections in that same area.

Because they were not located exactly on the surveyed cross sections, it was not possible to definitively determine bed elevation changes at the pump stations from the drawings available. While visual observations at the pump stations showed several feet of bed degradation when compared to the 1966 drawings, this is not necessarily indicative of a channelwide trend as it could be due to local scour. One drawing from 1966 did match well with a cross-section location from 1992-1998. Cross section number 6, near collector number 3 , is very close to the location of pipeline $\mathrm{B}$, which is shown in the 1966 drawings. Because the sections do not directly overlie one another, it is not possible to calculate exact amounts of channel change. Despite that, it is apparent from the drawings that there was approximately $7 \mathrm{ft}$ of bed degradation in this area between 1966 and 1998, with approximately $2 \mathrm{ft}$ of that occurring between 1992 and 1998.

For the other HBMWD cross sections, only cross section 7 showed obvious signs of bed degradation. Cross sections 1,4 , and 5 appeared to be relatively unchanged; cross sections 2 and 3 showed possible slight degradation; and cross section 8 showed possible slight aggradation. All of these cross sections cover the period from 1992 to 1998 with the exception of cross section 4, which covers the period from 1994 to 1998 . The possible slight changes in cross sections 2, 3, and 8 all appeared to be insignificant.

USACE. In 1970 and 1971 the Corps surveyed 30 river cross sections along the lower Mad River. The cross sections were numbered from downstream to upstream with cross section 1 located near the mouth of the river and cross section 30 located just below the fish hatchery near Blue Lake (see Figure 12 and Appendix B). The Corps sent the original cross section drawings, on 36- by 48-in. sheets, to the National Archives in San Bruno, CA for archiving, along with the original surveying field notes. When the Corps attempted to retrieve these materials from the National Archives in 1999, the drawing sheets were found along with a portion of the original surveying field notes, but the notes containing the cross section end point coordinates were missing. After an exhaustive search, the end point coordinates could not be found and were assumed lost.

In 1999 the Corps hired GeoTopo, a surveying firm from Oakland, CA, to relocate the end point coordinates from the 1971 cross-section surveys. After GeoTopo relocated and monumented the end points, local gravel operators were to have the cross sections surveyed. GeoTopo made several attempts to relocate the end points, all of which were unsuccessful due to gross errors in their surveying results. Errors included end point coordinates which placed some cross sections thousands of feet out into the Pacific Ocean, placed some cross sections in the wrong order, and placed some cross sections on the wrong side of Highway 299. Geotopo's last attempt to relocate the end points included enough

\footnotetext{
${ }^{1}$ Winzler and Kelly. (1998), op. cit., p. 9.
} 
significant errors that the horizontal and vertical positioning of the cross section end points and break points and was deemed too uncertain for use.

In early 2000, Pacific Affiliates and Streamline Planning Consultants attempted to assist GeoTopo in relocating the cross section end points. With their help, GeoTopo moved some cross section end points and left others in place. The gravel operators' consultants were able to complete all of the cross-section surveys, though some still had significant vertical errors. After talking with Pacific Affiliates about why and how they moved several of the GeoTopo crosssection end points, it was decided that the end point locations were of such poor quality and were based on such poor practices as to render the cross-section surveys useless.

By the latter half of 2000, the Corps had contracted another surveying firm, Richard B. Davis Inc. (R.B. Davis), to redo the entire survey. R.B. Davis conducted a thorough search for the original cross-section end points, using historical aerial photographs of the river from the time of the original survey and modern photogrammetric techniques. Despite their efforts, R.B. Davis was not able to locate very many of the original surveying end point monuments, though they did locate monuments, markers, and physical features from the 1971 survey at 17 of the cross sections. This was not particularly surprising given the amount of change that has occurred around the Mad River since 1971. By using original surveying end points, photogrammetric techniques, and physical feature descriptions included in the original 1971 survey cross-section drawings and field notes, R.B. Davis was able to re-establish end points for all 30 cross sections and to resurvey those cross sections (R. B. Davis, Inc. 2001).

Though all of the cross sections were resurveyed, there was still concern that some cross sections were not located in the same place as the original 1971 cross sections. Of particular concern were cross sections 8,11 , and 15 .

Because the 1971 cross sections were surveyed using NGVD-29 as the fixed vertical datum, they had to be adjusted to NAVD-88 for direct comparison with the R.B. Davis surveyed cross sections. R.B. Davis calculated the vertical adjustment from NGVD-29 to NAVD- 88 to be $+3.35 \mathrm{ft}$ and held this adjustment for all 30 cross sections. At several cross sections, it was evident that the original 1971 survey included vertical errors so the Corps asked R.B. Davis to adjust the cross-section drawings to reflect the probable 1971 conditions. R.B. Davis noted these errors in their field notes and on the cross-section drawings. After receiving the final R.B. Davis cross sections, every cross section line was walked to compare the physical features and sediment deposits to the 1971 and 2000 surveys. In some instances, the 3.35-ft adjustment from the 1971 survey (NGVD29) to NAVD-88, or the additional adjustment by R.B. Davis (based on field observations) did not appear to be accurate. For these cross sections, the 1971 cross sections were further adjusted (vertically) to match the likely 1971 conditions. While vertically adjusting historic survey information to match physical features may initially seem unusual, the errors identified with the 1971 survey and the fact that the adjustments were based on obvious physical features that were not likely to have changed since 1971 justified these actions. The cross section drawings presented in this report (see Appendix B) reflect the final vertical adjustments with the best estimates of the 1971 cross-section positions. Cross-section figures and notes are difficult to read in print but are clear in the electronic (PDF) version of this report. 


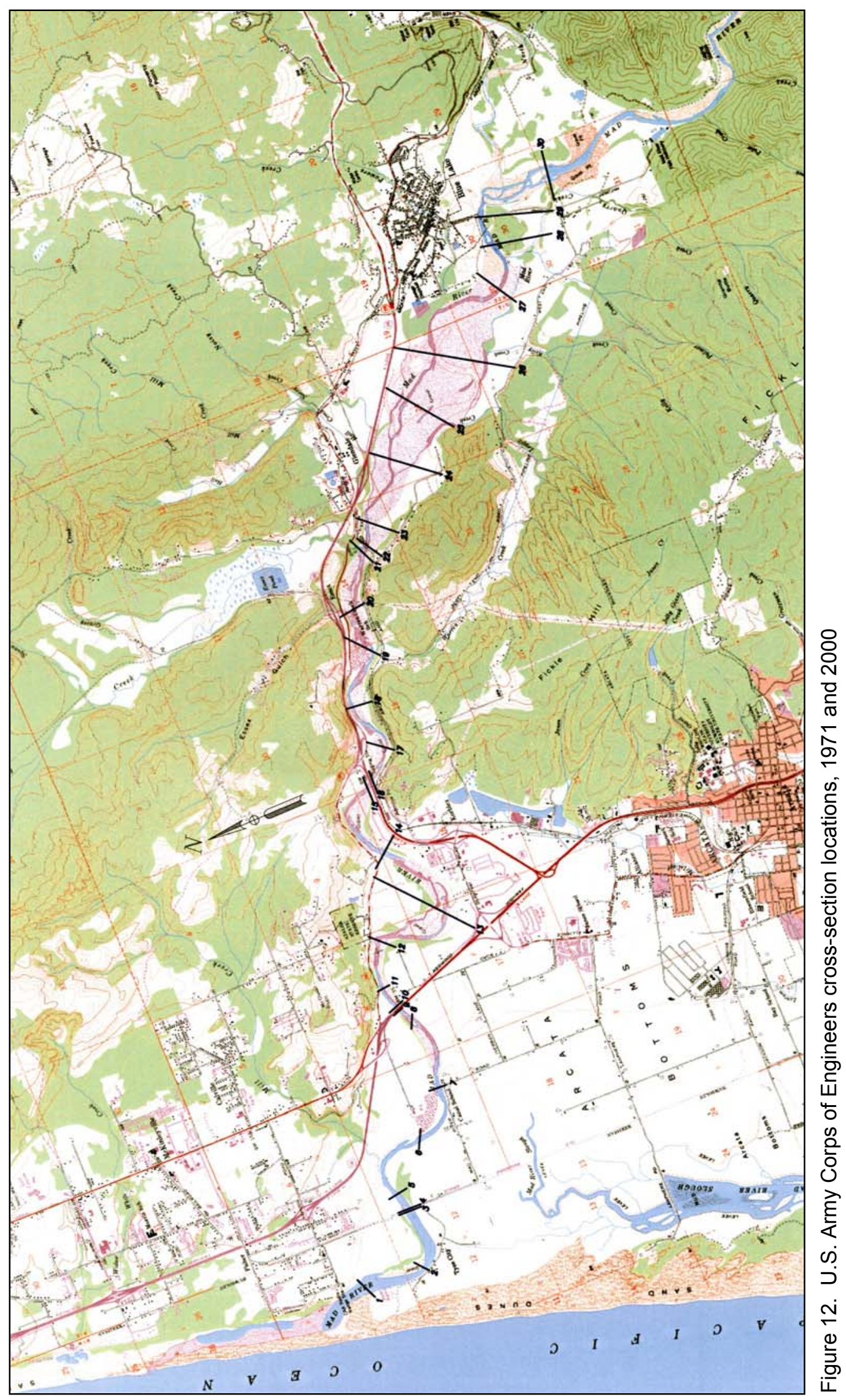


The 1971 and 2000 Corps of Engineers' cross sections were initially used to evaluate changes in river morphology and sediment transport in two ways. Initially, cross sections at specific locations from 1971 and 2000 were compared to each other to determine whether or not the river had widened, deepened, shallowed, or shifted. Average (across each cross section) changes in bed elevation were plotted along a longitudinal profile of the river and examined for vertical change trends (see Figure 13).

After the cross sections were examined individually, they were examined as a group using the average-end-area method to estimate the total storage change (gain or loss) in the study area between 1971 and 2000. This was done by calculating the change in cross-section area at each cross section, averaging the change between adjacent cross sections, and multiplying this average change by the distance between the adjacent cross sections. By applying this analysis along the entire study reach, the volumetric change in river sediment storage between 1971 and 2000 was estimated (Table 4).

\begin{tabular}{|c|c|c|c|}
\hline \multicolumn{4}{|c|}{\begin{tabular}{|l} 
Table 4 \\
Volumetric Change in River from Average-End-Area Method
\end{tabular}} \\
\hline Section of River & Total Change, cu yd & $\begin{array}{l}\text { Average Annual } \\
\text { Change, cu yd/year } \\
1971-2000\end{array}$ & $\begin{array}{l}\text { Average Annual } \\
\text { Change (tons/year) } \\
1971-2000\end{array}$ \\
\hline Above 101 Bridge & \begin{tabular}{|c|}
$-3,270,629$ \\
\end{tabular} & $\begin{array}{l}-109,021 \\
\end{array}$ & $-150,449$ \\
\hline $\mid$\begin{tabular}{||l|} 
Between $101 \& 299$ Bridges \\
\end{tabular} & 710,761 & 23,692 & $+32,695$ \\
\hline Above 299 Bridge & $-3,981,389$ & $-132,713$ & $-183,144$ \\
\hline
\end{tabular}

When assessing the results of this analysis method, it is important to consider that there may be considerable error due to having only 30 cross sections for a study area that is approximately 13 miles long and includes significant variations in cross section geometry. Additional errors in this analysis could result from year 2000 cross sections that were not located exactly in the same location as the year 1971 cross sections and from vertical errors in the 1971 cross-section surveys. To minimize these errors, it was assumed there was no change in cross sectional area between 1971 and 2000 at cross sections 8,11, and 15. While this is probably not correct, it was decided that it was better to assume no change than to assume too great a change due to the errors previously described. The results from this analysis are included in the sediment budget presented in the "Sediment Transport" section in this chapter. 


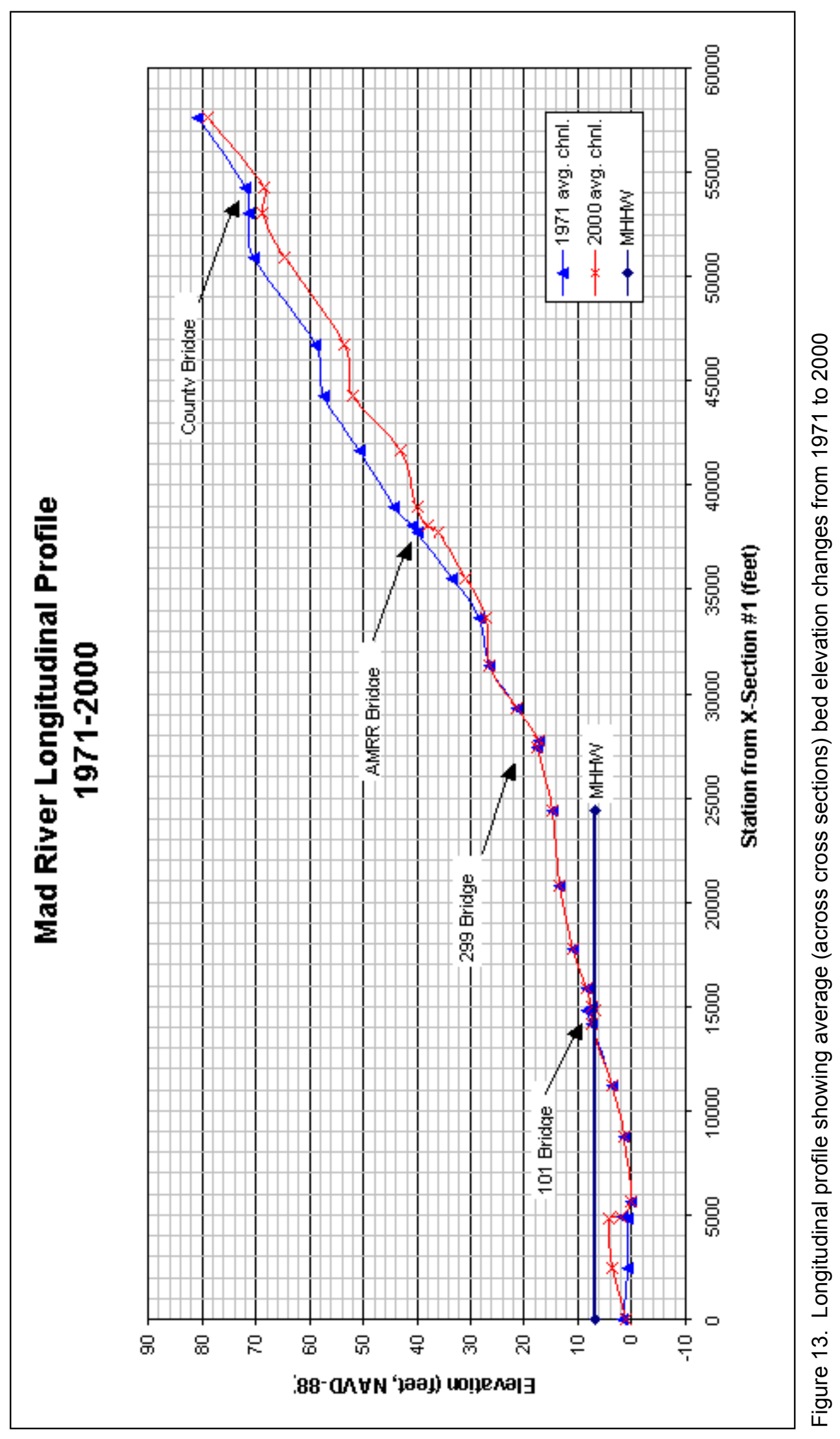




\section{Gravel extraction}

People have been extracting (mining) gravel from the Mad River since the 1800s but increased their activities dramatically in the early 1960s. The State of California has sporadic records of extraction volumes, but no compiled records were found for use in this study. Annual gravel extraction volumes used in this study were compiled by Mr. Randy Klein of CHERT and were reviewed and approved by the California State Office of Mine Reclamation (Mike Sandecki, Personal Communication, 21 September 2000) (see Appendix G, Tables G-1 and G-2). After a public presentation in Eureka, CA, in May 2001, Mr. Rob McLaughlin from Eureka Readymix commented that he felt some of the extraction volumes included in Mr. Klein's table were incorrect and offered to provide additional information on annual gravel extraction volumes. Mr. McLaughlin had Pacific Affiliates compile and provide this additional information in early 2002. Mr. Klein's table was updated accordingly (see Appendix G, Table G-3). For use in sediment budget calculations, the annual extraction volumes for the years 1971-2000 (inclusive) were used because the 1971 survey was completed prior to the 1971 gravel-mining season and the 2000 survey was completed after the 2000 gravel-mining season. While some cross section surveys may have been completed during periods of active gravel mining, and not prior to or after the gravel-mining season, including gravel extraction volumes for this full 30-year period provided the most representative data for analysis.

\section{Other sources of information}

Although this report is primarily original work, information from two other sources was found to be of particular use.

Andre Lehre, professor at Humboldt State University and a member of CHERT, authored the sediment transport portion of the 1993 PEIR on the Mad River (see Lehre et al. 1993). ${ }^{1}$ For his report, Lehre surveyed river cross sections in the area near the HBMWD facilities and collected bed-material data. It was difficult to add Lehre's cross section data to the Corps' cross section data due to vertical datum/control issues with his data. Nonetheless, Lehre's cross section data was found to be particularly useful in documenting recent changes in the area around the HBMWD facilities.

Tolhurst (1995) performed an analysis that included digitizing the channel boundaries shown on aerial photographs for year-to-year comparison. This is similar to the procedure previously described in the "Aerial photographs" section in this chapter. While it was difficult to perform this analysis, the information Tolhurst described was found to be of qualitative use.

\section{Sediment Transport}

Estimating the sediment transport capacity for the study reach of the Mad River was a critical portion of the sediment budget analysis. Although sediment

\footnotetext{
${ }^{1}$ Lehre, op. cit., p. 9.
} 
transport calculations that are based on sediment transport equations and models can have wide variability, a thorough analysis based on the appropriate equations can be useful when combined with other approaches. For the study, actual bed material and bed-load data were used as the basis for the sediment transport analysis. The majority of bed-material and bed-load data were collected for the Corps by the U.S.G.S. in 1972, 1973, and 1974. Additional bed-material data were collected by Andre Lehre ${ }^{1}$ in 1989. Sediment transport calculations were supplemented with historic data from the infilling of Sweasey Dam (U.S. Army Engineer District, San Francisco, 1964). ${ }^{2}$

\section{Bed load and bed material}

Bed load. The USGS collected bed-load samples during varying flows using a Helley-Smith bed-load sampler with a 3-in. opening. This type of bed-load sampler is commonly used but does have limitations. Specifically, with a 3-in. opening, the sampler can only collect sediment particles that are less than 3 in. in size and may undersample sediment particles greater than $1 \frac{1}{2}$ in. in size. Also, the sampler will only collect sediment particles within 3 in. of the riverbed. At high flows, the thickness of the bed-load layer may be thicker than this limit (resulting in undersampling) while at low flows the bed-load layer may be thinner, allowing the sampler to also collect suspended bed-material load or wash-load particles (resulting in oversampling).

Bed-load sampling results for the Arcata, Blue Lake, Kneeland, and Korbel gauge locations are presented in Appendix E, Table E-1. Each sample collected represents a composite or average of several samples taken across the width of the river channel at each specified flow rate. The number of samples collected at each location for each given flow rate is important due to the spatial variability of bed-load transport across a channel cross section. Larger numbers of samples are preferred to account for this variability and to present an accurate picture of the total average bed-load transport across the entire cross section. For the Arcata location, four to seven samples were collected for each flow rate. For the Blue Lake and Kneeland locations, five samples were collected for each flow rate. For the Korbel location, four samples were collected for the given flow rate. While it would have been preferable to have a greater number of samples for each flow rate, the numbers collected were greater than is often the case and can be expected to provide reasonable results.

The USGS sieved the bed-load samples to determine the grain-size distribution for each sample and its associated flow rate (see Appendix E, Tables E-2, E-3, and E-4). Conventional sediment transport theory leads to the assumption that with increasing flow rates and the accompanying increase in water depth and velocity (and thus an increase in bed shear stress) there should be an increase in the maximum and average size of particles transported as bed

\footnotetext{
${ }^{1}$ Lehre, op. cit., p. 9.

${ }^{2}$ U.S. Army Engineer District, San Francisco. (1964). Internal Memorandum documenting inspections and surveys of Sweasey Dam by the U.S. Army Engineer District, San Francisco.
} 
load. The grain-size distributions for bed-load samples from Arcata, Blue Lake, and Kneeland were plotted to examine coarsening and fining trends with varying flow rates. For these three locations, only the bed-load samples collected at the Kneeland gauge showed a steady coarsening of the D50 with increasing flow rates. The Arcata gauge D50 values appear reasonable at high flows but are highly variable at lower flow rates. There is no apparent trend for the D50 values at the Blue Lake gauge. With the limited number of samples collected at Kneeland and Blue Lake, the trends (or lack of trends) may or may not be significant. The number of samples collected at Arcata, however, led to questioning why the sample data did not exhibit the expected trend and whether or not this would affect sediment transport calculations. With the age of the data, and the changed river conditions since the time the data were collected, it was not possible to definitively conclude the reason for the absence of the expected trend. The apparent variability and lack of trend in grain-size distributions may be due to bed-load sampling during a moving pavement phase of sediment transport. Without detailed observations and field notes from the USGS bed-load sampling, however, this is difficult (if not impossible) to determine.

Bed material. During field observations of the Mad River no evidence of an armor layer on the bed was found anywhere within the study reach. However, there was slightly coarser sediment on the surface of the bed than $12 \mathrm{in}$. below the surface (see Figures 14 and 15). There were also significant differences between bed-material gradations in the areas where gravel mining occurred and where it did not occur (see Figures 14 and 16). Despite the much larger particles present in the area where mining did not occur, the distinct layer typical of armoring was still not noticed, only a fining of material with depth. Bed-material photos from the previous locations and additional locations are presented in Appendix F as Figures F-2, F-3, F-4, and F-5 for ease of comparison while examining bed-material data and graphs.

The USGS collected bed-material data at the Arcata gauge location during low-flow periods in 1969, 1972, and 1974. Though their records do not document the specific method used to collect the bed-material samples, the USGS believes the samples were collected using a normal shovel. ${ }^{1}$ As with the bed-load samples, the USGS sieved the bed-material samples to determine their grain-size distributions. USGS bed-material data are presented in Appendix F, Table F-1. A plot of the bed-material grain-size distributions is presented in Appendix F, Figure F-1.

Lehre $(1993)^{2}$ collected additional bed-material data near the Mad River fish hatchery (above USACE cross section 30 and below the Blue Lake gauge location) in 1989. Lehre used students from a Humboldt State University geology class and the pebble count method to collect two sets of bed-material samples. Lehre's bed-material sampling results are presented in Appendix F, Table F-2.

\footnotetext{
${ }^{1}$ Personal Communication, 22 September 2000, Mike Webster, Chief, USGS Field Office, Ukiah, CA..

${ }^{2}$ Lehre, op. cit., p. 9.
} 


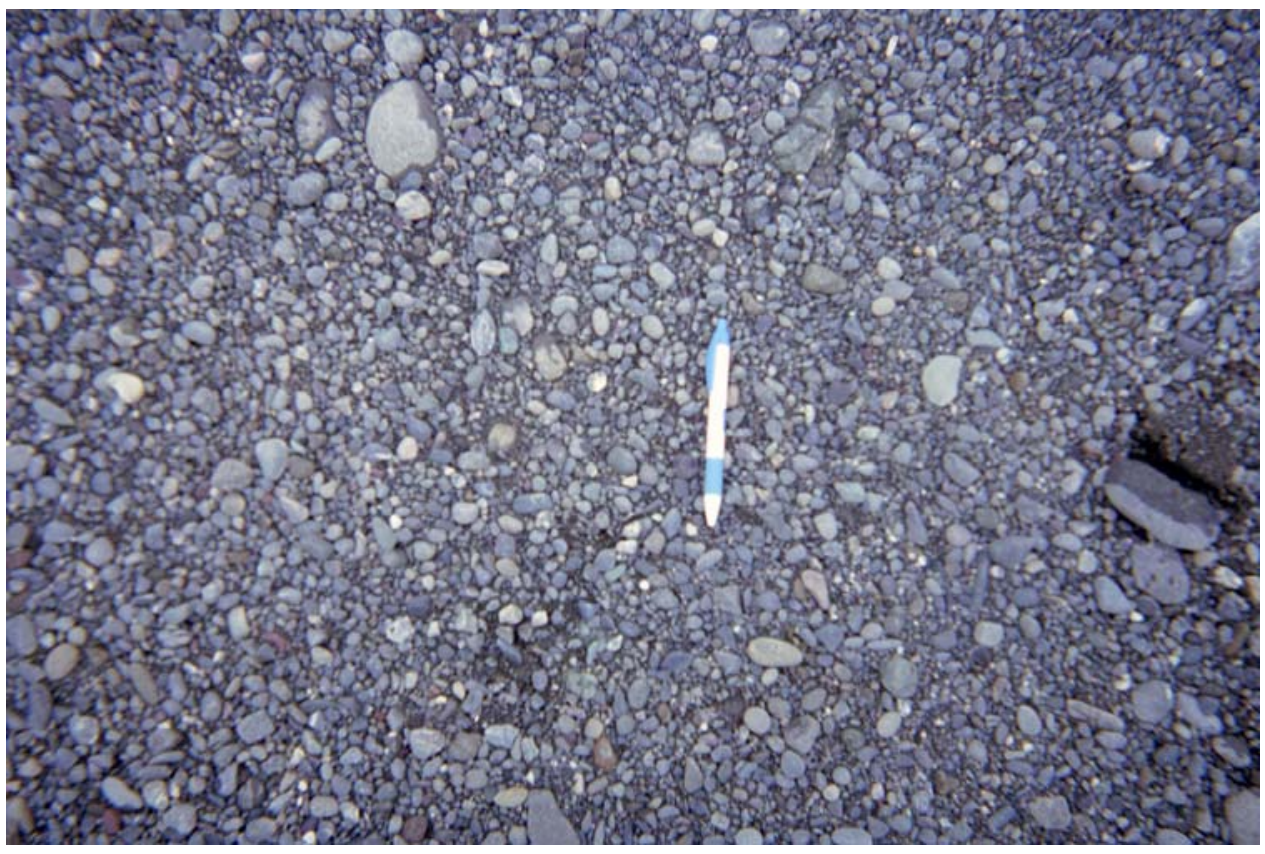

Figure 14. Bed material at surface in mining area, cross section 27 (right side)

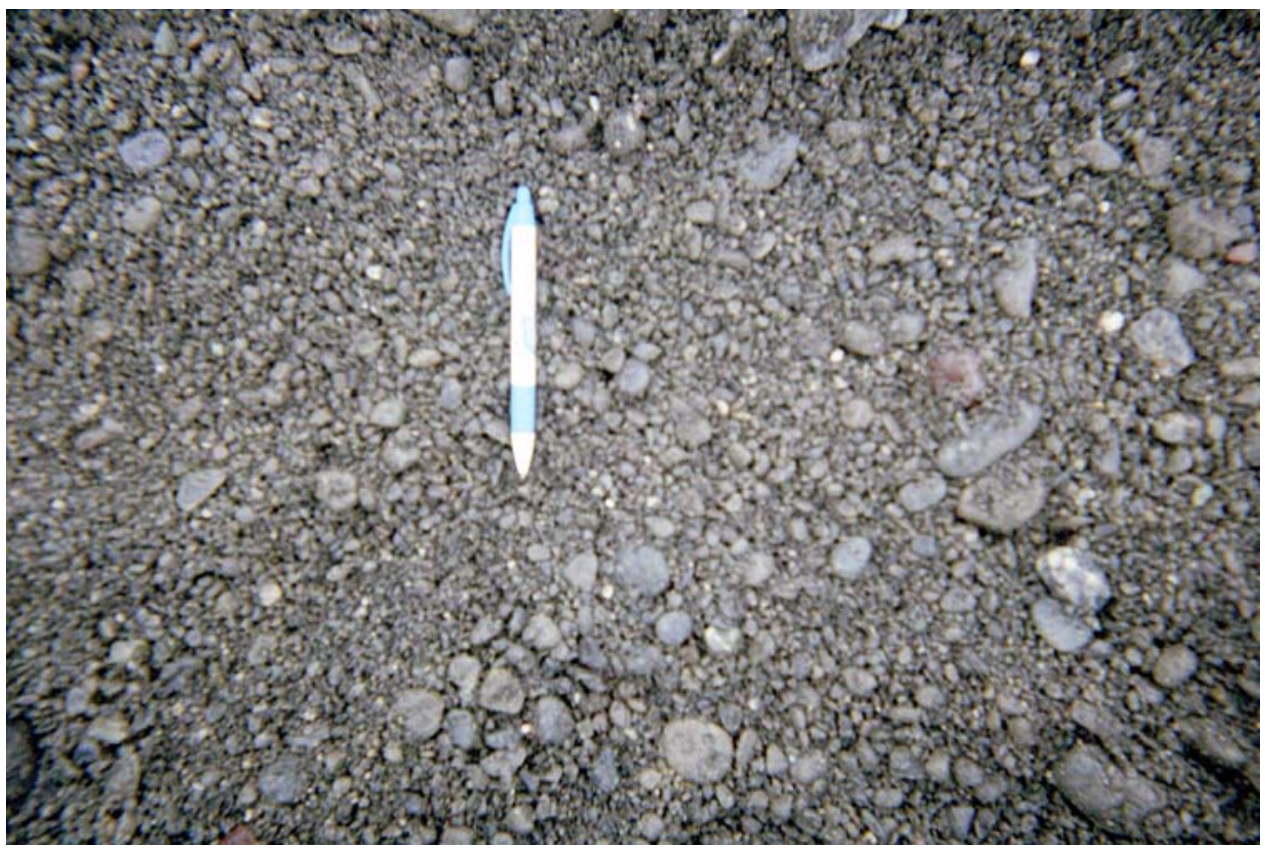

Figure 15. Bed material $1 \mathrm{ft}$ below ground surface, cross section 27 (right side) 


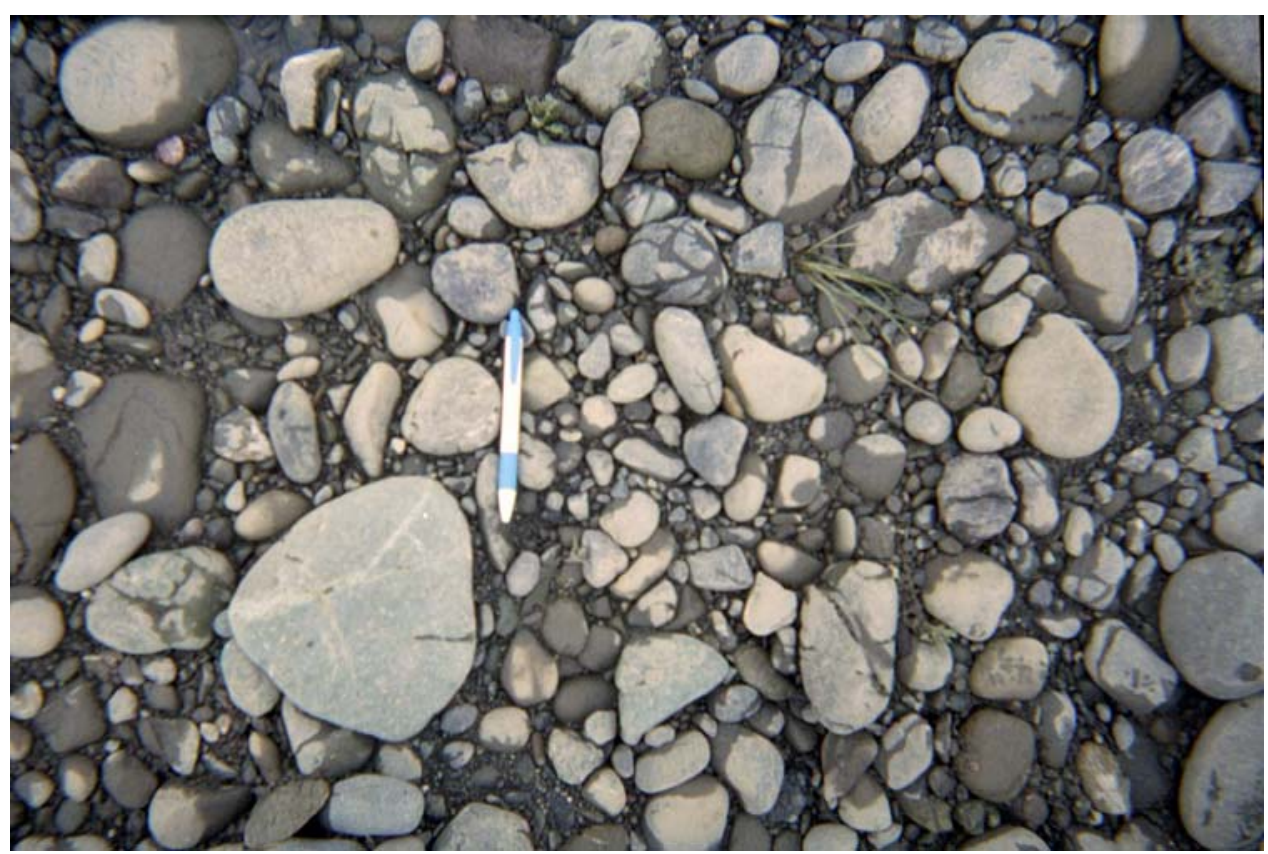

Figure 16. Bed material at surface, not in mining area, cross section 27 (right side)

Sediment rating curves. In the work it performed for the Corps in the early 1970s, the USGS collected bed-load samples at varying flow rates at the USGS gauging stations at Arcata, Blue Lake, and Kneeland and used this data to develop sediment rating curves. In its report (Brown 1975), the USGS presented the data it collected along with the sediment rating curves it developed from this data. As part of this analysis, the USGS sediment rating curve for the Arcata gauge was updated using additional bed-load and flow information obtained from the USGS. The resulting data points and curves for the Arcata, Blue Lake, and Kneeland gauges are presented in Figure 17. In this figure, the Arcata gauge data points are shown as solid diamonds, the Blue Lake Gauge data points are shown as hollow circles, and the Kneeland gauge data points are each depicted with an "x." Although the USGS did plot a sediment rating curve for the Blue Lake gauge data, it was not included in Figure 17 due to the limited amount of data and the tight cluster of the data. The decision to exclude the Blue Lake gauge rating curve from this figure should not be interpreted as a lack of confidence in the data collected. The distribution of bed-load data with varying flow rates found at Blue Lake is not at all unusual and indicates that the Blue Lake location likely transports more sediment for a given flow rate than does the Arcata location. For analysis of the sediment rating curve at Blue Lake, the curve developed by the USGS and presented in Brown's 1975 report is recommended.

\section{Sediment transport equations}

In performing the sediment transport analysis, several different sediment transport equations were included. The majority of these equations were developed for gravel transport situations, but a few were developed for sand 
transport situations. The equations considered, and the range of sediment sizes used to develop those equations, are listed in Table 5.

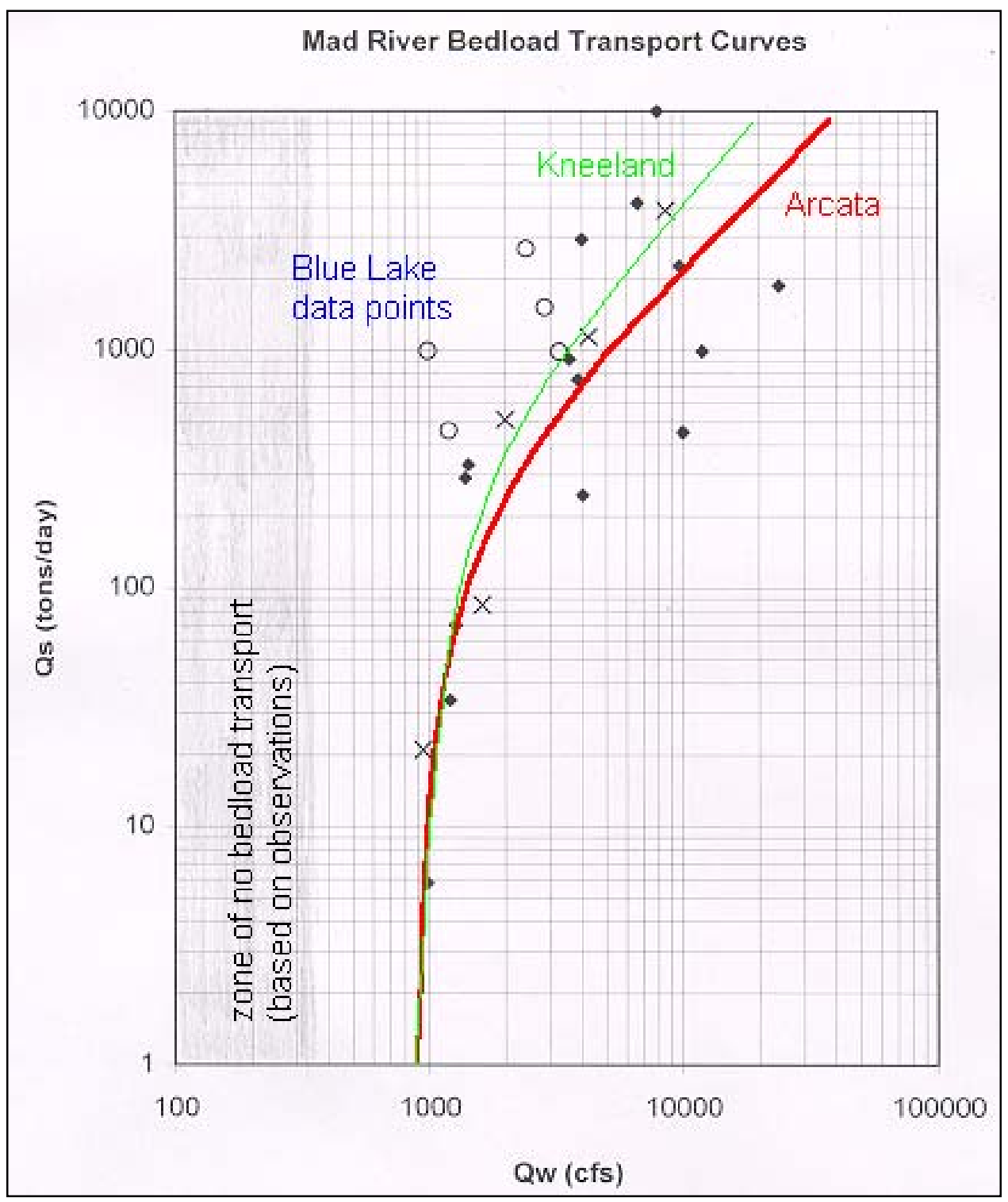

Figure 17. Bed-load data and sediment rating curves

\section{Table 5}

Sediment Transport Equations Evaluated for Lower Mad River

\begin{tabular}{||l|l|l||}
\hline \hline Equation & Particle Size Range, $\mathbf{~ m m}$ & Gravel or Sand \\
\hline \hline Ackers and White & $0.04-7.0$ & Both \\
\hline Bagnold & & Both \\
\hline Brownlie & $0.086-1.4$ & Sand \\
\hline Meyer-Peter and Muller & $0.4-29$ & Both \\
\hline Yang (sand) & $0.15-1.7$ & Sand \\
\hline Yang (gravel) & $2.5-7.0$ & Gravel \\
\hline
\end{tabular}


In selecting a specific equation to describe sediment transport in the Mad River, the equation that provided the best match to the measured data was sought. Each equation was plotted on a single figure that included the USGS measured data. This was done for each of the three USGS gauging stations with sediment data (Arcata, Kneeland, and Blue Lake). This analysis was performed using two different methods. Initially, each equation was plotted using three sets of values (variables) to represent the sediment and flow conditions at the three gauging stations in the river. After performing this analysis, the method was modified by using a range of values for each gauge location, based on transport of different sediment size classes at various flow conditions, with the total transport being the summed weighted averages. This method resulted in a more realistic and accurate representation of actual sediment transport. Results of sediment transport equations for Arcata, Blue Lake, and Kneeland are shown in Figures 18, 19, and 20 , respectively. On each of these plots, data for each equation are plotted along with a linearly regressed line. Original bed-load data, as collected and reported by the USGS, is also shown on the plots.

Comparison of the various sediment transport equations to the actual data collected at each location led to the selection of Brownlie's formula as the most representative for describing sediment transport in the study area. While this equation may initially seem inappropriate for use on the Mad River, due to its development as a sand transport equation, the goal of equation comparison is to identify the equation that most accurately reproduces the collected data. Brownlie's equation clearly does this for both the Arcata gauge (lower end of the study area) and the Blue Lake gauge (upper end of the study area).

In attempting to determine why an equation developed for sand transport conditions is such a good fit for a gravel-bed river, one must examine the grainsize distributions for the bed-load data and bed-material data on the Mad River. Figure E-1 shows the bed-load samples collected at the Arcata gauge to be primarily sand, while Figures E-2 and E-3 show the bed-load samples collected at the Blue Lake and Kneeland gauges to be primarily fine gravel. Figure F-1 shows the bed-material samples collected at the Arcata gauge to be primarily gravel. A possible explanation for this could be that the Kneeland and Blue Lake locations have the capacity to transport gravels, but the Arcata location does not. This is not the case, however, as an examination of the critical shear stress necessary to move various sized sediments at the three locations indicates that the Arcata location has the capacity to move much coarser sediments than were collected in bed-load samples under various flow conditions (see Figures 21 and E-1). The absence of coarser material in the bed-load samples collected at Arcata could be due to a decrease in the amount of coarse material upstream, caused by gravel mining, by the natural fining of sediments as they move downstream (not a likely cause in this situation), or by other conditions related to sampling methods or bed conditions at the time of sampling. Without the field notes of the USGS personnel who collected the samples, it is difficult (or impossible) to discern the precise cause of this situation. If one considers that the bed-load samples collected at Arcata might underrepresent the amount of gravel in the bed load, then the Meyer-Peter and Muller equation may be more appropriate for representing conditions on the Mad River (see Figures 18, 19, and 20). 


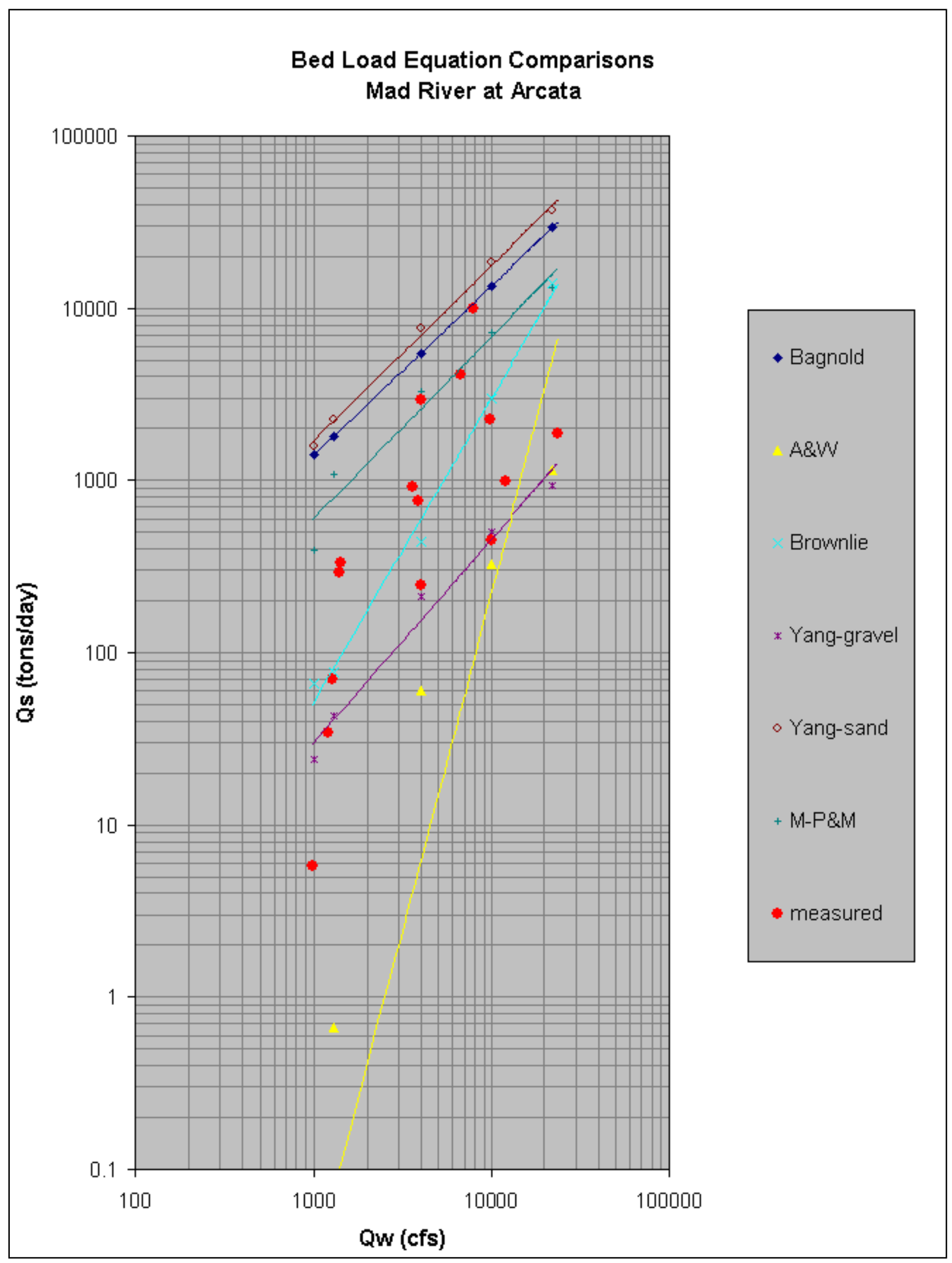

Figure 18. Bed-load equations and data for Arcata gauge 


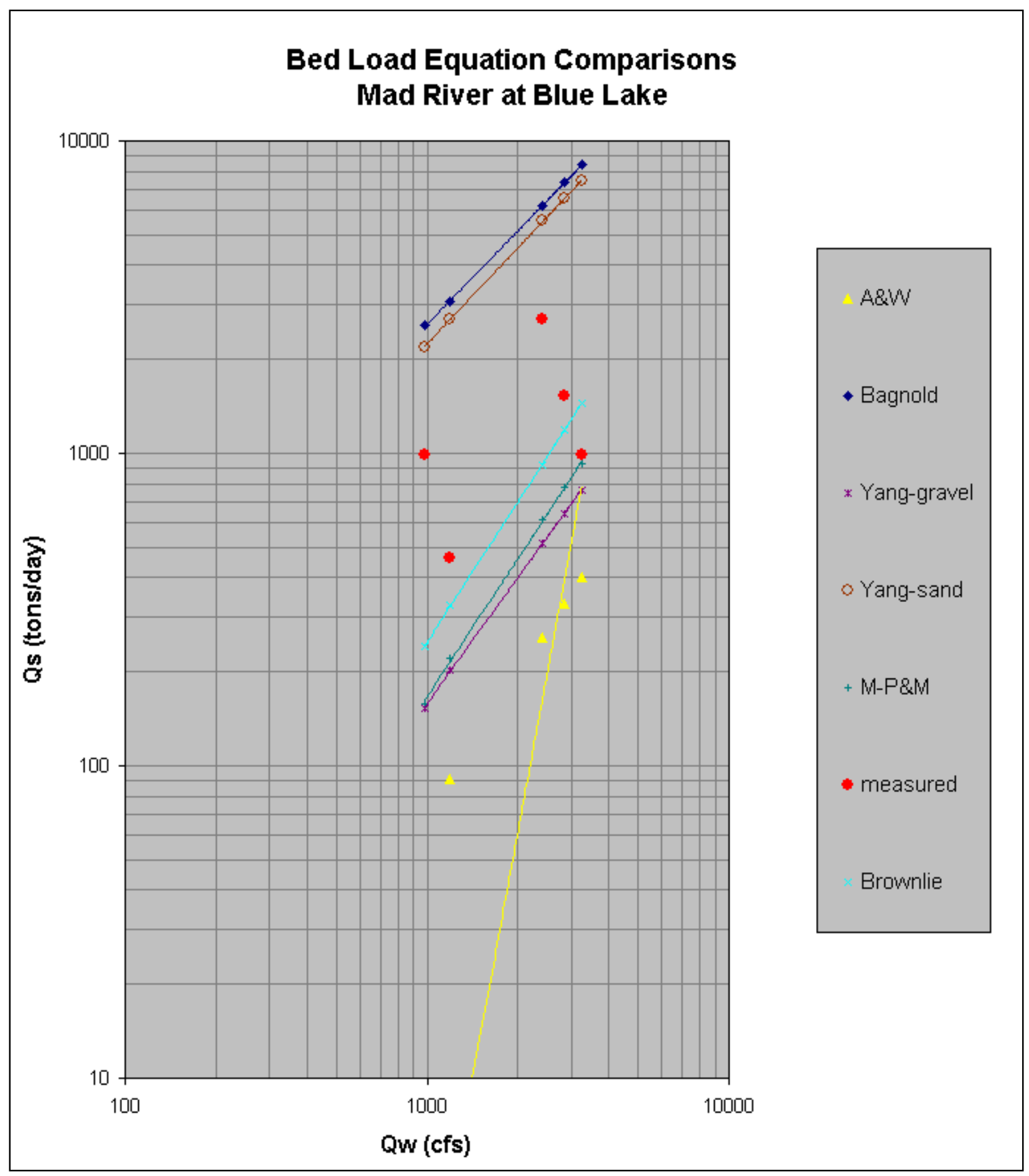

Figure 19. Bed-load equations and data for Blue Lake gauge 


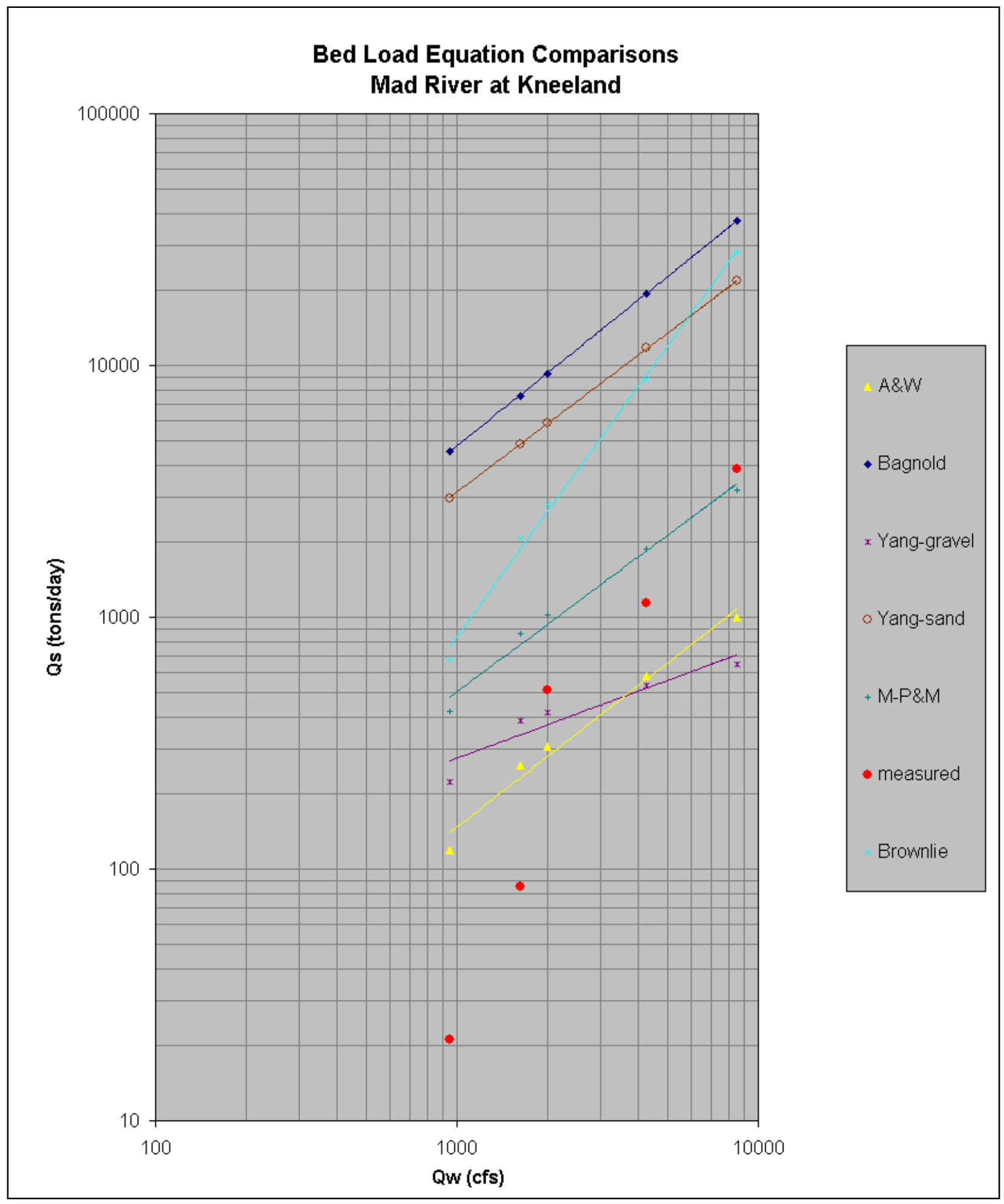

Figure 20. Bed-load equations and data for Kneeland gauge 


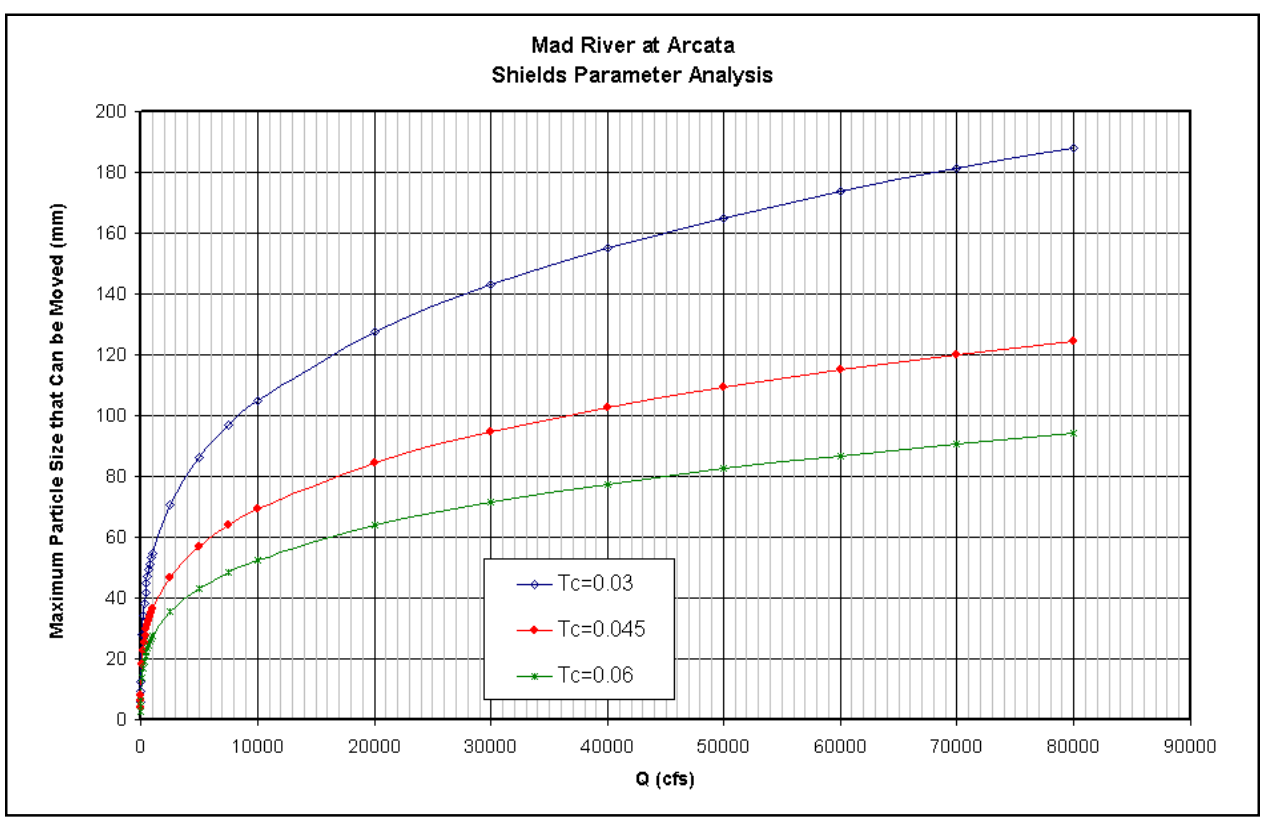

Figure 21. Shield's parameter analysis to estimate flows required to move various sized particles at Arcata gauge location

Though this could justify using the Meyer-Peter and Muller equation (which was developed using sand and gravel data) in lieu of Brownlie's equation, the justification is not adequate. Using the Meyer-Peter and Muller equation for sediment transport calculations would require assuming that the data collected were not representative of the actual conditions and would require speculating as to what those actual conditions should be. This would create additional uncertainty in the analysis.

\section{Sweasey Dam}

As previously mentioned in "Sediment rating curves," the bed-load data collected for Blue Lake makes it difficult to fit a bed-load transport curve or to match a transport equation to the data. As an alternate means of estimating bedload transport into the Mad River study area, records associated with Sweasey Dam, formerly located upstream of the Blue Lake gauge were examined. Sweasey Dam was constructed in 1938 as a water supply dam for the city of Eureka. Upon its completion, it had an (operational) impoundment capacity of 2,000 acre-ft and a total impoundment capacity of 3,000 acre-ft. Though Sweasey Dam was built with a low-elevation outlet designed to flush sediments from behind the dam, this outlet became inoperable in 1941, and the area behind the dam began to rapidly fill with sediment. Due to rapid sedimentation behind the dam, the Corps was periodically asked to examine the dam and to assess its life expectancy. Corps records indicate that 14 years after the sediment outlet became inoperational, the dam had trapped 1,530 acre-ft, or 2,468,400 cu yd, of sediment. ${ }^{1}$ This is an average annual sedimentation rate of $176,314 \mathrm{cu}$ yd per year. Assuming a bulk density of 1.38 tons/cu $\mathrm{yd}$, this is the equivalent of 243,314 tons per year.

\footnotetext{
${ }^{1}$ USAED, San Francisco, op. cit. p. 29.
} 
To estimate the portion of this material that would have completely passed through the study area, it was assumed that all but the coarse-sand and gravel particles would have moved as wash load. Using the 10 percent by weight grain size from bed-material samples from the Mad River for the cutoff was also considered, as this value is often used to estimate wash load. However, due to the absence of bed-material samples at Blue Lake, a lack of knowledge concerning the sampling procedures for the bed-load data USGS collected, the potential for a bed-load sampler to undersample large-sized particles, and the fact that the Mad River is a gravel-bed river, it was decided it would be better to assume throughput of sediments smaller than coarse sand. Because the percentage of fine to medium sand in the bed-load samples collected at Blue Lake was 25 percent, the transport rate into Sweasey Dam (and into the study area, since Sweasey Dam has been removed) was reduced by 25 percent to arrive at a total (gravel) bedload transport rate of 182,485 tons per year or $132,236 \mathrm{cu}$ yd per year.

\section{Bed load - suspended load relationship}

In sediment transport analyses, people often assume a relationship between bed load and suspended load. The most common relationship assumed is that bed-load transport is equal to approximately 5 to 10 percent of the suspendedload transport. This approach was considered for another estimate of bed-load transport due to the scarcity of bed-load data and abundance of suspended-load data for the area. Prior to using it, however, the suspended load data that were collected at the same times the bed-load samples were collected were examined and plotted against one another as shown in Figure 17. Along with the data, lines were plotted that represent 5 and 10 percent of the suspended-load values. The wide scatter of the data shown in Figure 17 led to the determination that it was not appropriate to use a percentage of the suspended-load transport to estimate bed-load transport.

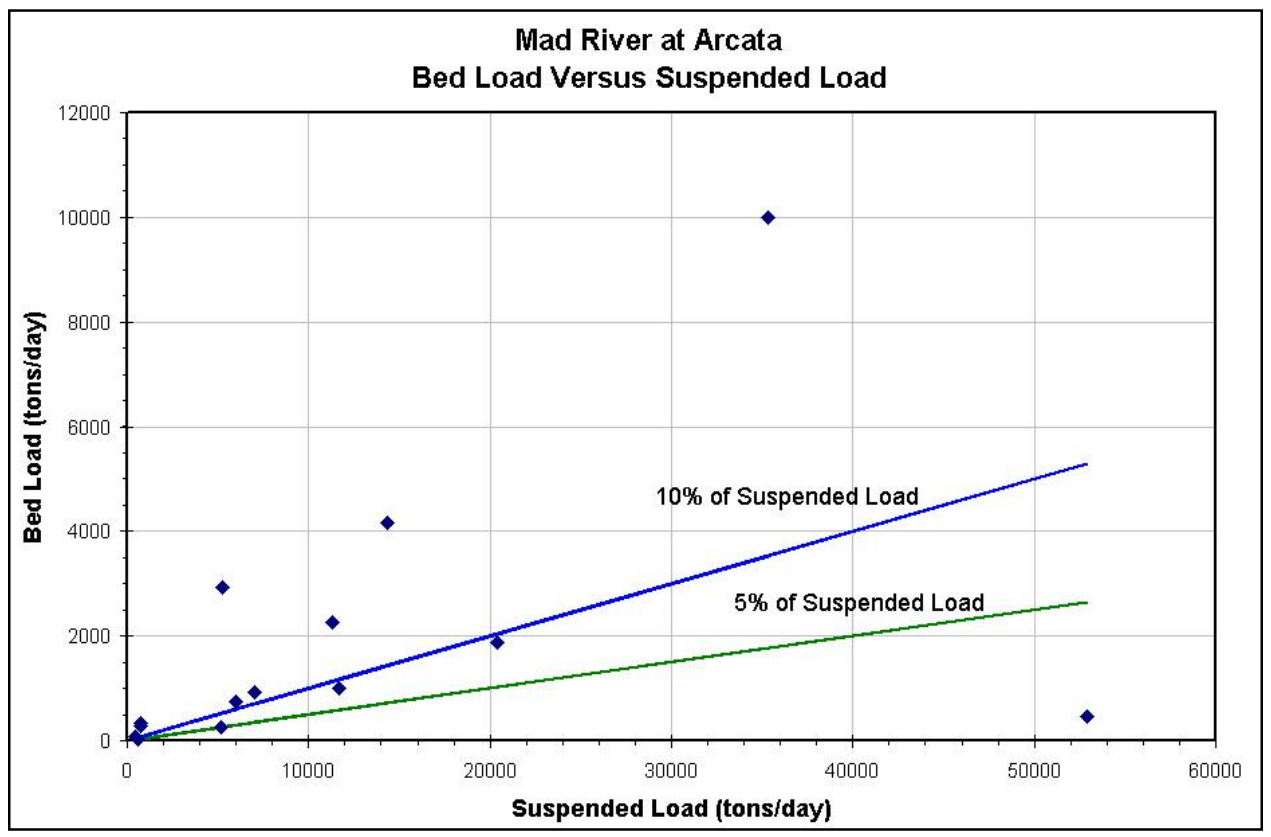

Figure 22. Bed-load transport versus suspended-load transport 


\section{Polygon Analysis}

The initial analysis used channel cross sections and the average-end-area method to calculate the volume of sediment gained or lost between each set of cross sections from 1971 to 2000 . This is a common method of volume calculation, though it can lead to significant errors if the cross sections are not properly located or are spaced too far apart. In the summer of 2001, G. Mathias Kondolf, professor at the University of California, Berkeley, had calculated a sediment budget for the lower Mad River using a geomorphic polygon analysis method. ${ }^{1}$ This method is based on identifying geomorphically similar sections of the river and defining those areas with polygons. After calculating the area of those polygons, the average vertical change in the polygons is determined from cross-section surveys and field investigations. Multiplying the area of a polygon by its average vertical change results in the volume of sediment change in that polygon over the given period of time. Kondolf used cross-section survey data provided to him by Pacific Affiliates, data that included end points relocated by GeoTopo, Inc., of Oakland, under a contract with the Corps.

As previously discussed in the "USACE" section in this chapter, the Corps found numerous significant errors in the surveying work done by GeoTopo and determined the work should not be released to the general public or used for any purpose. Because of this, a new polygon analysis was performed using the polygons defined by Kondolf and the more recent and more accurate crosssection survey data. The results of the volumetric polygon analysis are presented, along with Kondolf's results, in Appendix H, Table H-1. In reviewing this table, it is important to remain aware of the fact that Kondolf's analysis and the Corps' analysis used different cross-section survey data. As in Kondolf's analysis, all of the cross sections for this analysis were checked and adjusted based on field observations. The results of the volumetric polygon analysis are summarized in Table 6.

\begin{tabular}{|c|c|c|c|}
\hline \multicolumn{4}{|c|}{\begin{tabular}{|l} 
Table 6 \\
Volumetric Polygon Analysis Results
\end{tabular}} \\
\hline Section of River & Total Change, cu yd & $\begin{array}{l}\text { Average Annual } \\
\text { Change, cu yd/year } \\
1971-2000\end{array}$ & $\begin{array}{l}\text { Average Annual } \\
\text { Change, tons/year }{ }^{1} \\
1971-2000\end{array}$ \\
\hline River Mouth to 101 Bridge & $-47,759$ & -1,592 & $-2,197$ \\
\hline 101Bridge to 299 Bridge & 251,425 & 8,381 & 11,566 \\
\hline 299 Bridge to AMRR Bridge & $-206,255$ & $-6,875$ & $-9,488$ \\
\hline AMRR to Blue Lake & $-2,704,376$ & $-90,146$ & $-124,401$ \\
\hline Above Blue Lake & $-78,889$ & $-2,630$ & $-3,629$ \\
\hline Total above 101 Bridge & $-2,738,095$ & $-91,270$ & $-125,952$ \\
\hline Total below 299 Bridge & 203,666 & 6,789 & 9,369 \\
\hline Total above 299 Bridge & $-2,989,520$ & $-99,651$ & $-137,518$ \\
\hline
\end{tabular}

\footnotetext{
${ }^{1}$ Kondolf, op. cit. p. 19.
} 
This table shows the area with the most significant storage loss being the river reach between the AMRR bridge and Blue Lake, an area with active gravel mining activity. It also shows storage gain in the area between the Hwy 101 bridge and the Hwy 299 bridge. While this area is expected to be a natural deposition zone due to the influence of tidal currents and density differences in the river up to the area near the Hwy 101 bridge, the analysis results in this area are questionable due to uncertainty with the associated survey cross sections (see "USACE" section).

\section{Sediment Budget}

\section{Hwy 299 bridge to Blue Lake hatchery}

In calculating the sediment budget for the lower Mad River, the results from the various methods used to estimate sediment transport into and out of the study reach were considered. Because no bed-load or bed-material data from downstream of the Hwy 299 bridge were available, that bridge was used as the lower limit of the area for sediment budget calculations. The uppermost cross section, No. 30, just below the Blue Lake hatchery, was used as the upstream limit of the study area. Though the Blue Lake gauge was upstream of this cross section, the field investigation did not indicate significant changes in the bed and banks upstream of the hatchery. Thus, the Blue Lake gauge sediment data were assumed to be reasonably representative of the input conditions at cross section 30 .

Sediment transport into the study area from the main stem of the Mad River was estimated using three methods: the sediment rating curve for Blue Lake; sediment transport equations (specifically Brownlie); and the infill rate for Sweasey Dam. An estimate was added for sediment transport into the study area from the North Fork of the Mad River using relative watershed area. The USGSreported watershed area at the Korbel gauge is 10.3 percent of that at the Blue Lake gauge so North Fork sediment transport was assumed to be 10.3 percent of the main stem's transport at Blue Lake. With virtually no other data, this crude method should provide a reasonable estimate for the North Fork's sediment contribution.

Sediment transport out of the study area was estimated using two methods: the sediment rating curve at Arcata and sediment transport equations (Brownlie). In estimating the average annual sediment flow through the study area it is not possible to simply use an average daily flow value for a year and to multiply that value by 365 days/year. Because of this, the full record of average daily flows for the different gauging stations on the Mad River was used to develop flowduration curves for each station for the period from 1971 to 2000. Sediment discharge was then calculated for a range of flow intervals and those values were multiplied by the percent occurrence. This resulted in a statistically-based representation of average annual sediment transport over the study period for each gauging station location (see HQUSACE (1995) for a full description of this method). 
Because the Kneeland and Blue Lake gauges had much shorter data records than the Arcata gauge, the likelihood of high flow events was determined by using relationships between the flow characteristics at the Arcata gauge and the gauges at each of these sites and by extrapolating. The data for Kneeland and Blue Lake have a high correlation with the data for Arcata, as would be expected. Plots describing the flow relationships between Arcata and Blue Lake and between Arcata and Kneeland are shown in Figures 23 and 24, respectively.

Storage in the study reach was calculated using the method described in "Sediment Budget Concept," which can be represented as:

$$
Q_{\text {s-in, fluvial }}-\left(Q_{\text {s-out, fluvial }}+Q_{\text {s-out, gravel extraction }}\right)=\text { storage }
$$

For the average annual volume of gravel extracted from the study reach by gravel miners, the extraction data compiled by Randy Klein, of CHERT, was considered along with the modifications to that data suggested by Pacific Affiliates, on behalf of Eureka Readimix (see Appendix G). The results of the sediment budget calculations were compared to the volumetric change estimates made using both the average-end-area method (see "USACE" section) and the polygon analysis method (see "Sediment Transport" section). All information used to calculate and verify the sediment budget is presented in Table 7. For this table, input and output methods were kept the same for each individual analysis (e.g., Brownlie's equation for sediment flow into and out of the study reach) where possible. For the cases where Sweasey Dam values were used for inflow rates, it was not reasonable to also use those values for outflow rates. Instead, two different cases were used to represent scenarios using Sweasey Dam information for input, one that used the Arcata bed-load rating curve for output and one that used Brownlie's equation for output.

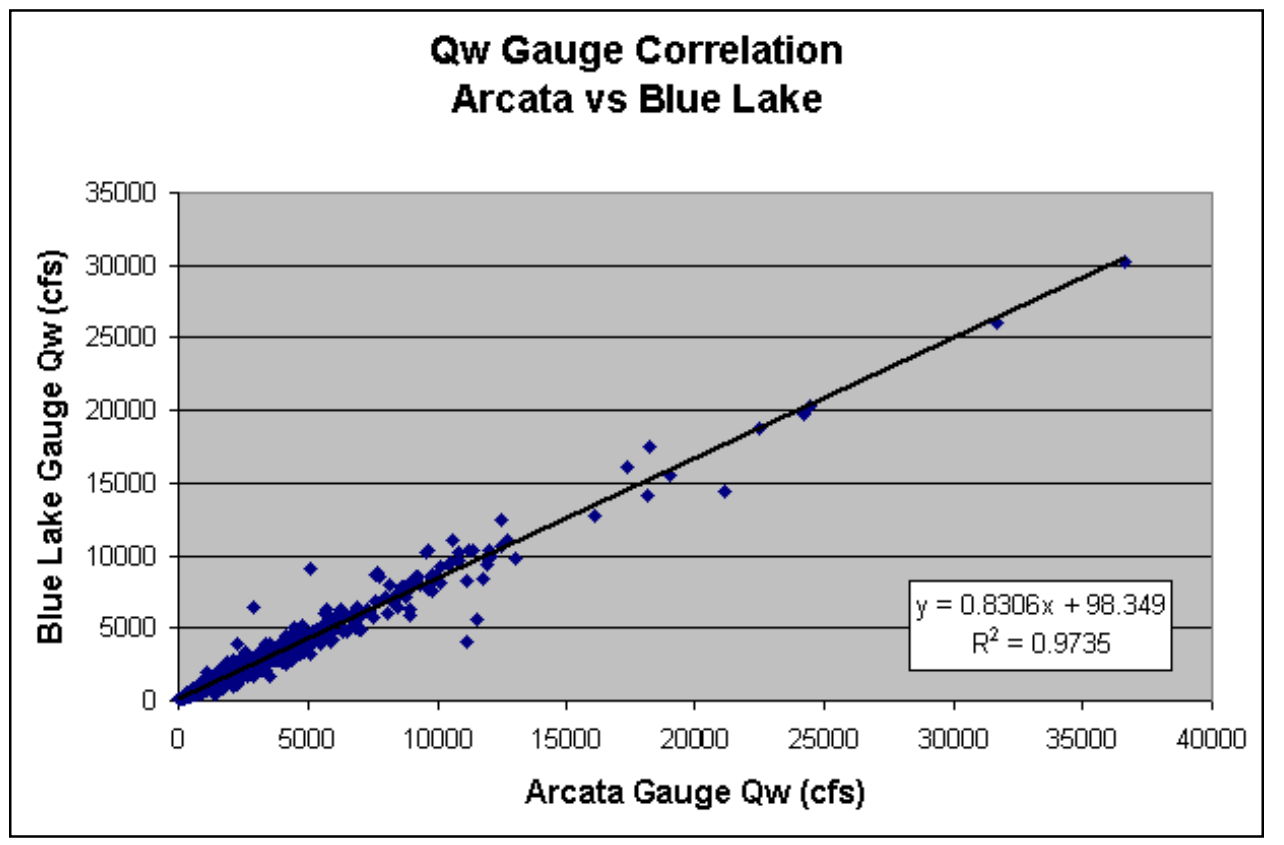

Figure 23. Flow correlation between USGS gauging stations at Arcata and Blue Lake 


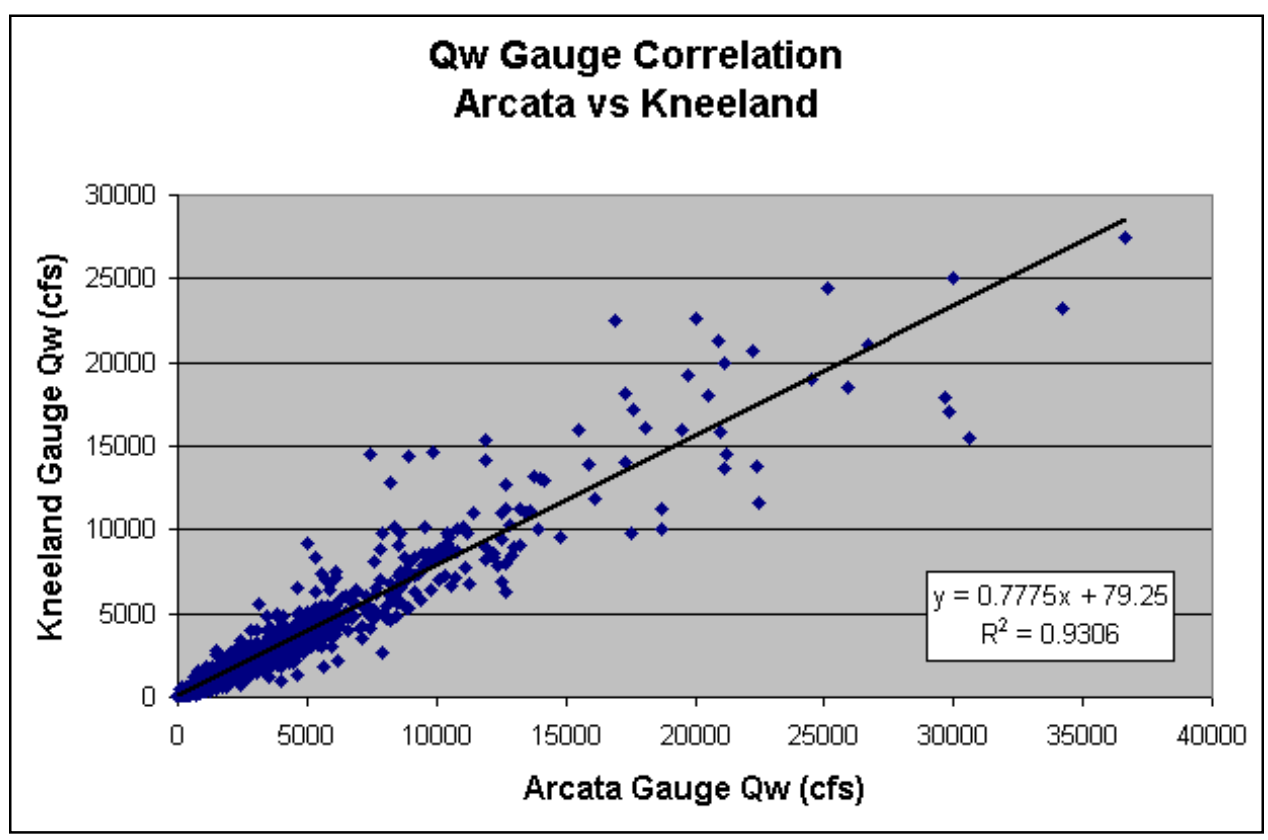

Figure 24. Flow correlation between USGS gauging stations at Arcata and Kneeland

If the Meyer-Peter and Muller equation had been used for sediment transport calculations the result would have been less transport into the study reach, more transport out of it, and less storage in the reach itself. This would have resulted in further discrepancy in the sediment budget results when compared to historic channel changes.

\section{Hwy 101 bridge to Hwy 299 bridge}

As previously stated, adequate sediment data were unavailable for the reach between the Hwy 101 bridge and the Hwy 299 bridge, the area immediately downstream from the study reach. In addition to the absence of sediment data, there were also concerns with the locations of cross sections in this area (see "USACE" section). These concerns prevented confident calculation of a value for sediment storage between the Hwy 101 and 299 bridges. If one were to assume there had been no significant change in measured cross sections in this area, and were also to assume a significant decrease in bed-load transport past the Hwy 101 bridge due to decreasing channel slope and the influence of tidal action, one might be able to estimate a crude sediment budget for this reach. Table 8 summarizes the data that could be used for this type of analysis and a range of possible results. 


\begin{tabular}{|c|c|c|c|c|c|c|c|c|c|c|}
\hline \multicolumn{11}{|c|}{$\begin{array}{l}\text { Table } 7 \\
\text { Sediment Budget Values for Lower Mad River (between Hwy } 299 \text { and the Blue Lake hatchery) }\end{array}$} \\
\hline & \begin{tabular}{|l|} 
Study \\
Area Input \\
from Main \\
Stem \\
(tons/year) \\
\end{tabular} & \begin{tabular}{|l|} 
Study \\
Area Input \\
from \\
North \\
Fork $^{*}$ \\
(tons/year) \\
\end{tabular} & \begin{tabular}{|l} 
Study \\
Area \\
Output \\
(tons/year) \\
\end{tabular} & \begin{tabular}{|l|} 
Study \\
Area \\
Storage \\
(w/out \\
mining) \\
(tons/year) \\
\end{tabular} & $\begin{array}{l}\text { Average } \\
\text { Gravel } \\
\text { Extraction } \\
\text { (tons/year) } \\
\end{array}$ & \begin{tabular}{|l|} 
Study \\
Area \\
Storage \\
(with \\
mining) \\
(tons/year) \\
\end{tabular} & $\begin{array}{l}\text { Volume of } \\
\text { Bed } \\
\text { Degradation } \\
\text { and Bank } \\
\text { Erosion } \\
\text { (avg-end- } \\
\text { area) } \\
\text { (tons/year) } \\
\end{array}$ & \begin{tabular}{|l|}
$\%$ \\
Difference \\
Between \\
Storage \\
Calculation \\
and \\
Volume \\
Change \\
Calculation \\
(avg-end- \\
area) \\
\end{tabular} & \begin{tabular}{|l|} 
Volume of \\
Bed \\
Degradation \\
and Bank \\
Erosion \\
(polygon) \\
(tons/year) \\
\end{tabular} & \begin{tabular}{|l}
$\%$ \\
Difference \\
Between \\
Storage \\
Calculation \\
and \\
Volume \\
Change \\
Calculation \\
(polygon) \\
\end{tabular} \\
\hline $1 \mathrm{a}$ & \begin{tabular}{|l}
$\begin{array}{l}\text { Bed load } \\
\text { rating } \\
\text { curve } \\
183,000\end{array}$ \\
\end{tabular} & 19,000 & \begin{tabular}{|l} 
Bed load \\
rating \\
curve \\
45,000
\end{tabular} & 157,000 & $\begin{array}{l}\text { CHERT } \\
265,000\end{array}$ & $-108,000$ & $-183,000$ & $41 \%$ & $-138,000$ & $22 \%$ \\
\hline $1 \mathrm{~b}$ & \begin{tabular}{|l} 
Bed load \\
rating \\
curve \\
183,000 \\
\end{tabular} & 19,000 & \begin{tabular}{|l|} 
Bed load \\
rating \\
curve \\
45,000 \\
\end{tabular} & 157,000 & $\begin{array}{l}\text { Pac.Aff. } \\
354,000\end{array}$ & $-197,000$ & $-183,000$ & $8 \%$ & $-138,000$ & $43 \%$ \\
\hline $2 a$ & \begin{tabular}{|l|} 
Brownlie \\
228,000 \\
\end{tabular} & 23,000 & \begin{tabular}{|l|} 
Brownlie \\
100,000 \\
\end{tabular} & 151,000 & \begin{tabular}{|l|} 
CHERT \\
265,000 \\
\end{tabular} & $-114,000$ & $-183,000$ & $38 \%$ & $-138,000$ & $17 \%$ \\
\hline $2 \mathrm{~b}$ & \begin{tabular}{|l} 
Brownlie \\
228,000 \\
\end{tabular} & 23,000 & $\begin{array}{l}\text { Brownlie } \\
100,000\end{array}$ & 151,000 & \begin{tabular}{|l} 
Pac.Aff. \\
354,000
\end{tabular} & $-203,000$ & $-183,000$ & $11 \%$ & $-138,000$ & $47 \%$ \\
\hline \begin{tabular}{|l|}
$3 a$ \\
\end{tabular} & $\begin{array}{l}\text { Sweasey } \\
\text { Dam } \\
182,000\end{array}$ & $\overline{19,000}$ & $\begin{array}{l}\text { Bed load } \\
\text { rating } \\
\text { curve } \\
45,000 \\
\end{array}$ & 156,000 & $\begin{array}{l}\text { CHERT } \\
265,000\end{array}$ & $-109,000$ & $-183,000$ & $40 \%$ & $-138,000$ & $21 \%$ \\
\hline $3 b$ & $\begin{array}{l}\text { Sweasey } \\
\text { Dam } \\
182,000\end{array}$ & 19,000 & \begin{tabular}{|l} 
Bed load \\
rating \\
curve \\
45,000 \\
\end{tabular} & 156,000 & \begin{tabular}{|l|} 
Pac.Aff. \\
354,000
\end{tabular} & $-198,000$ & $-183,000$ & $8 \%$ & $-138,000$ & $43 \%$ \\
\hline $4 a$ & \begin{tabular}{|l} 
Sweasey \\
Dam \\
182,000 \\
\end{tabular} & 19,000 & $\begin{array}{l}\text { Brownlie } \\
100,000\end{array}$ & 101,000 & $\begin{array}{l}\text { CHERT } \\
265,000\end{array}$ & $-164,000$ & $-183,000$ & $10 \%$ & $-138,000$ & $19 \%$ \\
\hline $4 b$ & $\begin{array}{l}\text { Sweasey } \\
\text { Dam } \\
182,000\end{array}$ & 19,000 & $\begin{array}{l}\text { Brownlie } \\
100,000\end{array}$ & 101,000 & \begin{tabular}{|l} 
Pac.Aff. \\
354,000
\end{tabular} & $-253,000$ & $-183,000$ & $38 \%$ & $-138,000$ & $83 \%$ \\
\hline
\end{tabular}




\begin{tabular}{|c|c|c|c|c|c|c|}
\hline \multicolumn{7}{|c|}{$\begin{array}{l}\text { Table } 8 \\
\text { Sediment Budget Values for Region Between Hwy } 101 \text { and Hwy } \\
299 \text { Bridges }\end{array}$} \\
\hline $\begin{array}{l}\text { Throughput } \\
\text { from Hwy } \\
299 \text { bridge, } \\
\text { tons/year }\end{array}$ & $\begin{array}{l}\text { Study } \\
\text { Area } \\
\text { Output }\end{array}$ & $\begin{array}{l}\text { Study } \\
\text { Area } \\
\text { Storage, } \\
\text { tons/year }\end{array}$ & $\begin{array}{l}\text { Average } \\
\text { Gravel } \\
\text { Extraction, } \\
\text { tons/year }\end{array}$ & $\begin{array}{l}\text { Volume of } \\
\text { Bed } \\
\text { Degradation } \\
\text { and Bank } \\
\text { Erosion }\end{array}$ & $\begin{array}{l}\text { Sustainable } \\
\text { Yield, } \\
\text { tons/year }\end{array}$ & Comment \\
\hline \multirow{2}{*}{$\begin{array}{l}\text { Bed load } \\
\text { rating curve } \\
45,000\end{array}$} & \multirow[t]{2}{*}{ ? } & \multirow{2}{*}{$\begin{array}{l}\leq 0 ? \\
\text { to } \\
45,000\end{array}$} & \multirow[t]{2}{*}{99,000} & $?$ & $\begin{array}{l}? \\
\leq 45,000\end{array}$ & $\begin{array}{l}\text { Too many } \\
\text { unknowns }\end{array}$ \\
\hline & & & & $\begin{array}{l}\text { Assume zero } \\
(0)\end{array}$ & $?$ & $\begin{array}{l}\text { Does not } \\
\text { balance }\end{array}$ \\
\hline \multirow[t]{2}{*}{$\begin{array}{l}\text { Brownlie } \\
100,000\end{array}$} & \multirow[t]{2}{*}{ ? } & \multirow{2}{*}{$\begin{array}{l}\leq 0 ? \\
\text { to } \\
100,000\end{array}$} & \multirow[t]{2}{*}{99,000} & $?$ & $\begin{array}{l}? \\
\leq 100,000\end{array}$ & $\begin{array}{l}\text { Too many } \\
\text { unknowns }\end{array}$ \\
\hline & & & & $\begin{array}{l}\text { Assume zero } \\
(0)\end{array}$ & $\begin{array}{l}? \\
\leq 100,000\end{array}$ & $\begin{array}{l}\text { Assumes } \\
\text { no output, } \\
\text { which is } \\
\text { unlikely }\end{array}$ \\
\hline
\end{tabular}

When considering the information in this table, one should remain aware of the unknowns and uncertainty associated with the data. Based on this data, an estimate of sustainable yield for this portion of the Mad River should either be less than $45,000 \mathrm{cu}$ yd/year or less than $100,000 \mathrm{cu} \mathrm{yd} /$ year, depending on which method of calculating input is deemed most appropriate.

\section{Hwy 101 bridge to mouth of river}

This region is dominated by a combination of density driven (tidal) flows and fluvial flows. The interaction of these two forcing mechanisms, combined with the chemical effects of salt water on fine-grained sediments, could lead to increased sedimentation in this area, as has periodically been observed in the past. Sediments in this area could be from fluvial sources or nearshore coastal sources. No data were available to estimate a sediment budget in this section of the Mad River.

\section{Sediment Budget Error Range}

In examining the sediment budget values, it is important to note the closeness of the Blue Lake values calculated using the bed-load rating curve and Brownlie's equation. The values are remarkably close. It is possible that the USGS used the Sweasey Dam information to calibrate its rating curve for the Blue Lake gauge, but this is unlikely due to the Corps' memo documenting Sweasey Dam sedimentation (which was probably not available to USGS) and the assumptions used regarding wash load. Overall, the similarity between these two values and the good agreement between the inflow and outflow rates calculated by the different methods lends significant confidence to the sediment budget values. There is also good agreement between the average annual 
volumetric channel change rates calculated using the average-end-area method and the polygon analysis method.

The average annual gravel extraction rates obtained from CHERT agreed with the sediment budget calculations and estimates of average annual channel change better than the rates obtained using the additional data from Pacific Affiliates. In using the CHERT extraction rates as part of the actual sediment budget, the agreement with the calculated total channel change is good, with an error range of 9 to 28 percent for the average-end-area method and an error range of 17 to 22 percent for the polygon analysis method. If the additional gravel extraction data provided by Pacific Affiliates is found to be accurate, the error associated with these sediment budget values will increase. 


\section{Study Limitations}

\section{Method}

The method used in this analysis to estimate a sediment budget for the lower Mad River is based on a statistical representation of the average annual flow regime for the river. This method is adequate for a basic analysis but is not as accurate as the results from a detailed numerical model that uses actual average daily flow data for the period of interest. The method used also assumes channel uniformity between cross sections. With only 30 cross sections along a 13-mile stretch of a geomorphically dynamic river, there are certainly irregularities that the cross section spacing masks. The average-end-area and polygon methods for estimating volume of channel both have deficiencies, but their results were close enough to increase confidence in this area. This study used a crude method to estimate sediment transport into the study area from the North Fork of the Mad River. Input from the North Fork is probably significant; additional sediment and flow data for this tributary would improve the analysis.

\section{Values}

All available and newly-collected data have uncertainties associated with them that limit the accuracy of the study. Specific data and their associated uncertainties are discussed in the following sections.

\section{Survey data}

Vertical accuracy of the local benchmark is good, but the errors found in the original 1971 cross section data were significant. Some of these cross sections appear to have been off by several inches. The new, 2000, cross section surveys were of much better horizontal and vertical accuracy, but only for the locations where original 1971 end points could be found. In a few instances (see "USACE" section) the locations of the new cross sections were so questionable as to render them essentially unusable. 


\section{Sediment data}

Bed-load data are highly variable, both spatially and temporally. The bedload data collected at each gauging station was sufficient for estimating bed-load rating curves, but only with a large amount of uncertainty. Each reported bedload sample was a composite of several samples collected on the same day and at the same flow. The number of samples used for each composite, however, were fewer than is recommended to overcome the spatial variability in bed-load transport. Perhaps most significant with respect to the sediment, however, is the fact that the sediment data were only available for the beginning of the study period. Sediment conditions in a river often change dramatically over time so assuming the data from the early 1970s were also representative of conditions in 2000 is highly questionable. Bed-load data collected at the Arcata gauge appeared to undersample large particle sizes and did not follow the expected coarsening trend with increasing flows and depths.

\section{Sweasey Dam}

The analysis assumed that the sediment that had collected behind Sweasey Dam was completely flushed through the study reach and did not have a lingering or significant effect on sediment transport in the study area. This may or may not be accurate. If the sediment from the dam had not completely flushed through the study reach by the time the Corps surveyed the 1971 cross sections, those cross sections could represent an aggraded condition.

\section{Bulk density}

The analysis used a bulk density of 1.38 tons/cu yd for gravel in the Mad River. This is a commonly used value, but other values may be closer to the actual value. Ranga Raju suggested using 1.38 tons/cu yd for coarse sand and 1.48 tons/cu yd for gravelly sand (Garde and Raju 1985). Many other texts and references suggest other values.

\section{Sediment rating curves}

The sediment rating curves for the three gauging stations were all based on a small number of data points. Though the curves for Arcata and Kneeland seem reasonable, given the positioning of the data points, the USGS curve for Blue Lake is less certain. Small errors in drawing the sediment rating curves can result in large errors in sediment transport estimates based on the curves. Sediment transport rates calculated using curves such as that for Blue Lake should be verified by another method, as is shown in Table 7 .

\section{Changes in Gravel Mining Practices}

This study uses two conditions, 1971 and 2000, to calculate average annual conditions during that time period. This assumes that conditions and gravel 
mining practices were essentially constant during that time. However, gravelmining practices on the Mad River changed somewhat after CHERT completed its PEIR in 1993. It is possible that gravel-mining practices prior to 1993 created a degraded condition and that the river has been static, or slowly recovering since that time. Unfortunately, there is no way at the present time to assess the effects, if any, of changes that resulted from the PEIR. 


\section{Comparison with Previous Studies}

Previous sediment budgets for the lower Mad River have been prepared by Lehre et al. (1993), ${ }^{1}$ and Kondolf and Lutrick (2001). ${ }^{2}$ Though the procedures used in each of these studies were different, both approaches were reasonable. This study was originally more similar to the analysis completed by Lehre but was expanded to include a polygon analysis similar to Kondolf's. Table 9 provides a comparison of the three studies' results, though it is important to remember that Kondolf was given survey data for his analysis that is considered inappropriate. Had he been given the newer (R.B. Davis, Inc.) survey data, his results would have been different and probably would have been closer to those described in the analysis.

\begin{tabular}{|c|c|c|c|}
\hline \multicolumn{4}{|c|}{$\begin{array}{l}\text { Table } 9 \\
\text { Comparison of Sediment Budgets for the Lower Mad River from } \\
\text { the Hwy } 299 \text { Bridge to the Blue Lake Hatchery }\end{array}$} \\
\hline & $\begin{array}{l}\text { Lehre } \\
(1962-1992)\end{array}$ & $\begin{array}{l}\text { Kondolf } \\
(1970-1999)\end{array}$ & \\
\hline $\begin{array}{l}\text { Natural storage between } 299 \& \text { Hatchery } \\
\text { (sustainable yield) }{ }^{1}\end{array}$ & $\begin{array}{l}150,000^{3} \mathrm{cy} / \mathrm{yr} \\
96,000^{4} \mathrm{cy} / \mathrm{yr}\end{array}$ & $125,000^{5} \mathrm{cy} / \mathrm{yr}$ & $\begin{array}{l}73,000-114,000 \\
\text { cy/yr }\end{array}$ \\
\hline Measured Net Loss in Storage ${ }^{2}$ & $-144,000 \mathrm{cy} / \mathrm{yr}$ & $-67,000 \mathrm{cy} / \mathrm{yr}$ & $\begin{array}{l}-133,000^{6} \mathrm{cy} / \mathrm{yr} \\
-100,000^{7} \mathrm{cy} / \mathrm{yr} \\
\end{array}$ \\
\hline \multicolumn{4}{|c|}{$\begin{array}{l}1 \text { The amount of bed material that would naturally collect in the study area with no gravel mining } \\
{ }^{2} \text { The measured net change in channel (bed and bank) volume in the study area. } \\
{ }^{3} \text { Total rate of gravel transport into study area (does not account for gravel leaving the area below } \\
299 \text { ) } \\
{ }^{4} \text { Values based on USGS bed load rating curves } \\
{ }^{5} \text { Value not presented in Kondolf report, but obtained (by this author) by subtracting the CHERT } \\
\text { data for average annual gravel mining volumes from Kondolf's calculated value for (annualized) } \\
\text { net change in storage } \\
{ }^{6} \text { Values obtained using the average-end-area method } \\
{ }^{7} \text { Values obtained using the volumetric polygon analysis method }\end{array}$} \\
\hline
\end{tabular}

\footnotetext{
${ }^{1}$ Lehre, op. cit., p. 9.

${ }^{2}$ Kondolf, op. cit., p. 19.
} 


\section{Conclusions and Recommendations}

Existing data and the analysis presented in this study indicate that the portion of the lower Mad River between the Highway 299 bridge and the Blue Lake hatchery had an average annual sustainable gravel yield of 73,000-114,000 cu yd from 1971 to 2000 . Due to the uncertainty commonly associated with sediment transport estimates, and the importance of the gravel mining industry to the local economy, it is probably prudent to err on the high side and to use $114,000 \mathrm{cu}$ yd as the average annual sustainable yield for this reach of river. This is a figure based on a basic analysis, however, and should be recognized as such. Overall, this value is in reasonable agreement with values estimated in previous studies.

Because this type of analysis is relatively basic, it is not recommended that its results be used as the sole source of information for setting maximum annual gravel-mining extraction volumes. A more rigorous numerical modeling study would yield more realistic results and could be used to evaluate the effects the removal of Sweasey Dam had on the lower Mad River.

For long-term monitoring and future evaluations, the cross sections surveyed as part of this study will provide a reasonable base. However, it would be much better to have a single, detailed aerial survey done of the entire lower Mad River using photogrammetry or LIDAR/SHOALS techniques. This survey would serve as a detailed baseline and could be used to extract cross sections at any location at any time in the future. HBMWD already has its region of the river, between the Highway 299 bridge and the AMRR bridge, surveyed aerially on a regular basis. With the various interested parties (HBMWD, NMFS, USACE, HSU, and the gravel operators), a cost-shared aerial baseline survey might be cost-effective for all stakeholders.

Additional bed-load and bed-material sampling data, upstream and downstream of the study reach (as a minimum), are essential to a proper evaluation of sediment transport capacity in the lower Mad River. With the local expertise at HSU and in Humboldt County, and with the experience and interest of the Corps and USGS, a coordinated sampling effort would seem to be a worthy pursuit.

A detailed photogrammetric analysis, similar to the one described in the "Aerial photographs" section in Chapter 3, though much more rigorous and properly controlled, would be beneficial. It would allow the analysis of actual 
geomorphic changes in the river over a long period of time (greater than 50 years). It could also be used as part of the evaluation of the effects of removing Sweasey Dam.

Because of NMFS' concern over salmonid habitat in the lower Mad River, gravel mining practices should be managed in a way that addresses habitat concerns. It is possible to have a river that is degrading, widening, or aggrading but still provides good habitat. It is also possible to have a river that is in equilibrium, in terms of its sediment budget, that provides poor habitat. An interdisciplinary team of biologists, geomorphologists, hydraulic engineers, and gravel operators should discuss habitat needs and the limitations/capabilities of gravel operators and their heavy equipment. Ideal management scenarios are probably impractical and unlikely. However, having biologists who understand the limitations of scrapers, dozers, loaders, hoes, and graders and having gravel operators who understand the habit preferences of salmonids (or other species of concern) can only help the overall management of the system. 


\section{References}

Baily, E. H., Irwin, W. P., and Jones, D. L. (1964). "Franciscan and related rocks, and their significance in the geology of Western California," California Division of Mines and Geology Bulletin 183.

Brown, W. M. (1973). "Streamflow, sediment, and turbidity in the Mad River Basin, Humboldt and Trinity counties, California," U.S. Geological Survey Water Resources Investigation, 36-73.

Brown, W. M. (1975). " Sediment transport, turbidity, channel configuration and possible effects of impoundment of the Mad River, Humboldt County, California," U.S. Geological Survey Water Resources Investigations, 26-75.

California Department of Water Resources. (1982). "Mad River watershed erosion investigation," State of California.

California Department of Water Resources. (1965). "Land and water use in Mad River - Redwood Creek Hydrographic Unit," Bulletin No. 94-7.

Copeland, R. R., McComas, D. N., Thorne, C. R., Sour, P. J., Jonas, M. M., and Fripp, J. B. (2001). "Hydraulic design of stream restoration projects," ERDC/CHL TR-01-28, U.S. Army Engineer Research and Development Center, Vicksburg, MS.

Emmett, W. W. (1975). "The channels and waters of the upper Salmon River, Idaho," U.S. Geological Survey Professional Paper 870A.

Federal Register. (1993). "Affirmation of vertical datum for surveying and mapping activities," 58, 120.

Garde, R. J., and Ranga Raju, K. G. (1985). Mechanics of sediment transportation and alluvial stream problems. John Wiley and Sons, New York.

Headquarters, U.S. Army Corps of Engineers. (1995). EM 1110-2-4000, "Sedimentation Investigations of Rivers and Reservoirs," Washington, DC.

. (1967). Interim Review Report for Water Resources Development on Mad River, California.

Hey, R. D., and Thorne, C. R. (1986). "Stable channels with mobile gravel beds," Journal of Hydraulic Engineering, ASCE, 112, 6, 671-689. 
Lane, E. W. (1955). "Design of stable channels," Transactions of the American Society of Civil Engineers. 120, 1234-1279.

Leopold, L. B., Wolman, M. G., and Miller, J. P. (1964). Fluvial processes in geomorphology. W.H. Freeman and Company, San Francisco.

R.B. Davis, Inc. (2001). "Cross section surveys of the lower Mad River, Humboldt County, California," Prepared under contract for the U.S. Army Corps of Engineers, San Francisco District.

Soar, P. J., and Thorne, C. R. (2001). "Channel restoration design for meandering rivers," ERDC/CHL CR-01-1, U.S. Army Engineer Research and Development Center, Vicksburg, MS.

Thorne, C., Hey, R., and Newson, M. (1997). Applied fluvial geomorphology for river engineering and management. John Wiley and Sons: New York.

Tolhurst, J. (1995). "Historical analysis of geomorphic channel changes, lower Mad River, Humboldt County, California," M.S. thesis, Humboldt State University, Arcata, CA.

U.S. Geological Survey. (1976). Discharge Measurement Summary Sheet, Form 9-207, for the Mad River near Blue Lake, California. Includes sheets from 1972-1976.

U.S. Geological Survey. (1974a). Discharge Measurement Summary Sheet, Form 9-207, for the Mad River near Kneeland, California. Includes sheets from 1965-1974.

U.S. Geological Survey. (1974b). Discharge Measurement Summary Sheet, Form 9-207, for the Mad River near Korbel, California. Includes sheets from 1957-1965 and 1972-1974.

Williams, G. P. (1986). "River meanders and channel size," Journal of Hydrology 88, 147-164.

Williams, G. P. (1978). "Bankful discharge of rivers," Water Resources Research 14(6), 1141-1154.

Wolman, M. G. (1955). "The natural channel of Brandywine Creek Pennsylvania,” U.S. Geological Survey Professional Paper 271. 


\section{Appendix A Aerial Photographs}




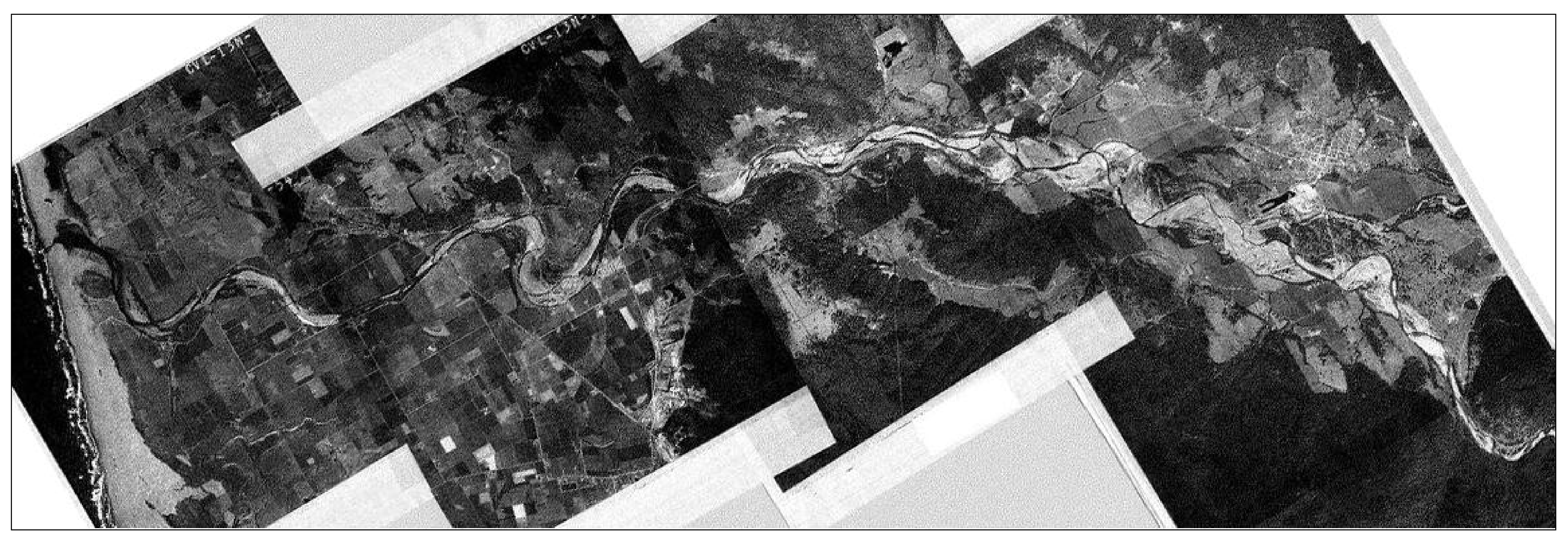

Figure A1. Composite aerial photo of lower Mad River, 1954 


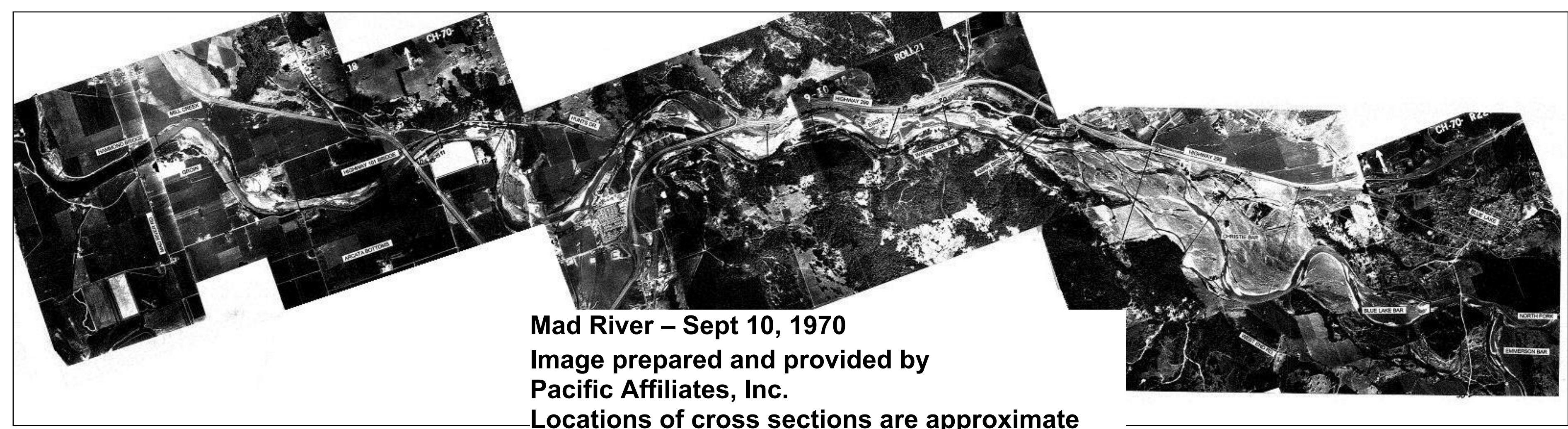

Figure A2. Composite aerial photo of lower Mad River, 1970

Locations of cross sections are approximate

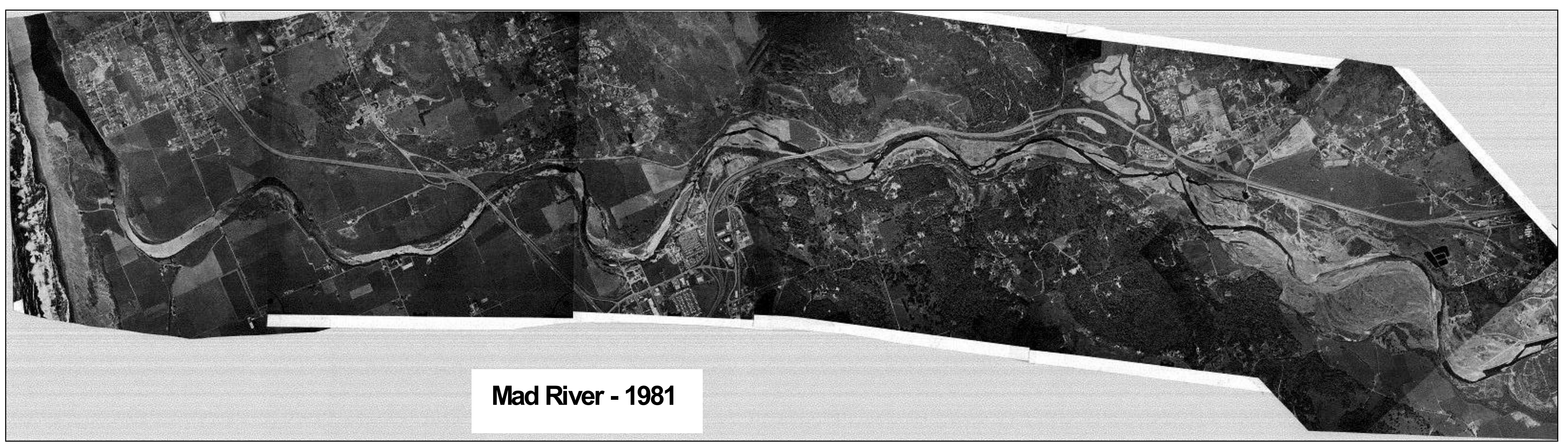

Figure A3. Composite aerial photo of lower Mad River, 1981 


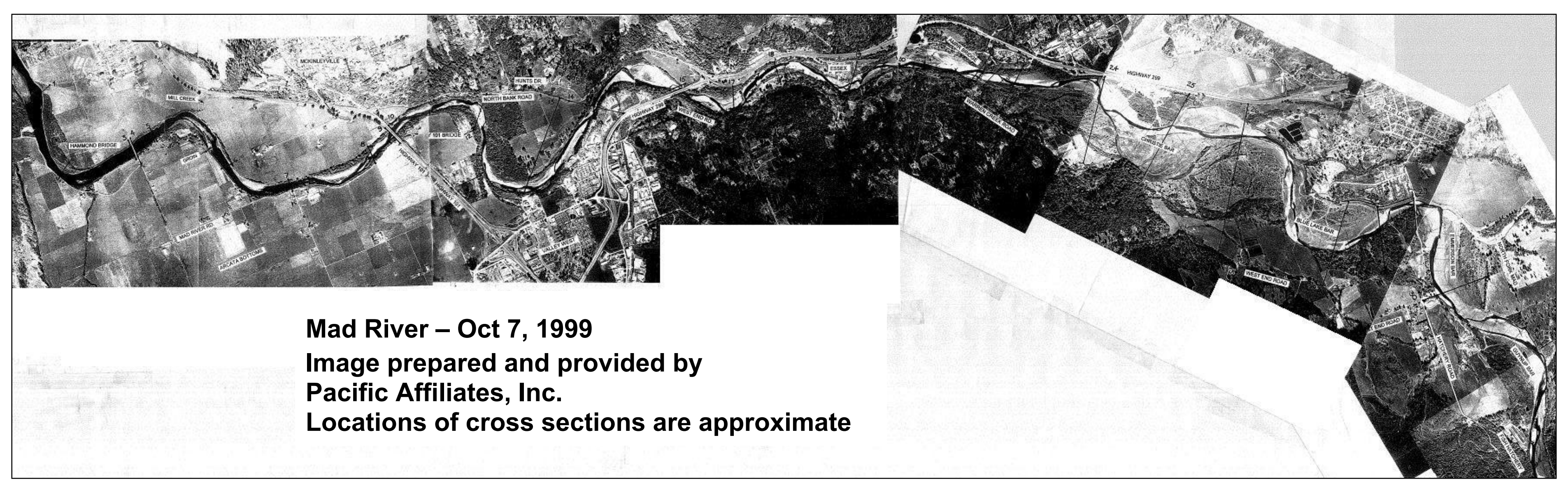

Figure A4. Composite aerial photo of lower Mad River, 1999 


\section{Appendix B USACE Surveyed Cross Sections}

(Note: Cross section figures are presented at a reduced scale, see PDF document version for details.) 


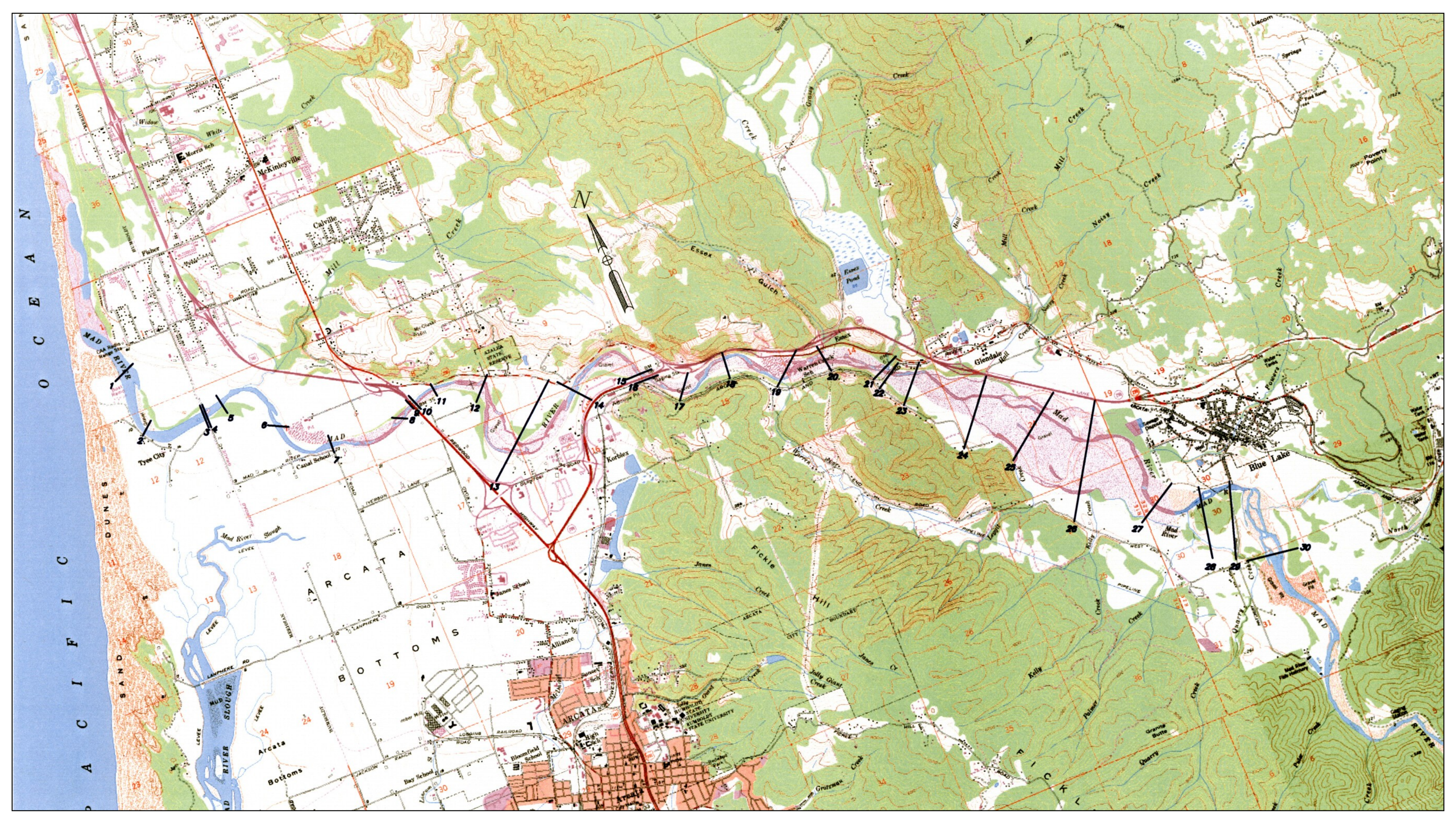

Figure B1. Location map for Mad River cross section surveys 


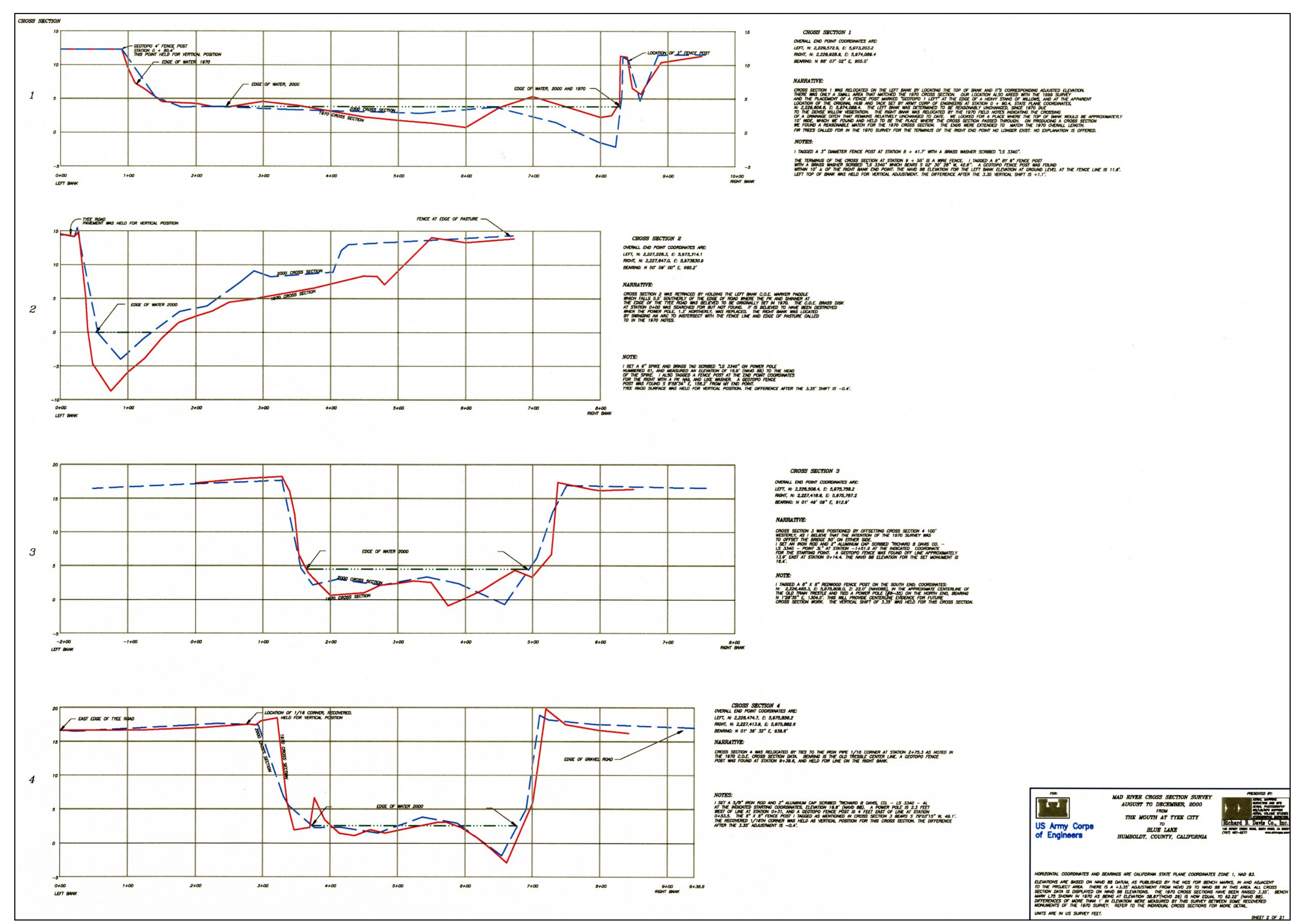

Figure B2. Surveys of Mad River cross sections 1, 2, 3, and 4 


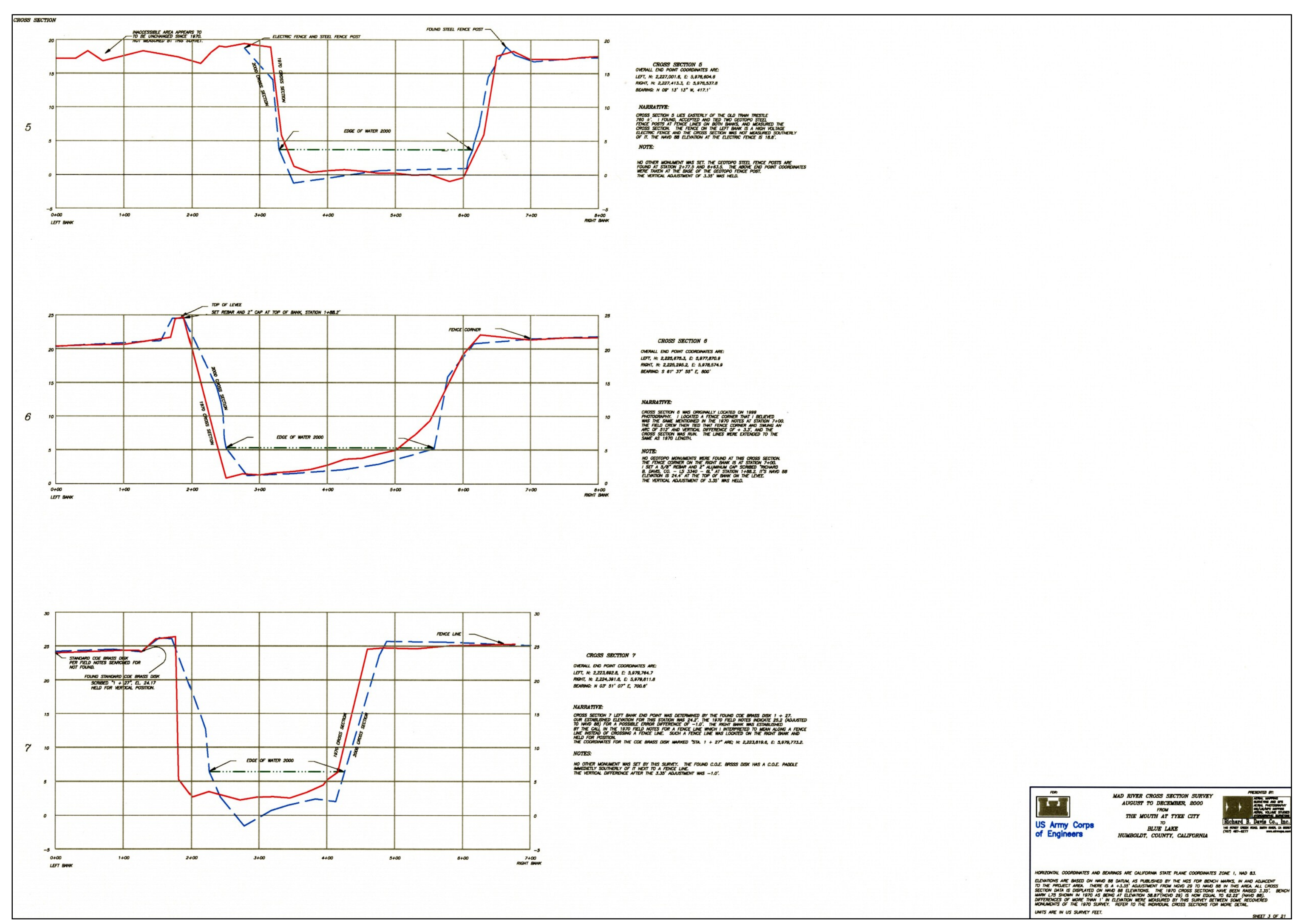

Figure B3. Surveys of Mad River cross sections 5, 6, and 7 


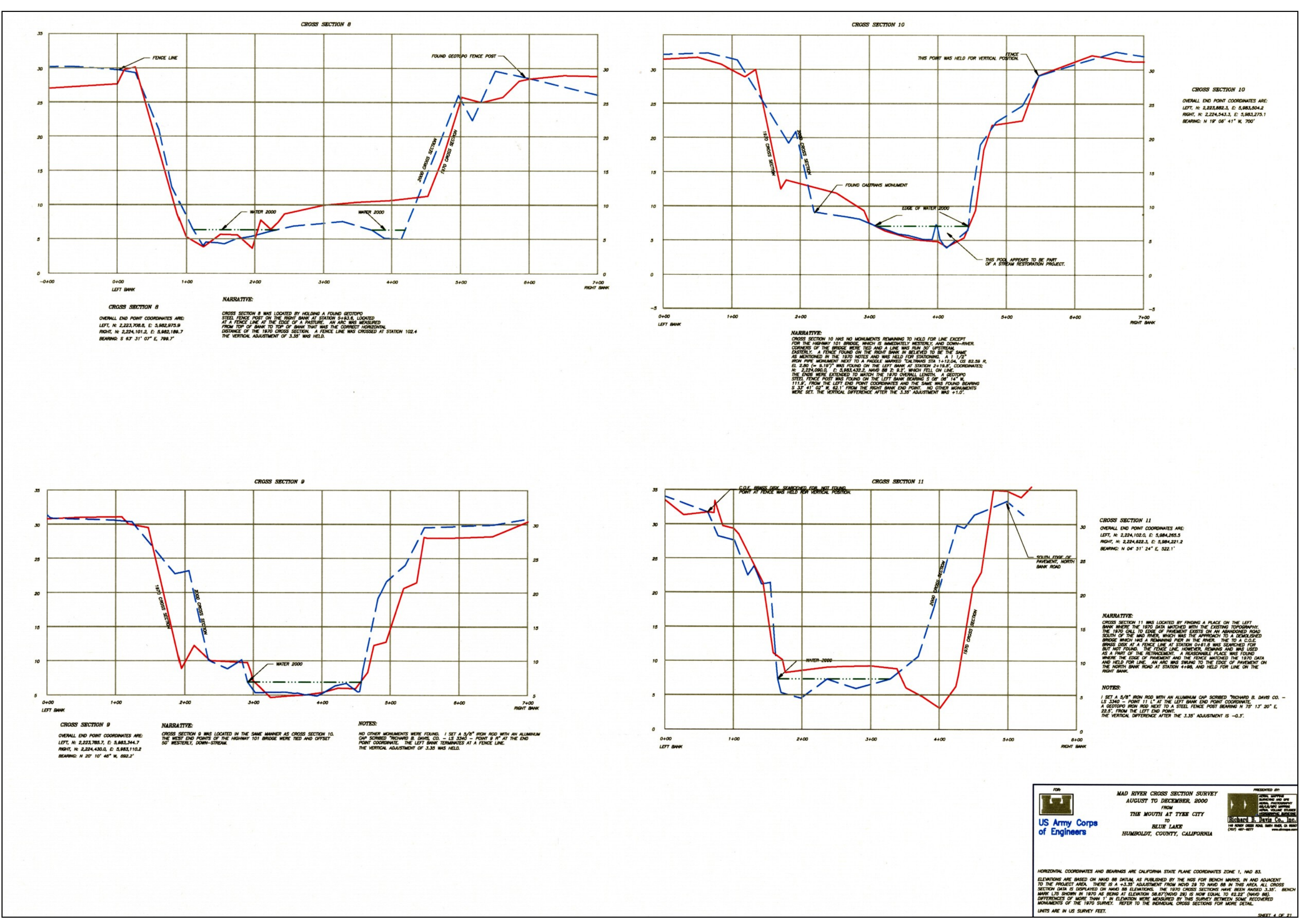

Figure B4. Surveys of Mad River cross sections 8, 9, 10, and 11 


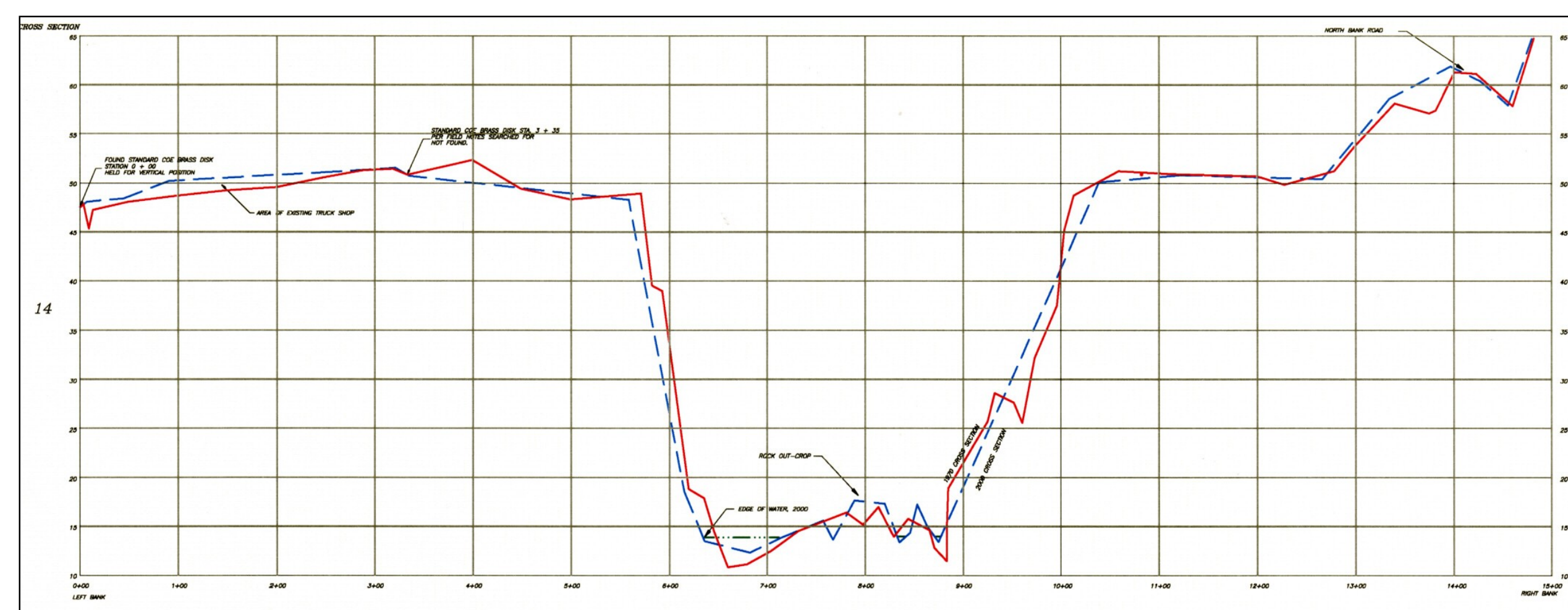

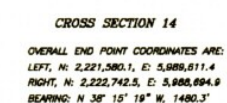

\section{-}

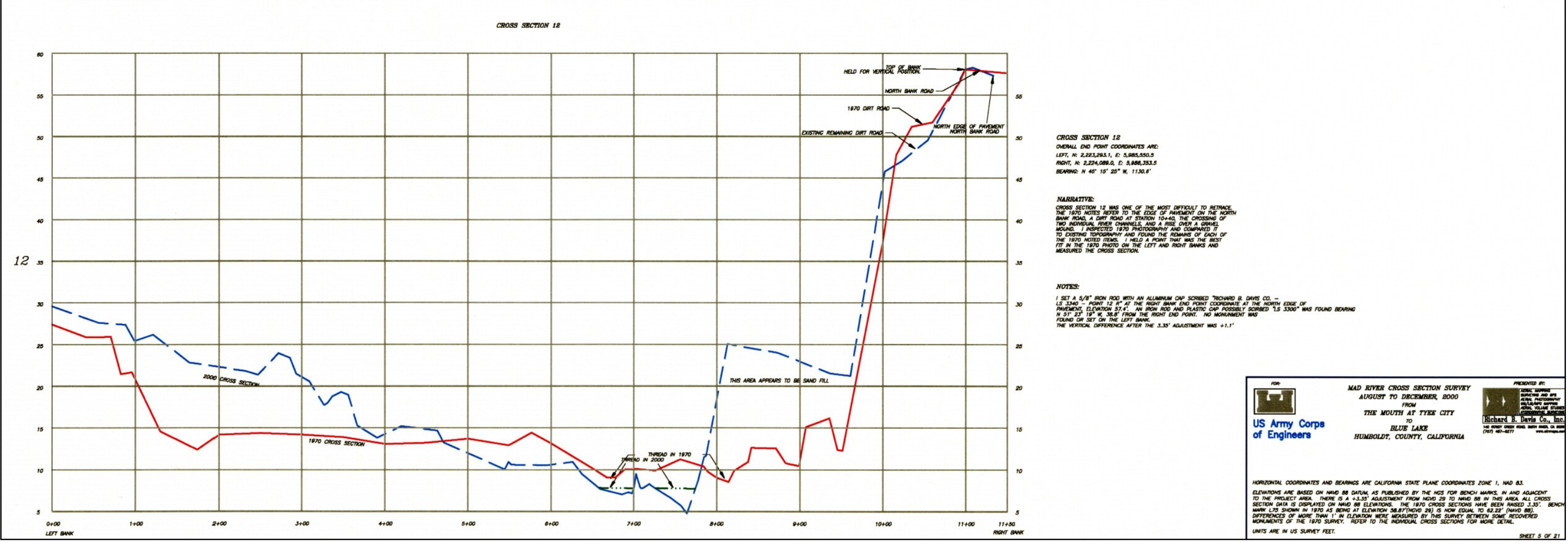

Figure B5. Surveys of Mad River cross sections 12 and 14 


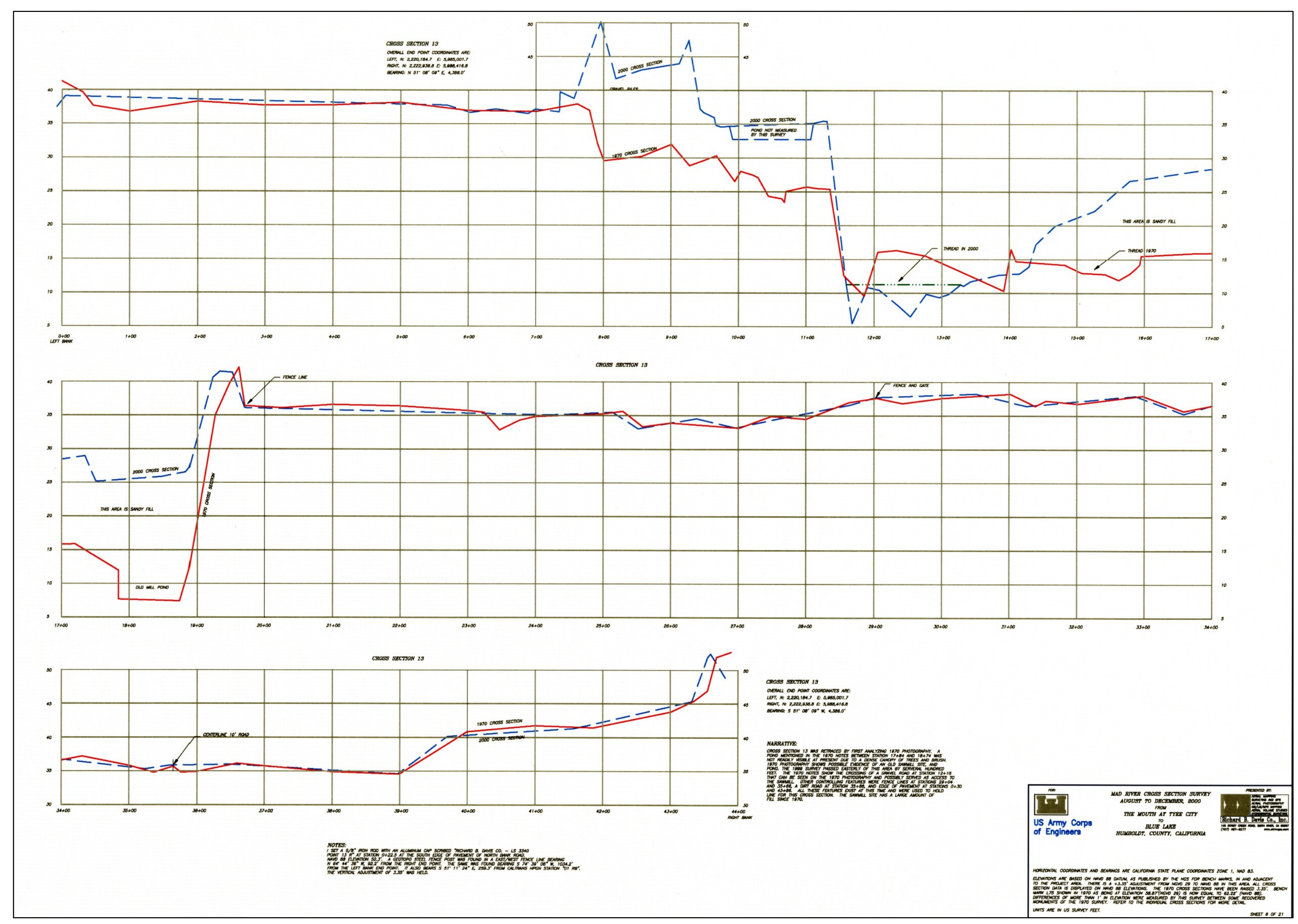

Figure B6. Survey of Mad River cross section 13 


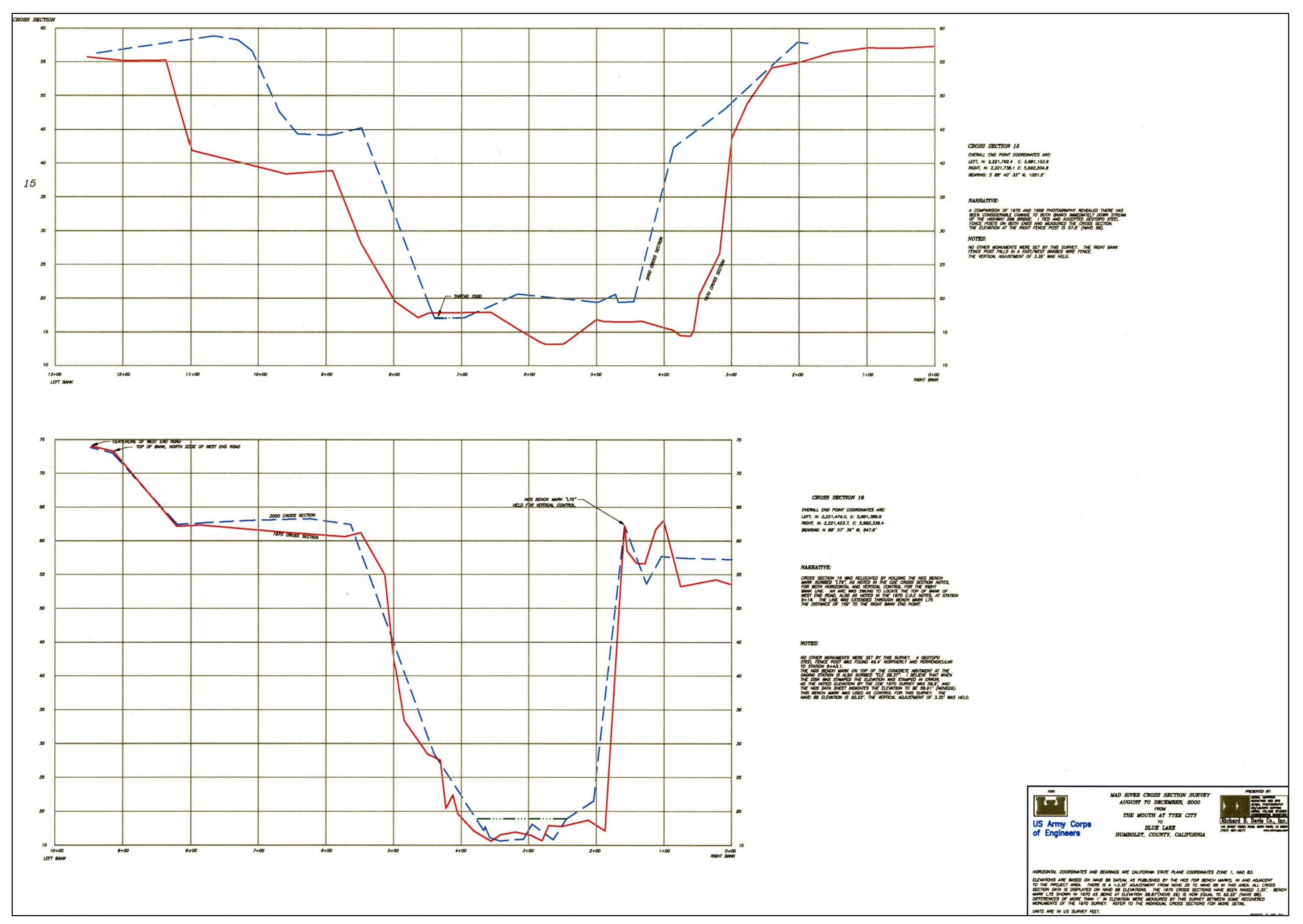

Figure B7. Survey of Mad River cross sections 15 and 16 


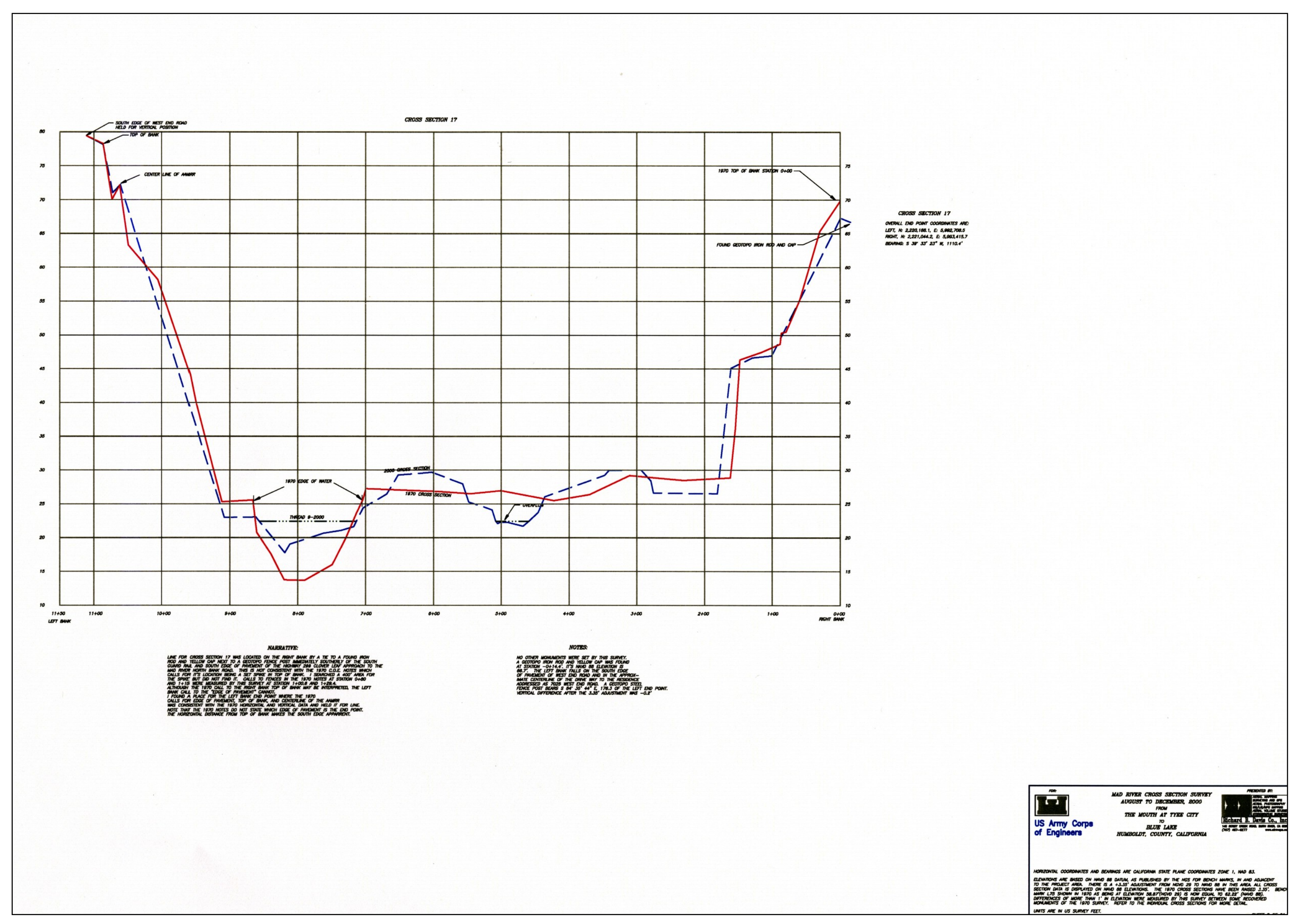

Figure B8. Survey of Mad River cross section 17 


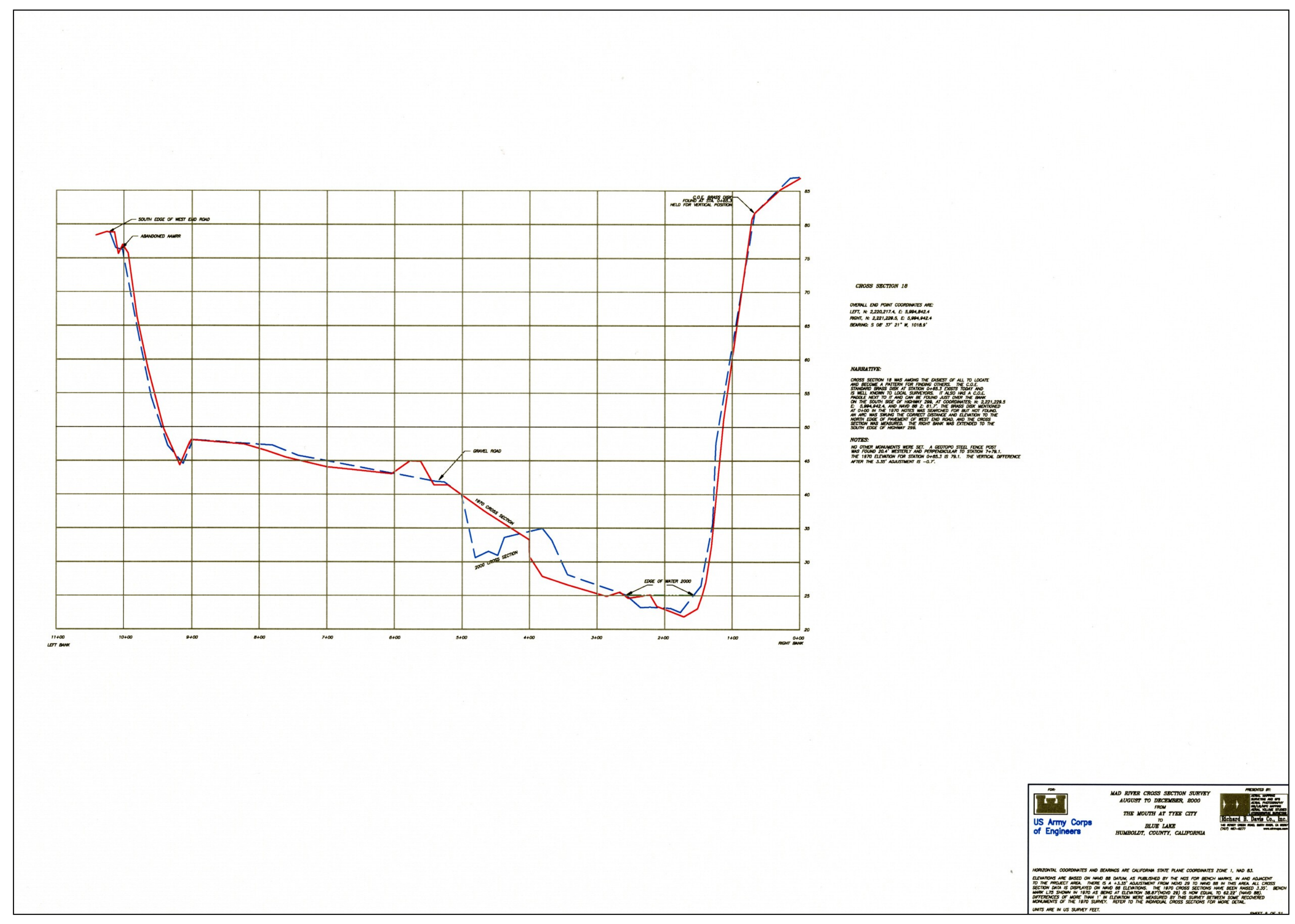

Figure B9. Survey of Mad River cross section 18 


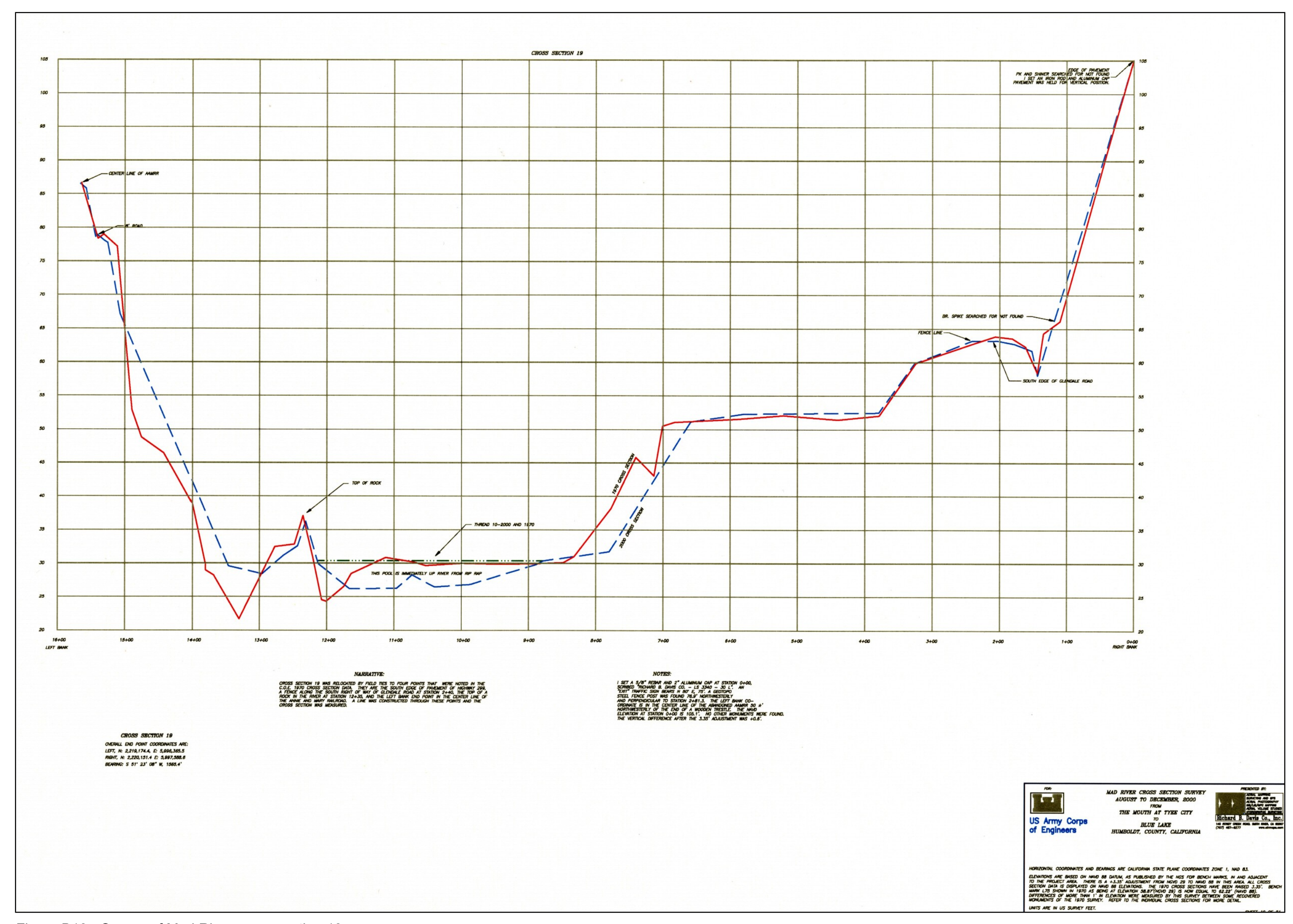

Figure B10. Survey of Mad River cross section 19 


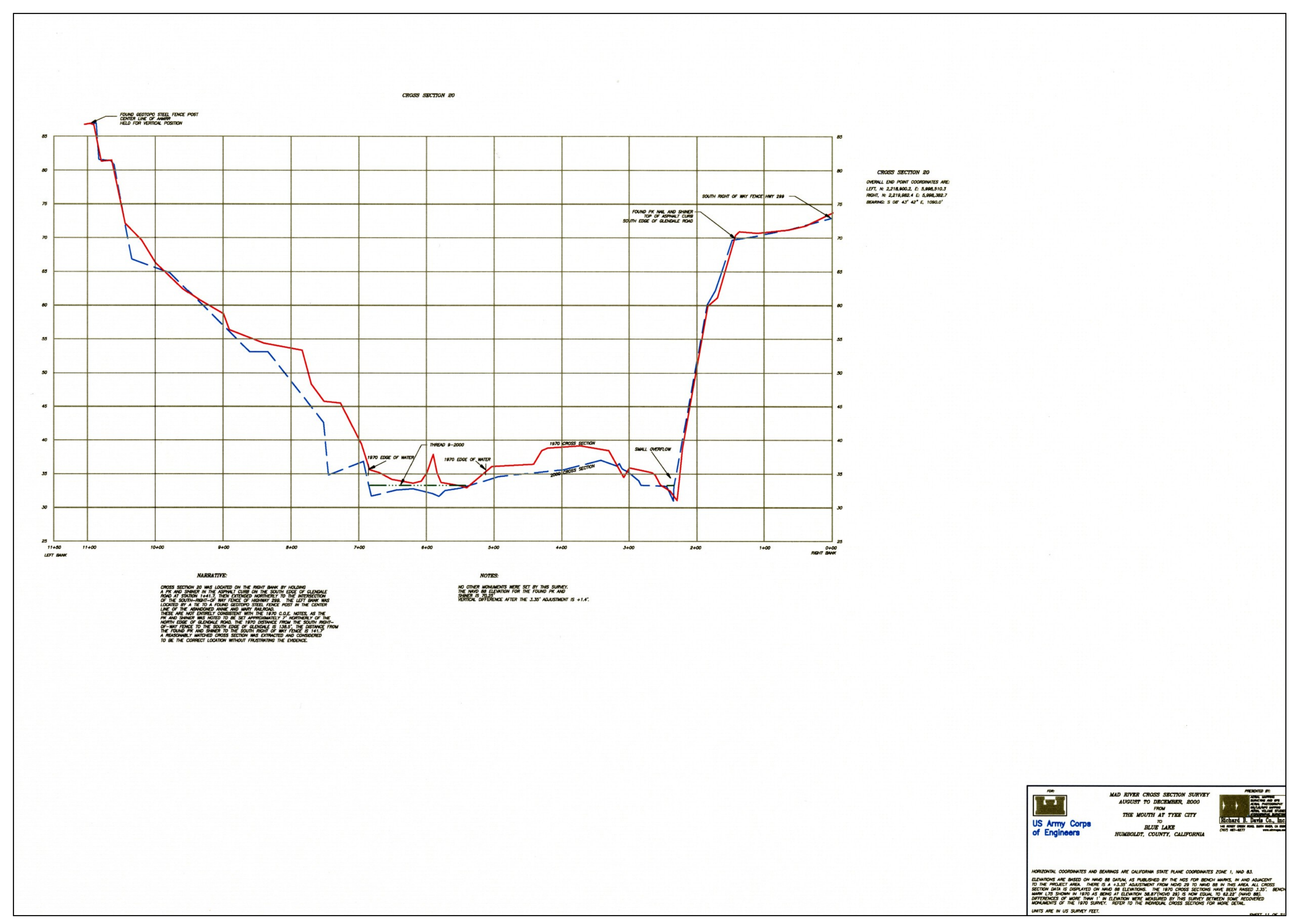

Figure B11. Survey of Mad River cross section 20 


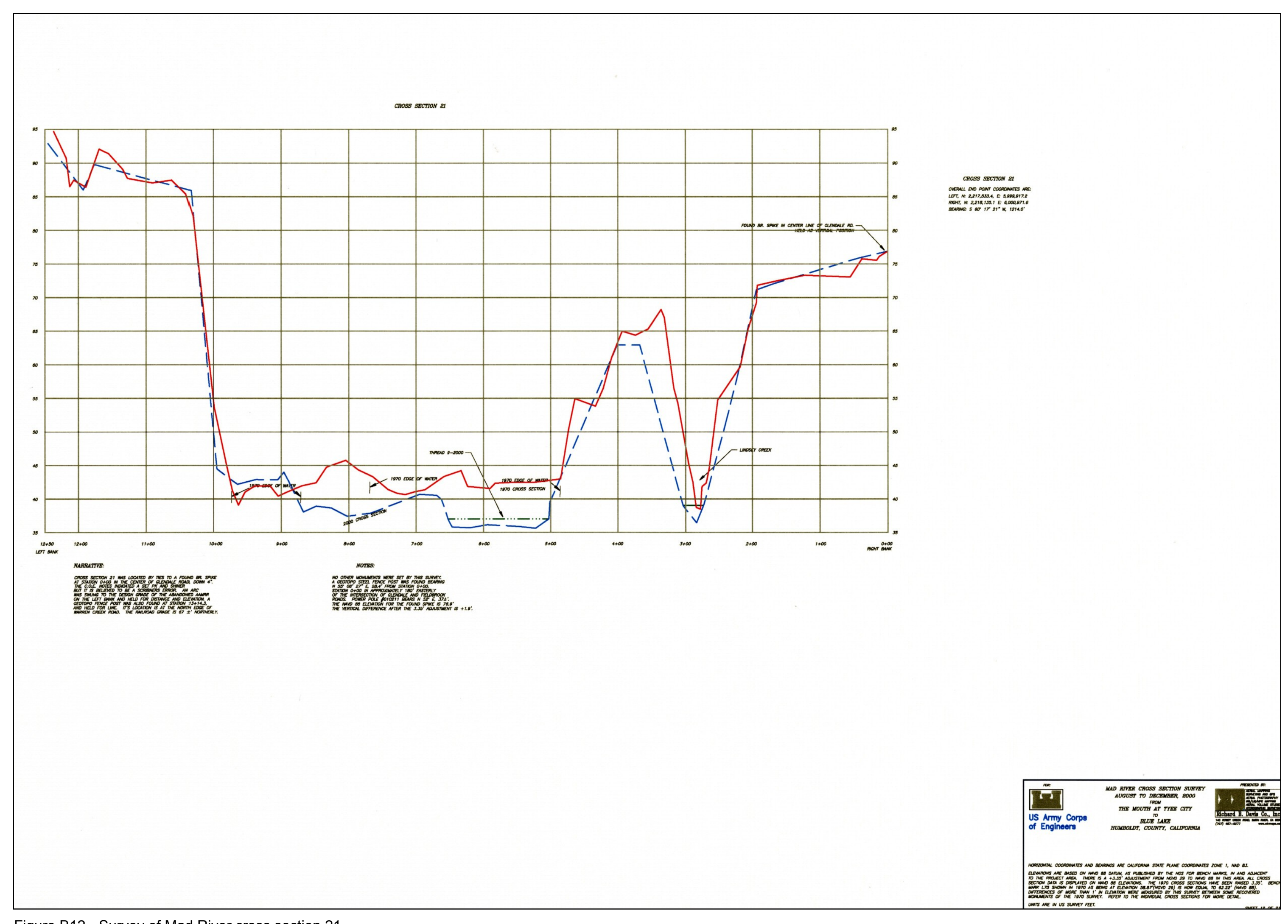




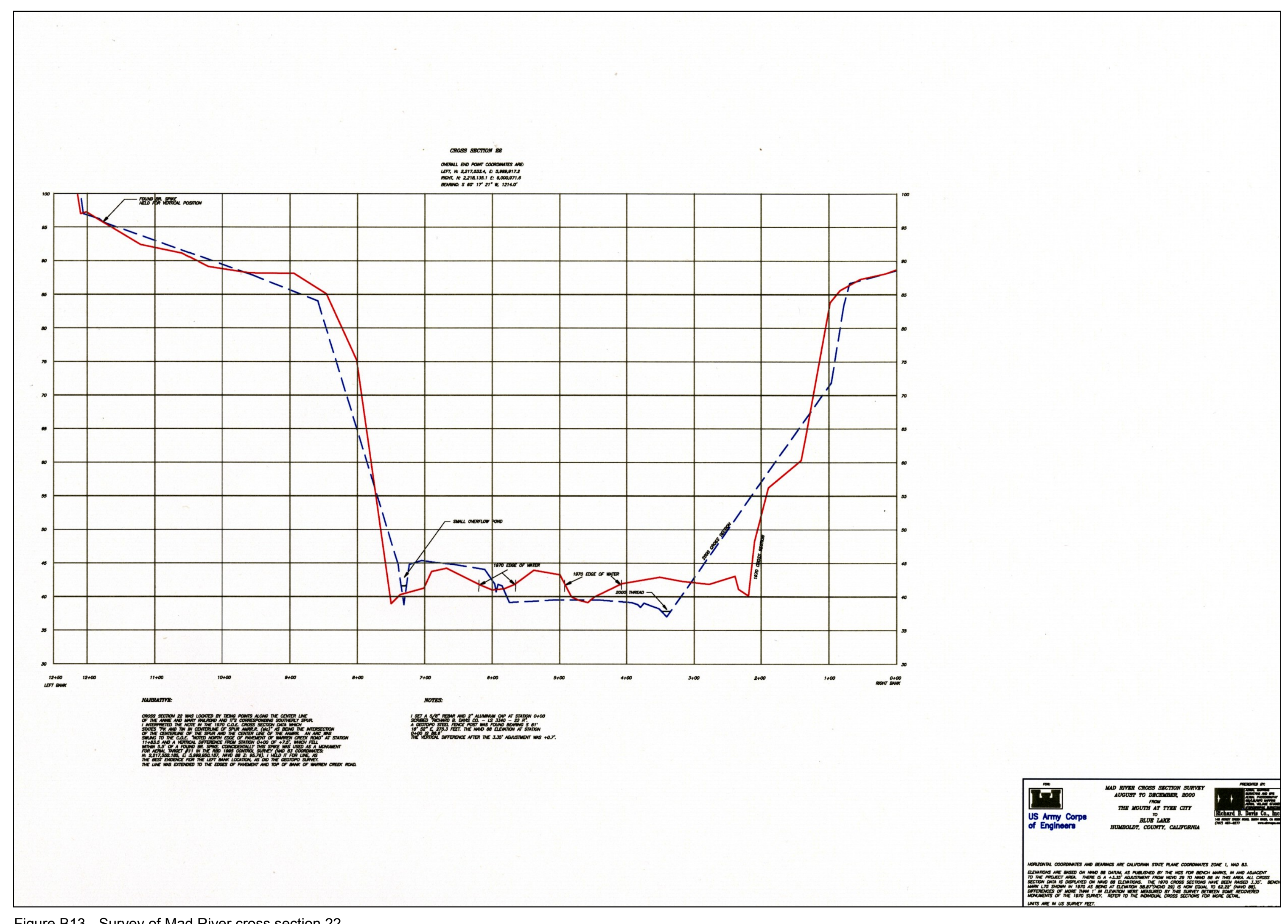




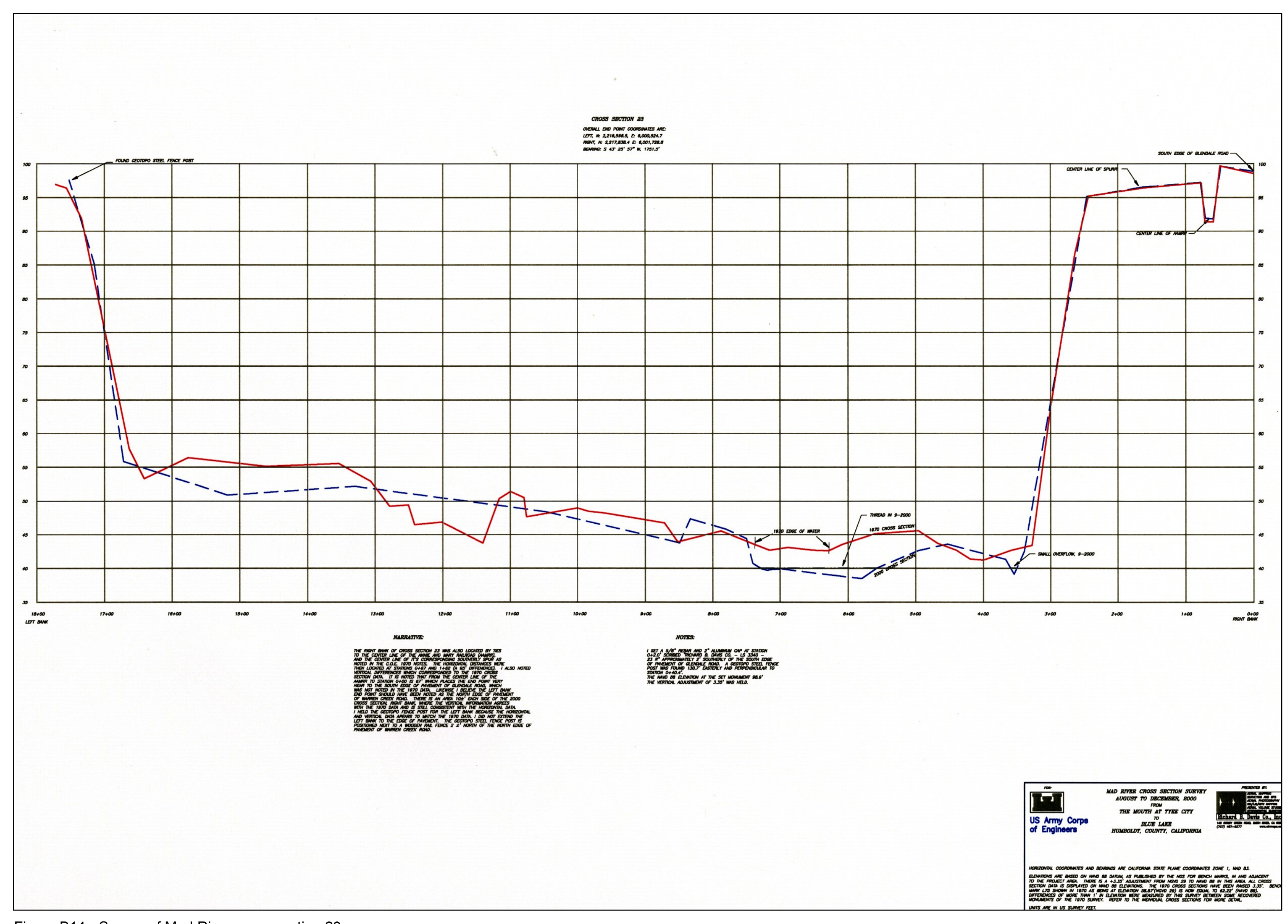




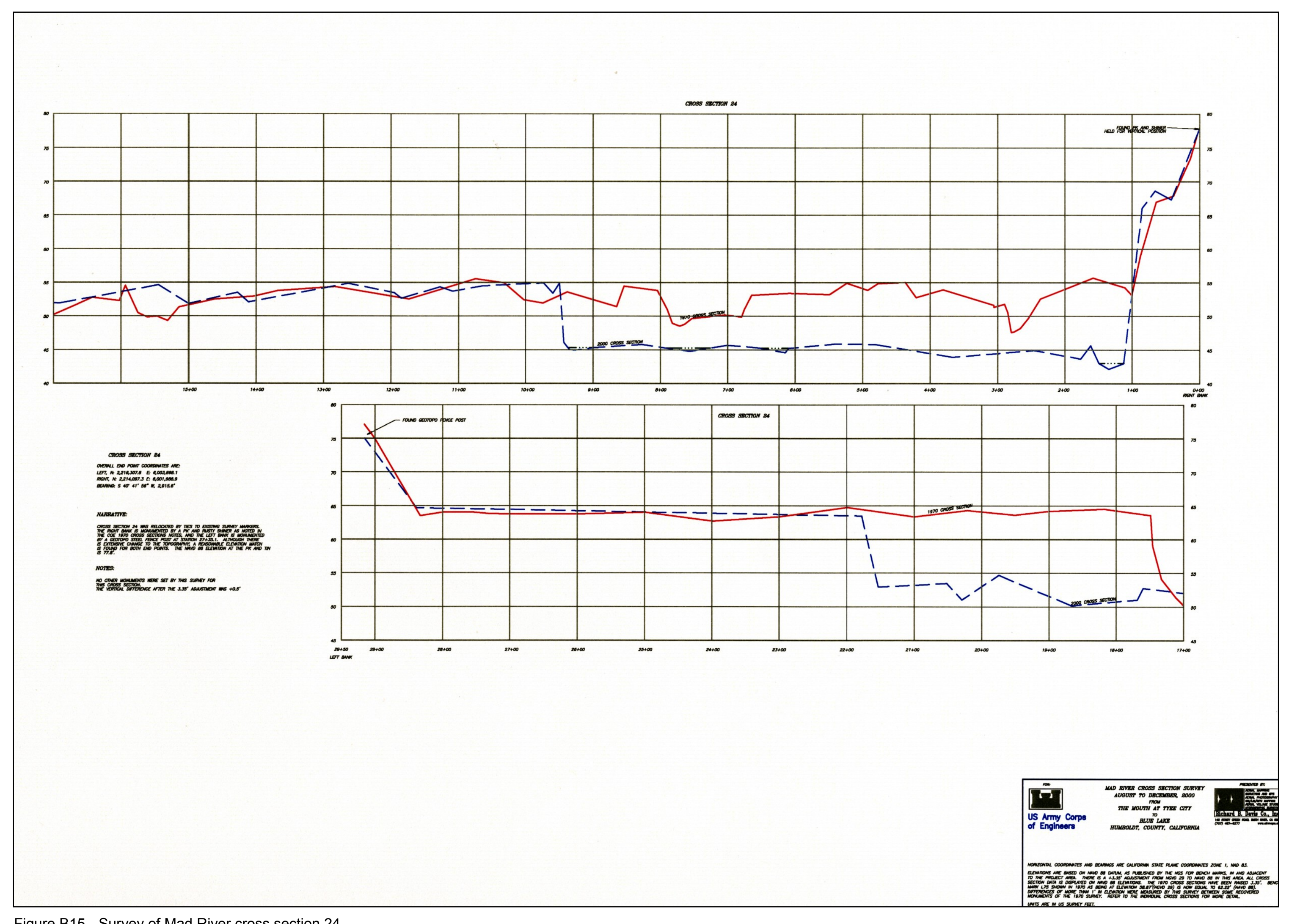

Figure B15. Survey of Mad River cross section 24 


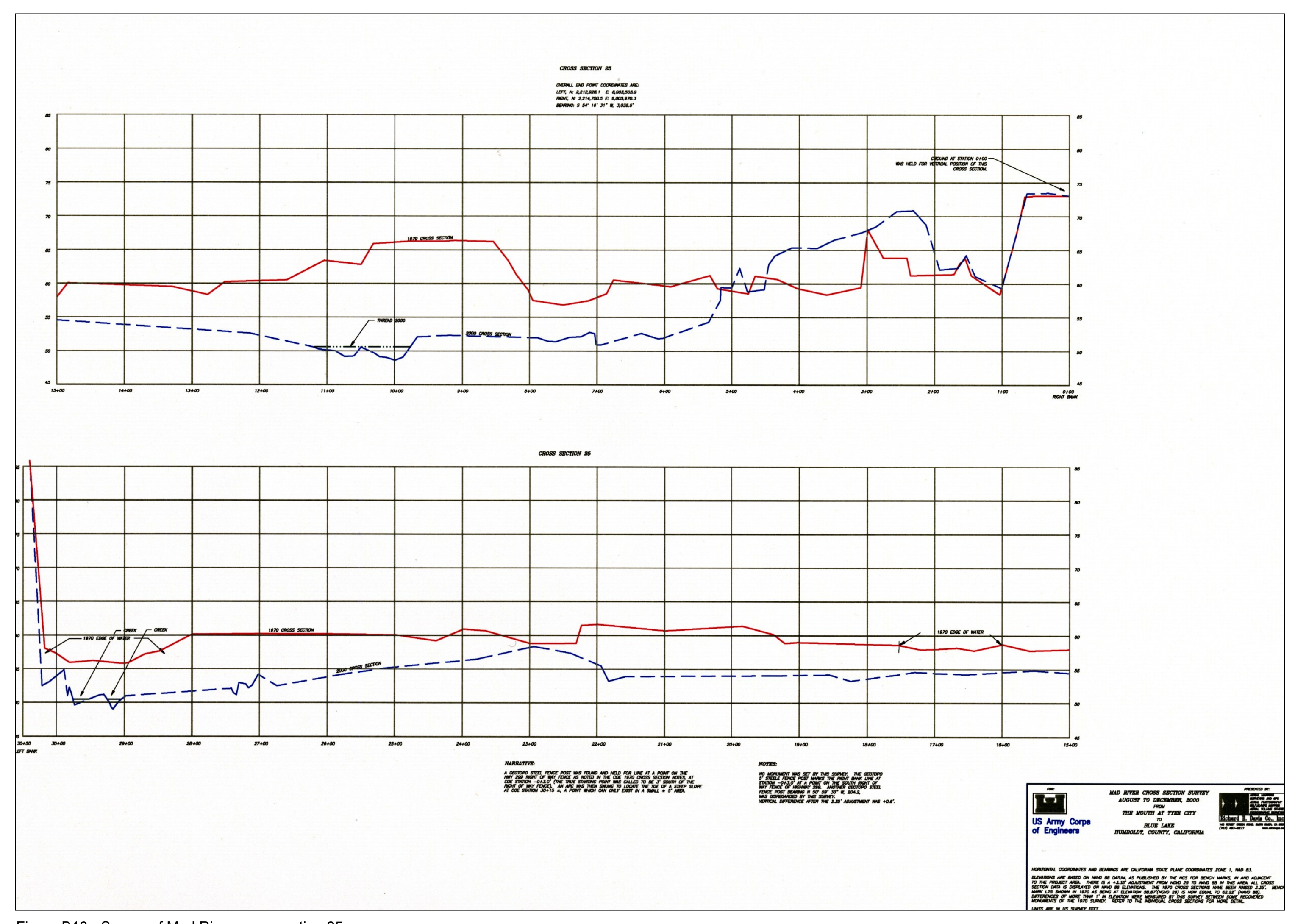

Figure B16. Survey of Mad River cross section 25 


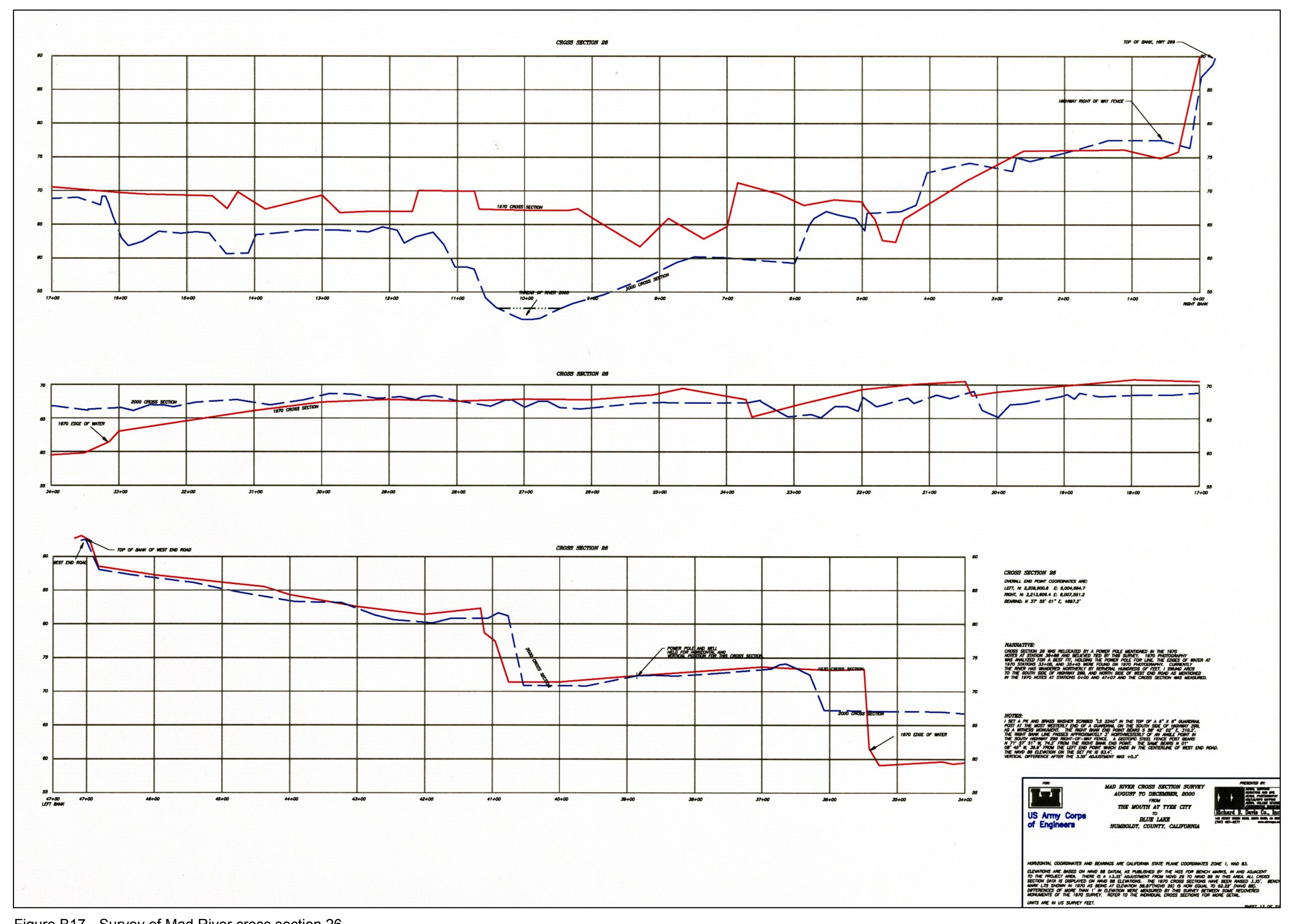

Figure B17. Survey of Mad River cross section 26 


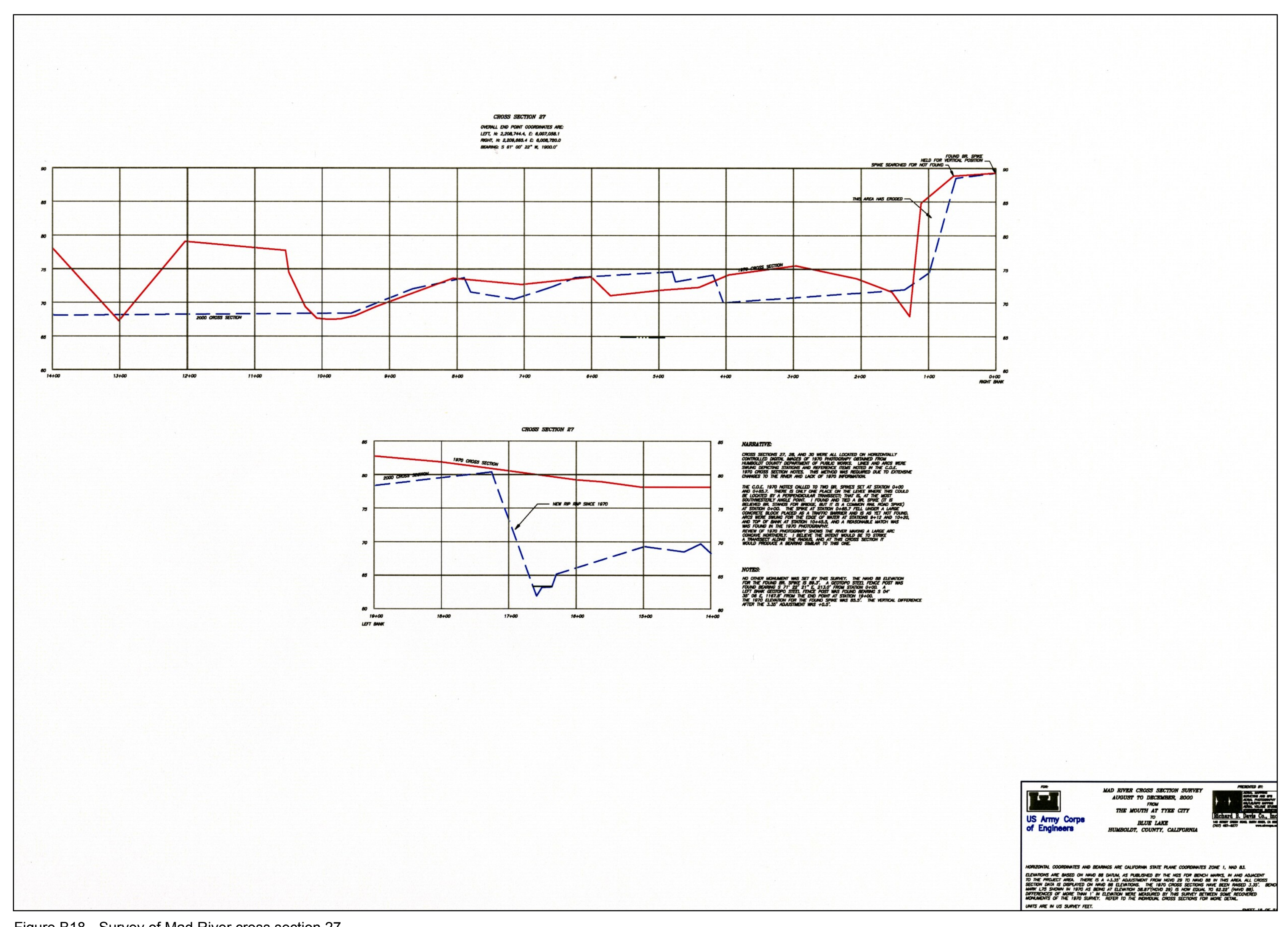




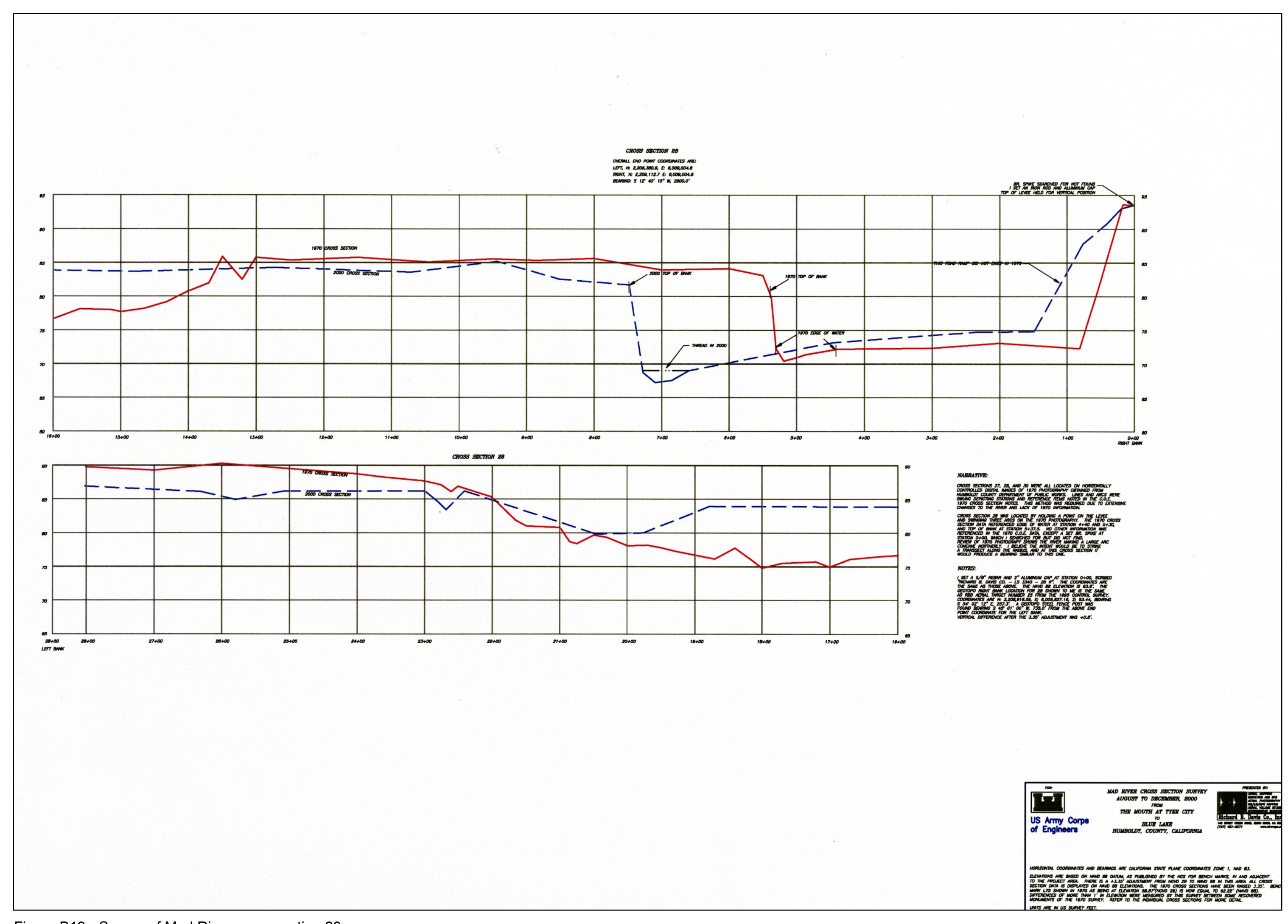

Figure B19. Survey of Mad River cross section 28 


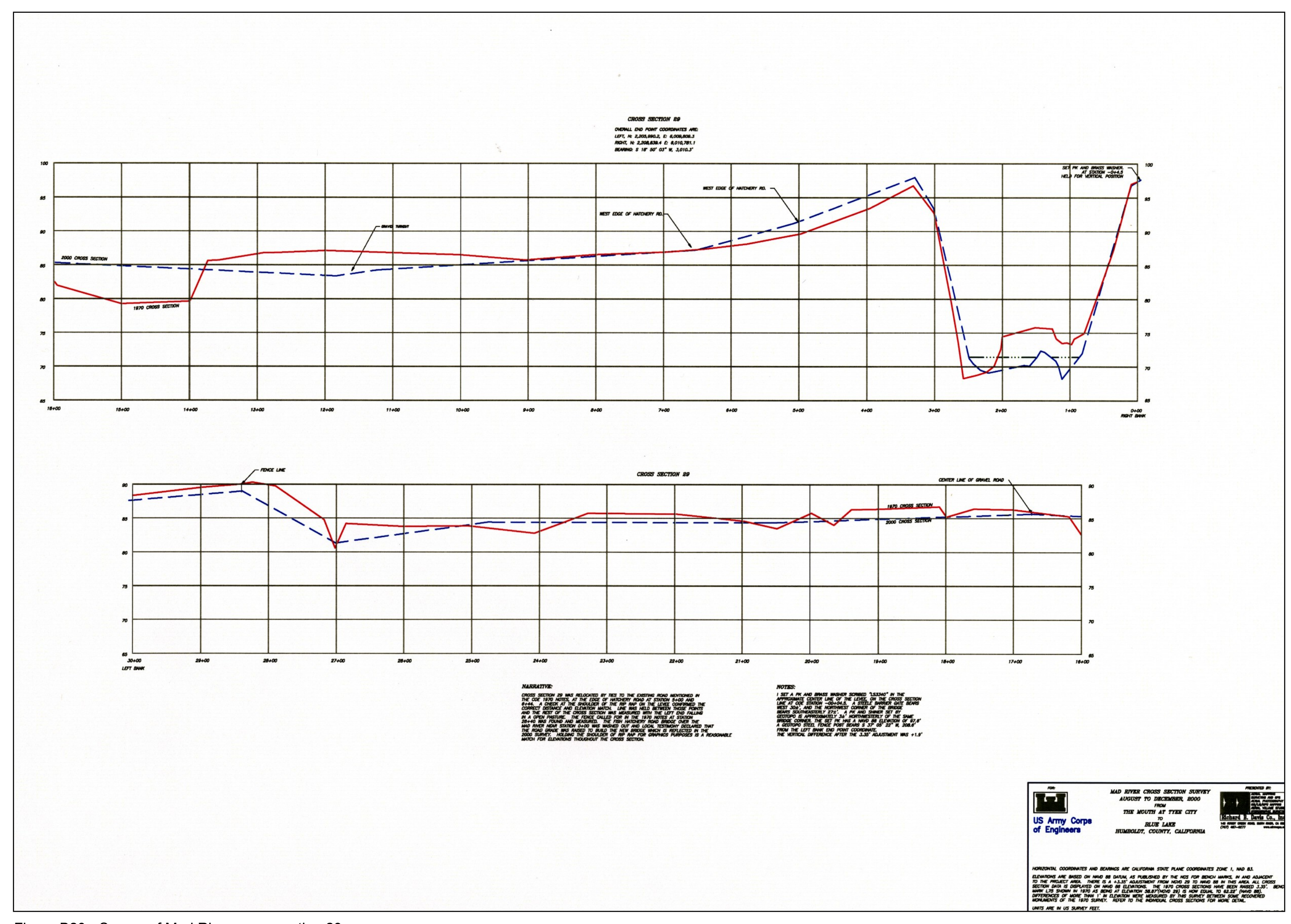

Figure B20. Survey of Mad River cross section 29 


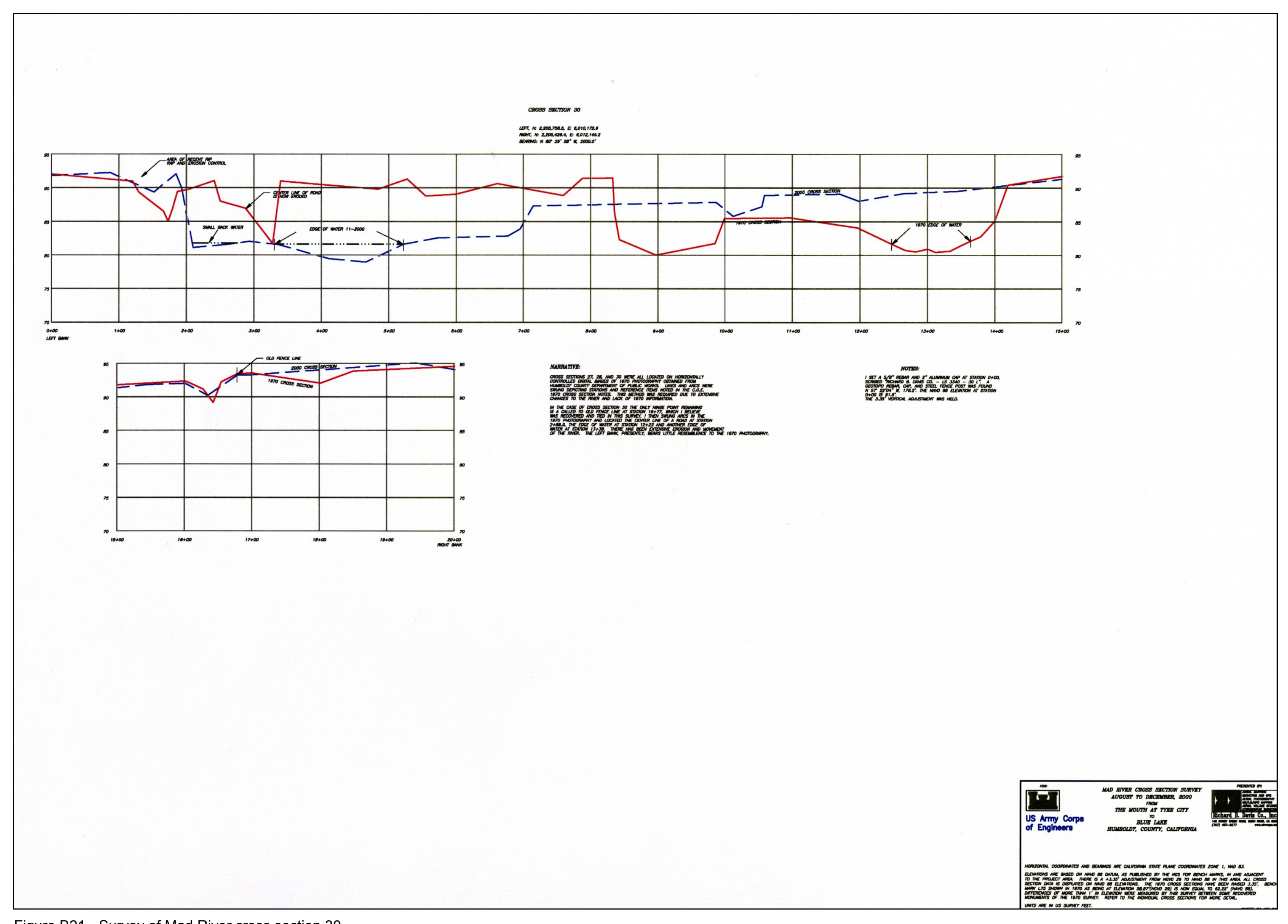




\section{Appendix C Photographs of USACE Cross- Section Locations}

(All photographs were taken February 27, February 28, or March 1, 2001. Average daily flow in the Mad River during these days was steadily decreasing from 1,120 cfs to $919 \mathrm{cfs}$. Photographs were not taken during a low-flow period in the river due to the time it took to complete the cross-section surveys and our desire to take these photographs immediately after completion of the surveying work.)

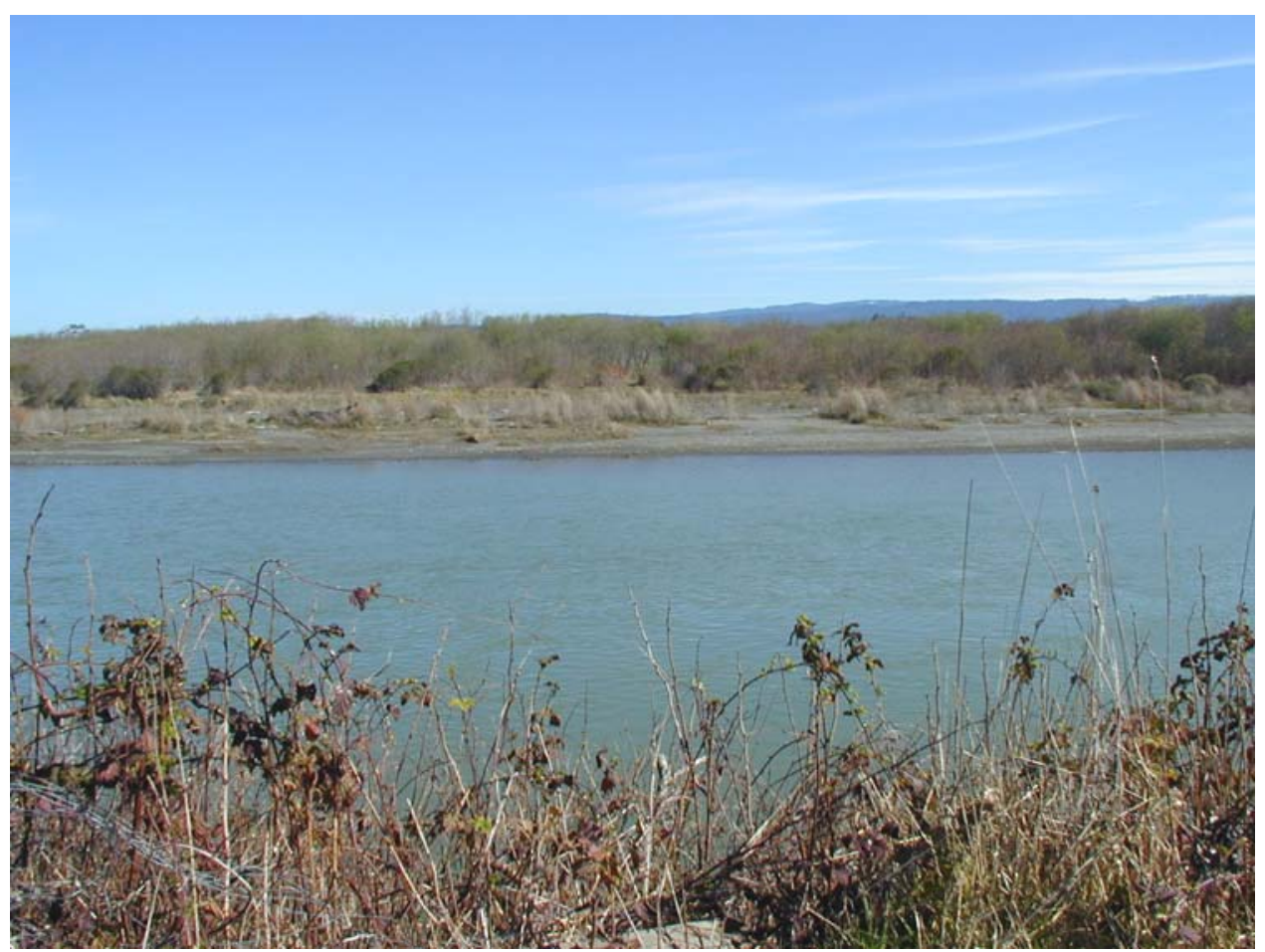

Figure C1. XC2 (left bank) 


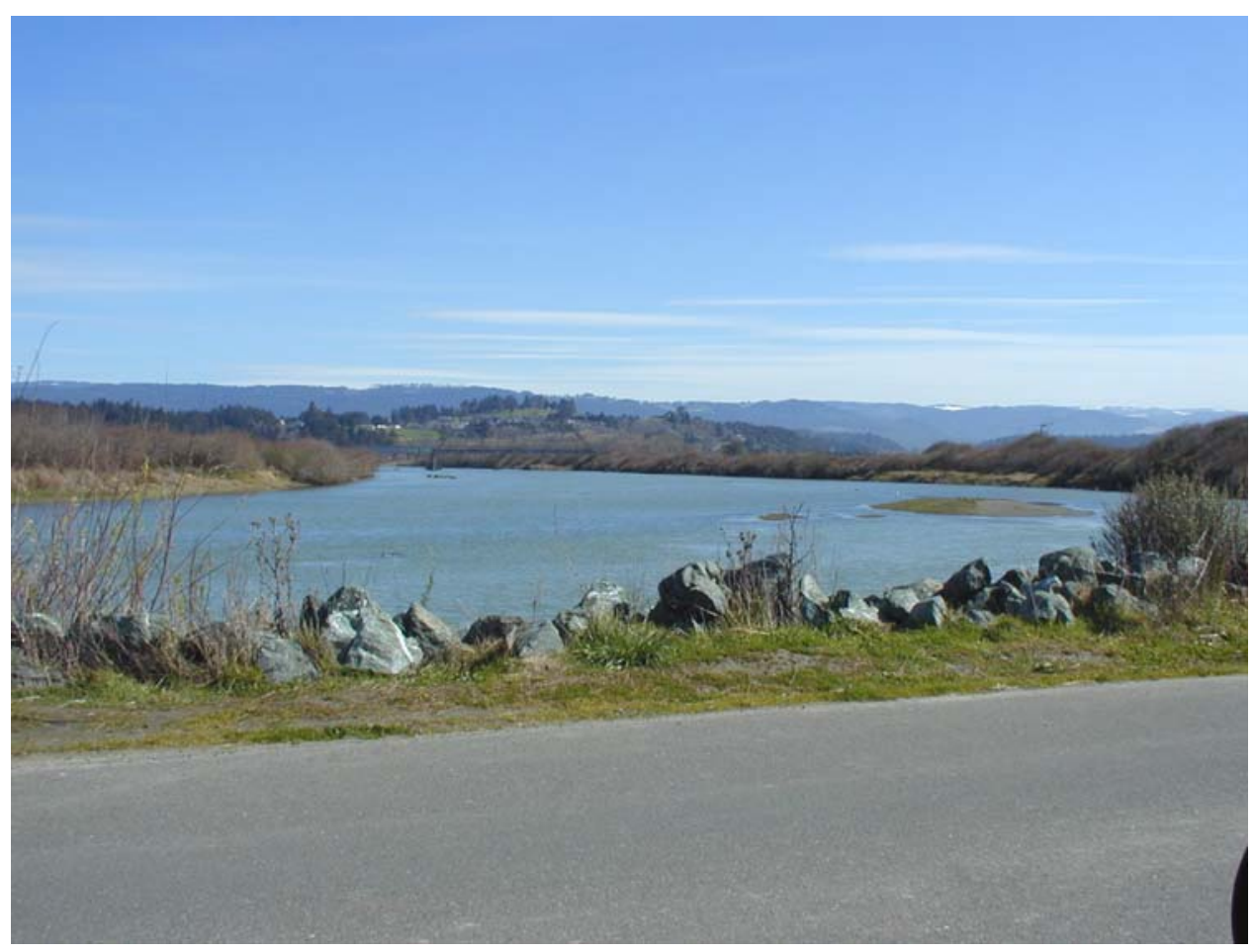

Figure C2. XC2 (left bank) - Taken just upstream of cross section looking at old railroad bridge

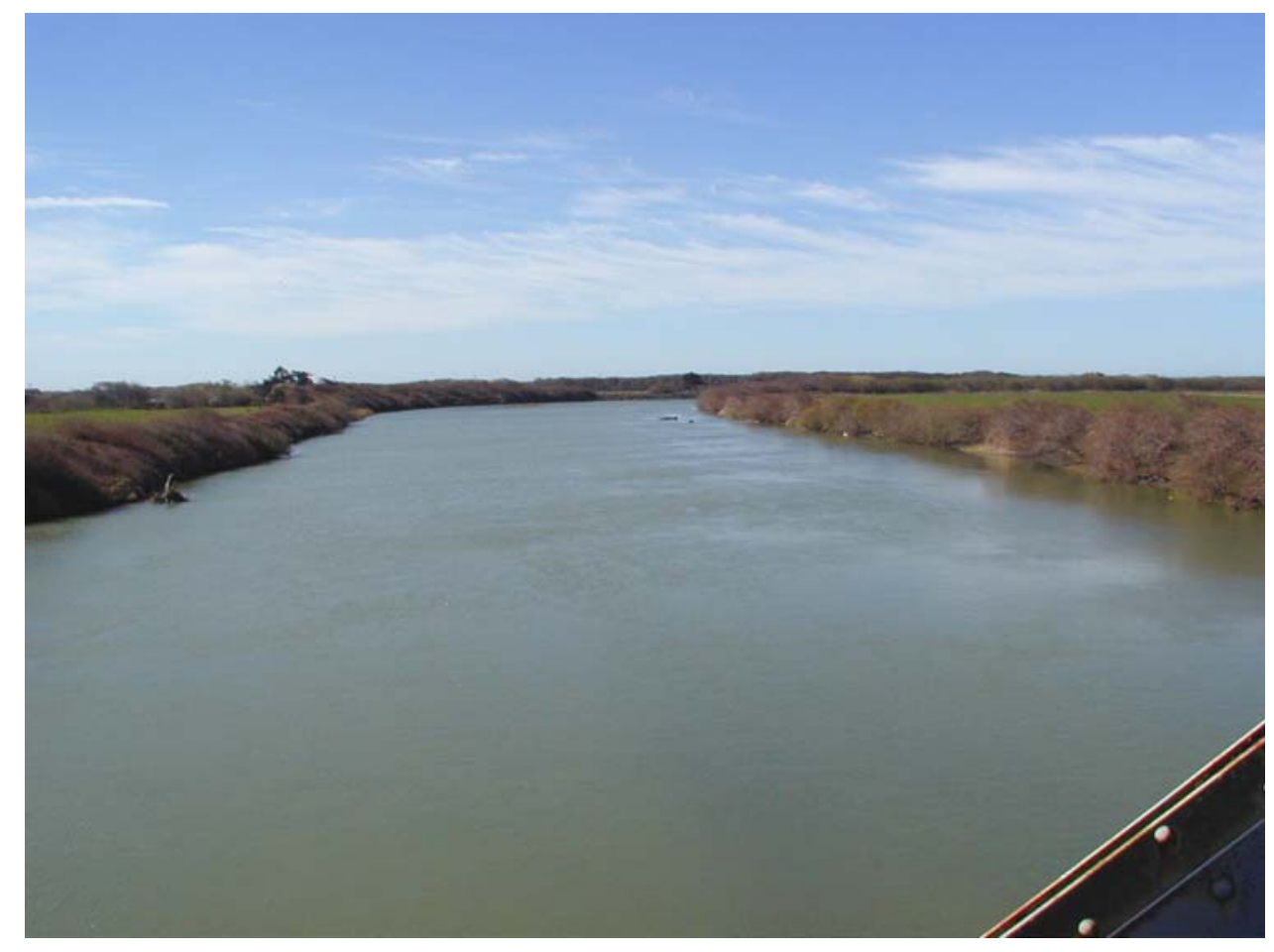

Figure C3. XC3 - Looking downstream from old railroad bridge 


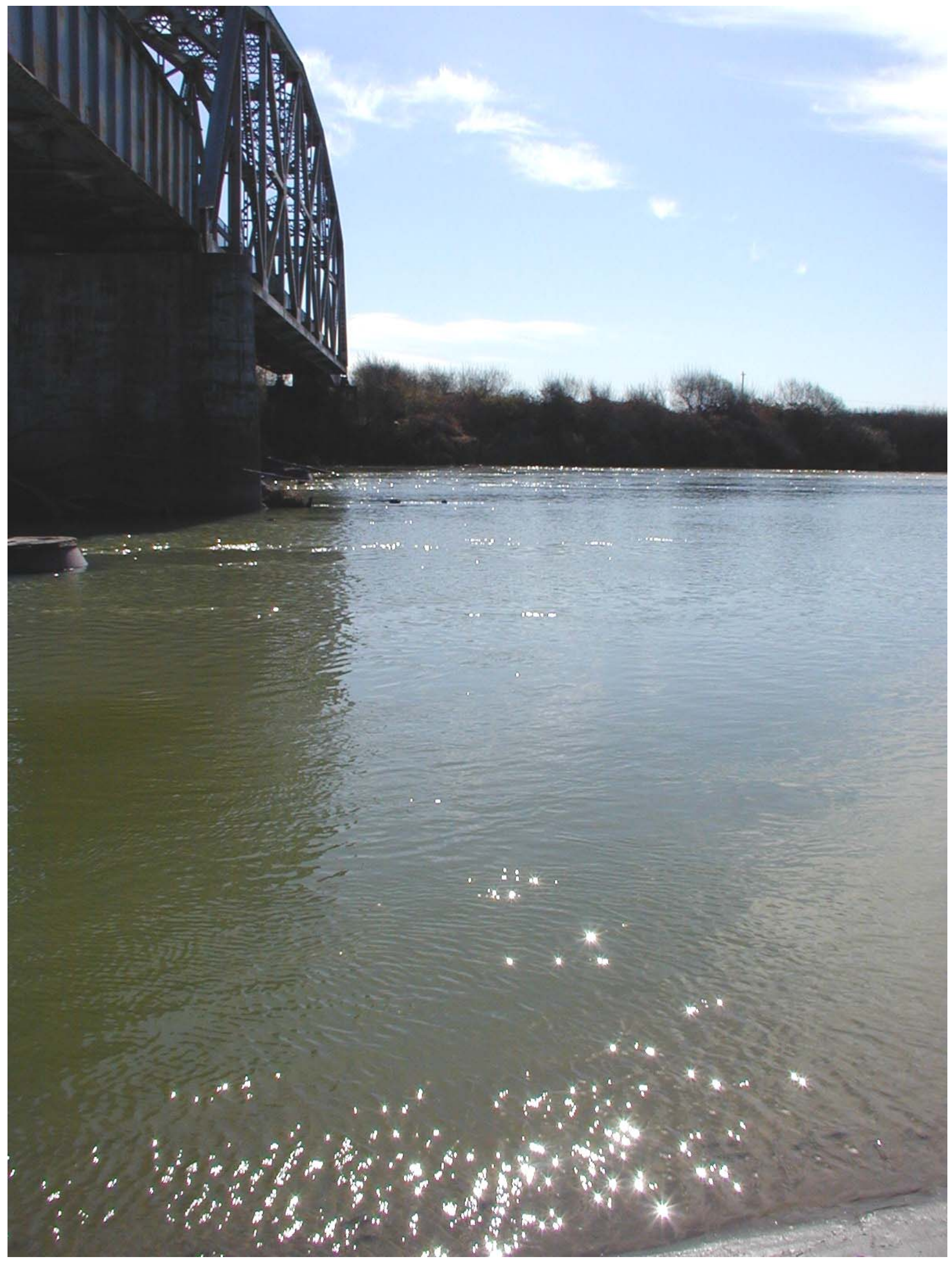

Figure C4. XC3 (right bank) - Looking under old railroad bridge 


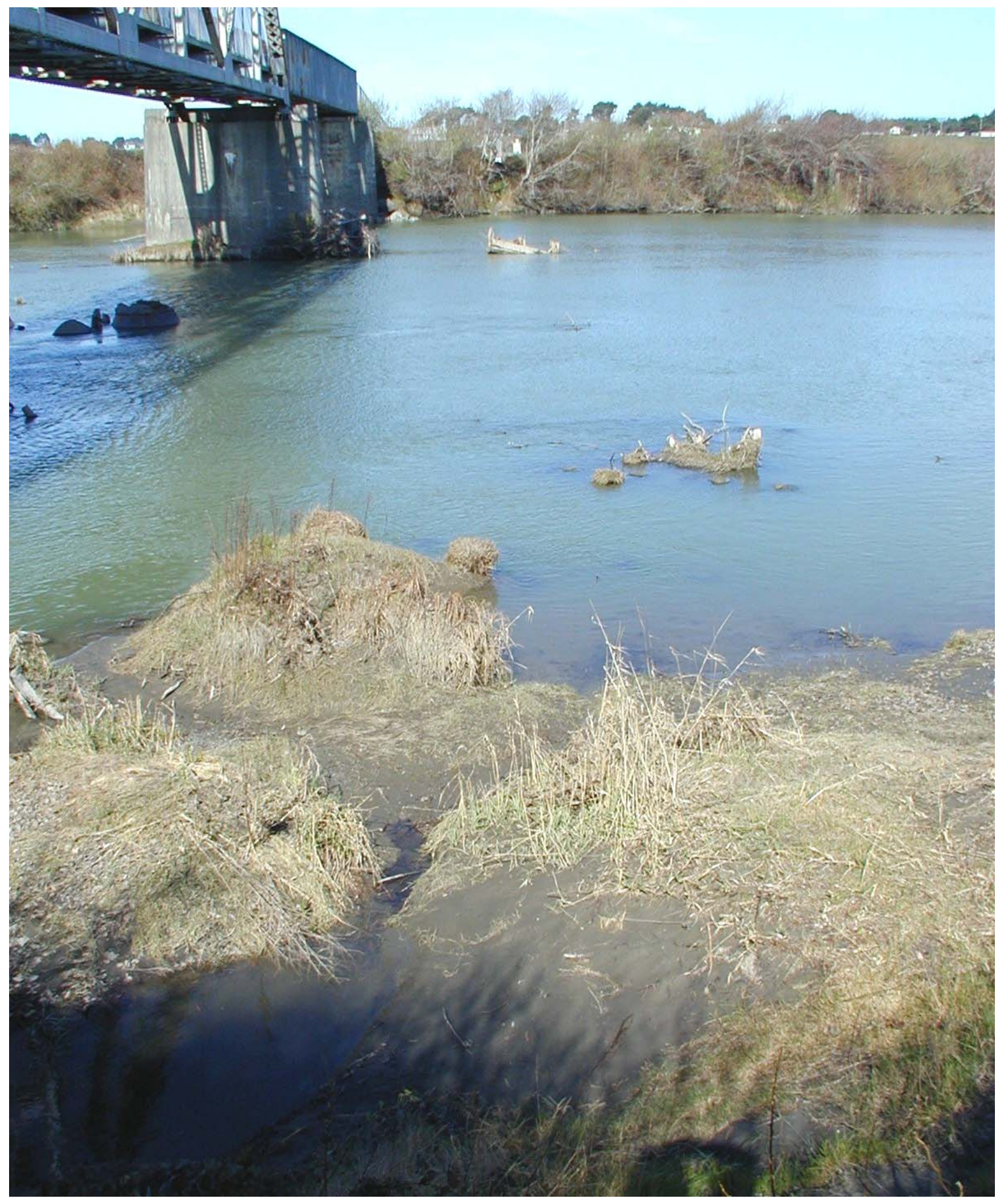

Figure C5. XC4 (left bank) 


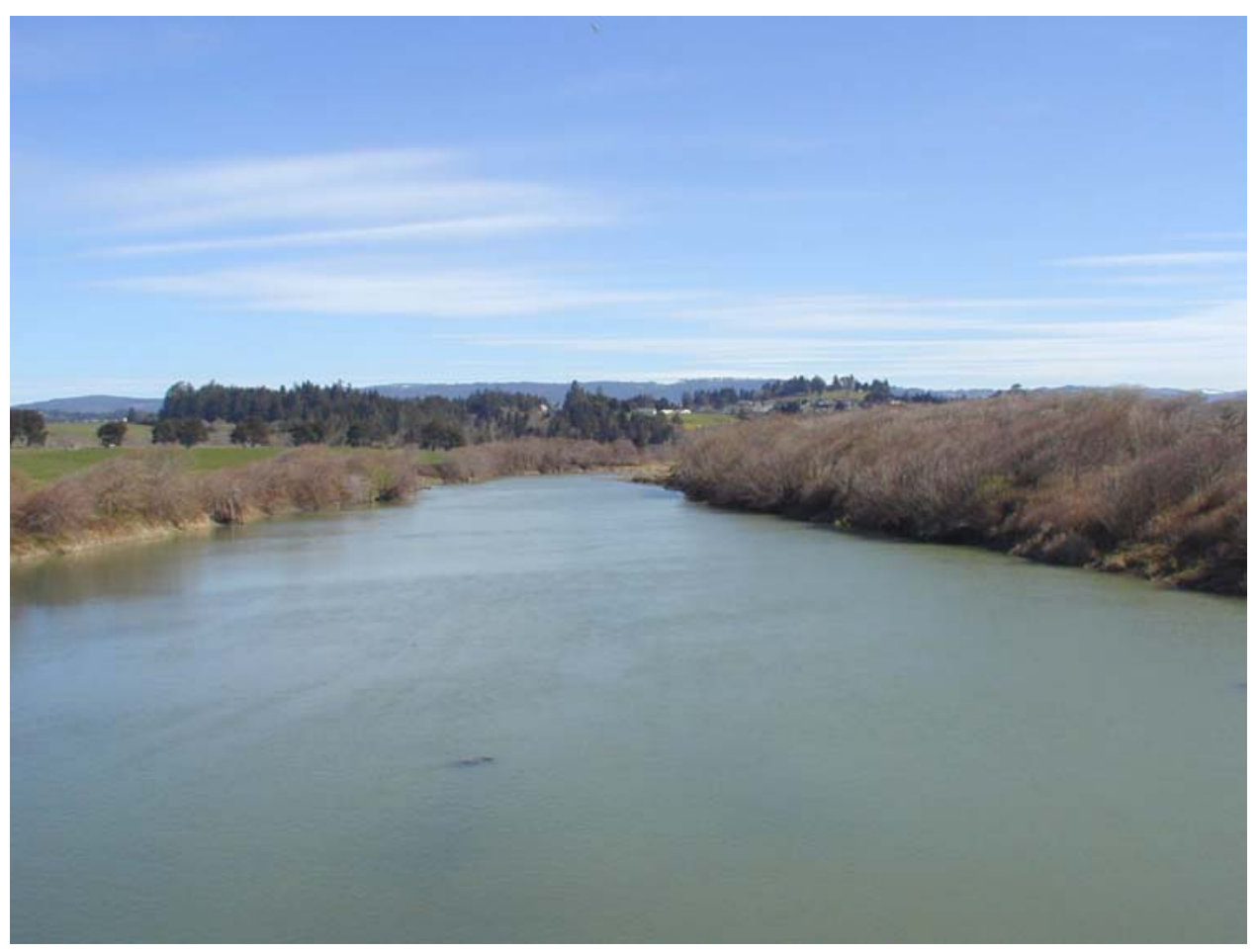

Figure C6. XC4 - Looking upstream from old railroad bridge

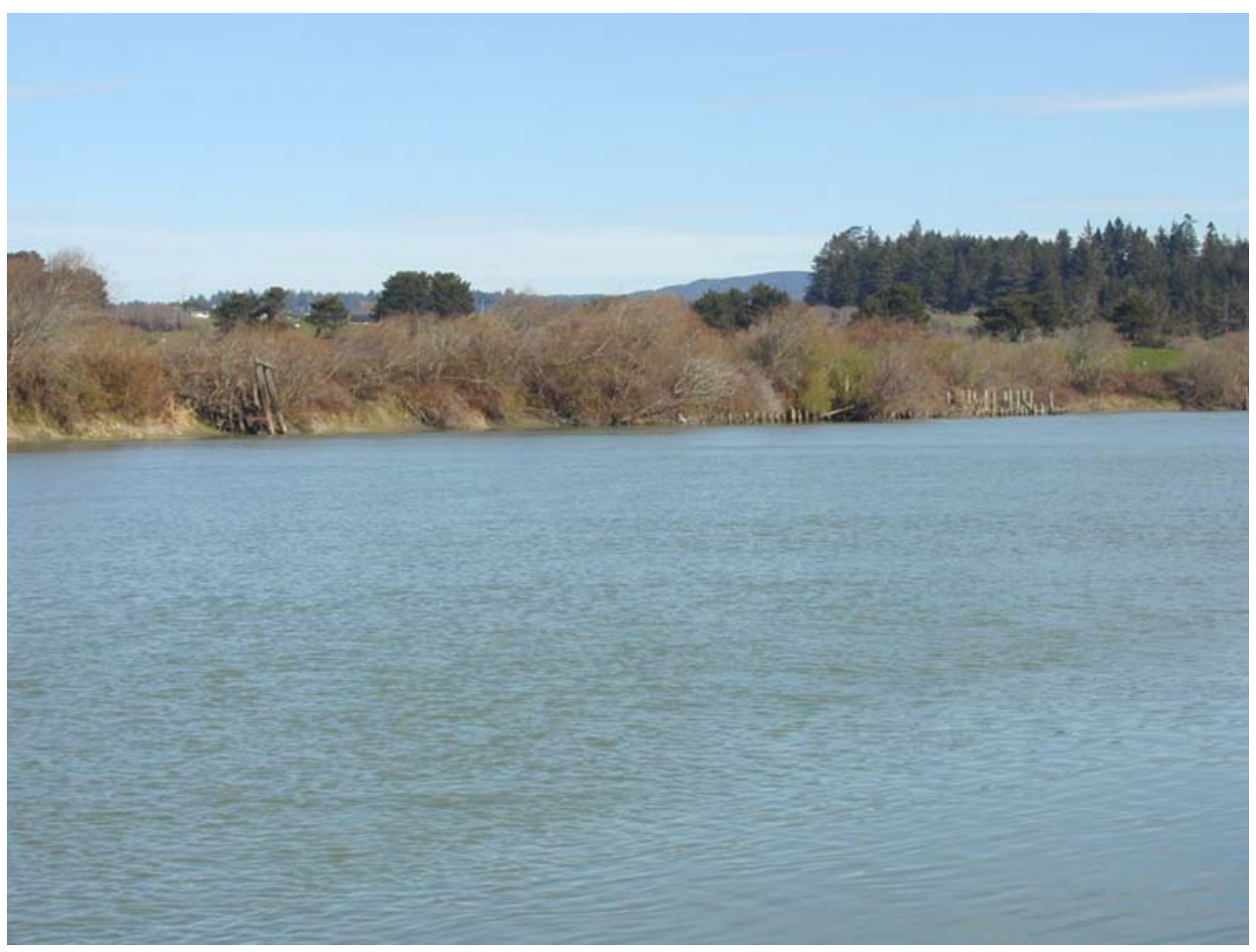

Figure C7. XC4 - Upstream of cross section looking at old protection on right bank 


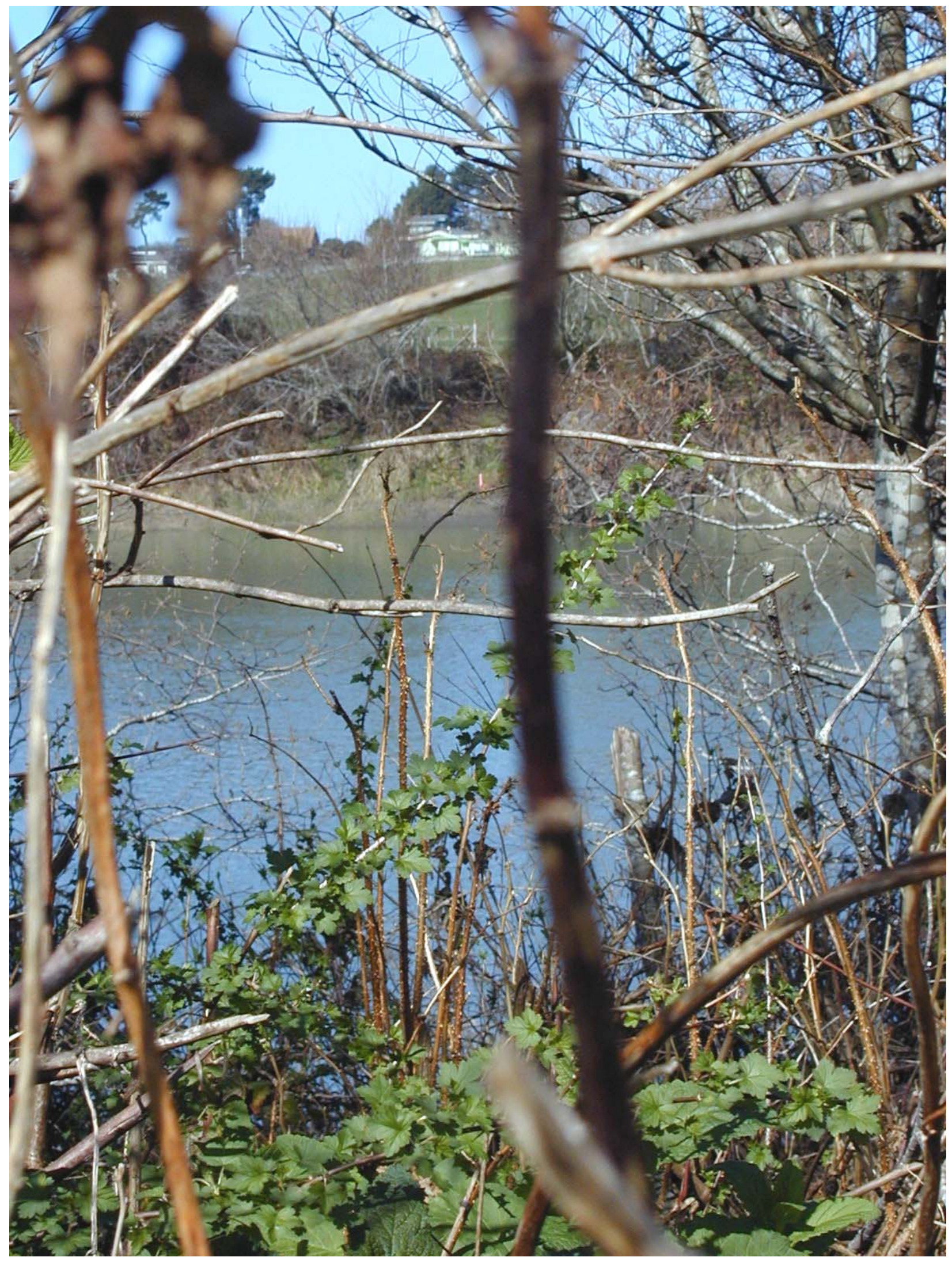

Figure C8. XC5 (left bank) 


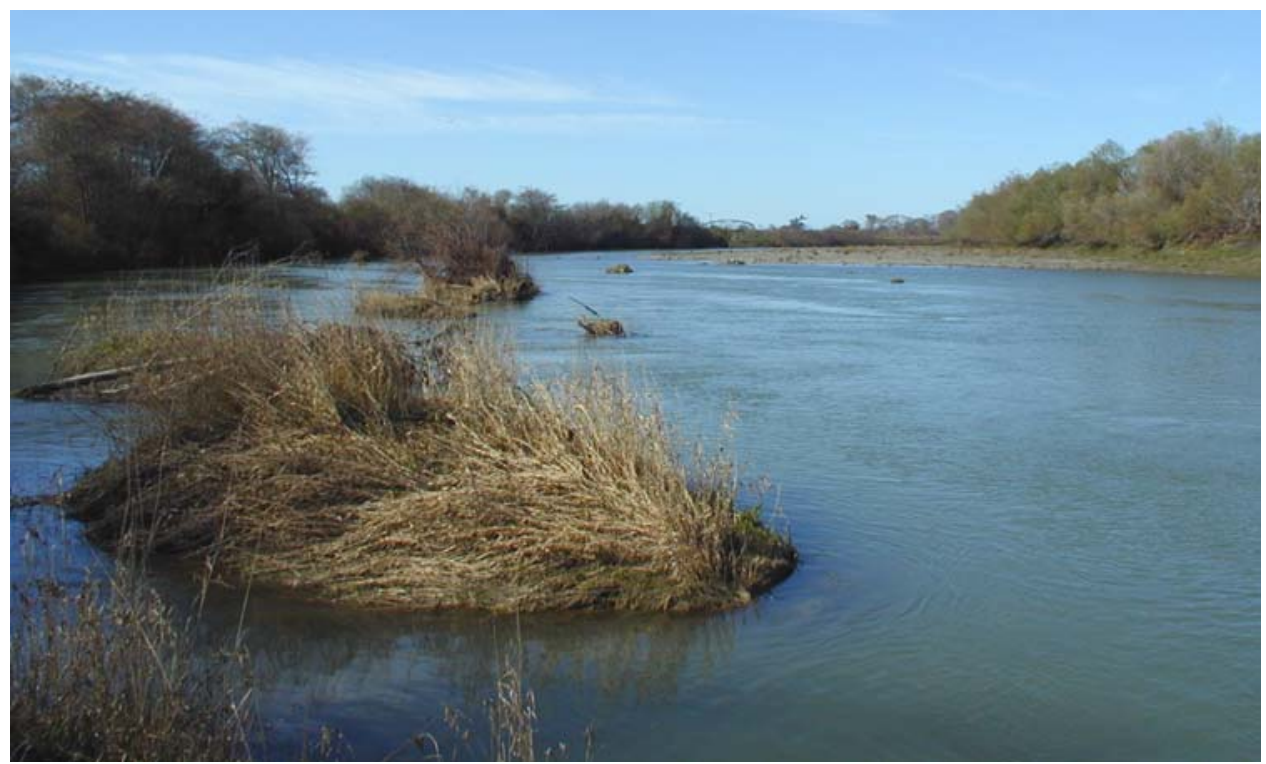

Figure C9. XC6 - Looking upstream of cross section from western point (right side) where Mad River Road meets river

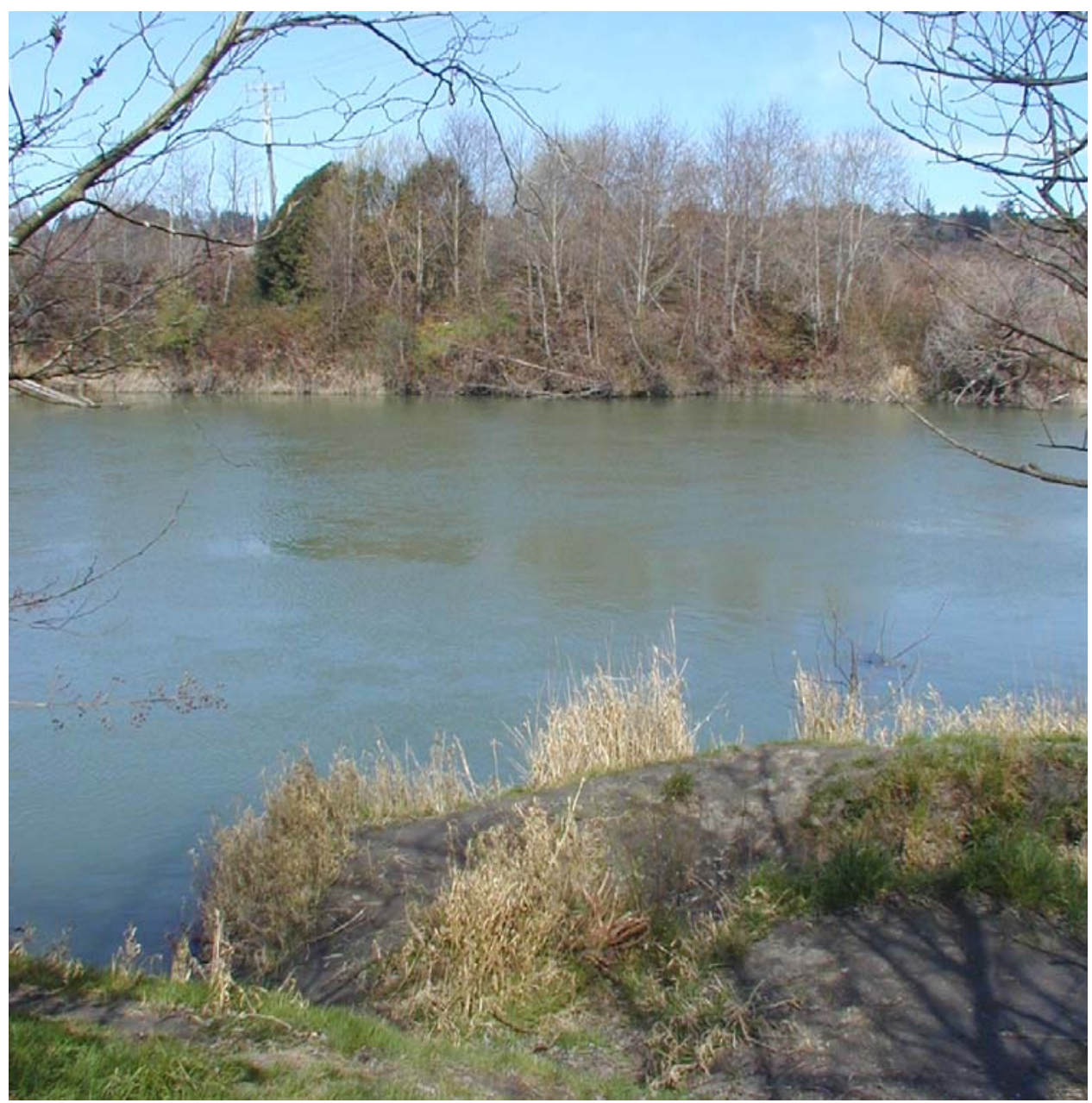

Figure C10. XC7 (left bank) 


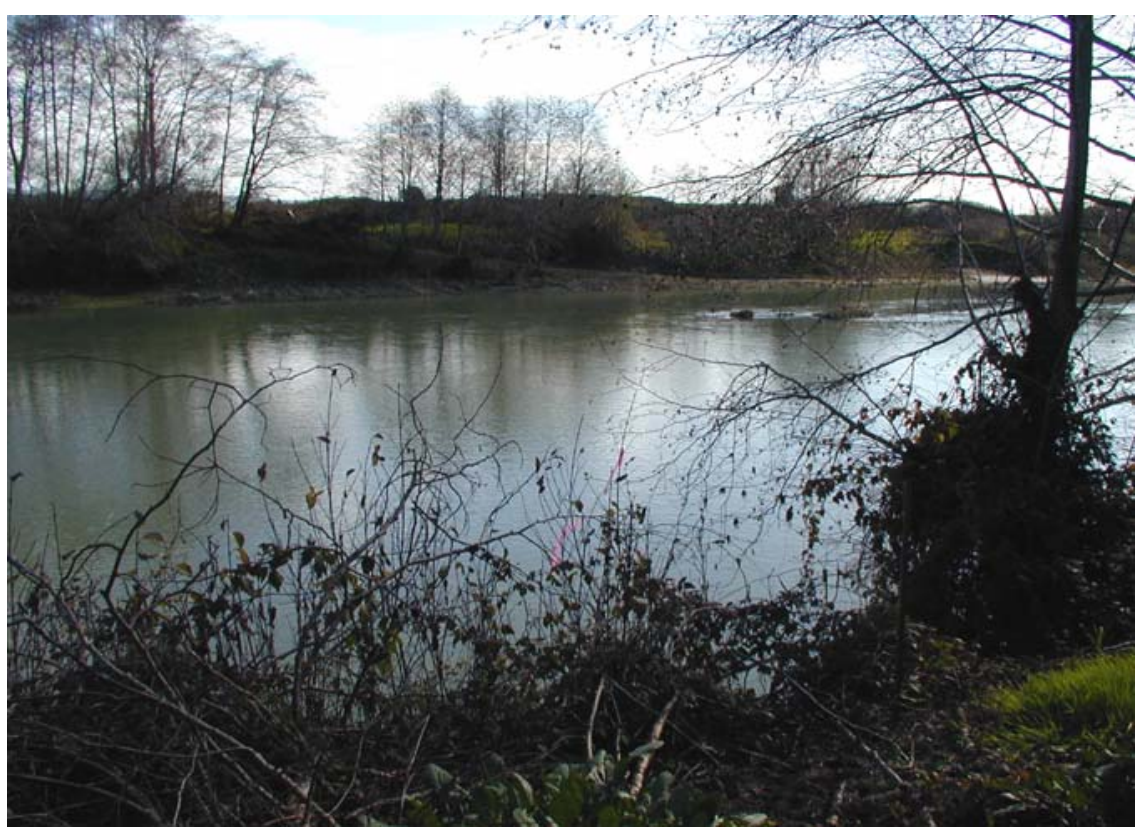

Figure C11. XC8 (right bank)

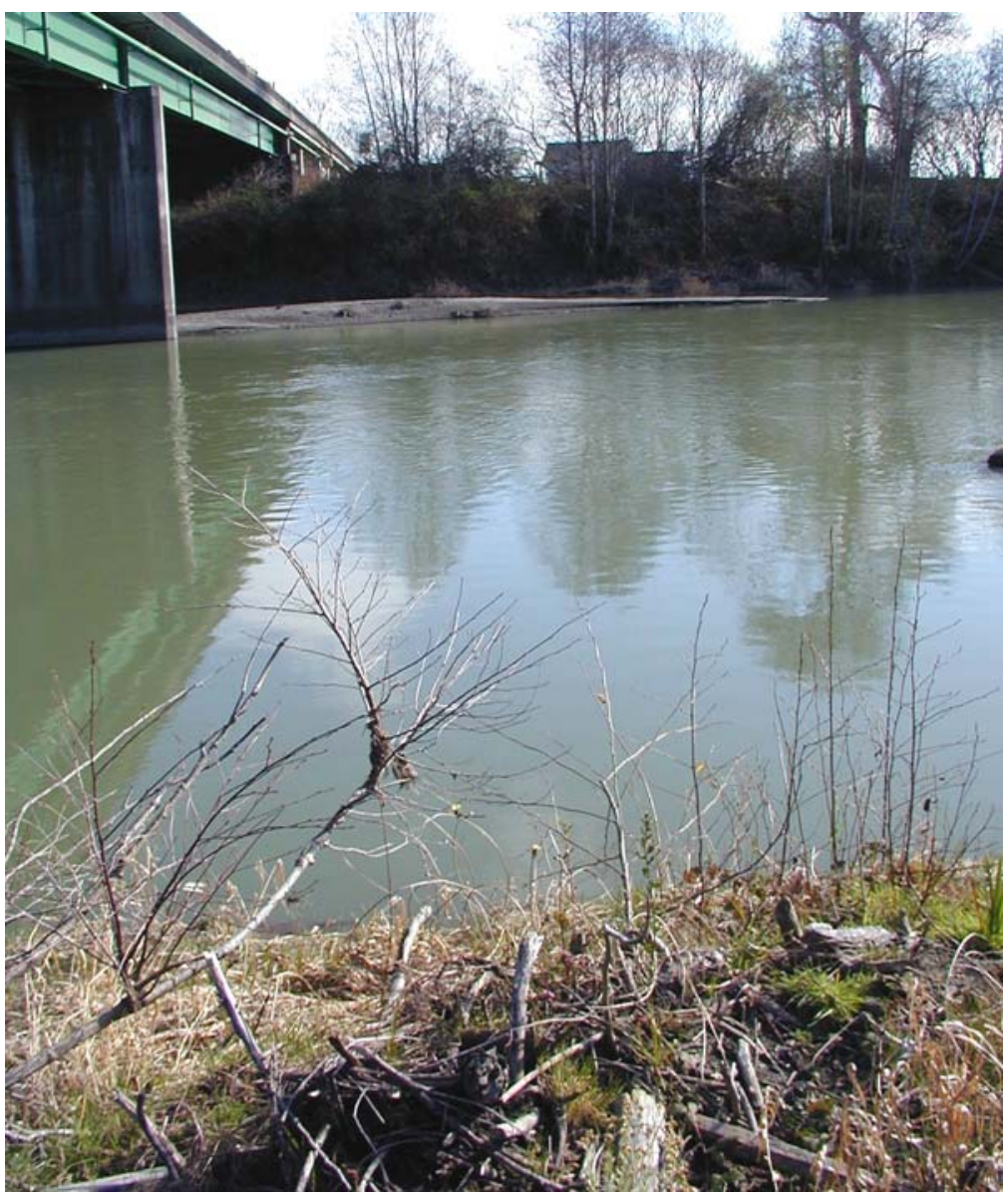

Figure C12. XC9 (right bank) - Highway 101 bridge 


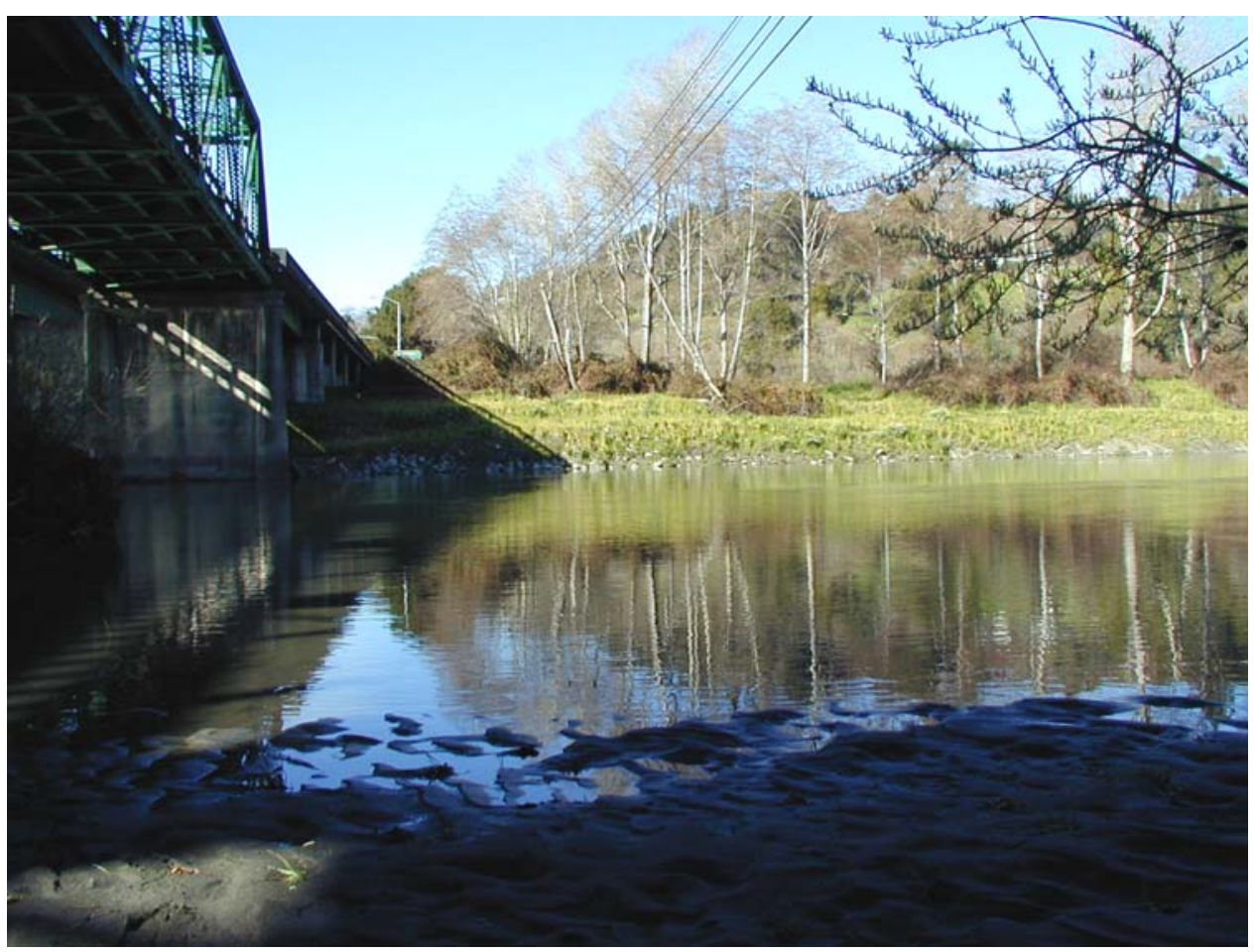

Figure C13. XC10 (left bank) - Highway 101 bridge

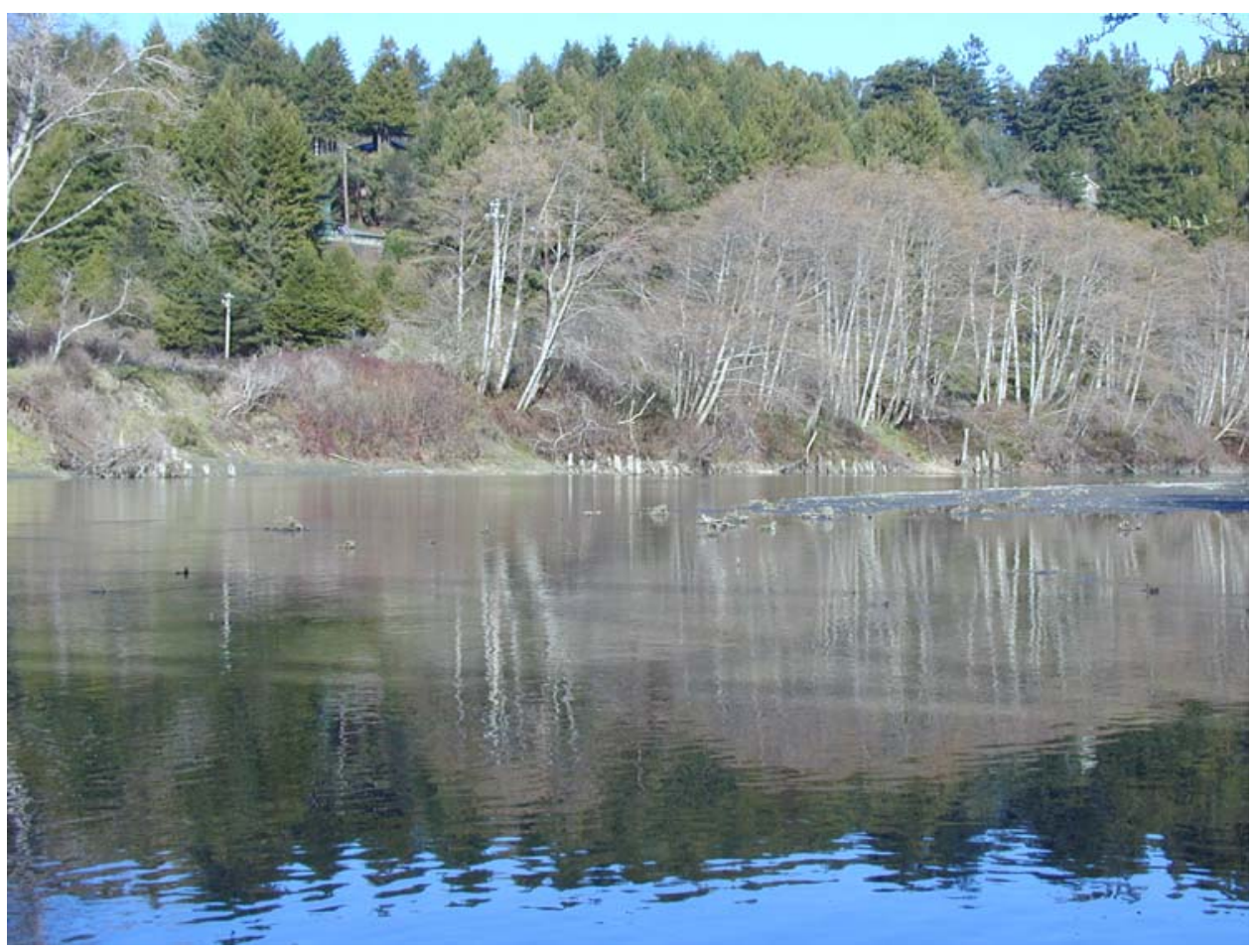

Figure C14. XC10 (left bank) - Looking upstream at old protection on right bank 


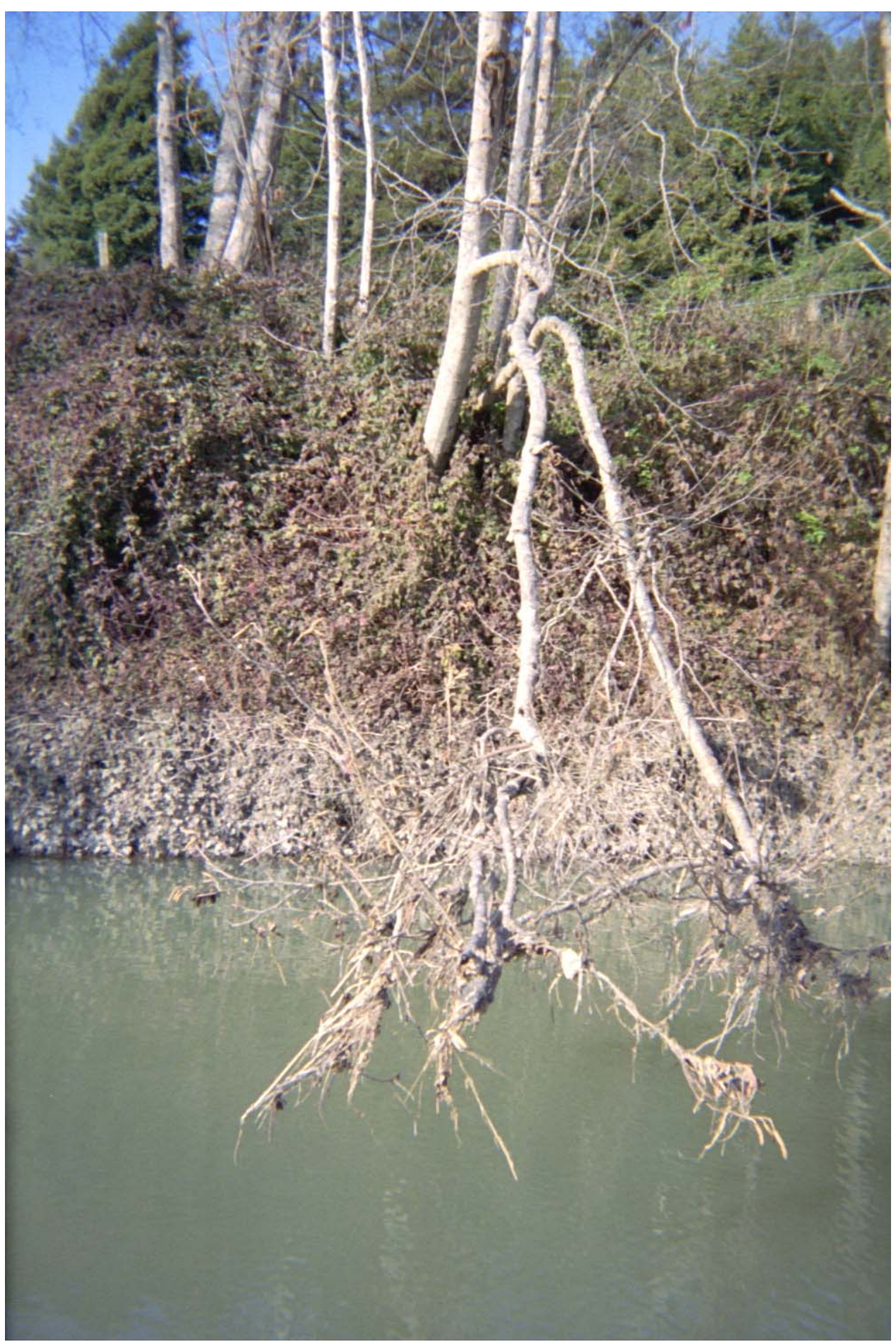

Figure $\mathrm{C} 15 . \mathrm{XC11}$ (right bank) - Looking at right bank 


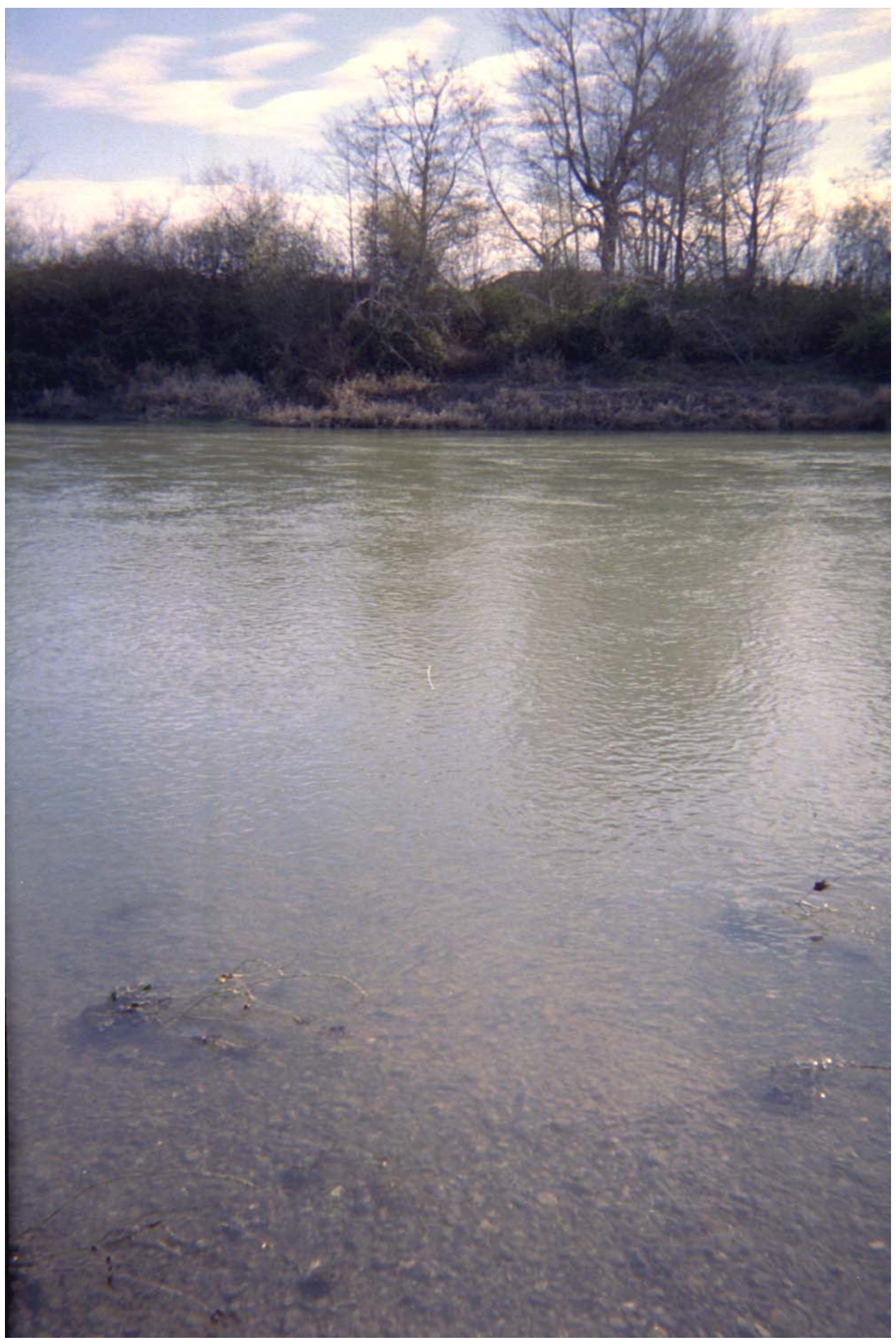

Figure C16. XC11 (right bank) - Looking at left bank 


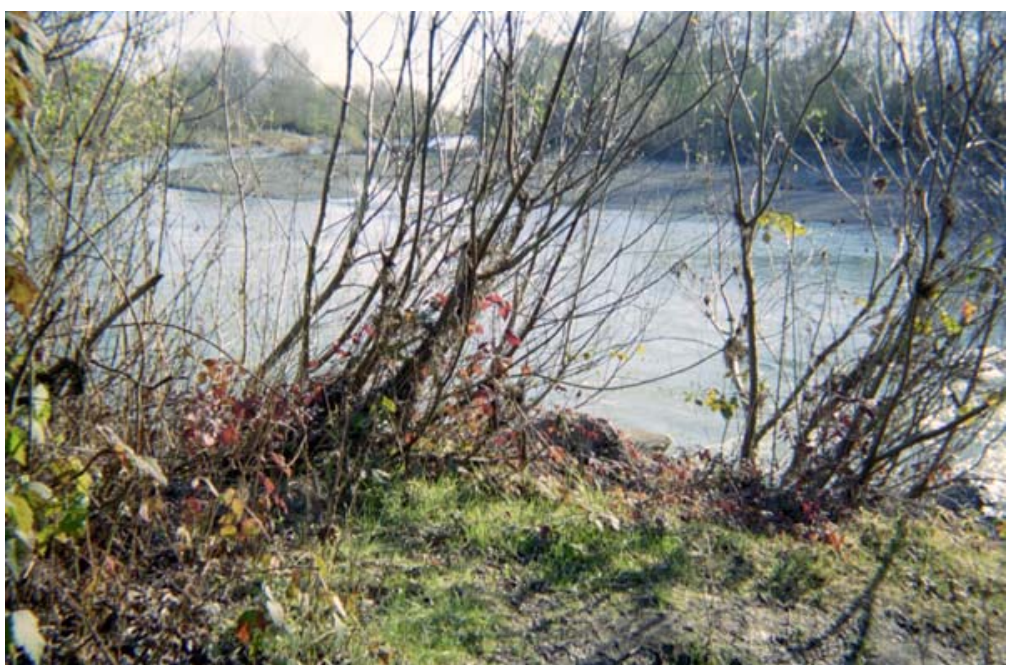

Figure $\mathrm{C} 17$. XC12 (right bank) - Looking from fill and riprap

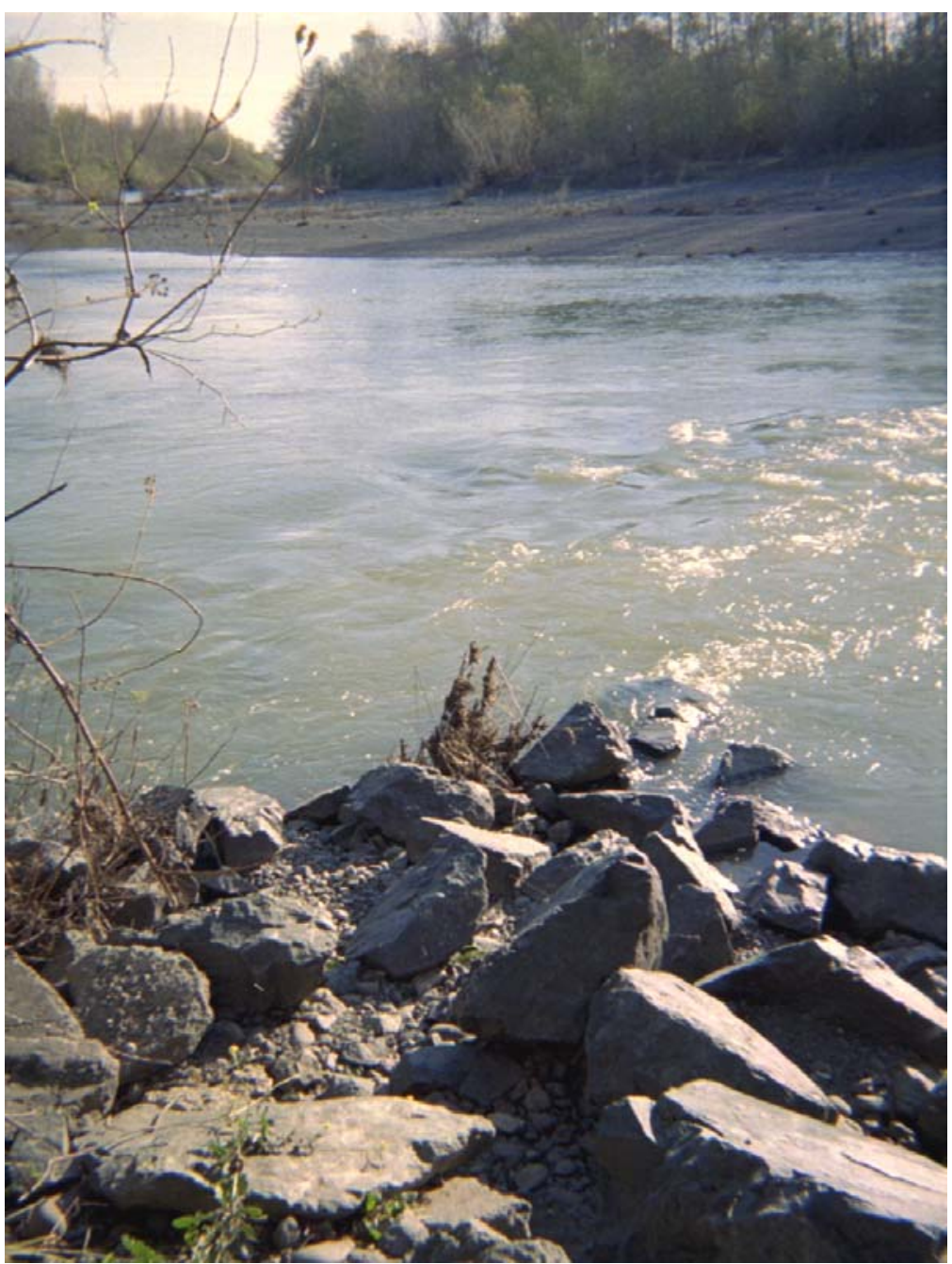

Figure C18. XC12 (right bank) - Looking from fill and riprap 


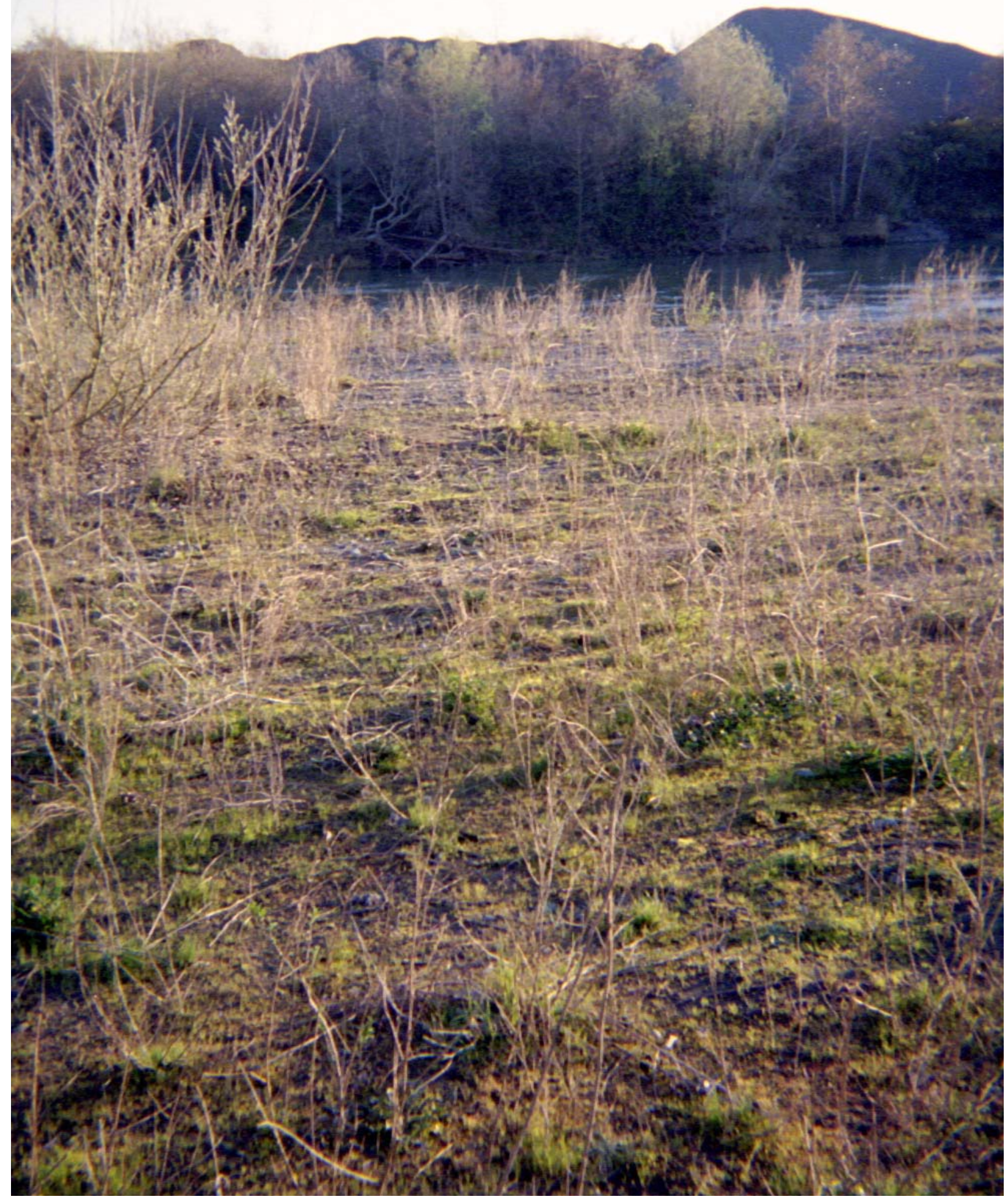

Figure C19. XC13 (right bank) 


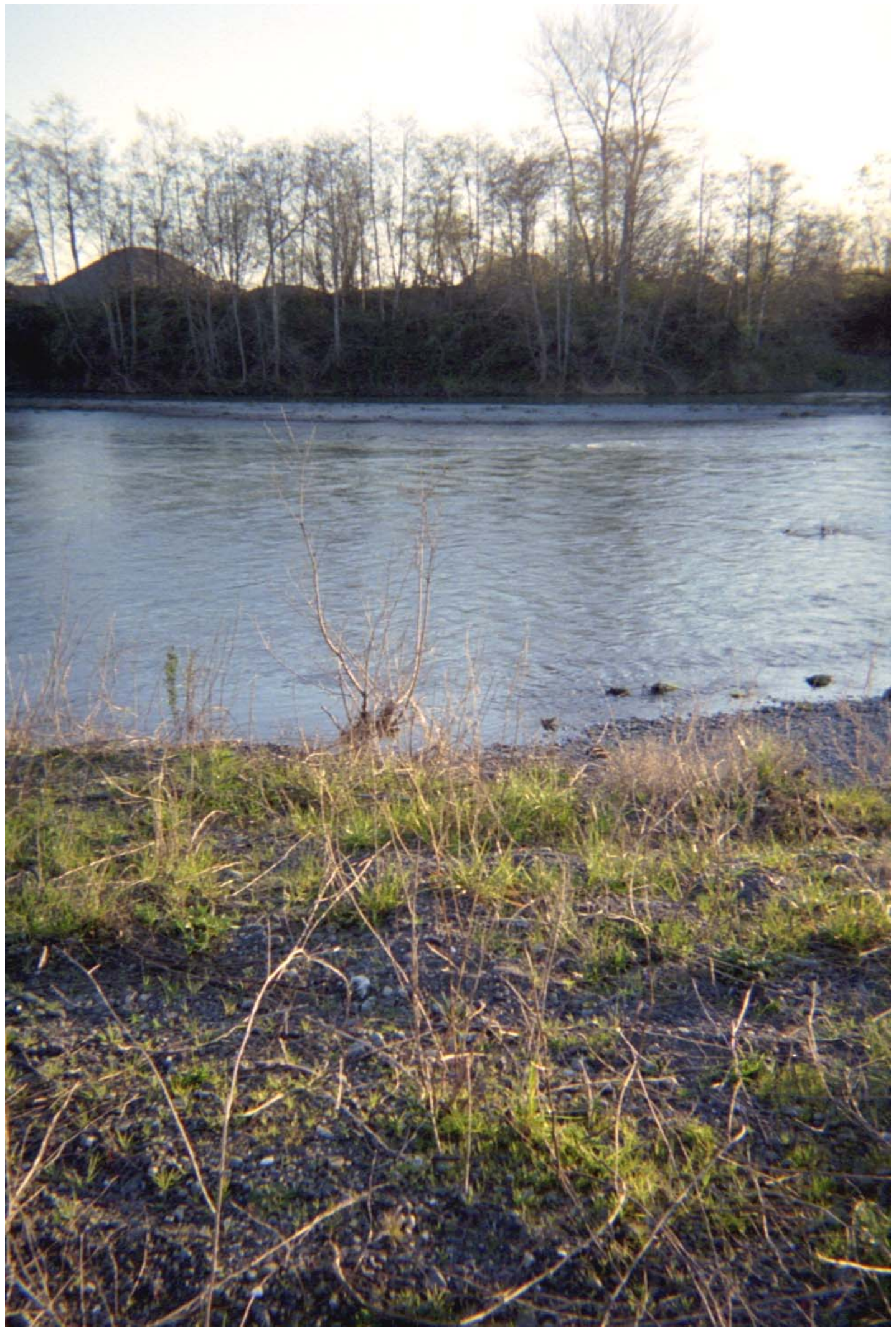

Figure C20. XC13 (right bank) 


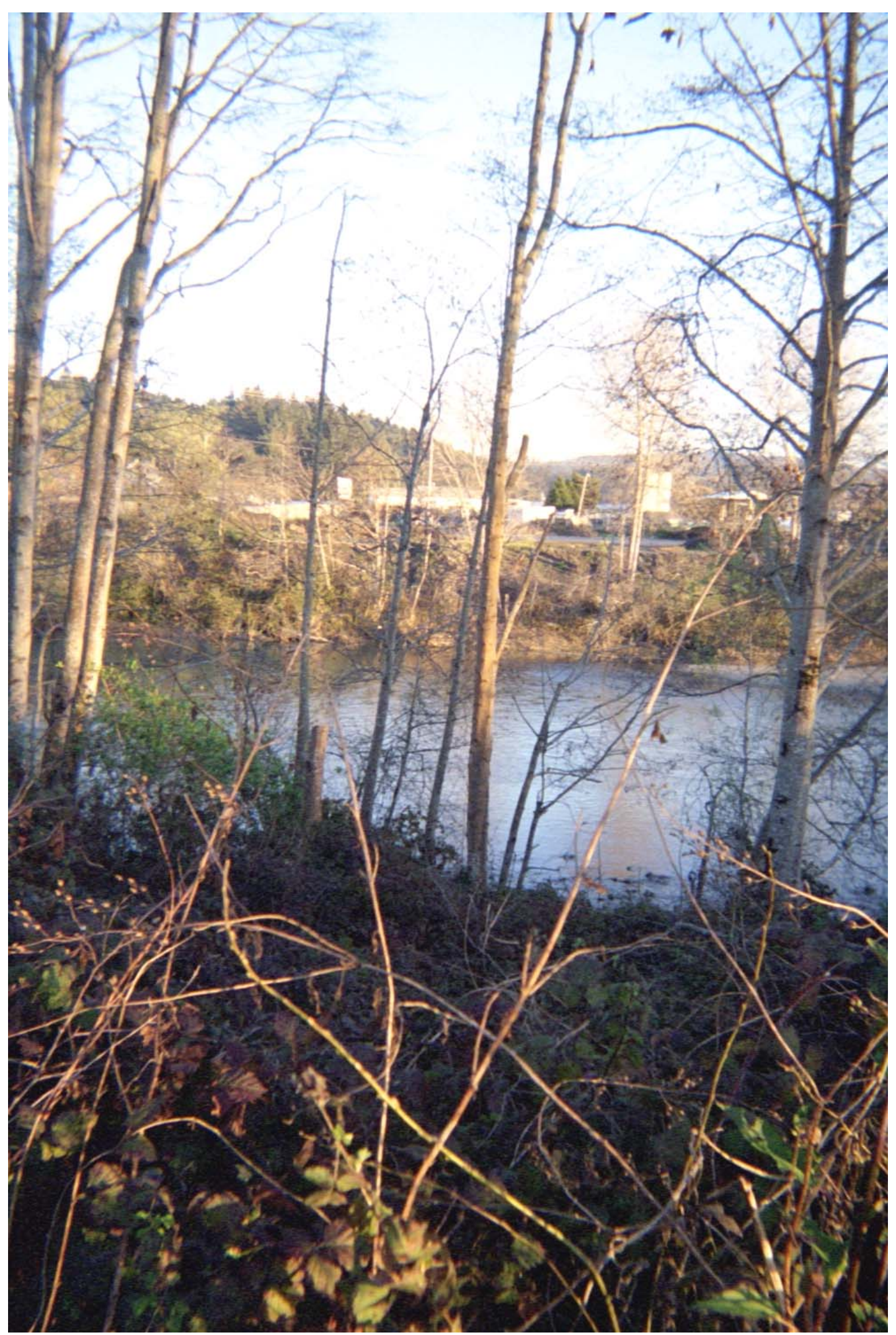

Figure C22. XC14 (right bank) - Just downstream of cross section 


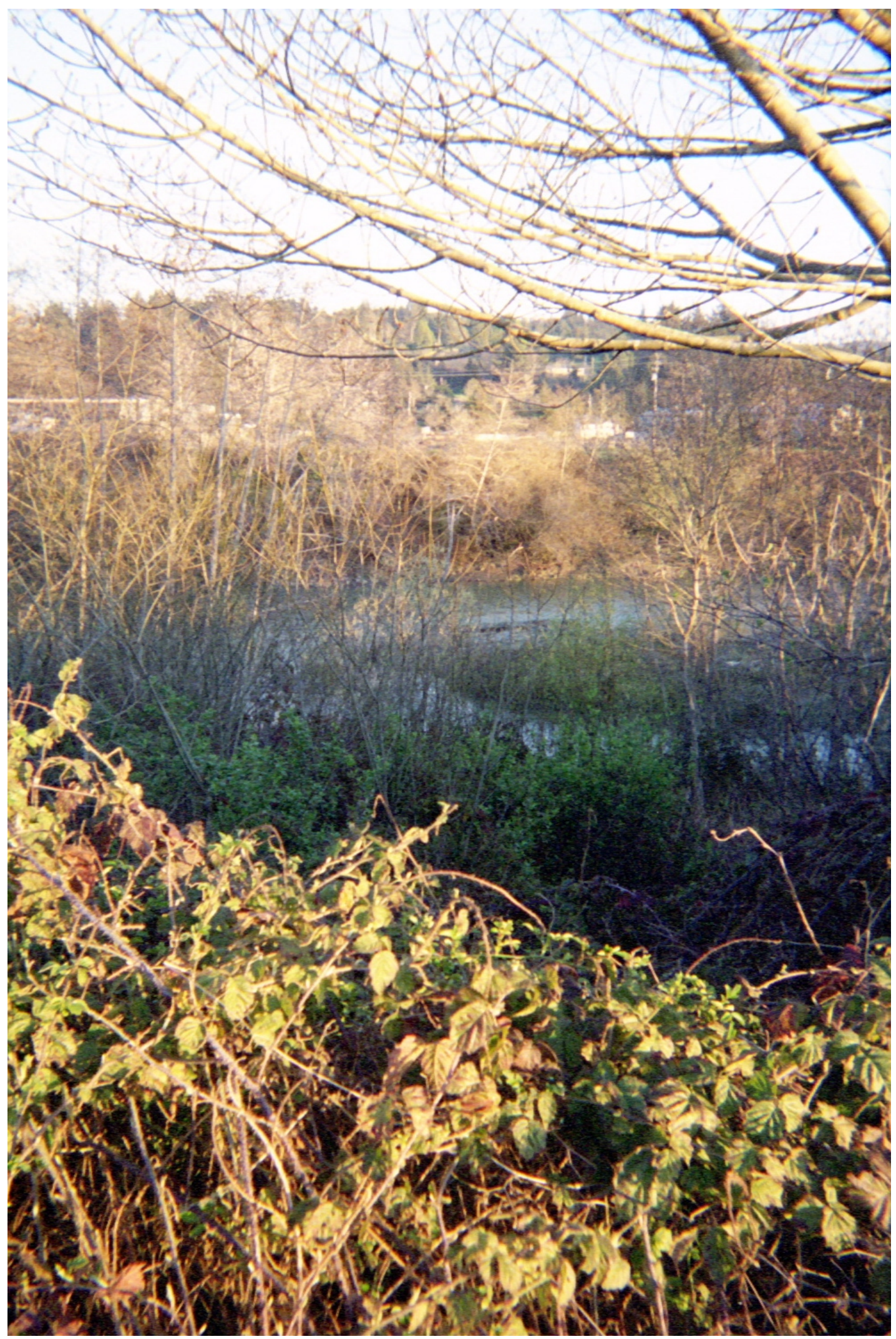

Figure C23. XC14 (right bank) 


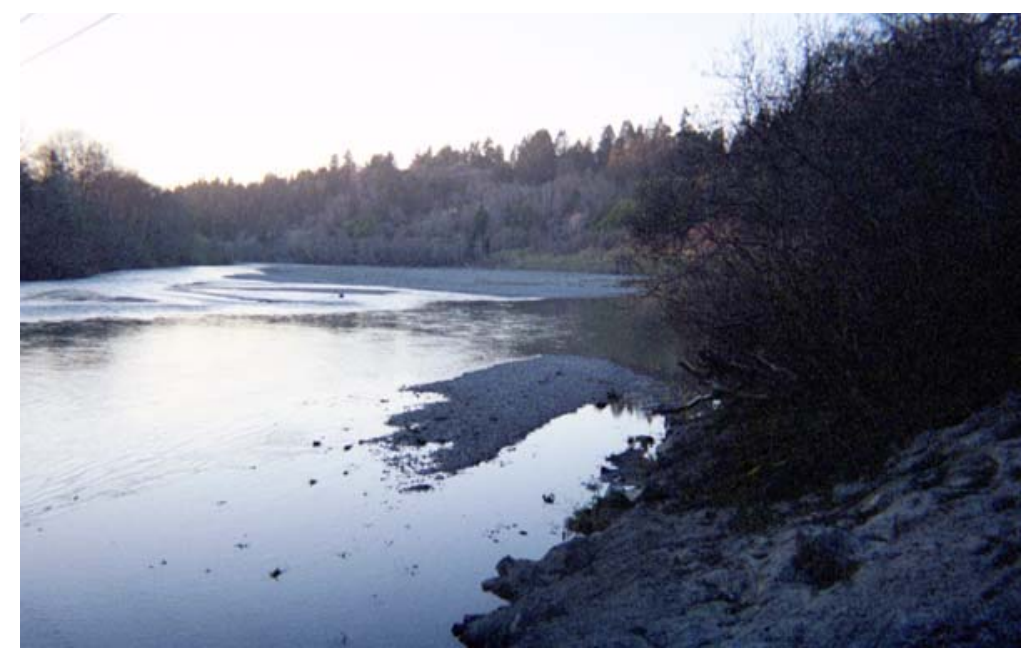

Figure C24. XC15 (right bank) - Looking downstream

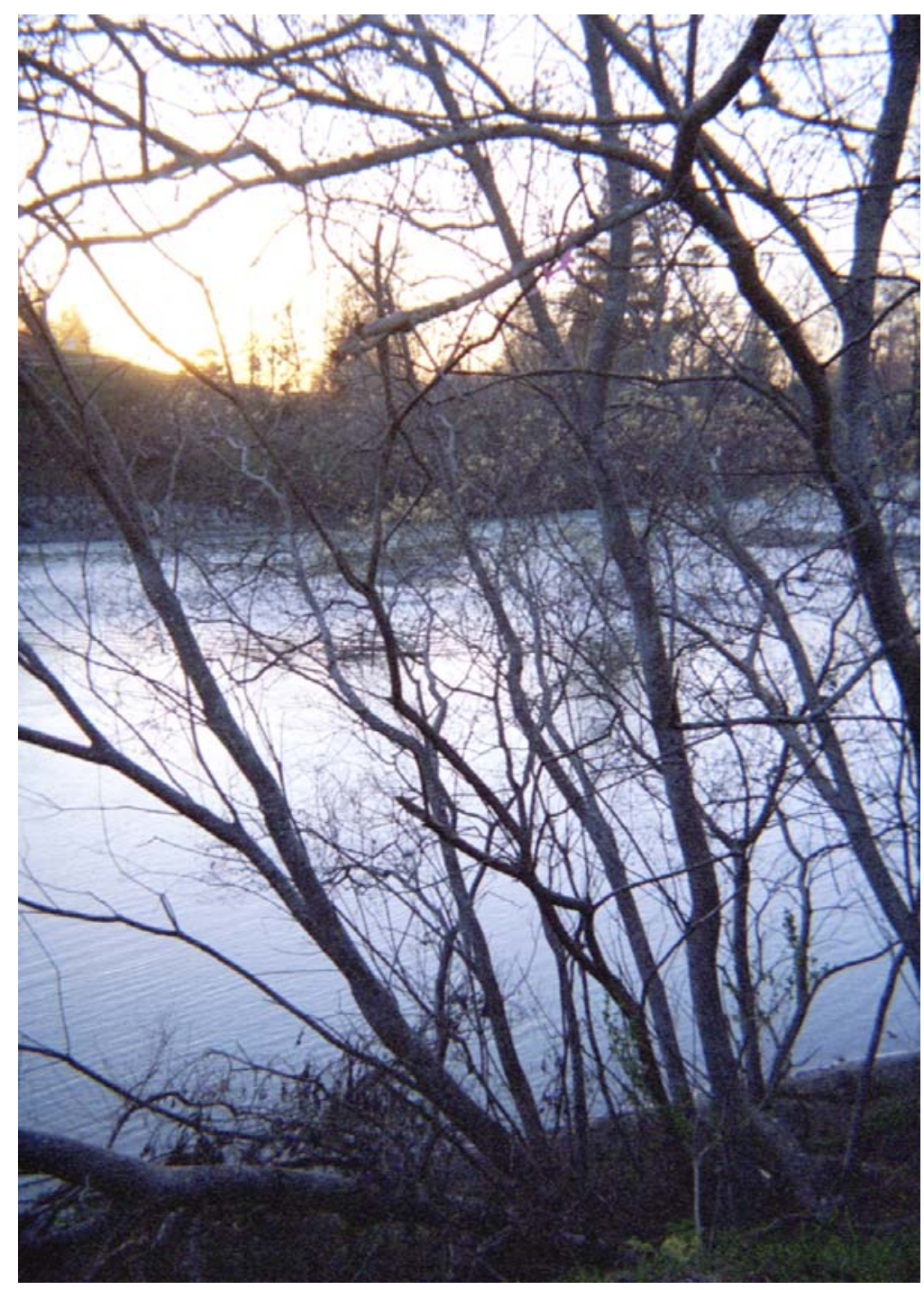

Figure C25. XC15 (right bank) 


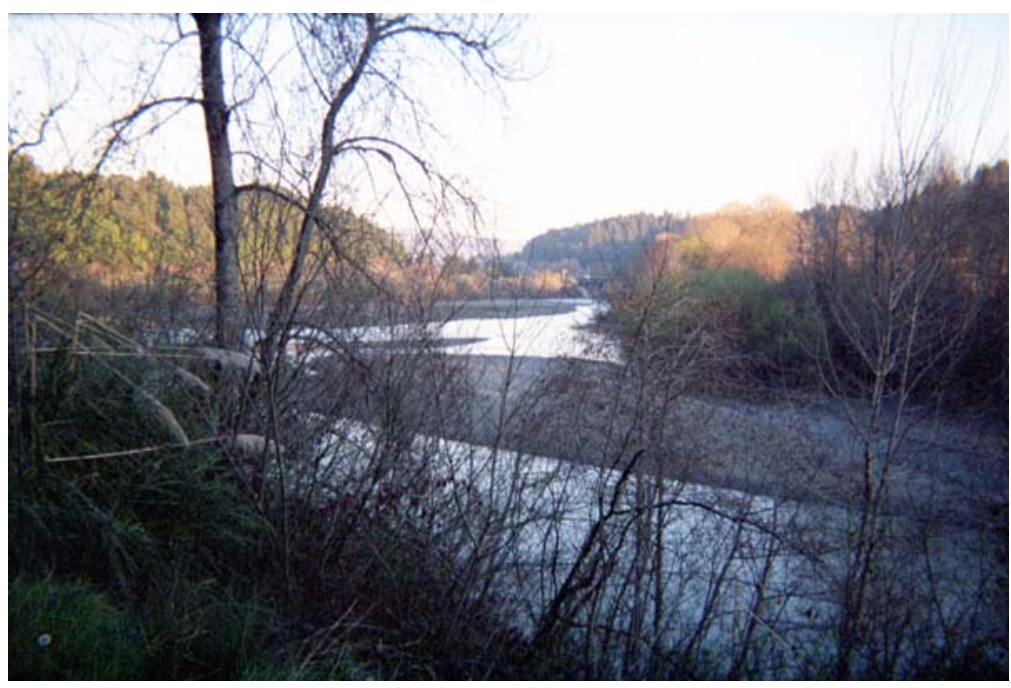

Figure C26. XC15 - Looking upstream at XC15 from North Bank Road above XC14

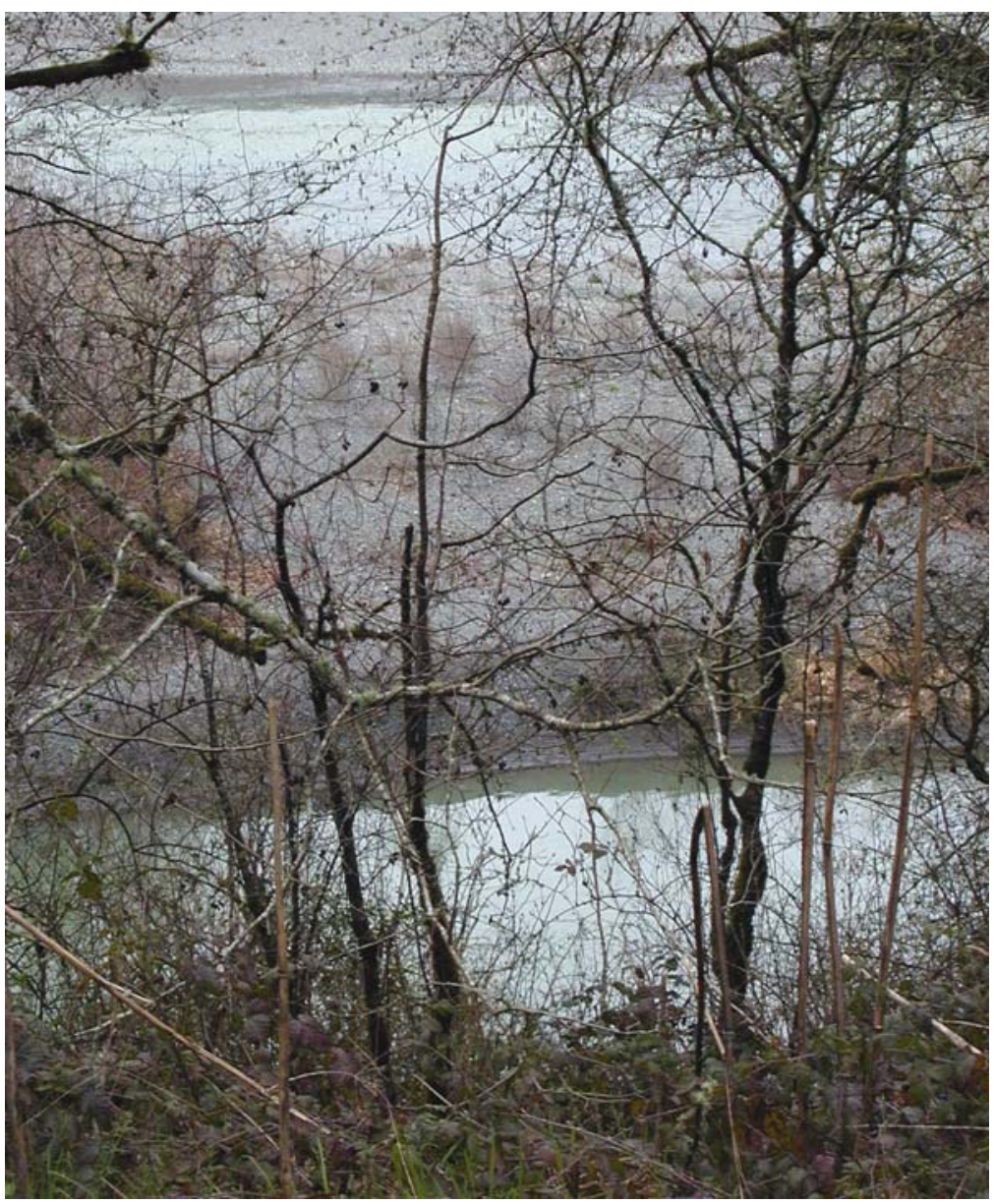

Figure C27. XC17 (left bank) - Taken from approximately $100 \mathrm{ft}$ downstream of XC17 


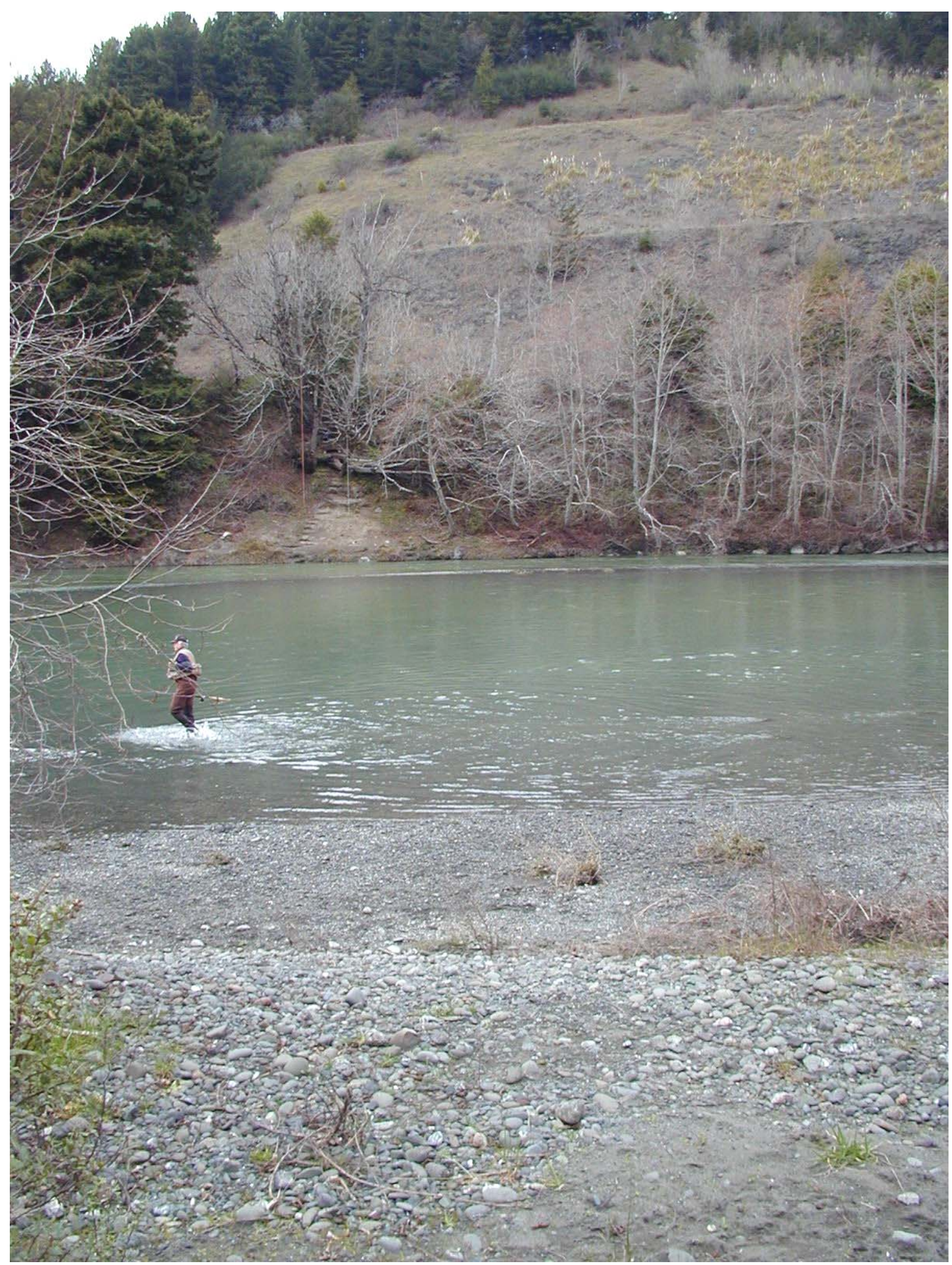

Figure C28. XC18 (left bank) - Near HBMWD Essex facility 


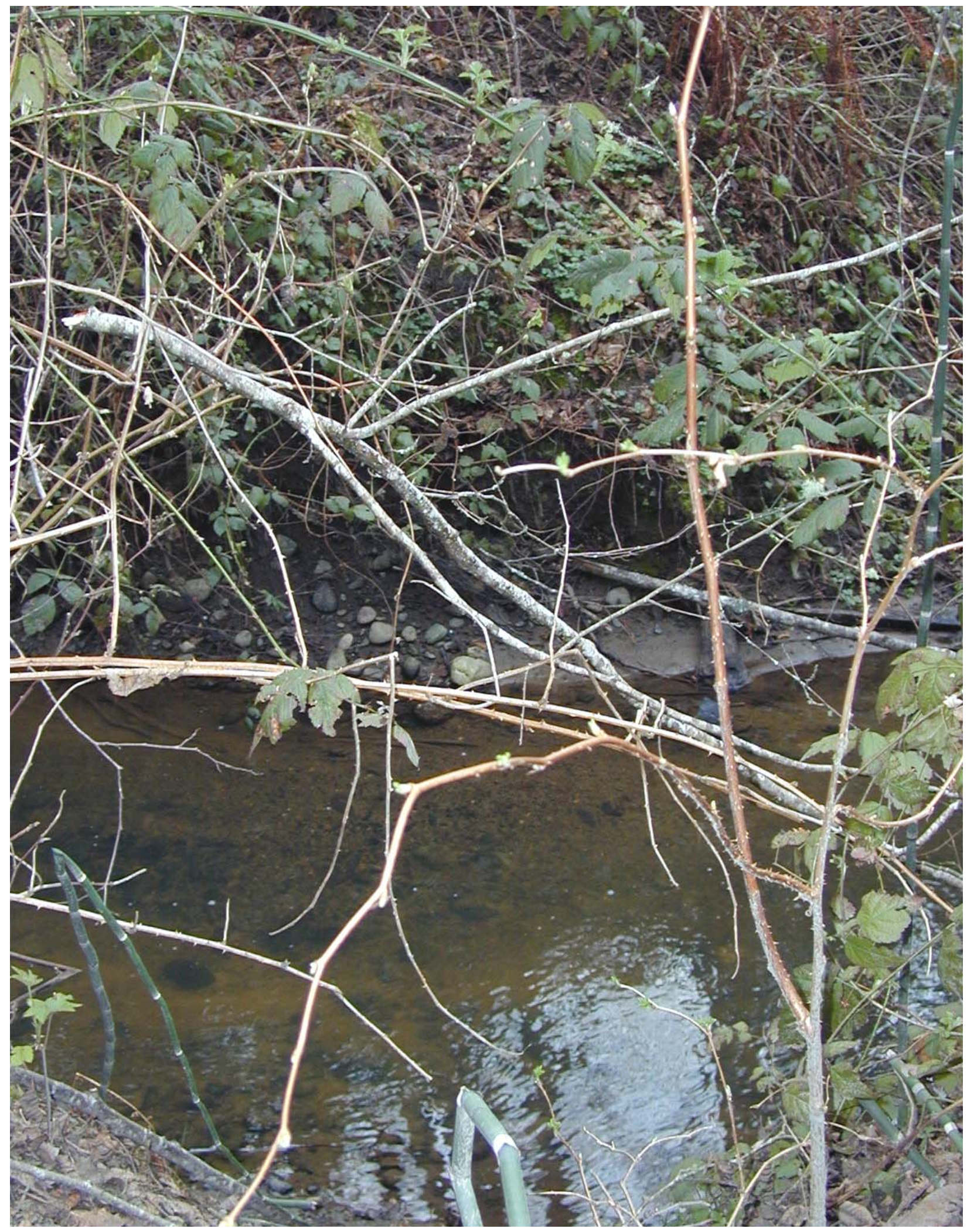

Figure C29. XC19 (left bank) - approximately $3 \mathrm{ft}$ of incision on Warren Creek downstream of AMRR crossing 


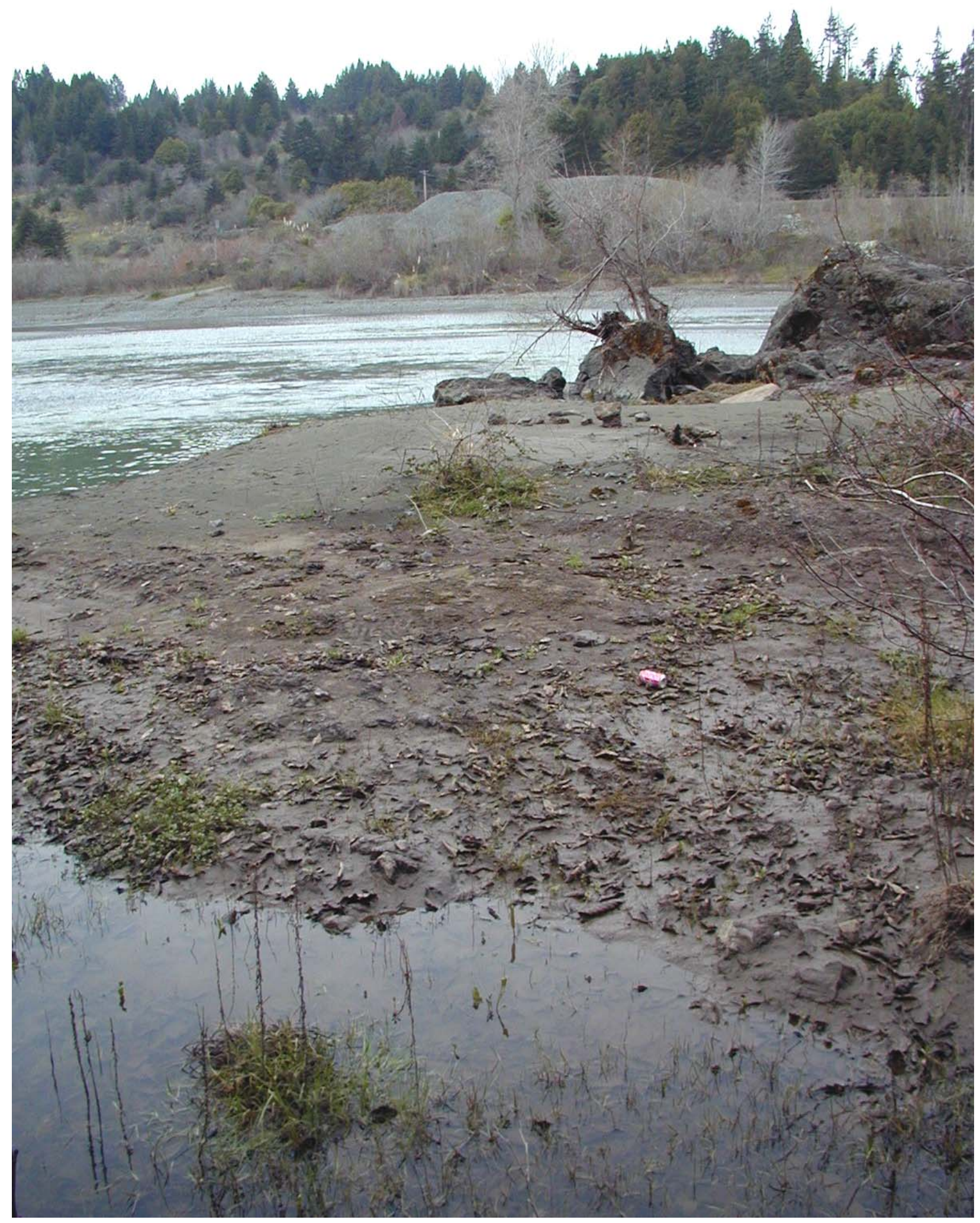

Figure C30. XC19 (left bank) - Looking at right bank from mouth of Warren Creek 


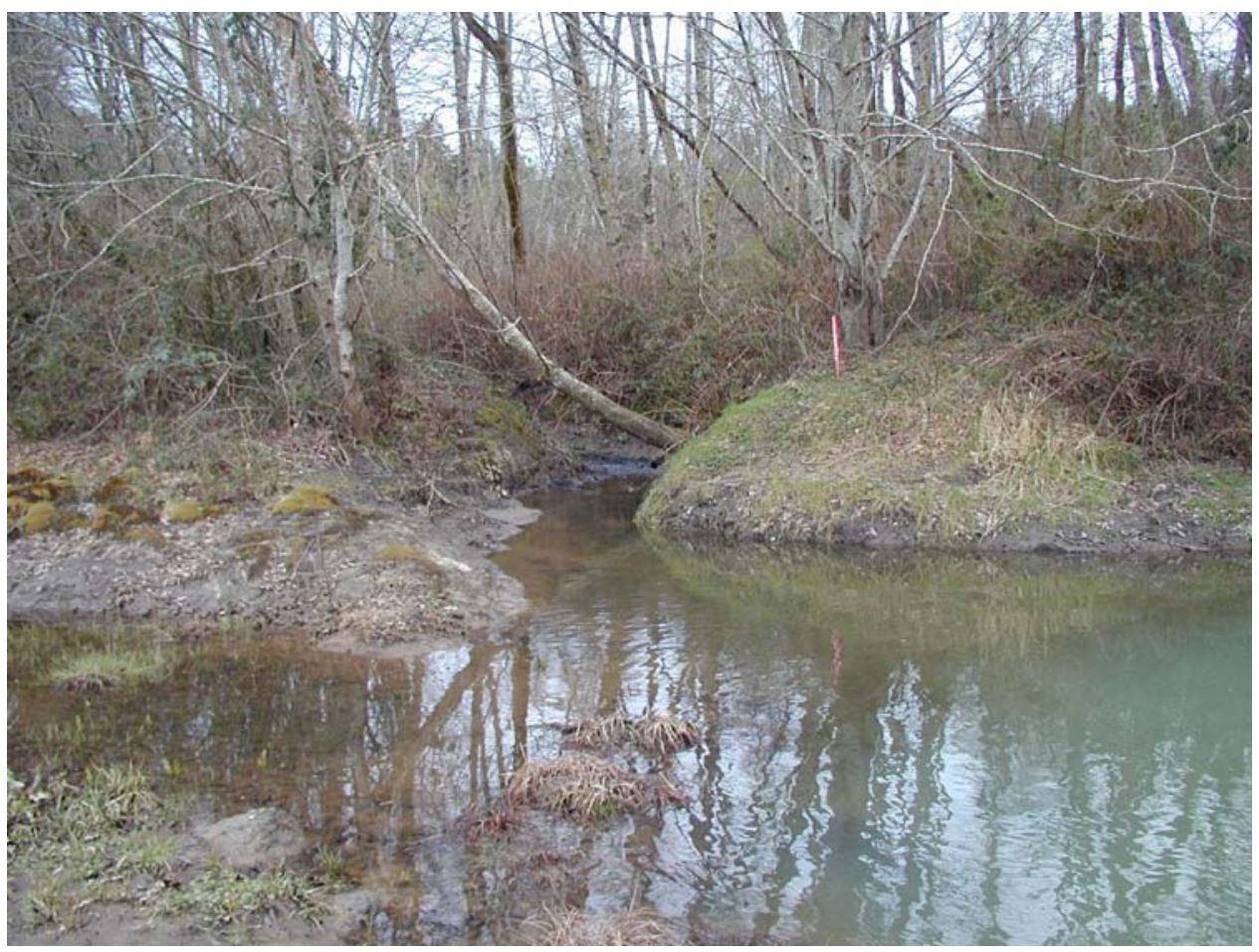

Figure C31. XC19 (left bank) - Mouth of Warren Creek

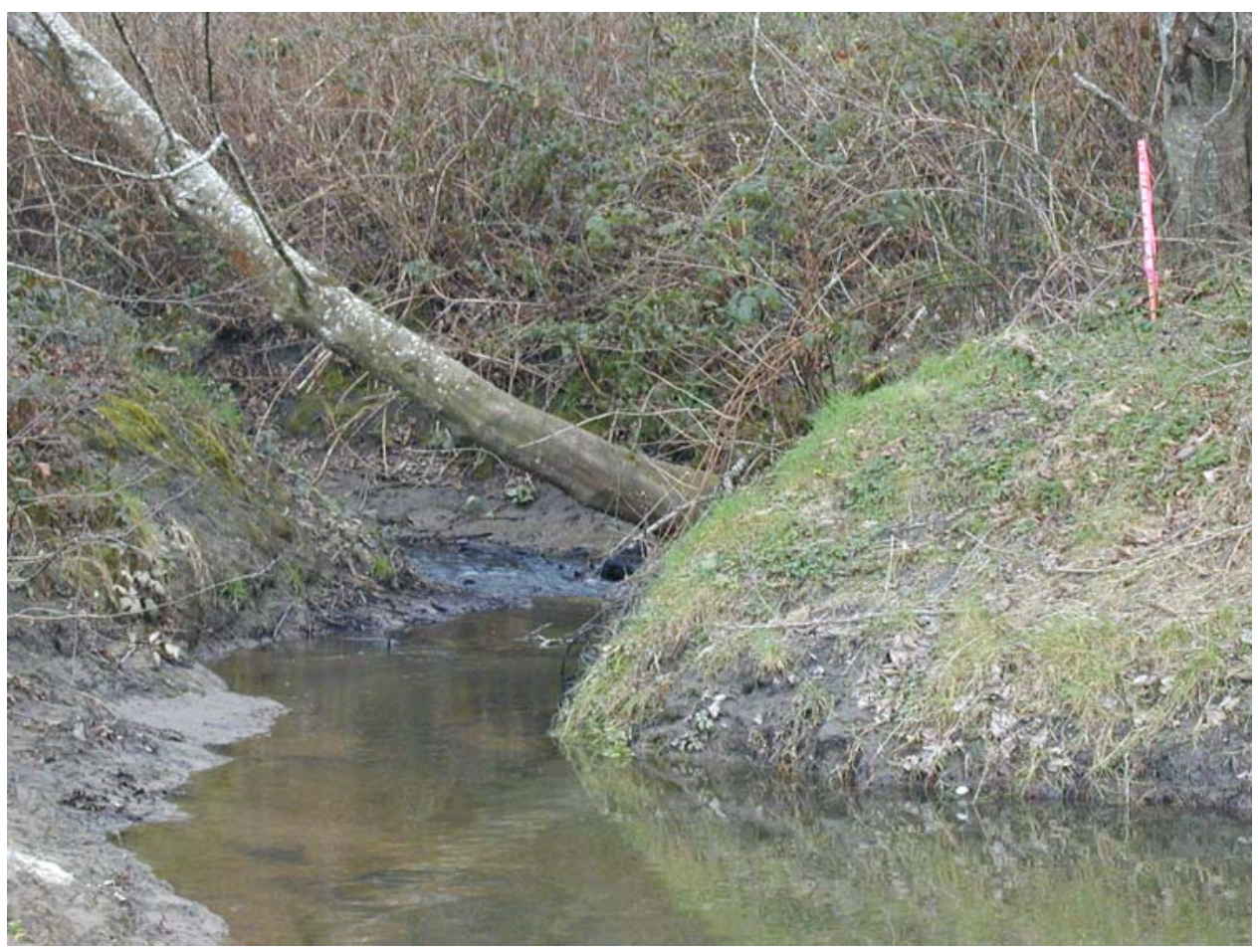

Figure C32. XC19 (left bank) - Mouth of Warren Creek 


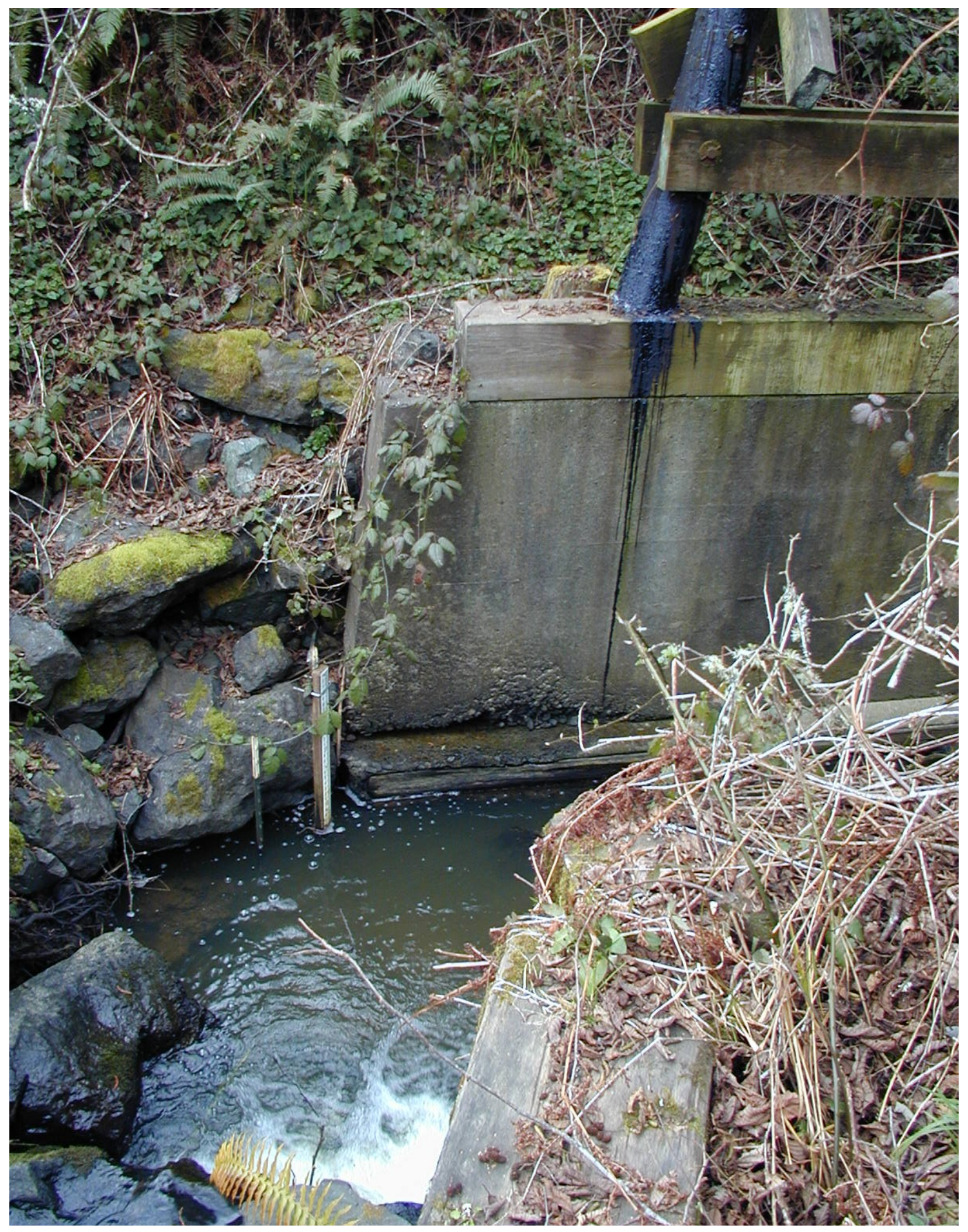

Figure C33. XC19 (left bank, tributary) - AMRR crossing over Warren Creek 


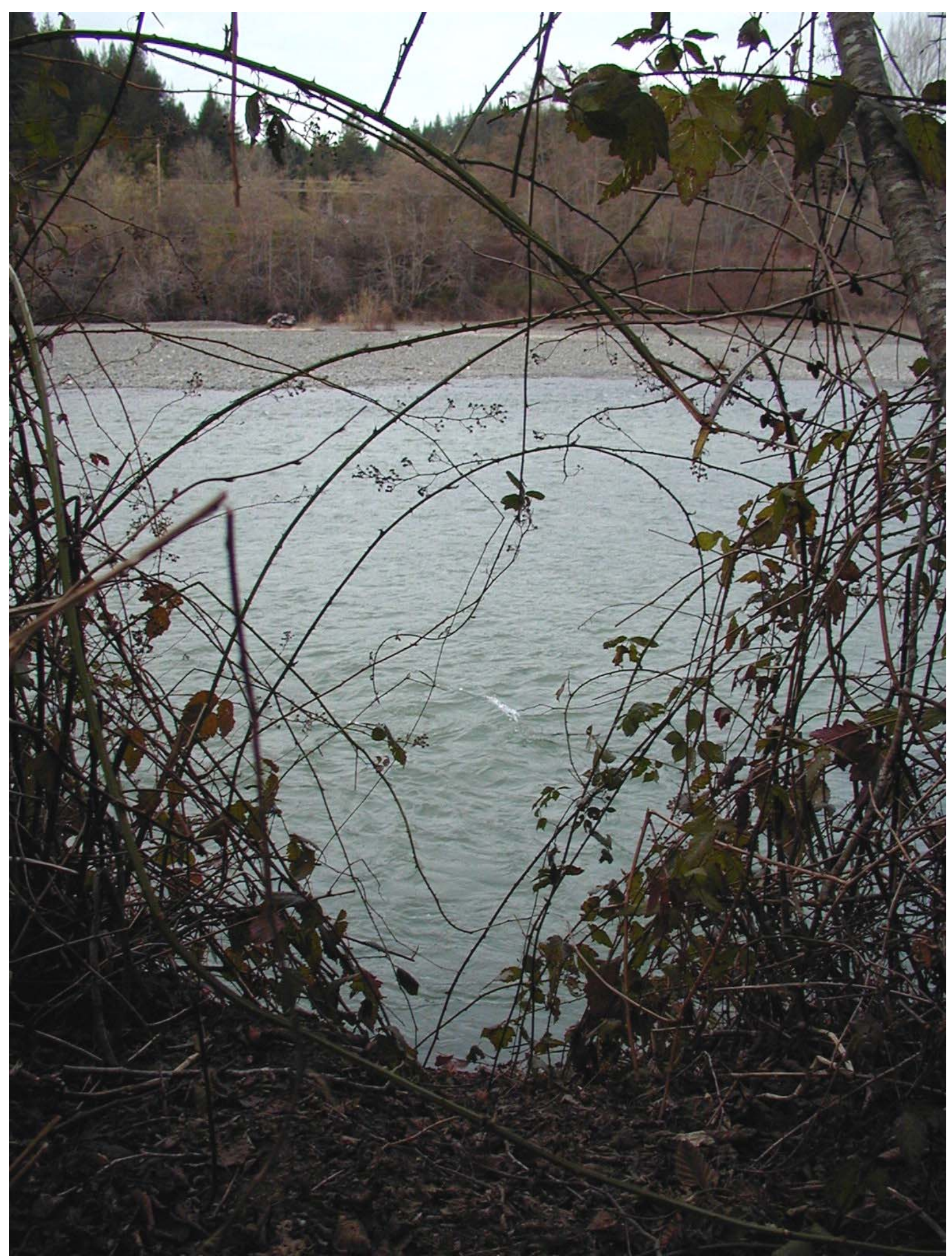

Figure C34. XC20 (left bank) - Taken just downstream of cross section 


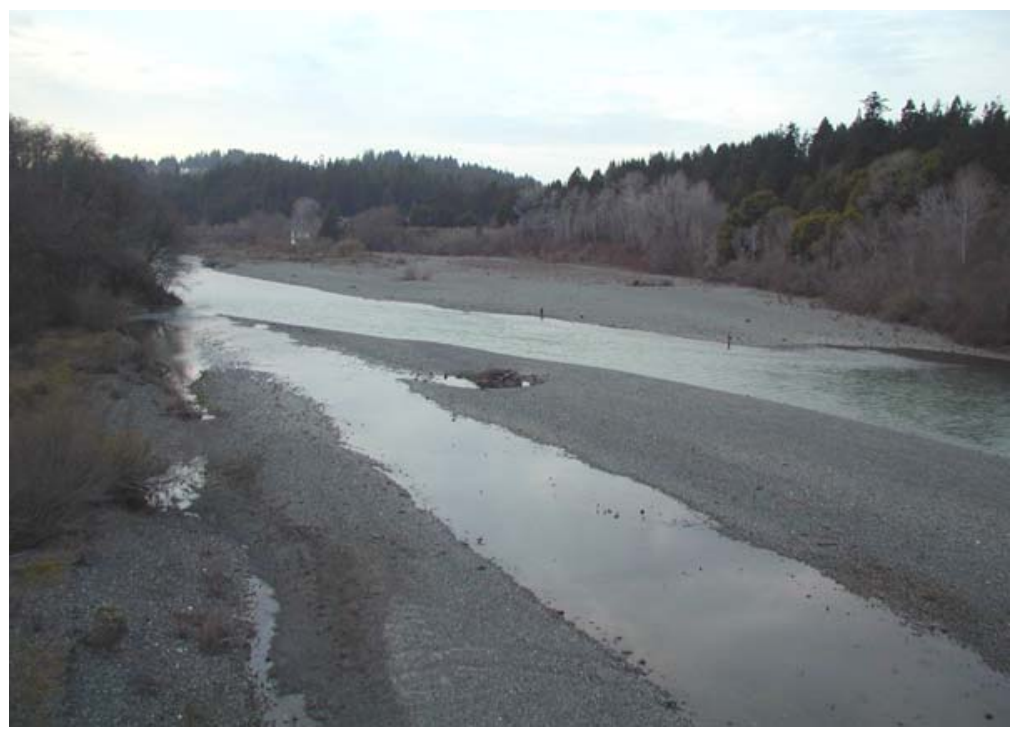

Figure C35. XC21 (left bank) - Looking downstream from AMRR bridge

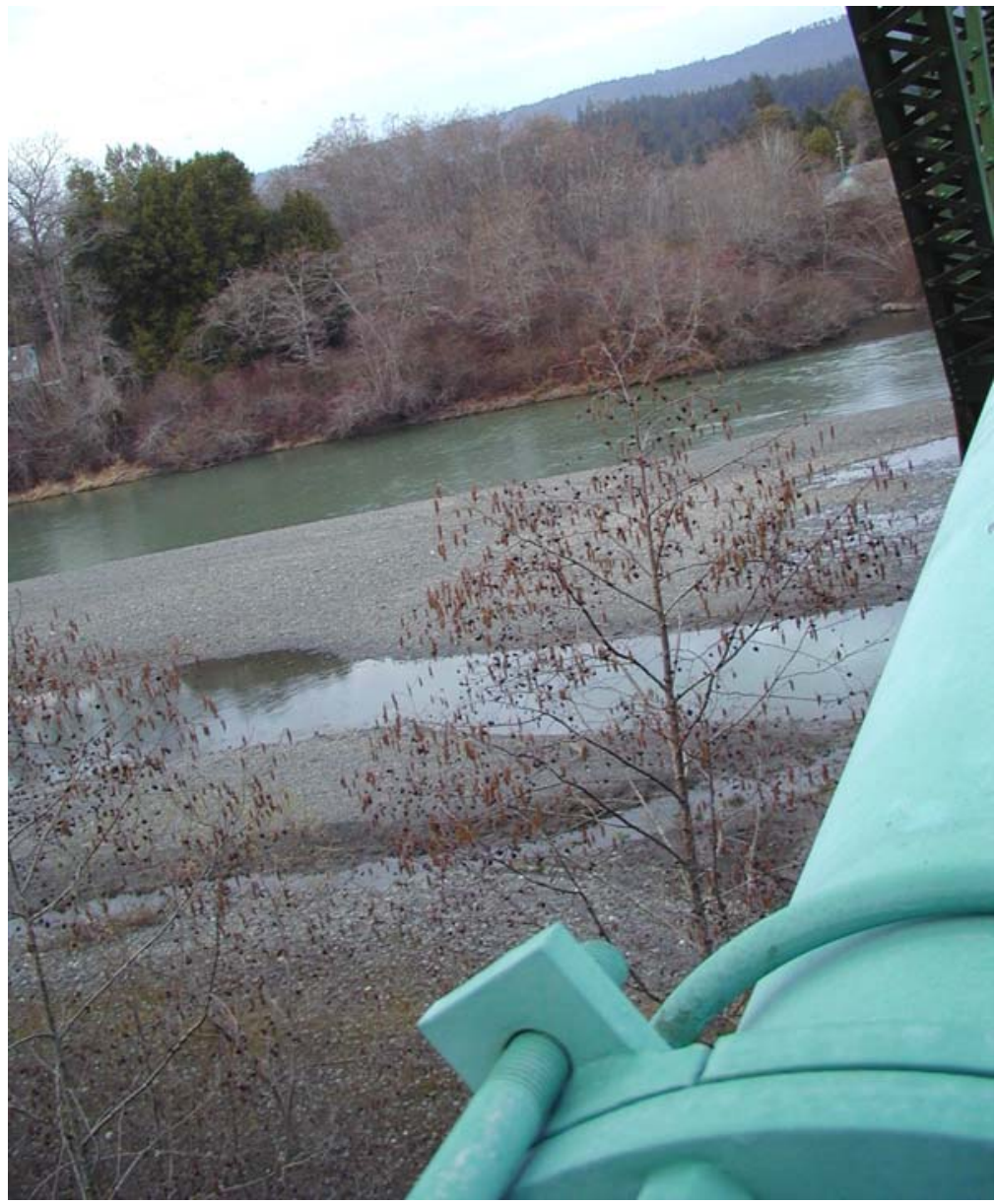

Figure C36. XC21 (left bank) - Taken from AMRR bridge 


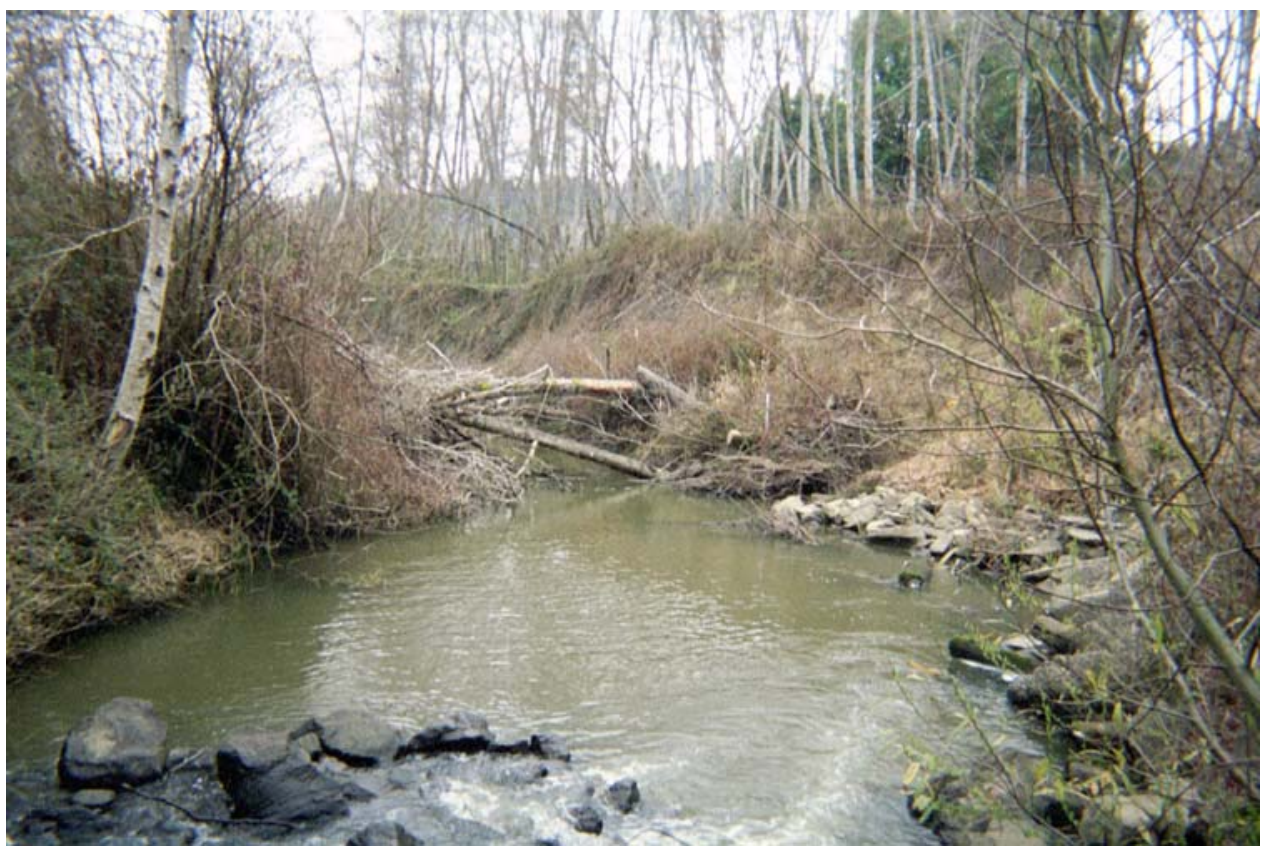

Figure C37. XC21 (right bank) - Lindsay Creek looking downstream from North Bank Road

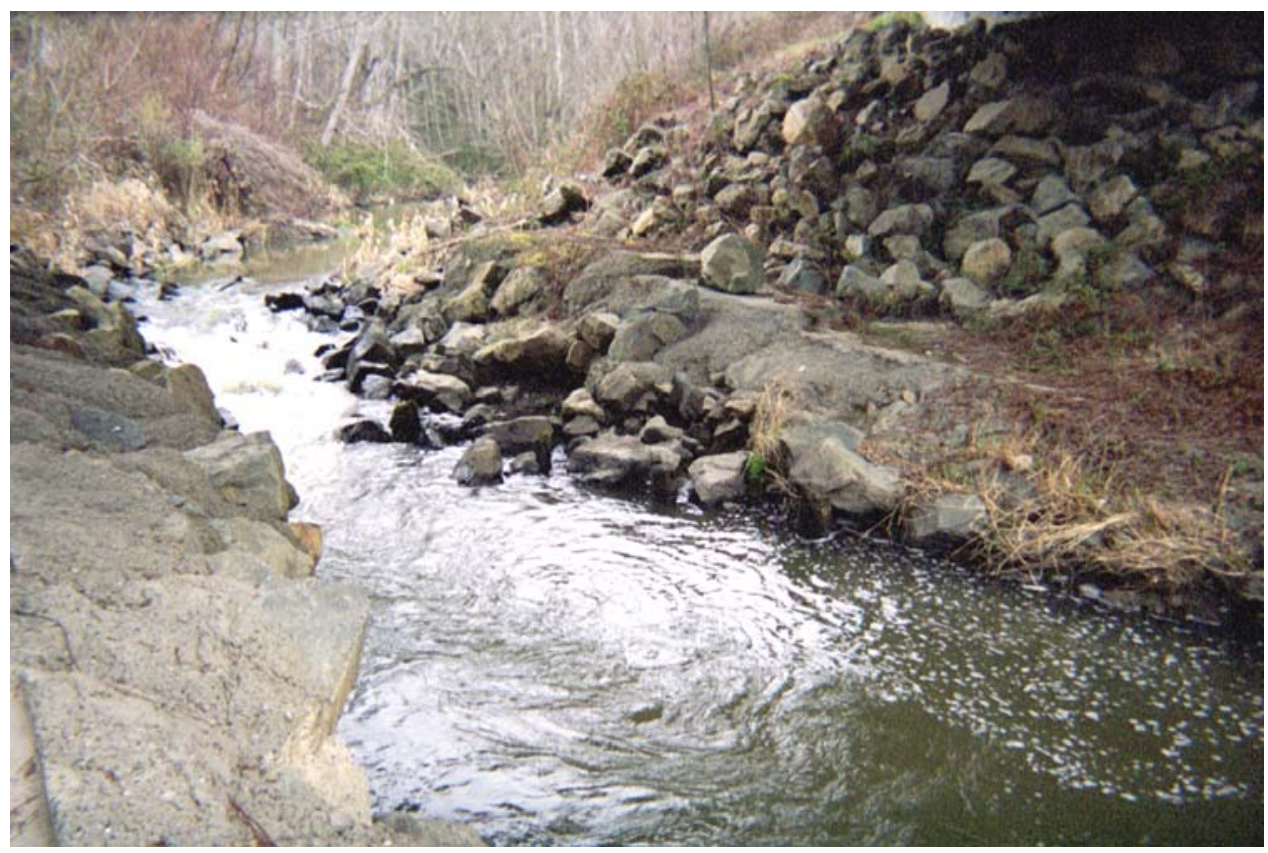

Figure C38. XC21 (right bank) - Lindsay Creek under North Bank Road (downstream bank erosion below this point) 


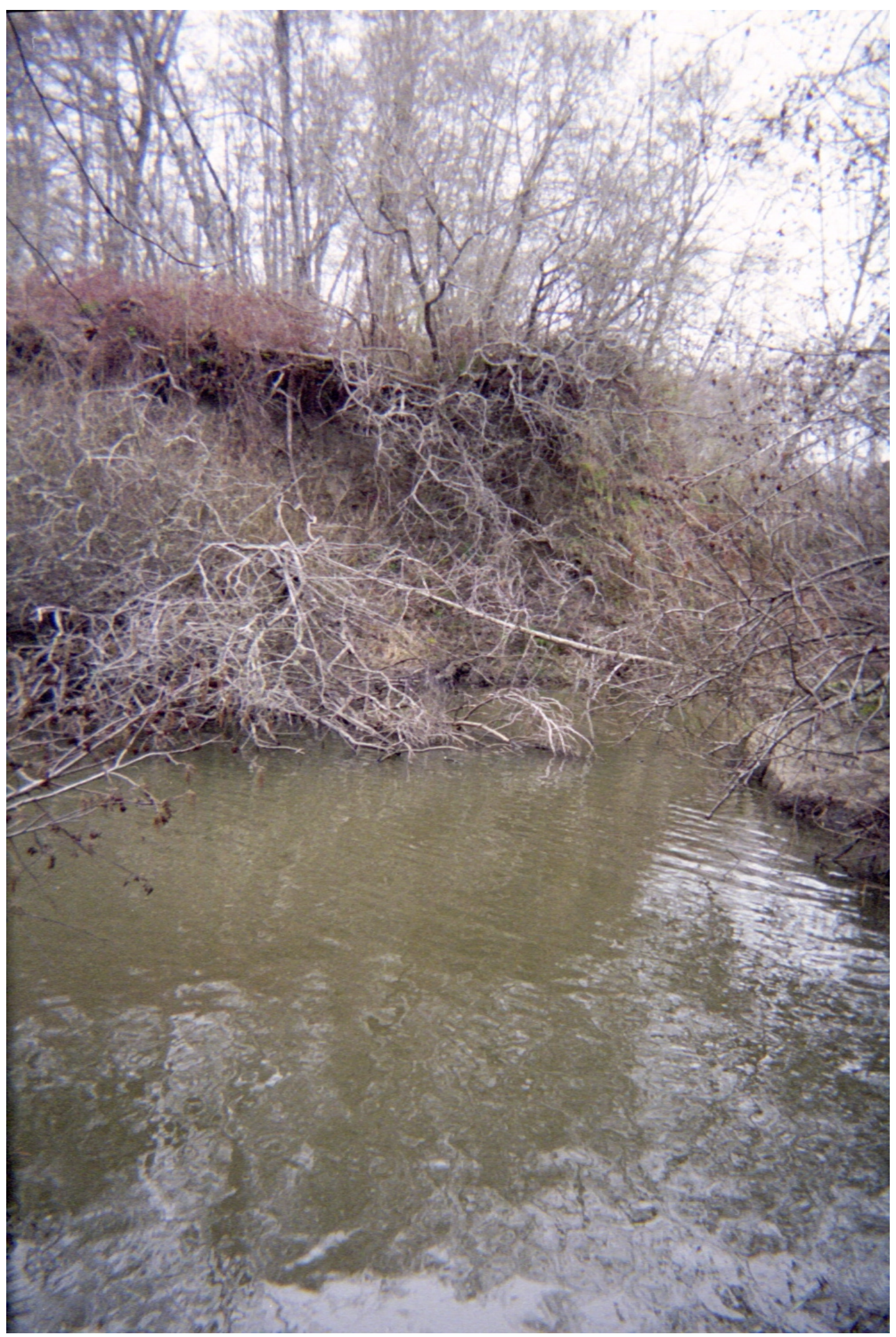

Figure C39. XC21 (right bank) - Looking at (incised) mouth of Lindsay Creek 


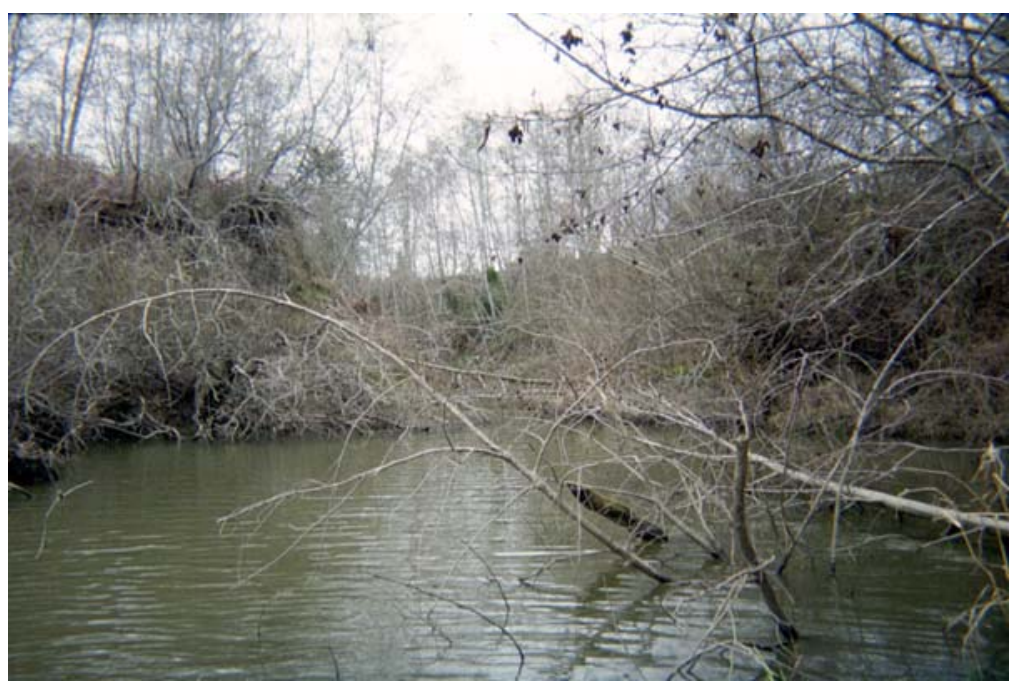

Figure C40. XC21 (right bank) -Looking at (incised) mouth of Lindsay Creek

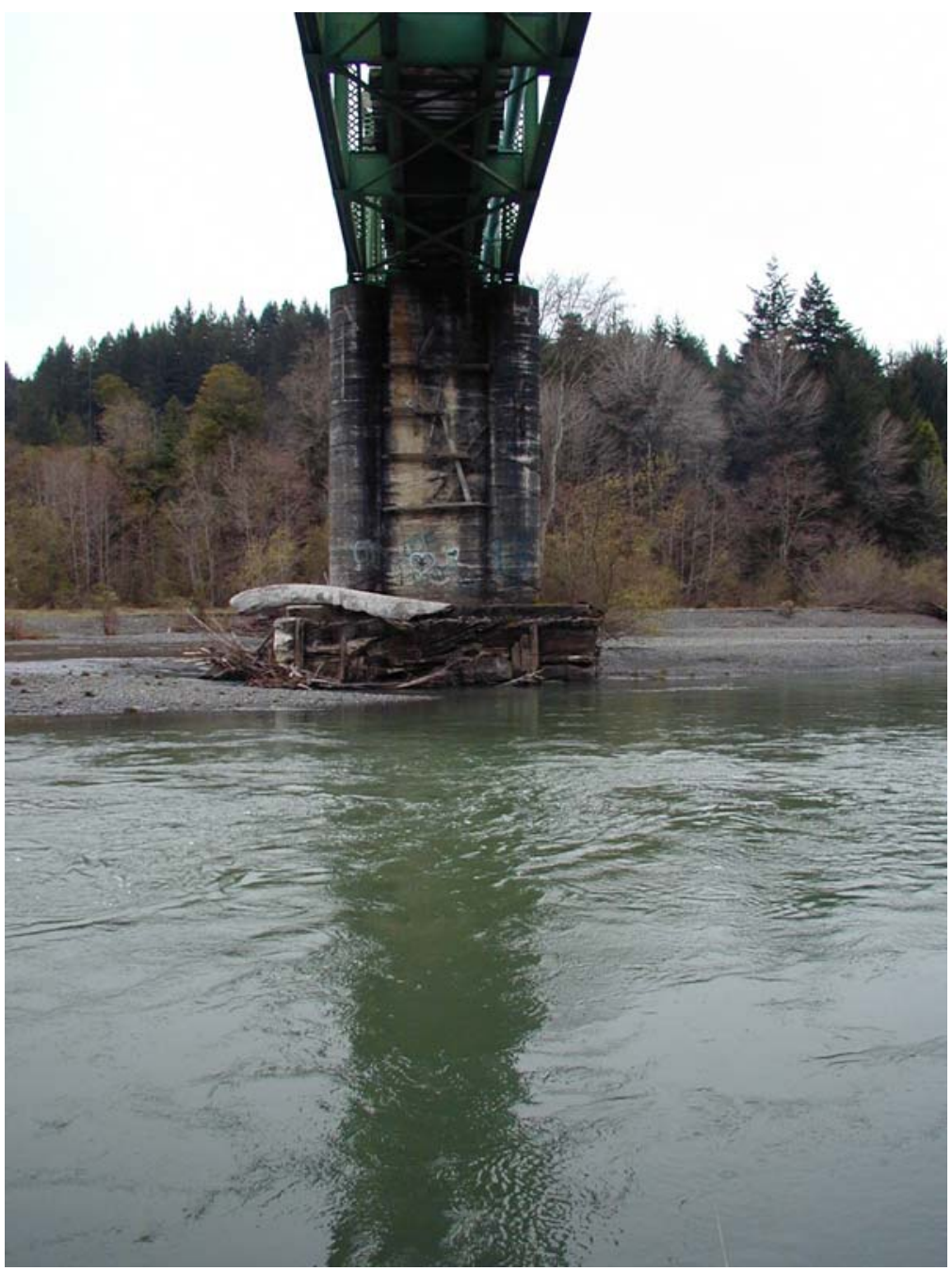

Figure C41. XC21 (right bank) - Looking at degradation near pier 


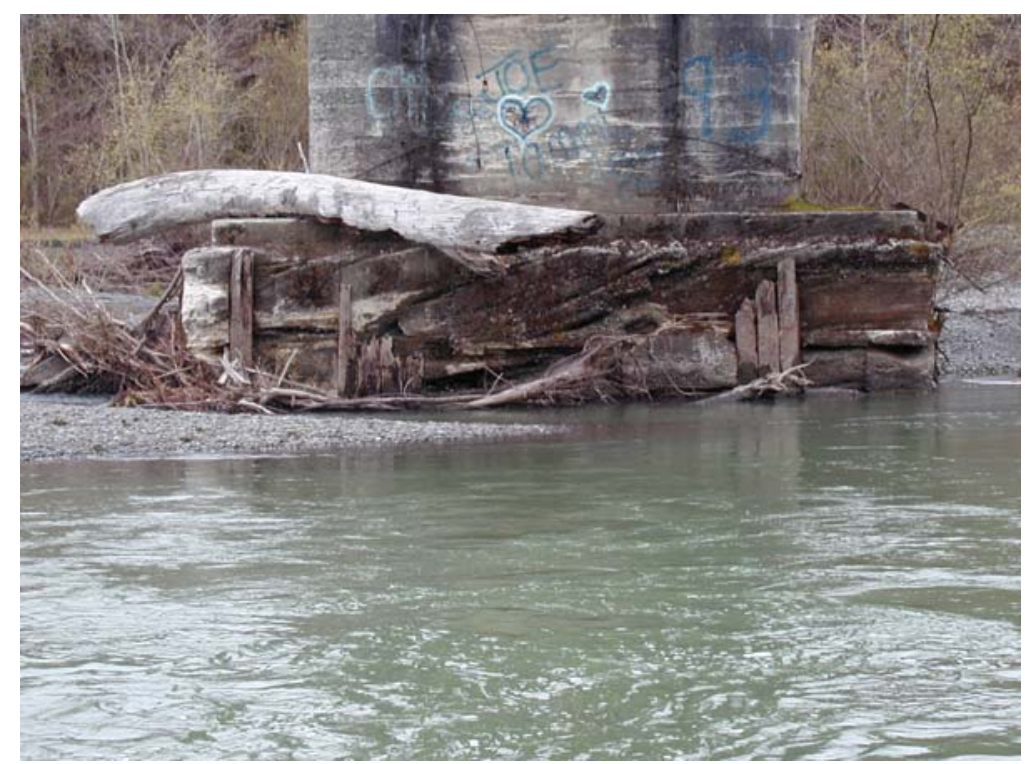

Figure C42. XC21 (right bank) - Looking at degradation near pier

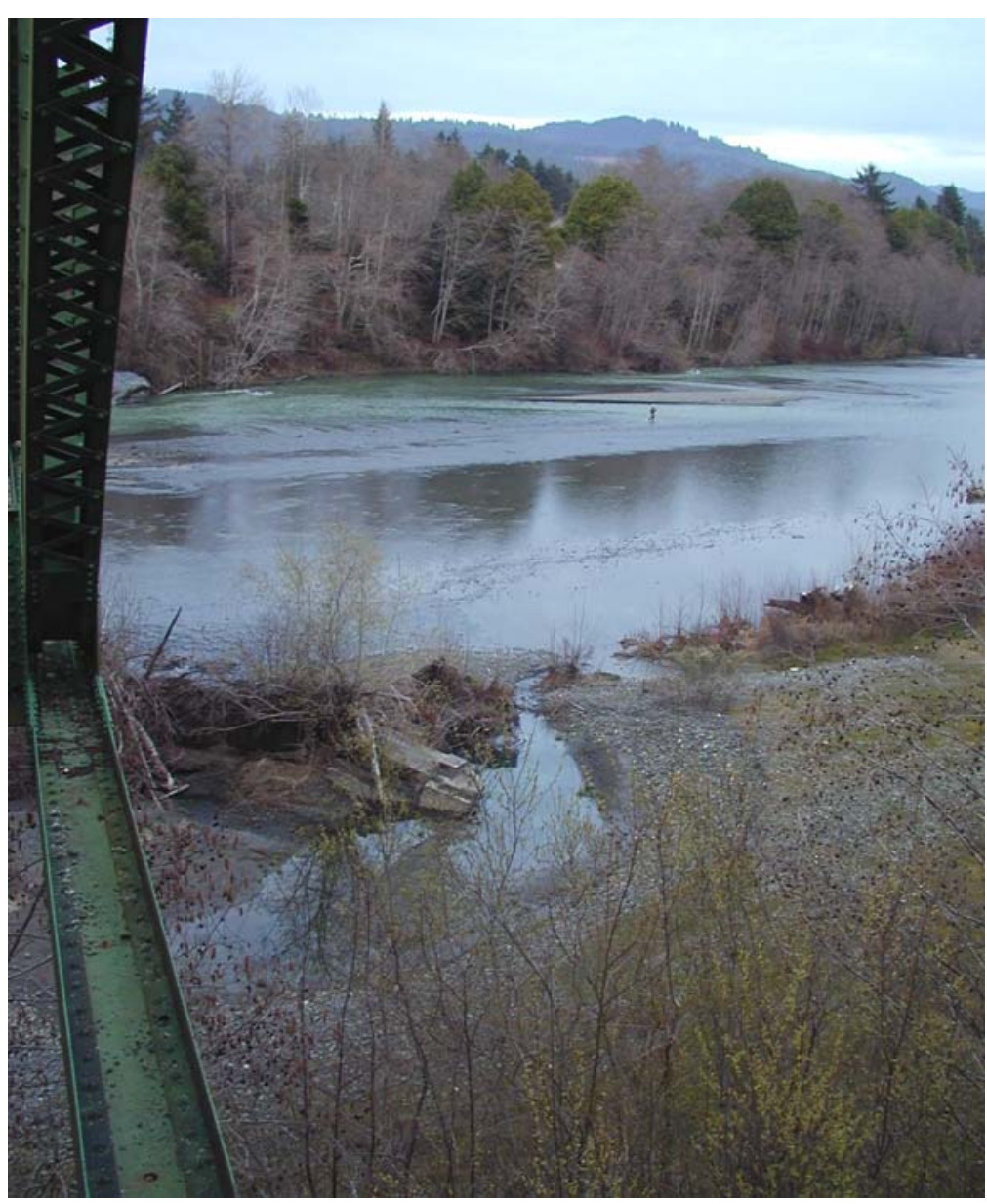

Figure C43. XC22 (left bank) - Taken from AMRR bridge 


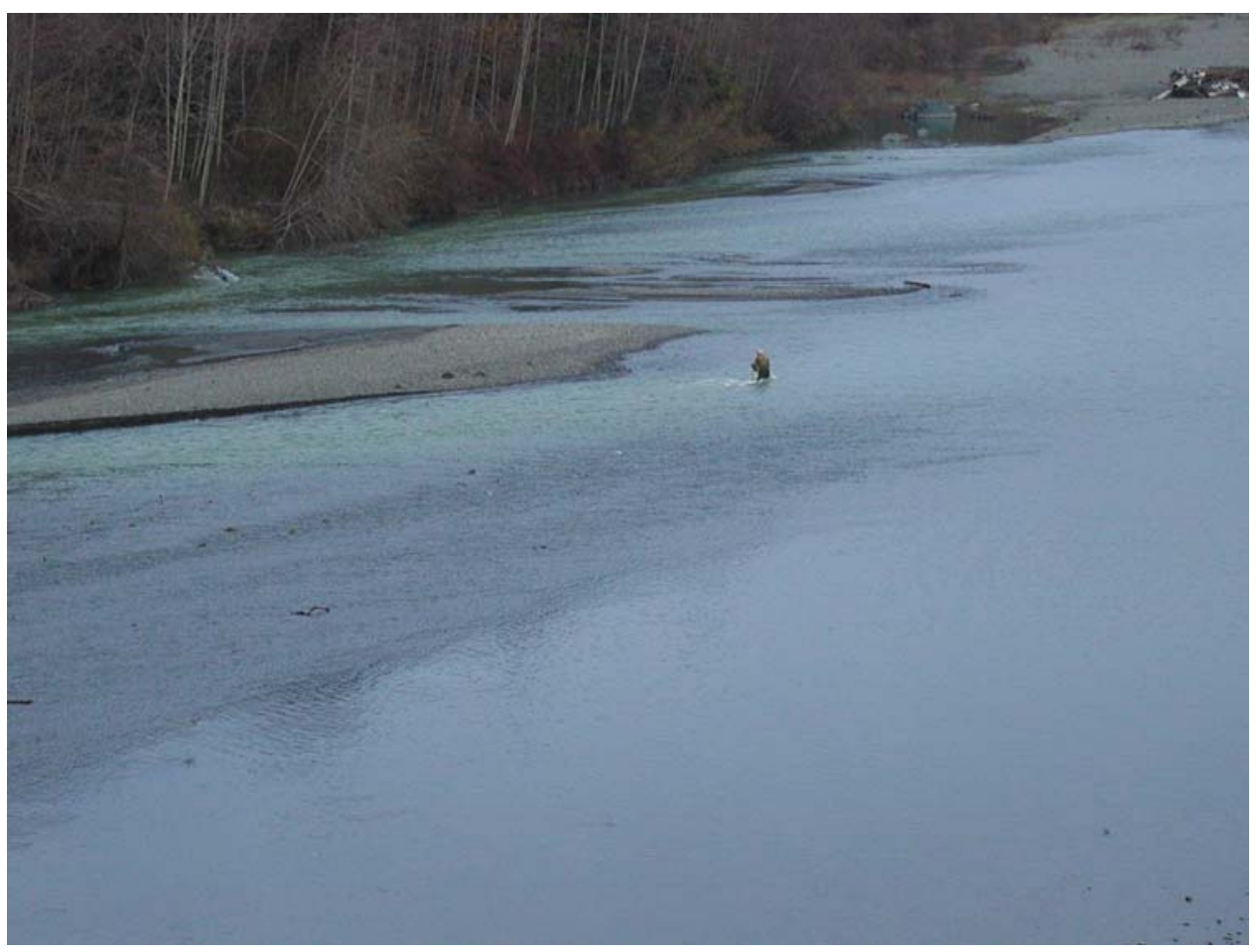

Figure C44. XC22 - Looking upstream from AMRR bridge

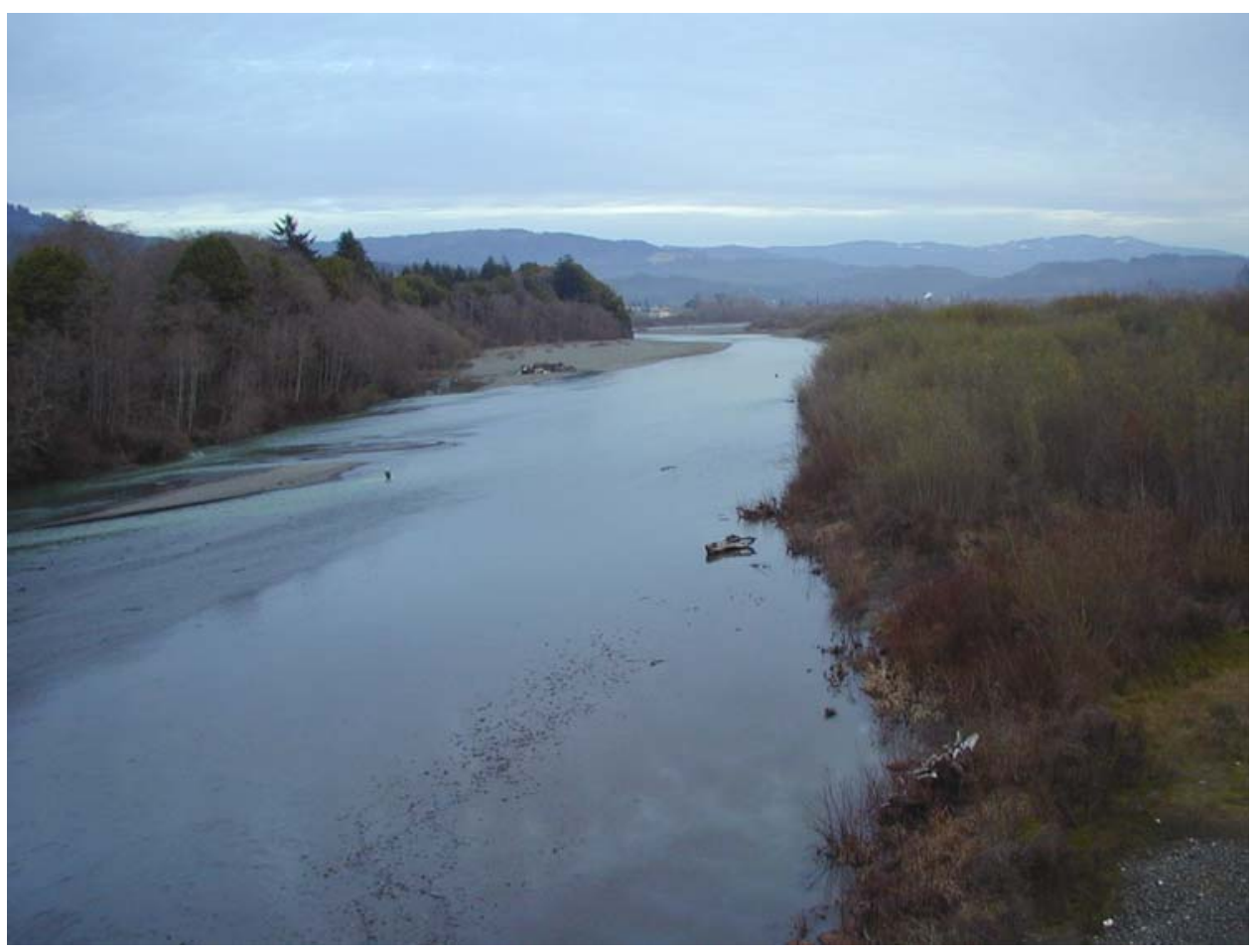

Figure C45. XC22 - Looking upstream from AMRR bridge 


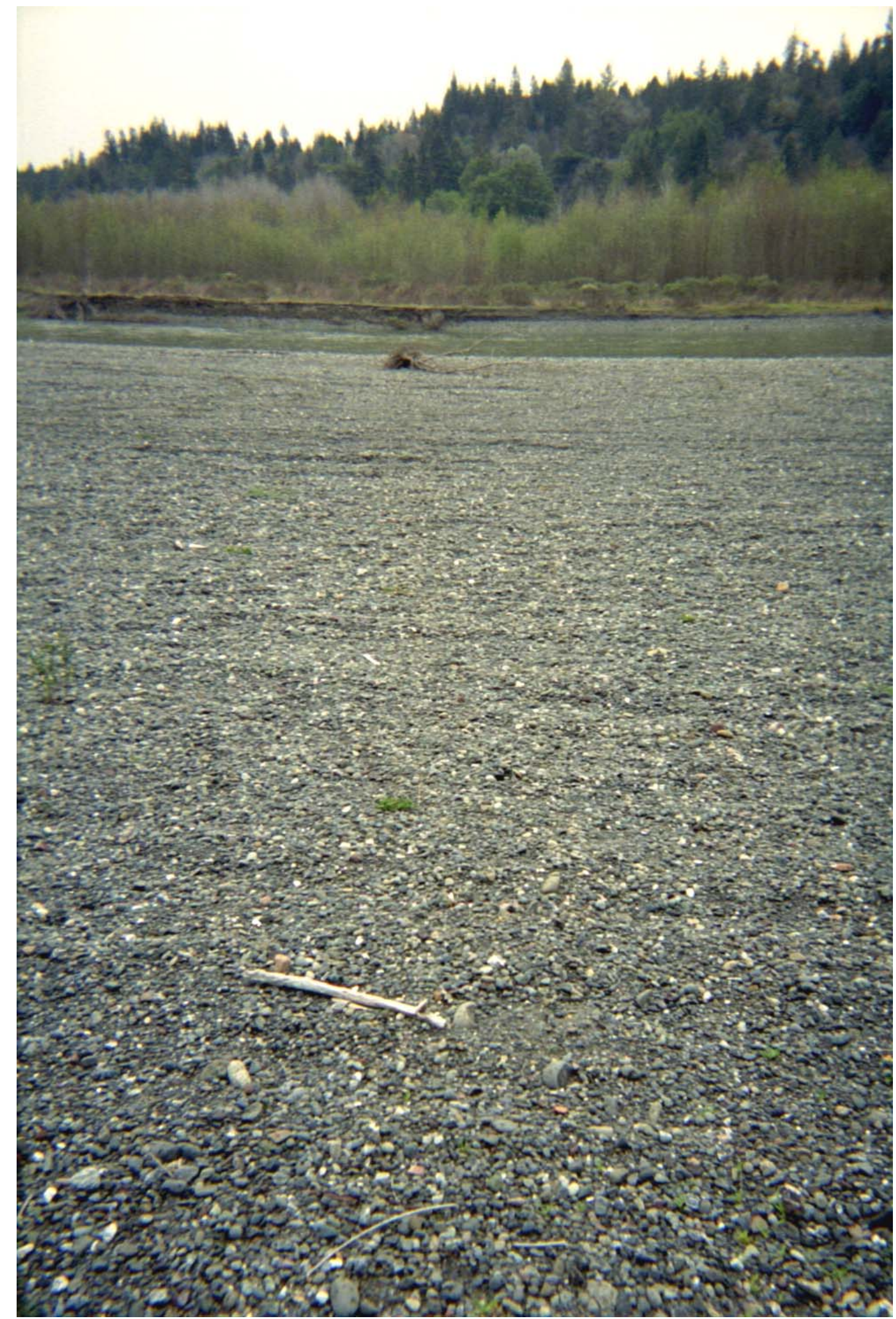

Figure C46. XC23 (right bank) - Looking at left bank 


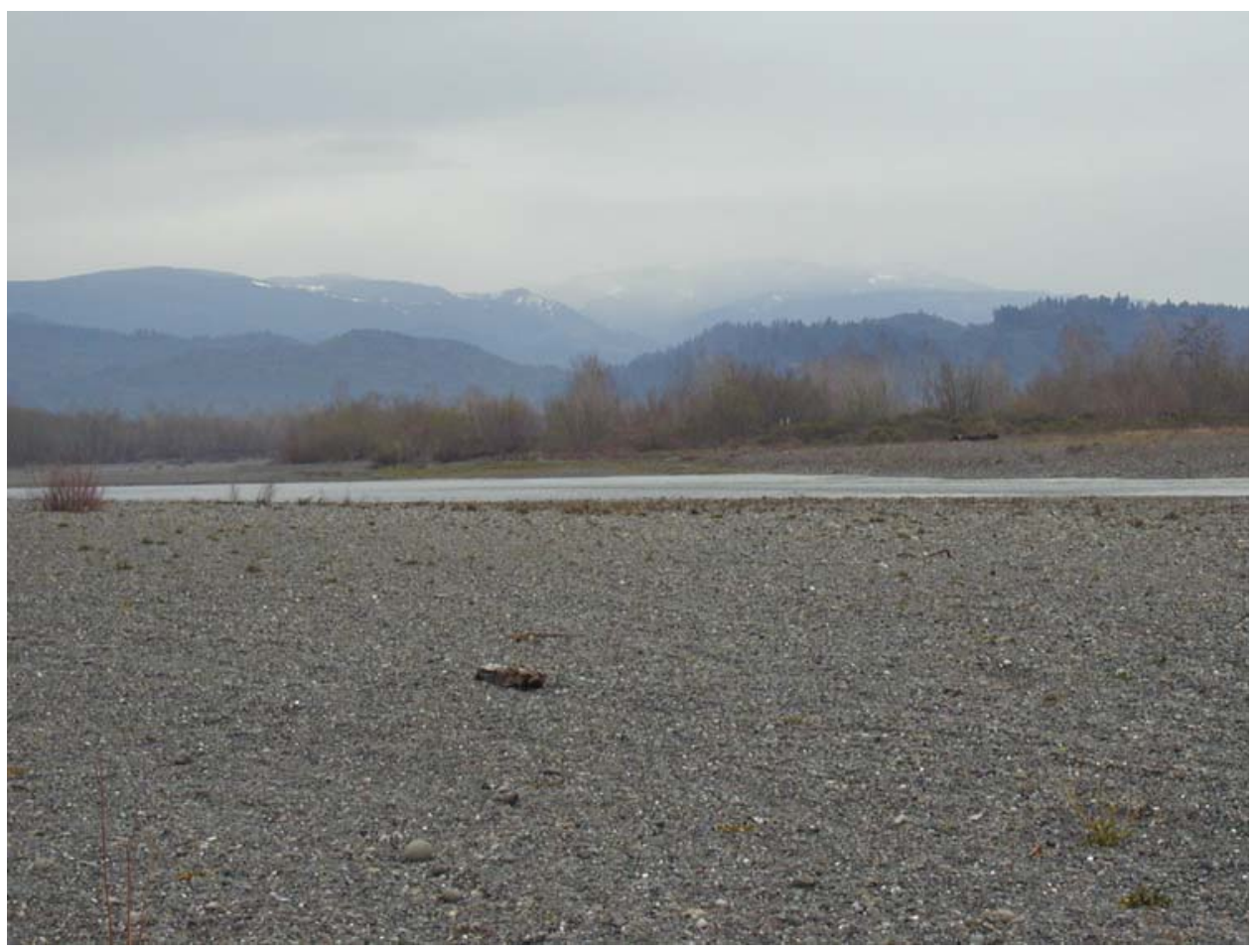

Figure C47. XC23 (right bank)

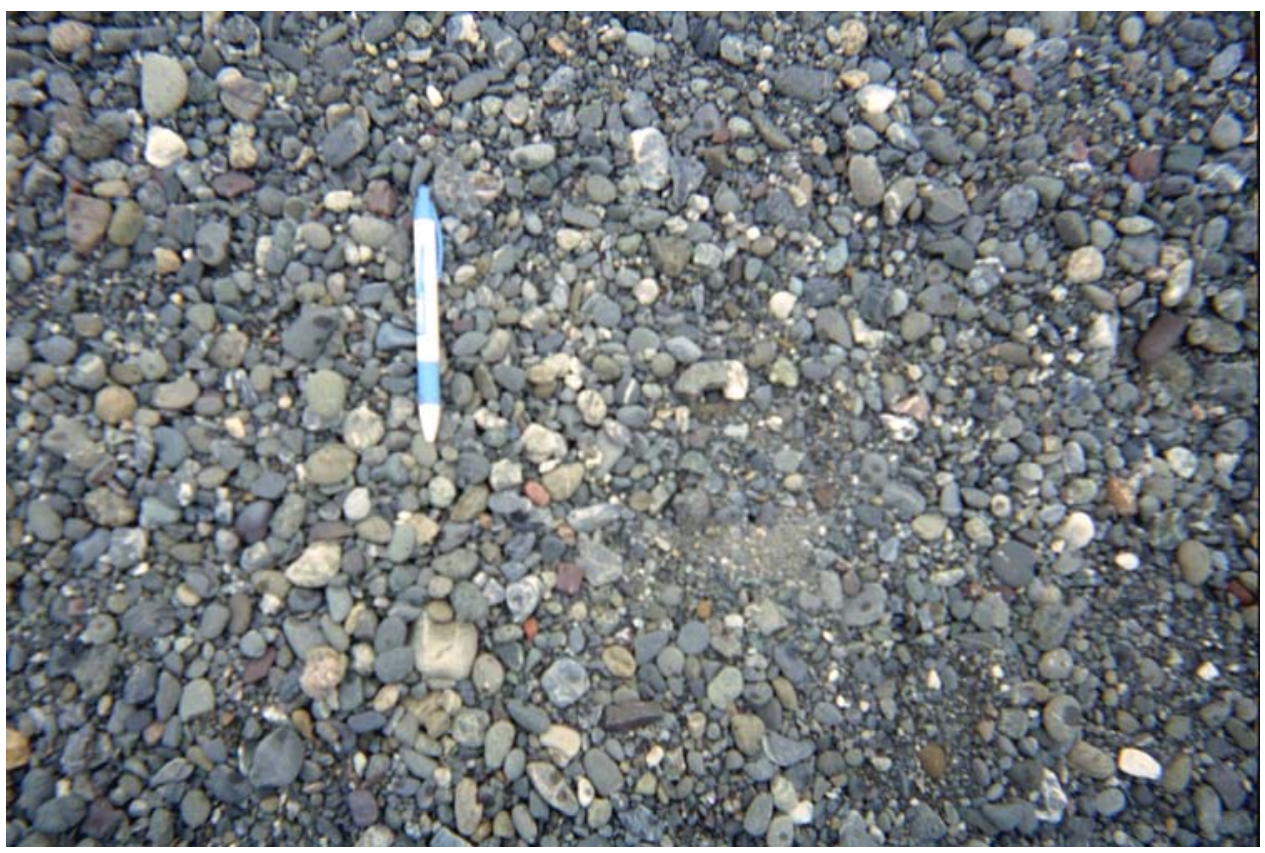

Figure C48. XC23 (right bank) - Bed material 


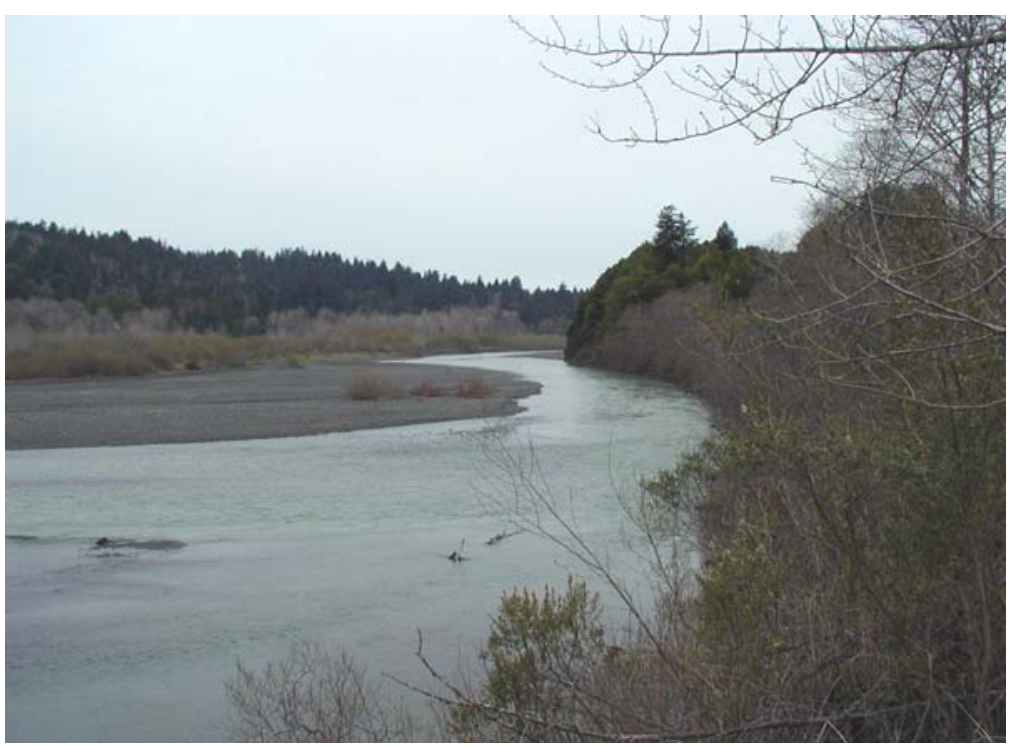

Figure C49. XC24 (right bank) - Looking downstream from cross section

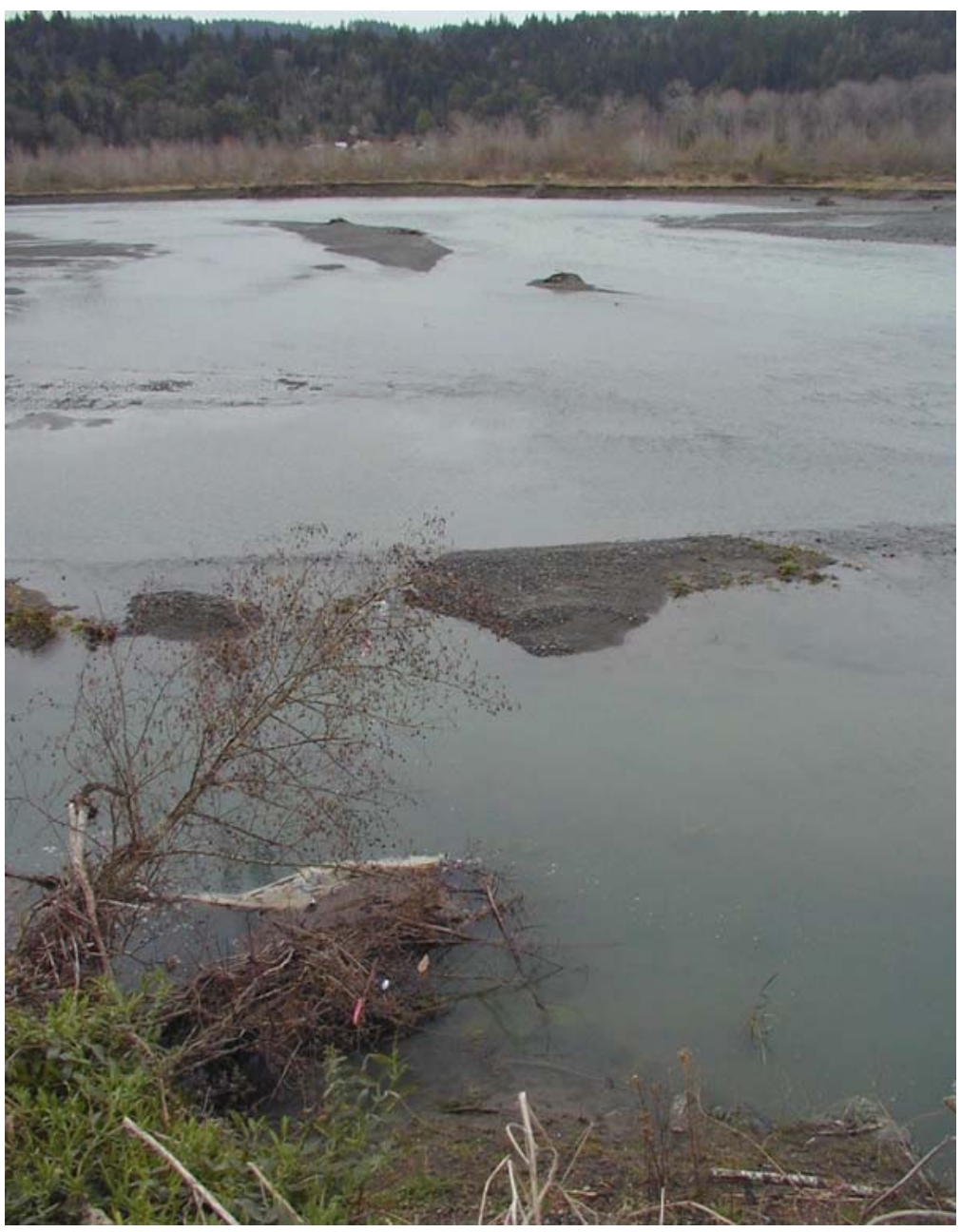

Figure C50. XC24 (right bank) 


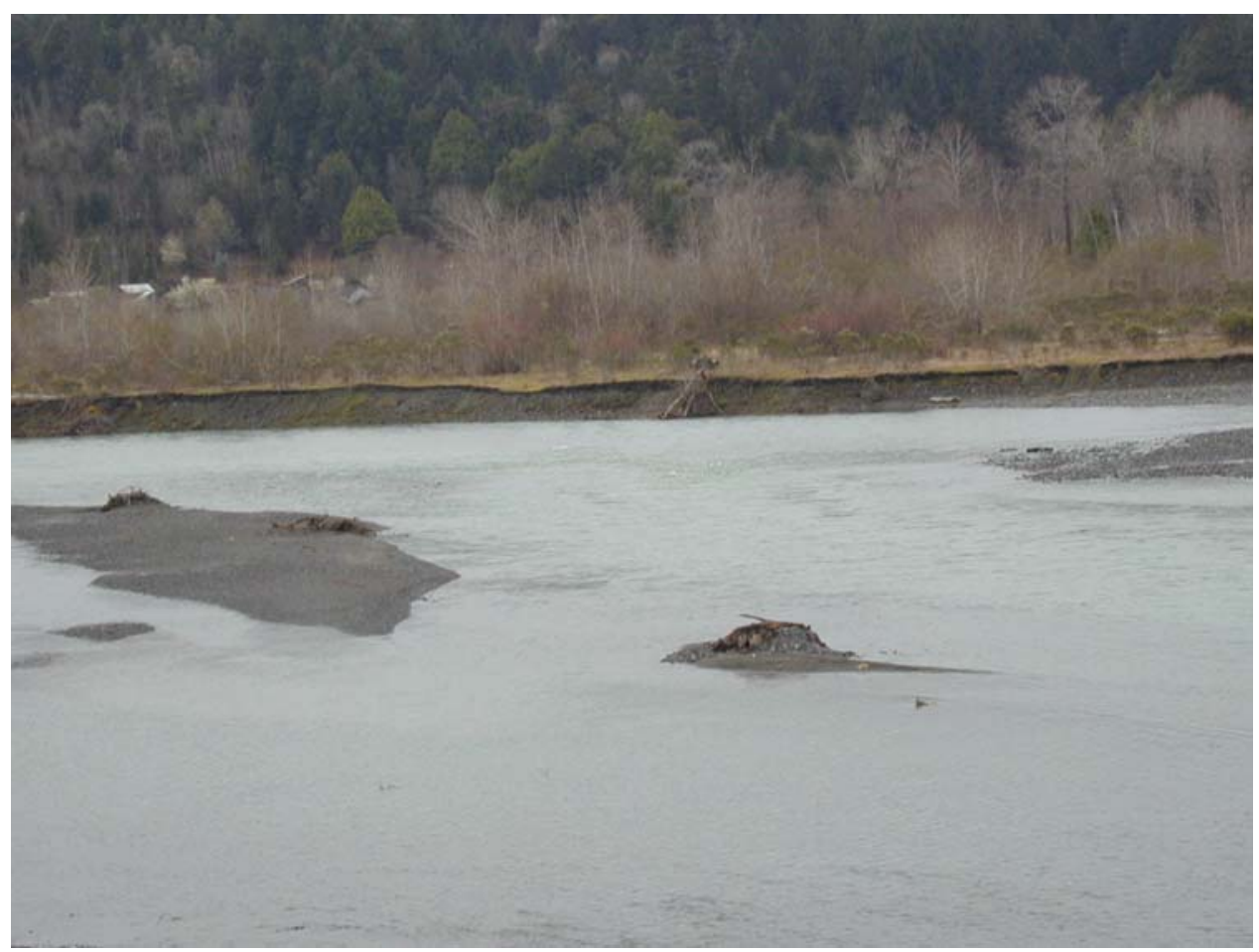

Figure C51. XC24 (right bank) - Close-up of erosion on left bank

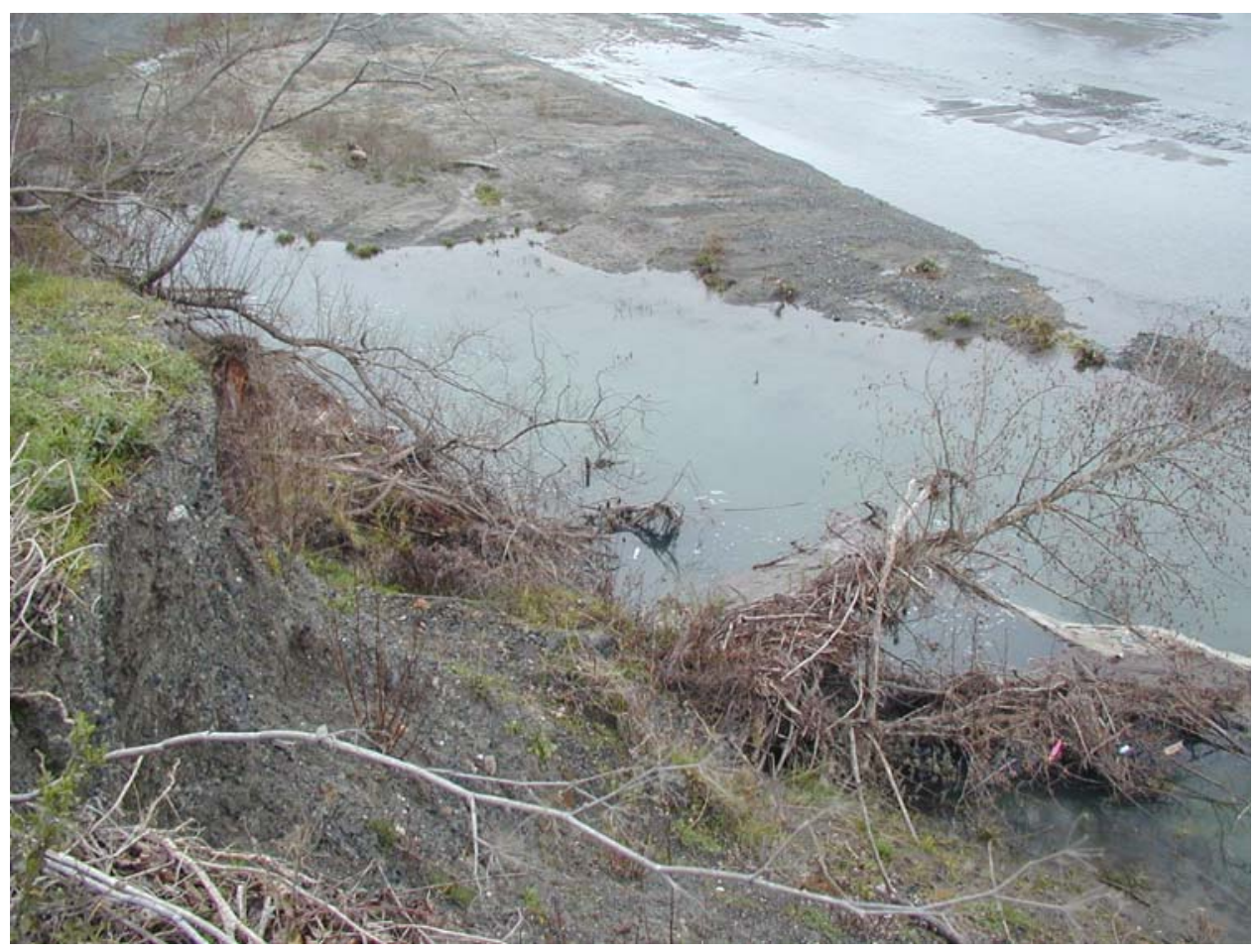

Figure C52. XC24 (right bank) - Erosion on right bank 


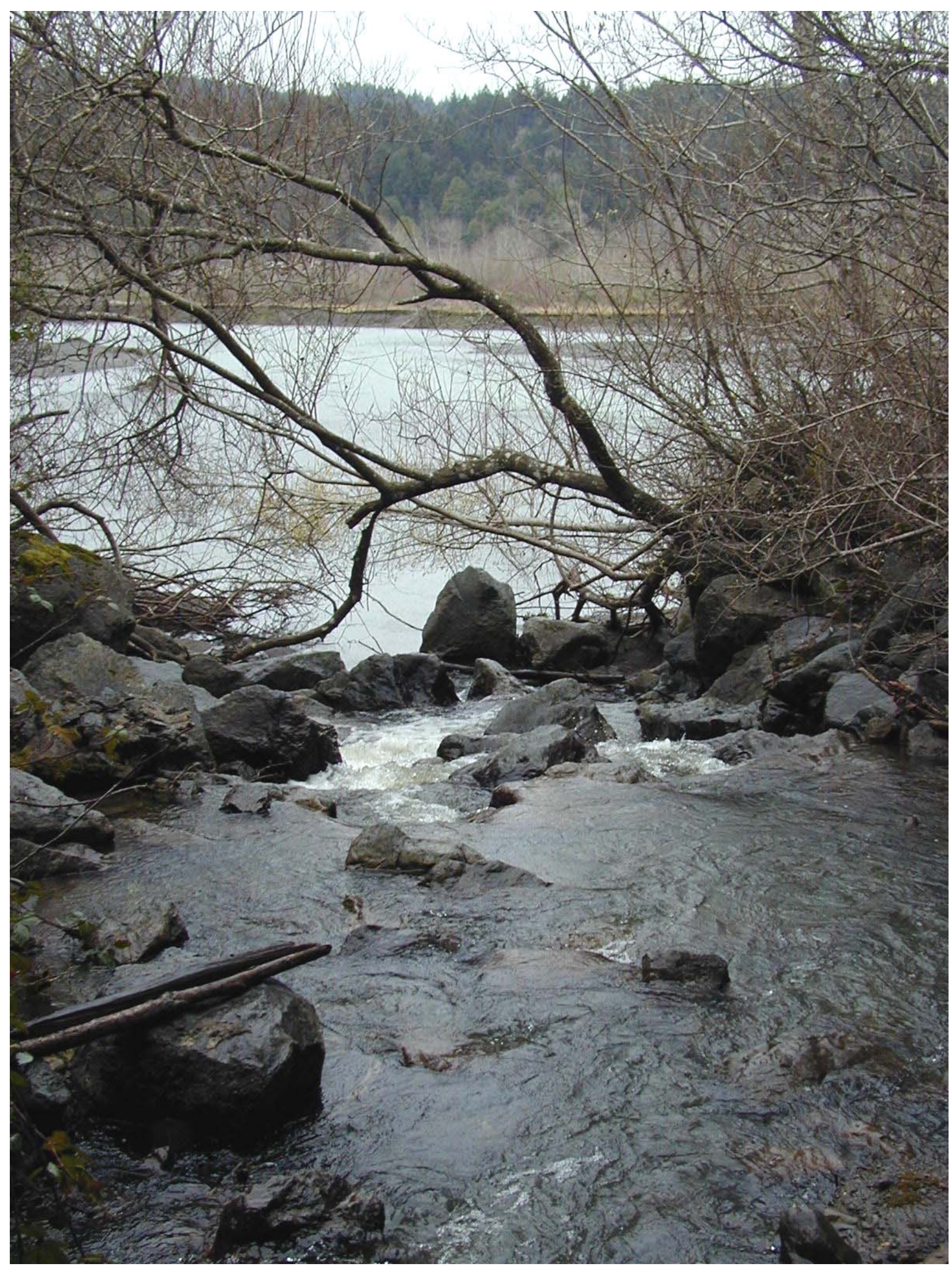

Figure C53. XC24 (right bank) - View from mouth of Hall Creek 


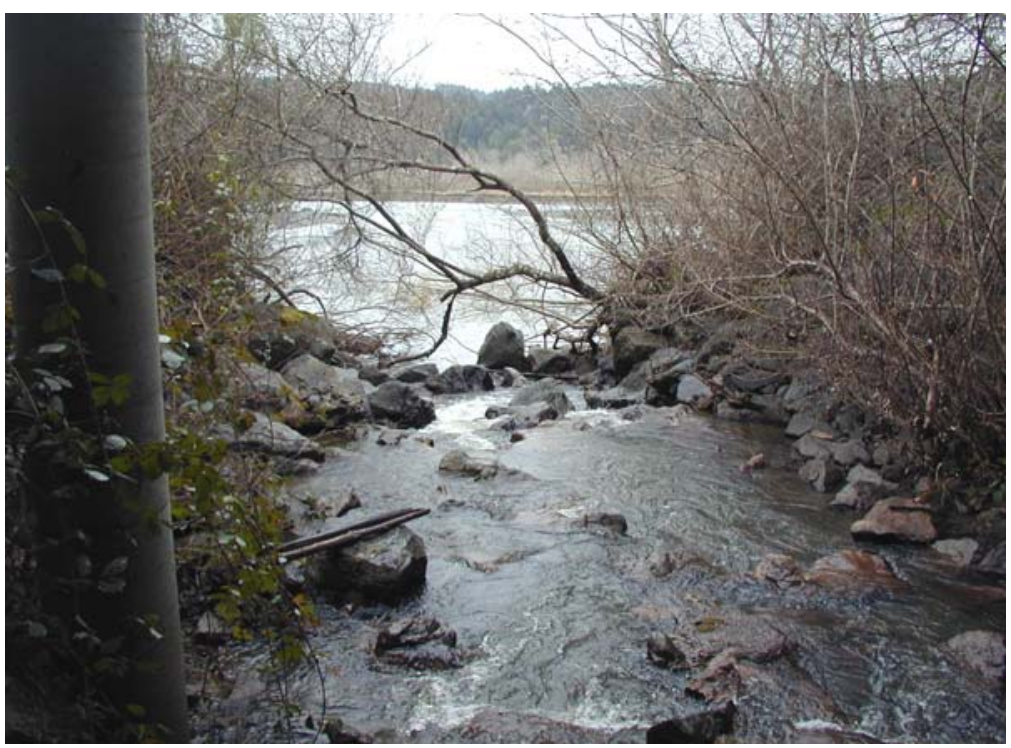

Figure C54. XC24 (right bank) - View from mouth of Hall Creek (note steep slope)

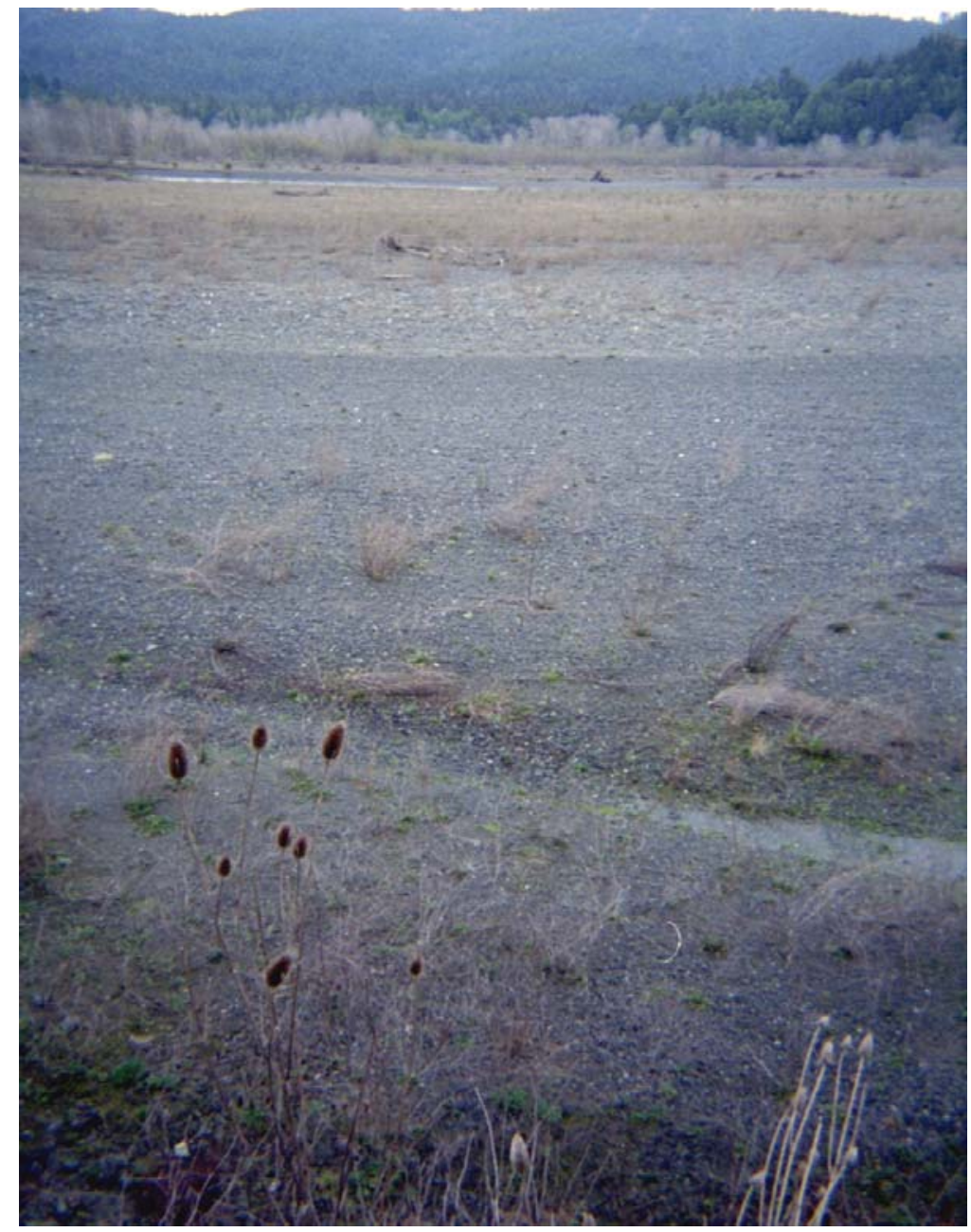

Figure C55. XC25 (right bank) 


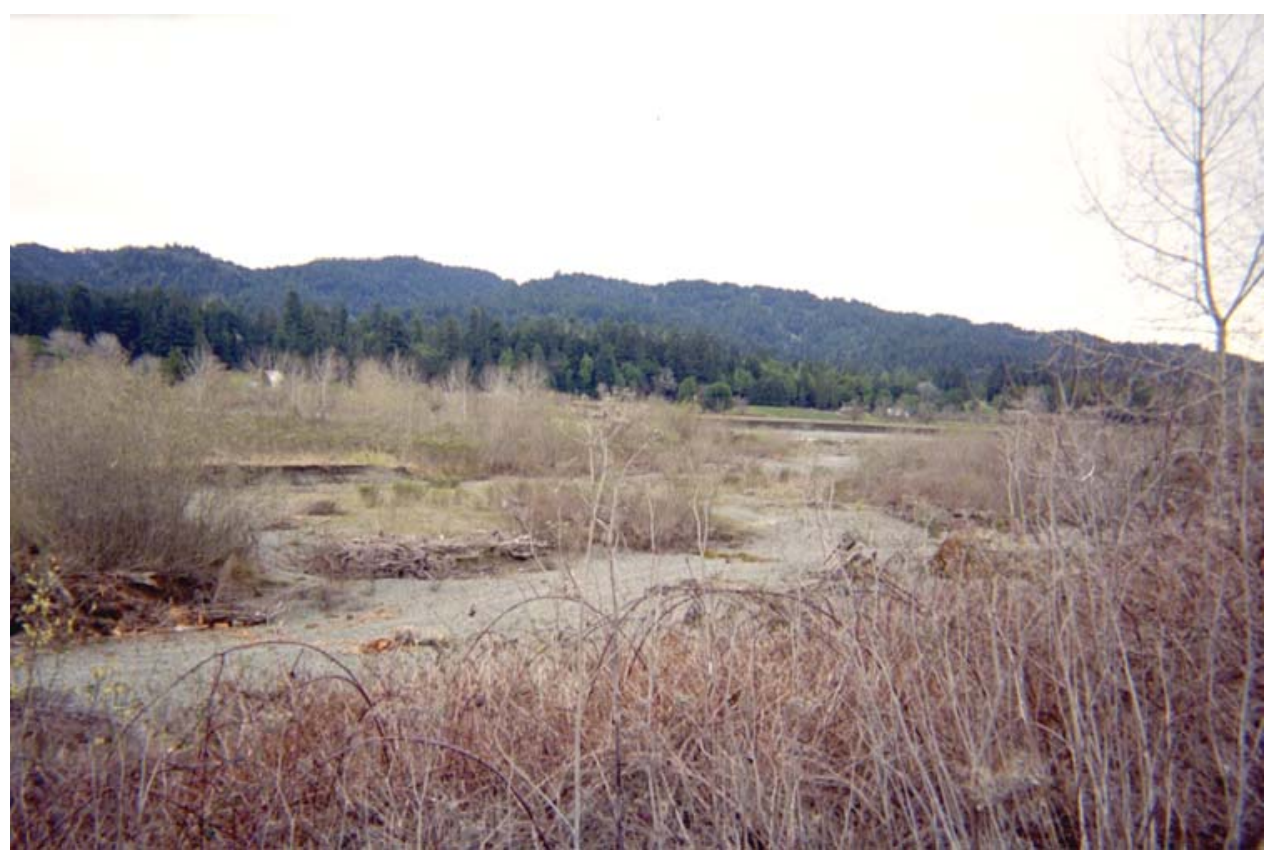

Figure C56. XC27 (right bank) - Standing on levee at cross section end point

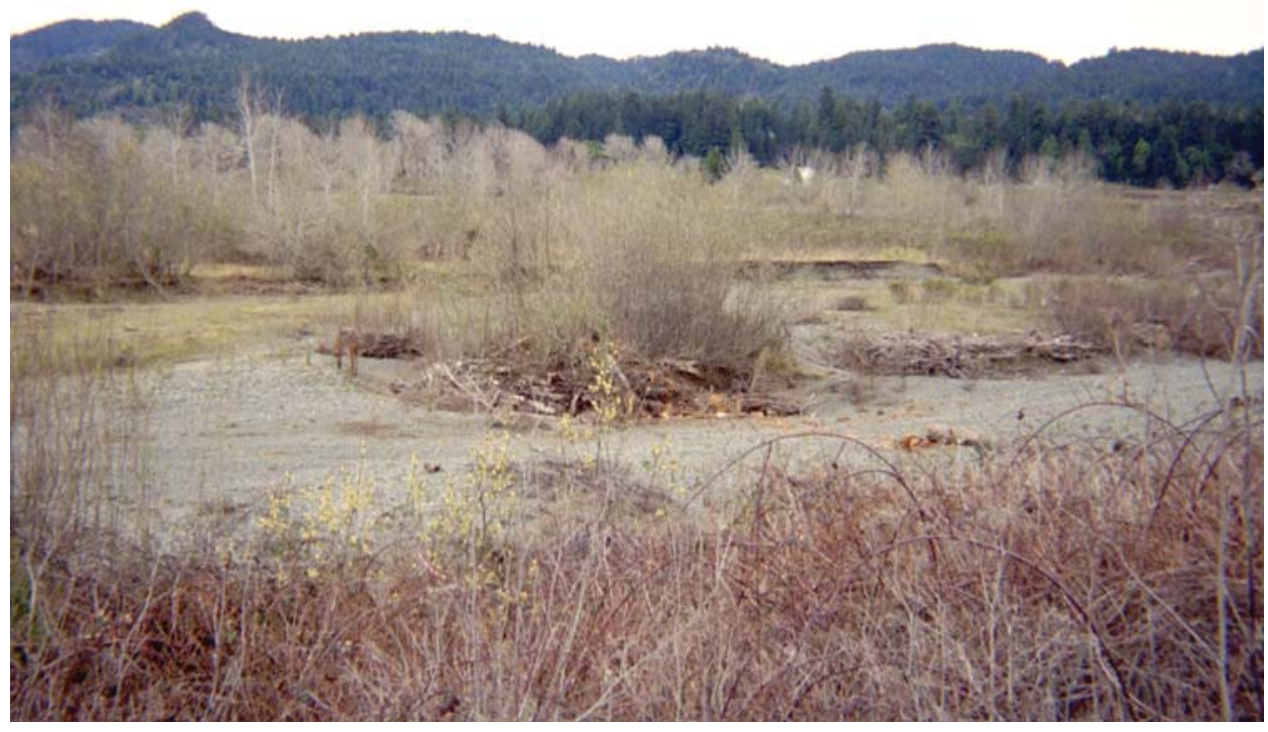

Figure C57. XC27 (right bank) - Standing on levee at cross section end point 


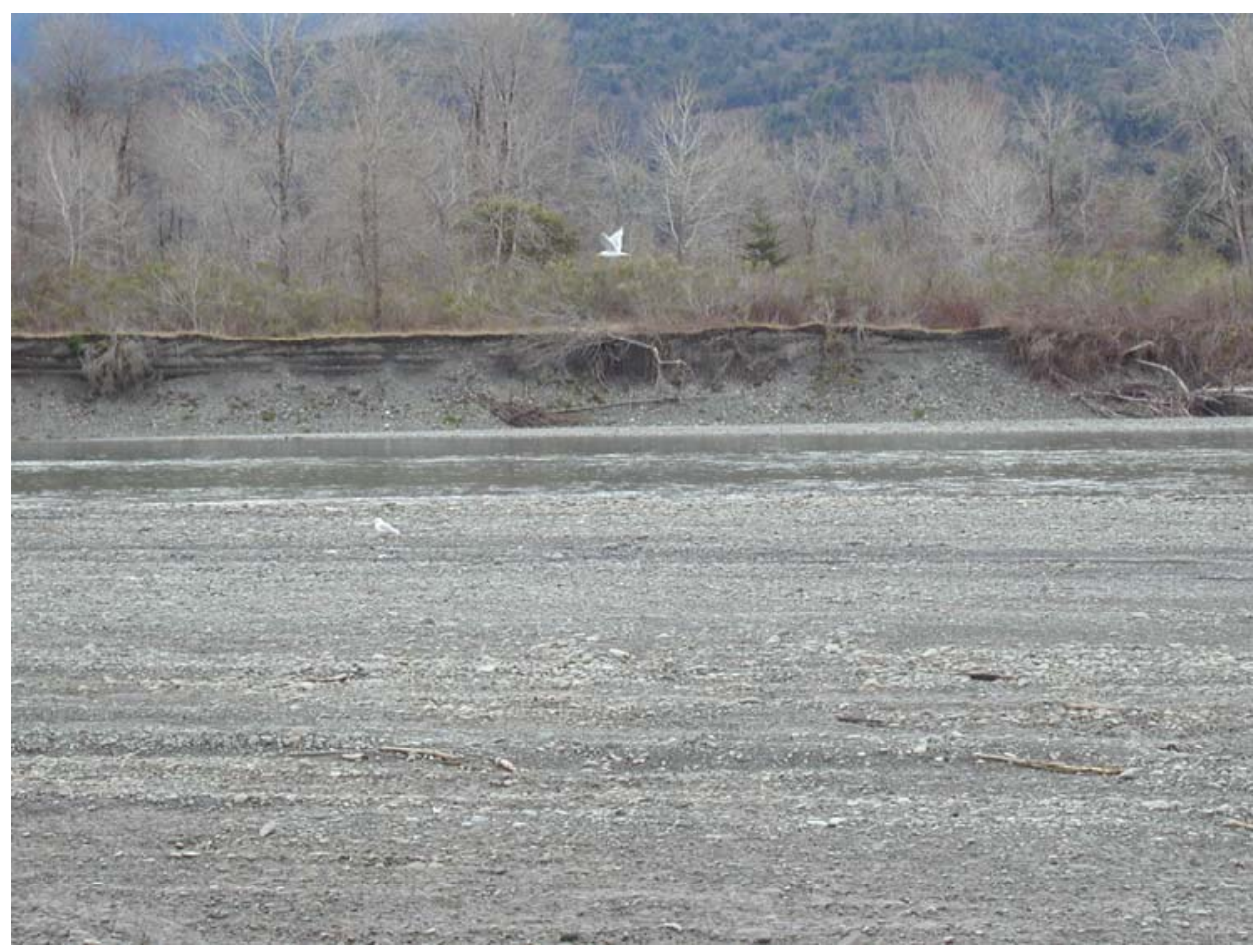

Figure C58. XC27 (right bank) - Looking at erosion of left (gravel) bank

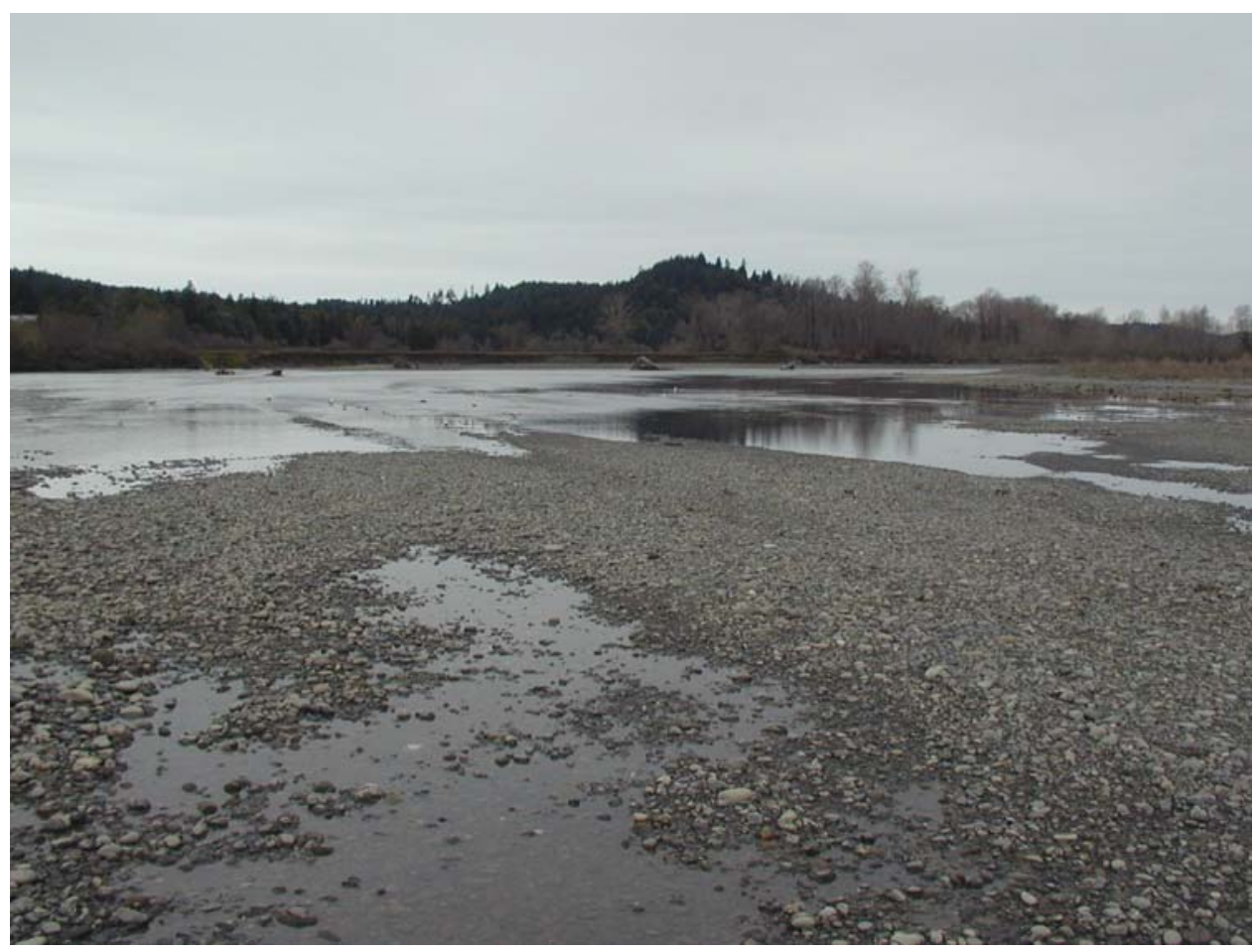

Figure C59. XC27 (right bank) -Looking downstream at erosion of left bank 


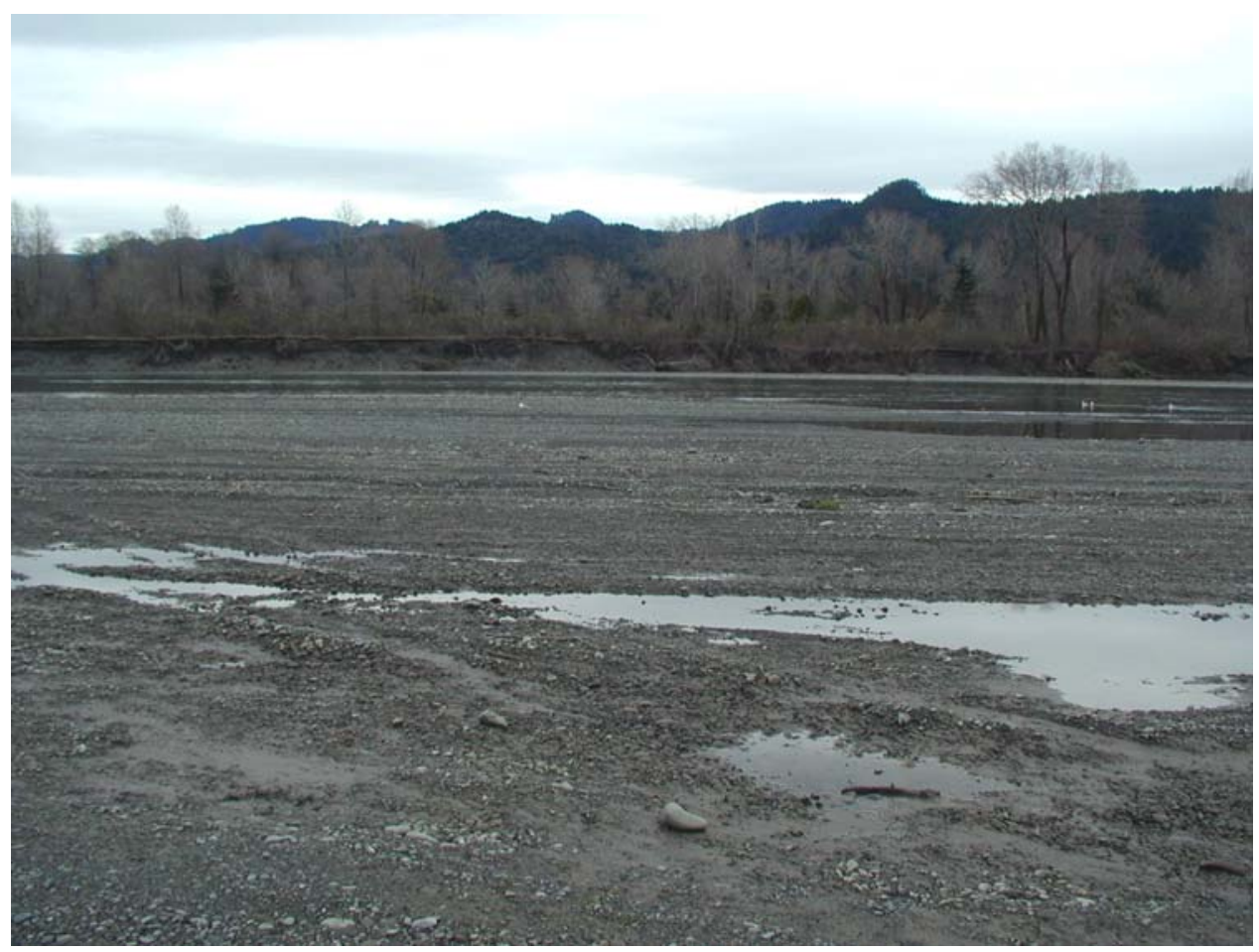

Figure C60. XC27 (right bank) - In channel looking at edge of water and left bank

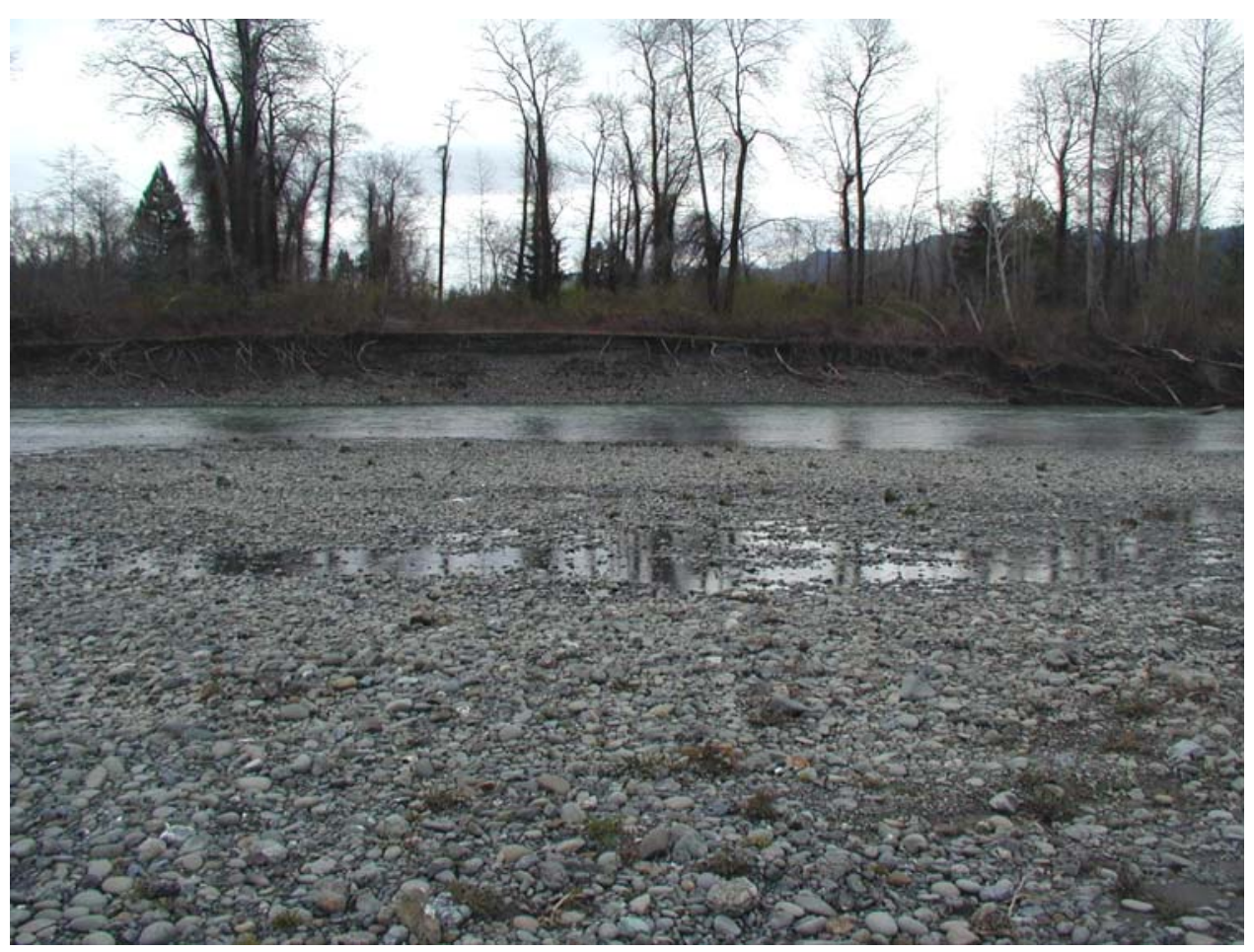

Figure C61. XC28 (right bank) - In channel near edge of water 


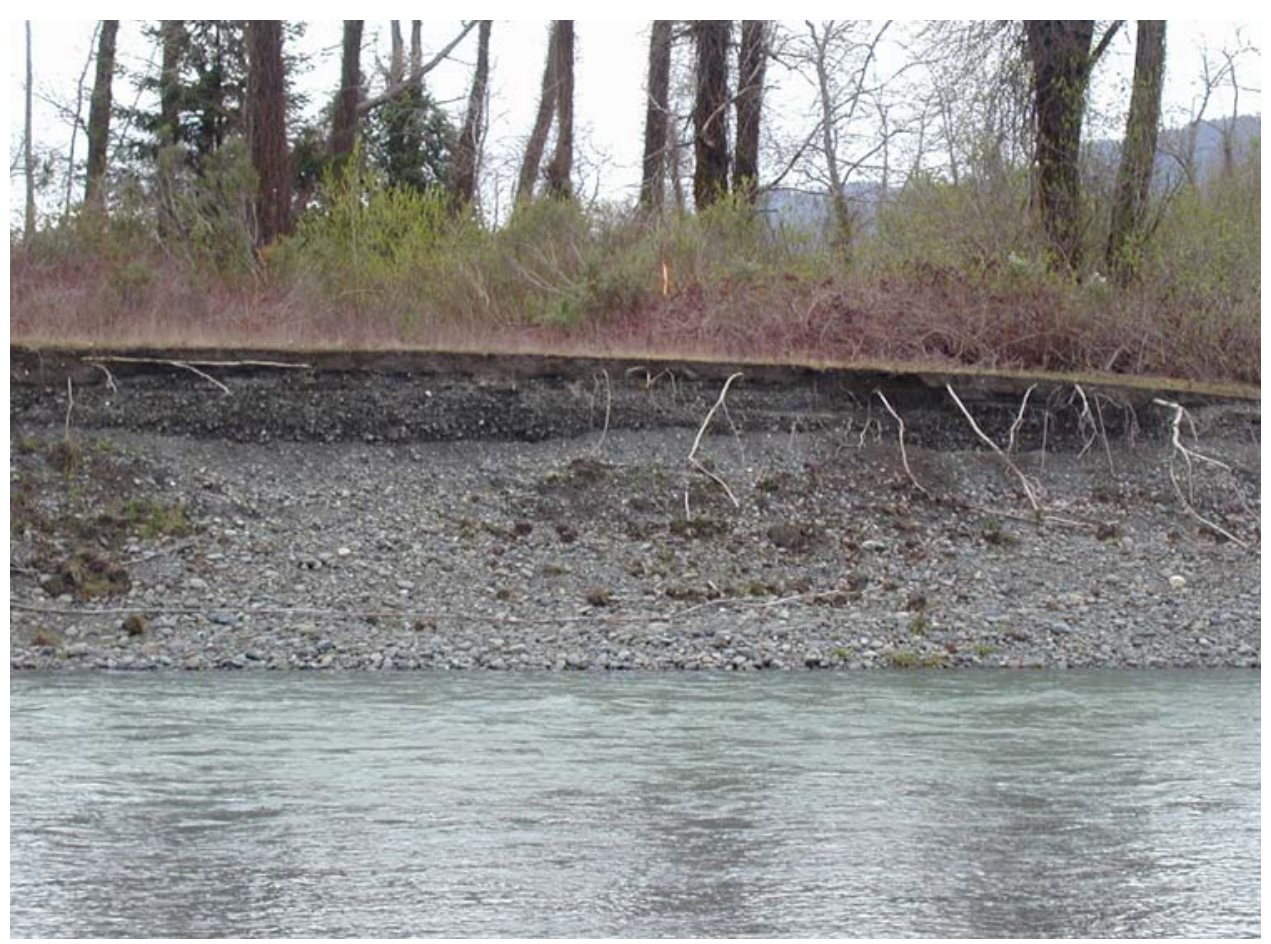

Figure C62. XC28 (right bank) - Looking at erosion of left (gravel) bank

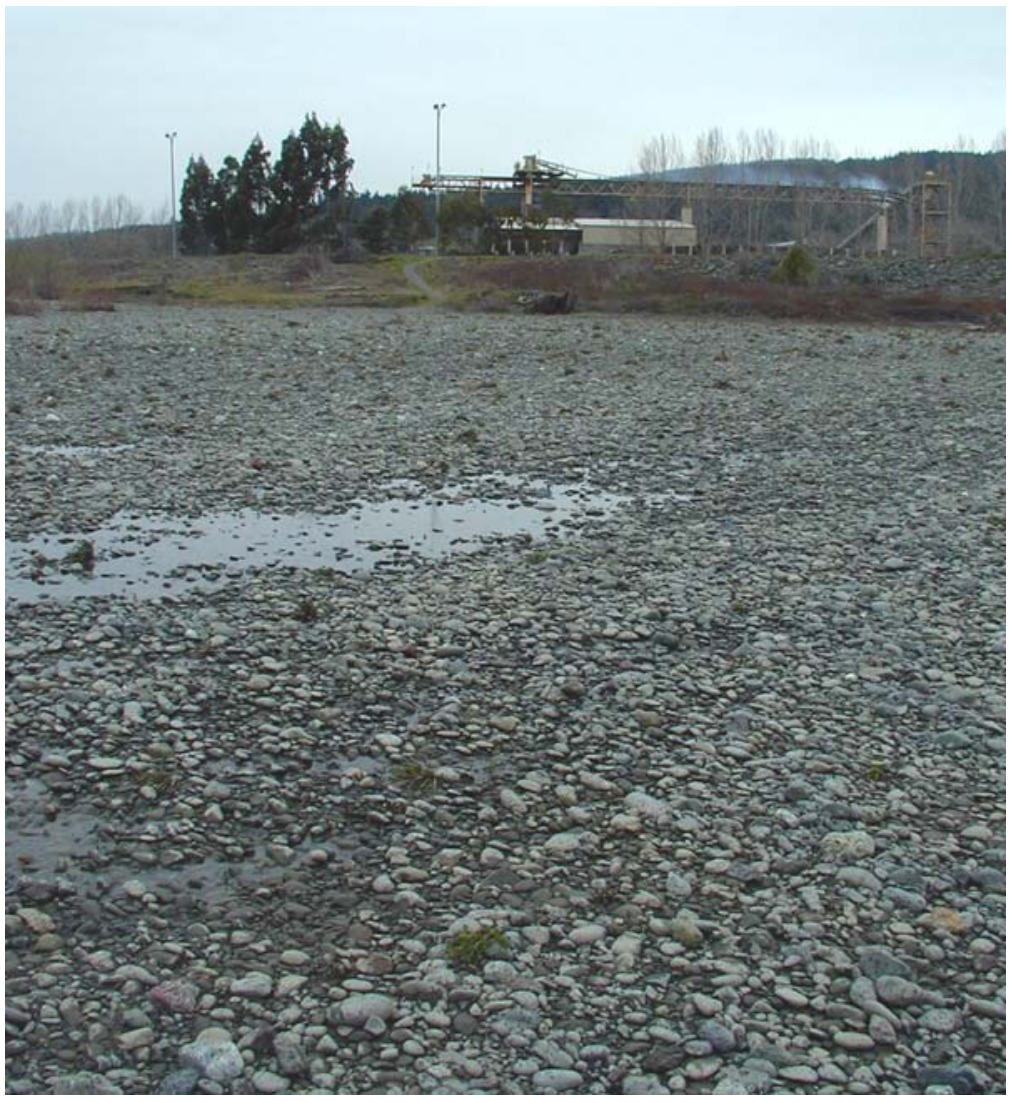

Figure C63. XC28 (right bank) - Looking at right bank from edge of water 


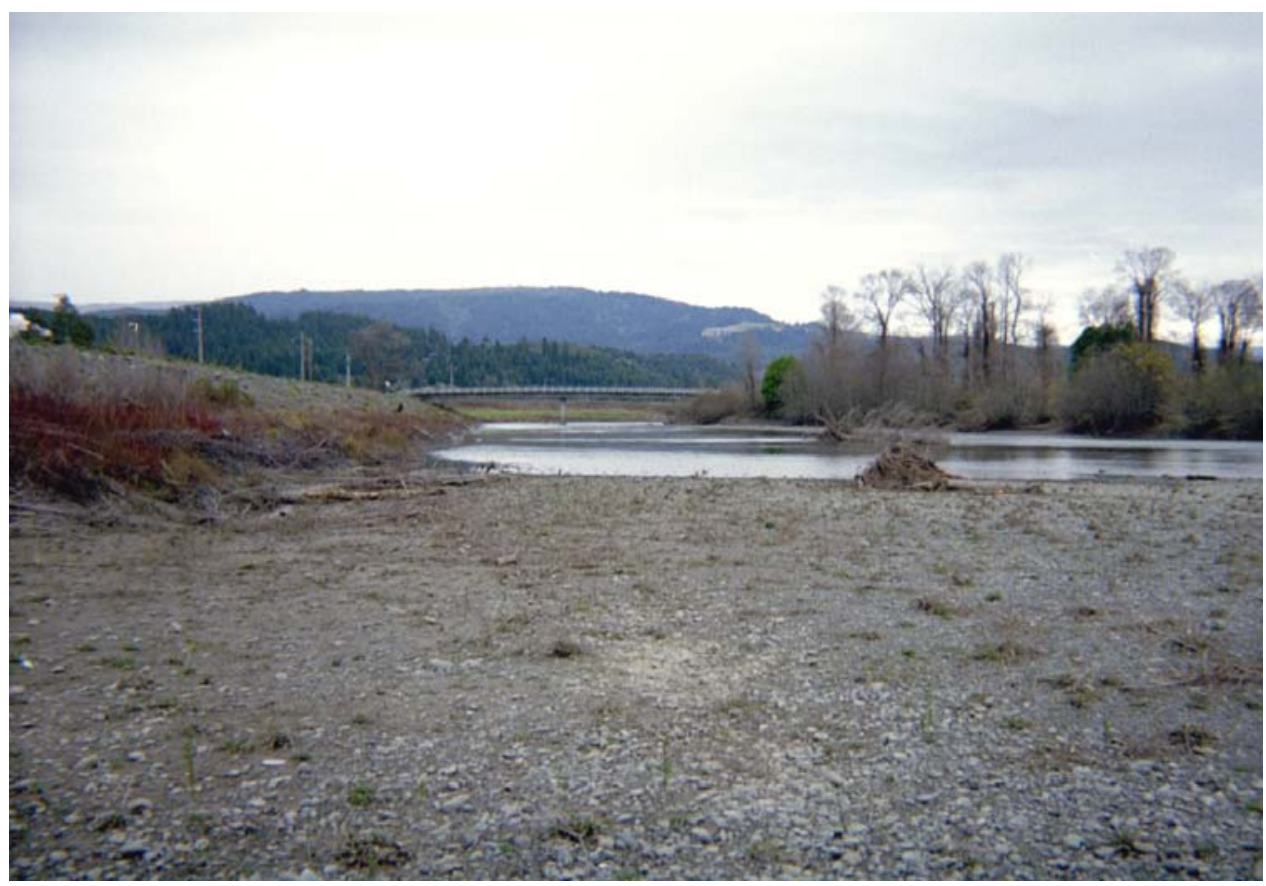

Figure C64. XC28 (right bank) - Looking upstream from toe of right bank levee

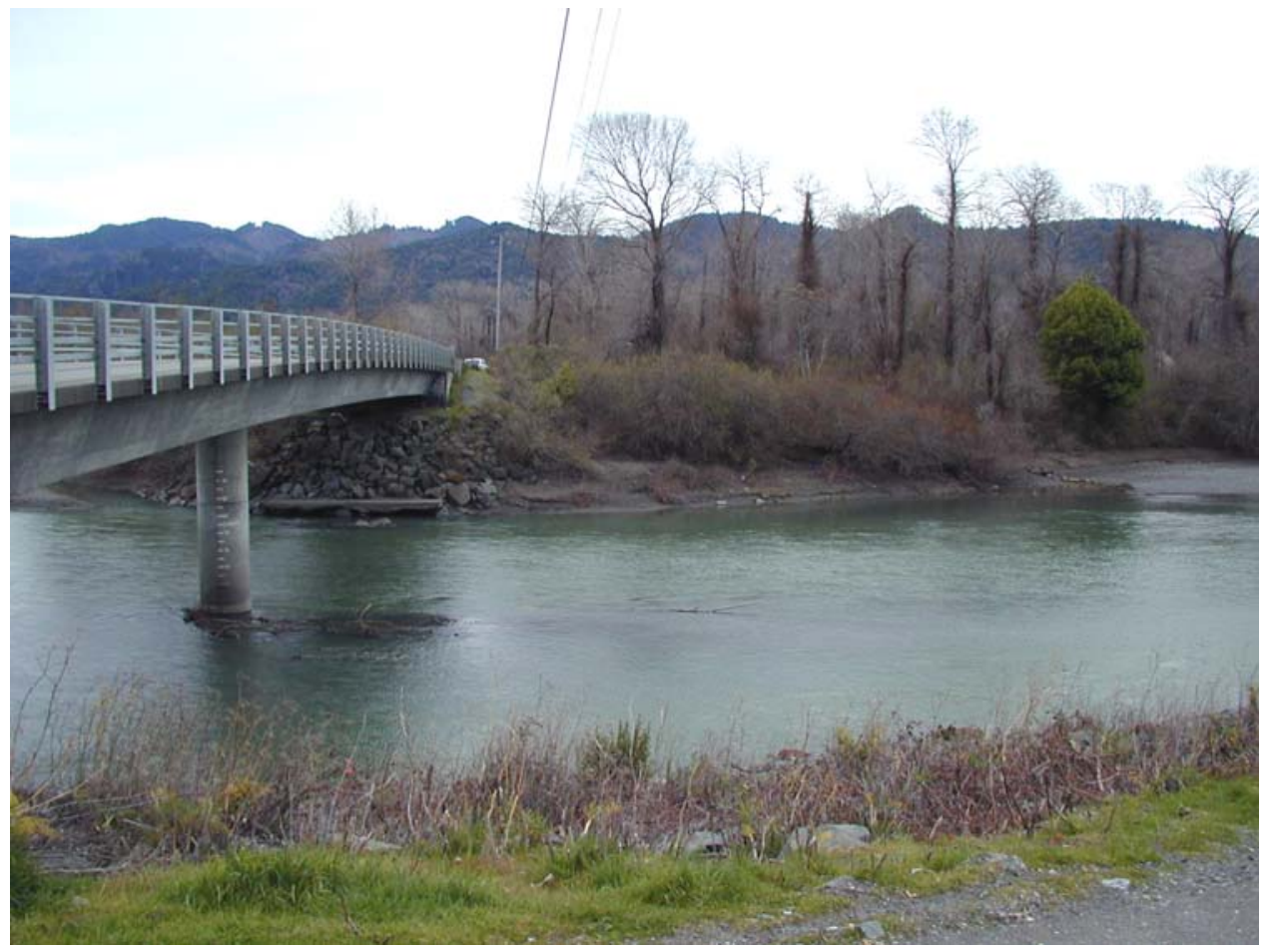

Figure C65. XC29 (right bank) 


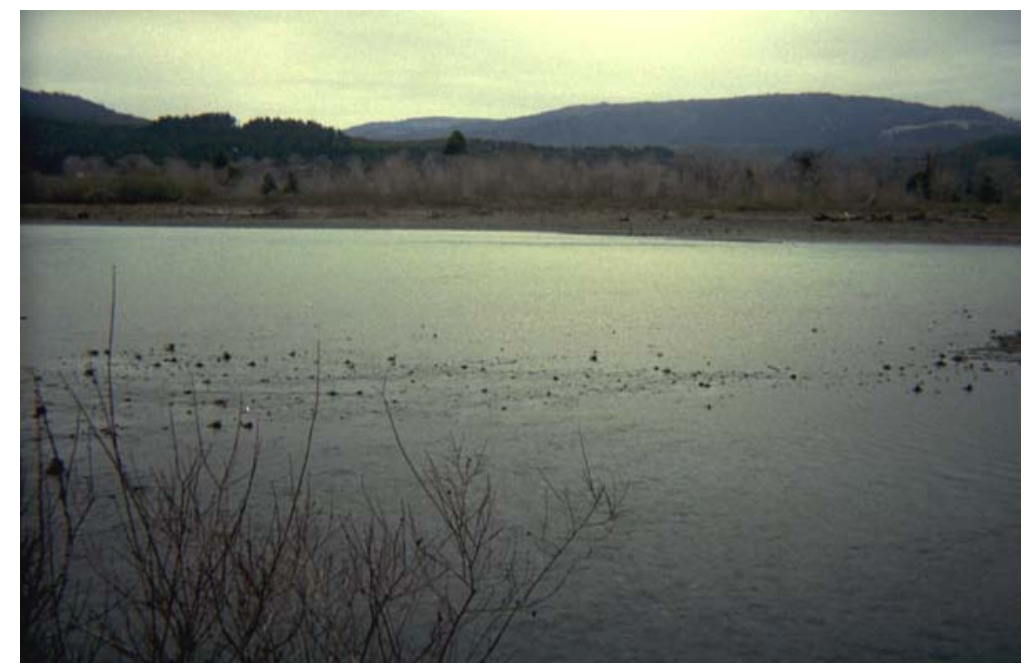

Figure C66. XC30 (left bank) - Looking at right bank

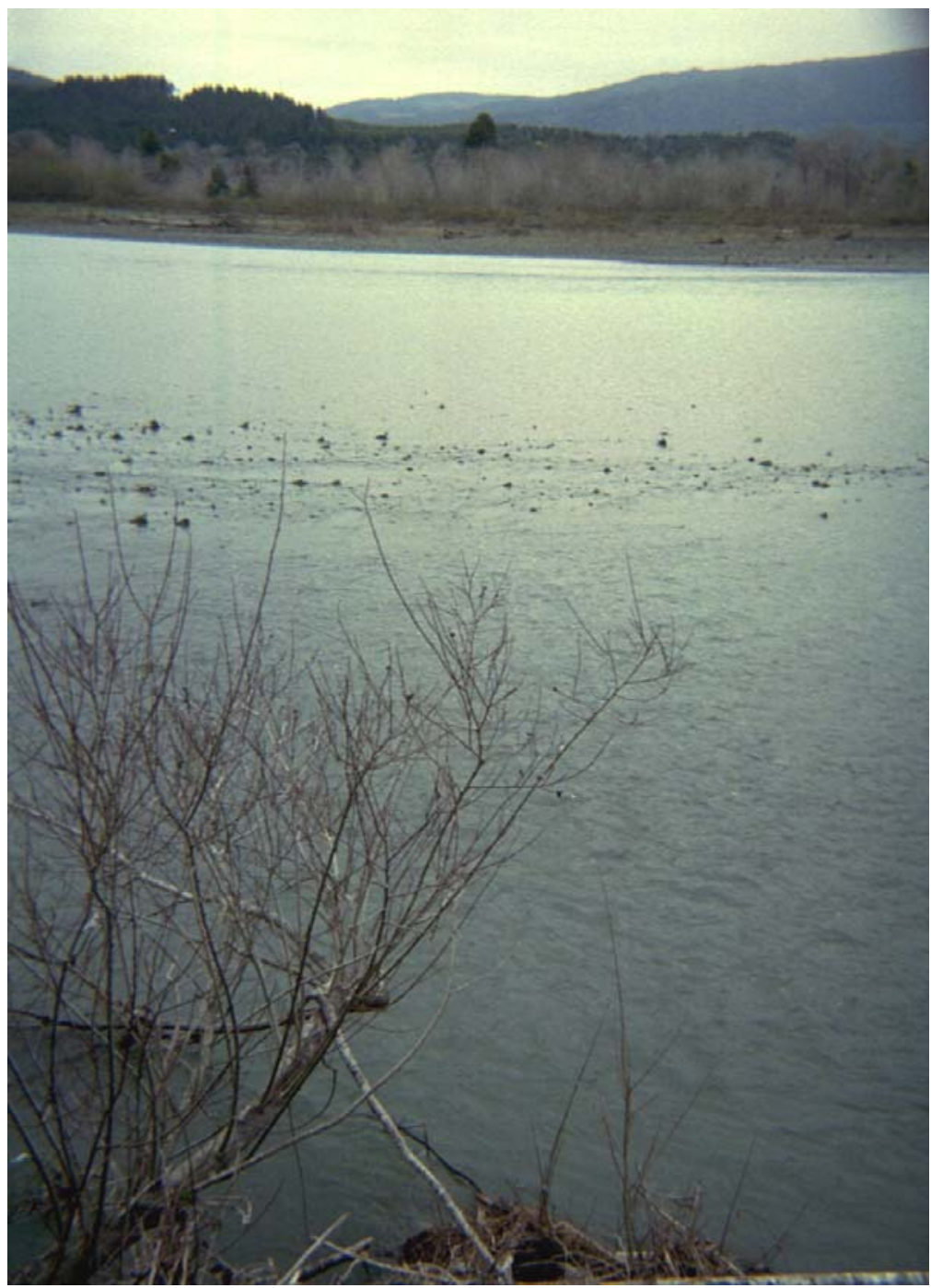

Figure C67. XC30 (left bank) - Looking at right bank 


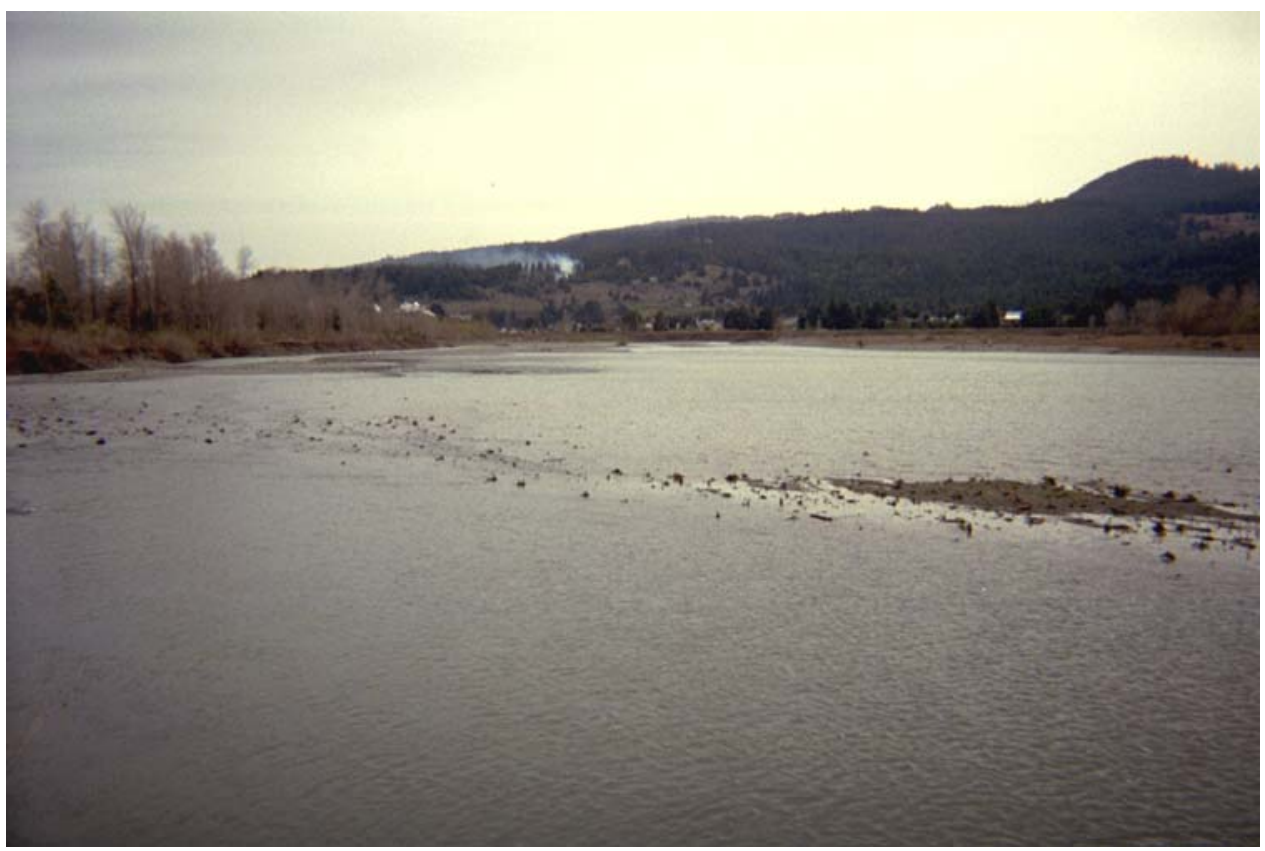

Figure C68. XC30 (left bank) - Looking downstream

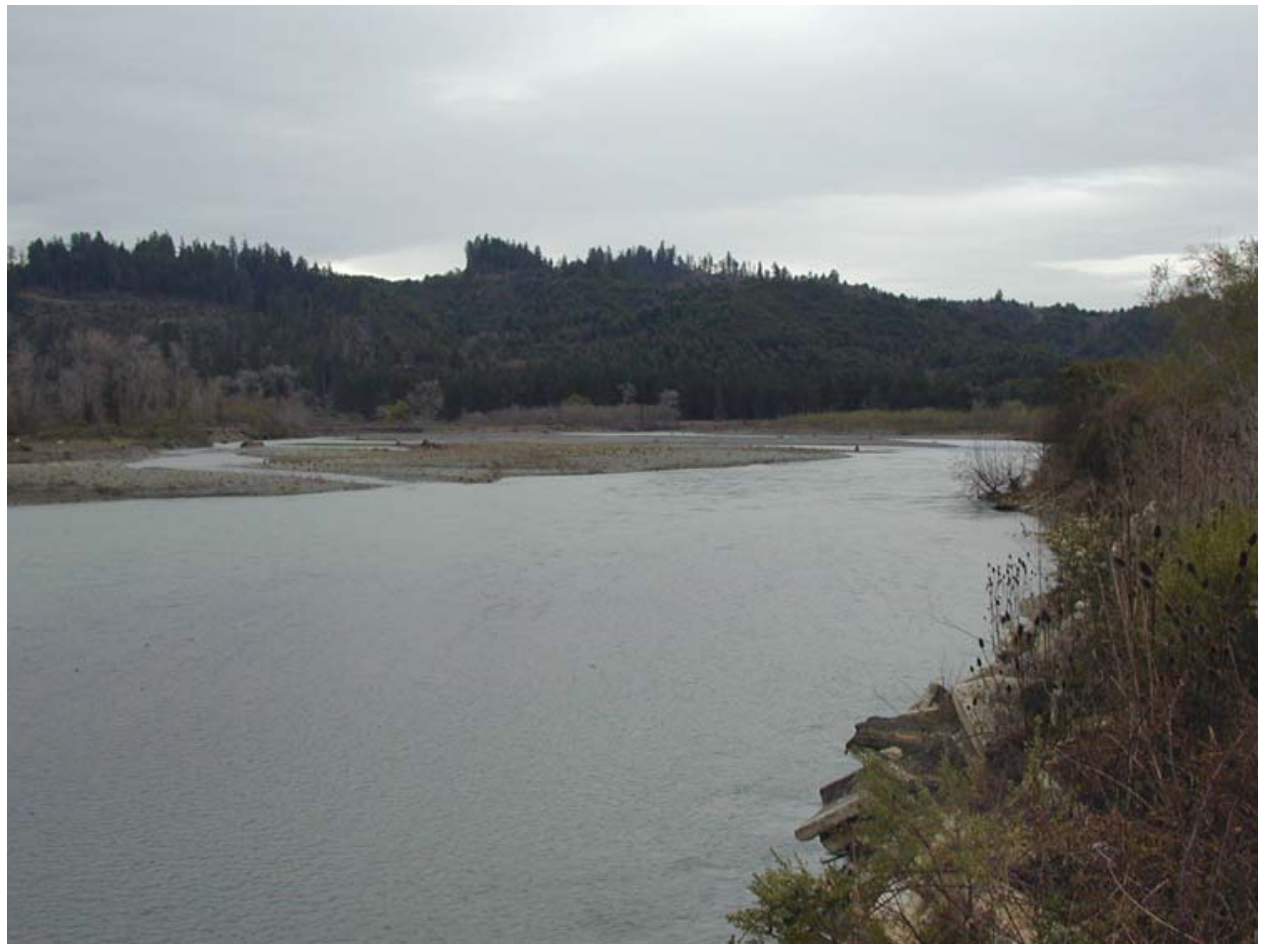

Figure C69. XC30 (left bank) - Looking upstream 


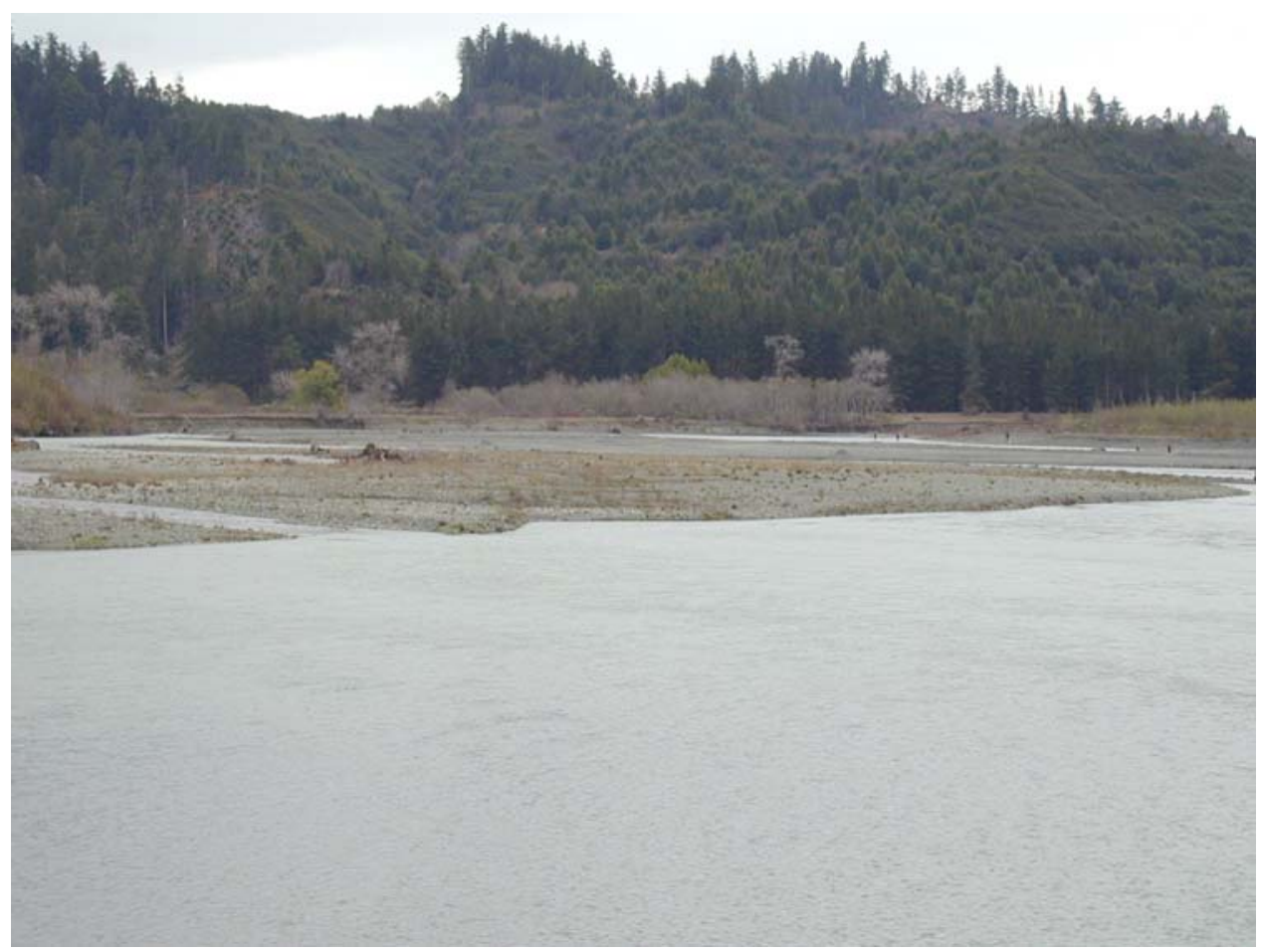

Figure C70. XC30 (left bank) - Looking upstream

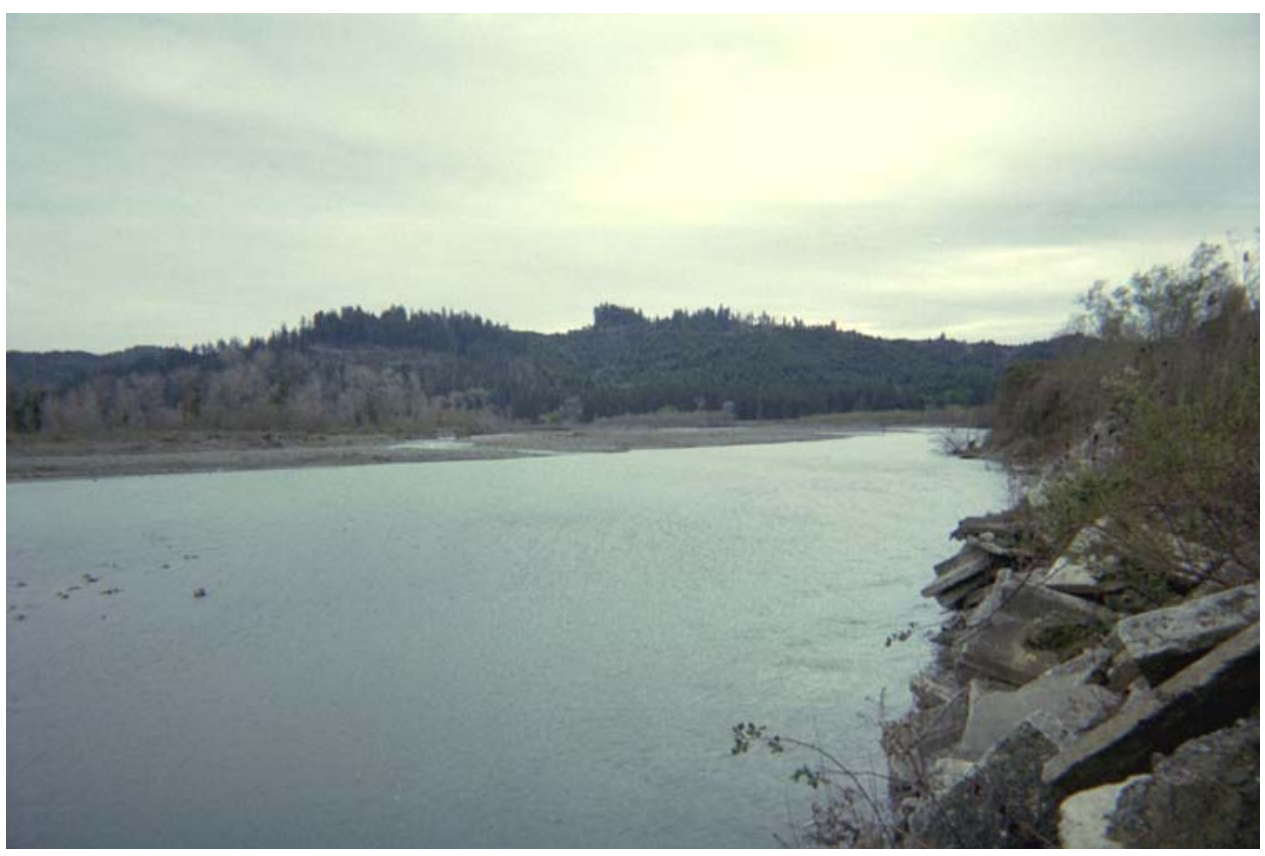

Figure C71. XC30 (left bank) - Looking upstream 


\section{Appendix D \\ Additional Photographs of Mad River and North Fork of Mad River (April 28, 2001 - Average Daily Flow was 488 cfs)}

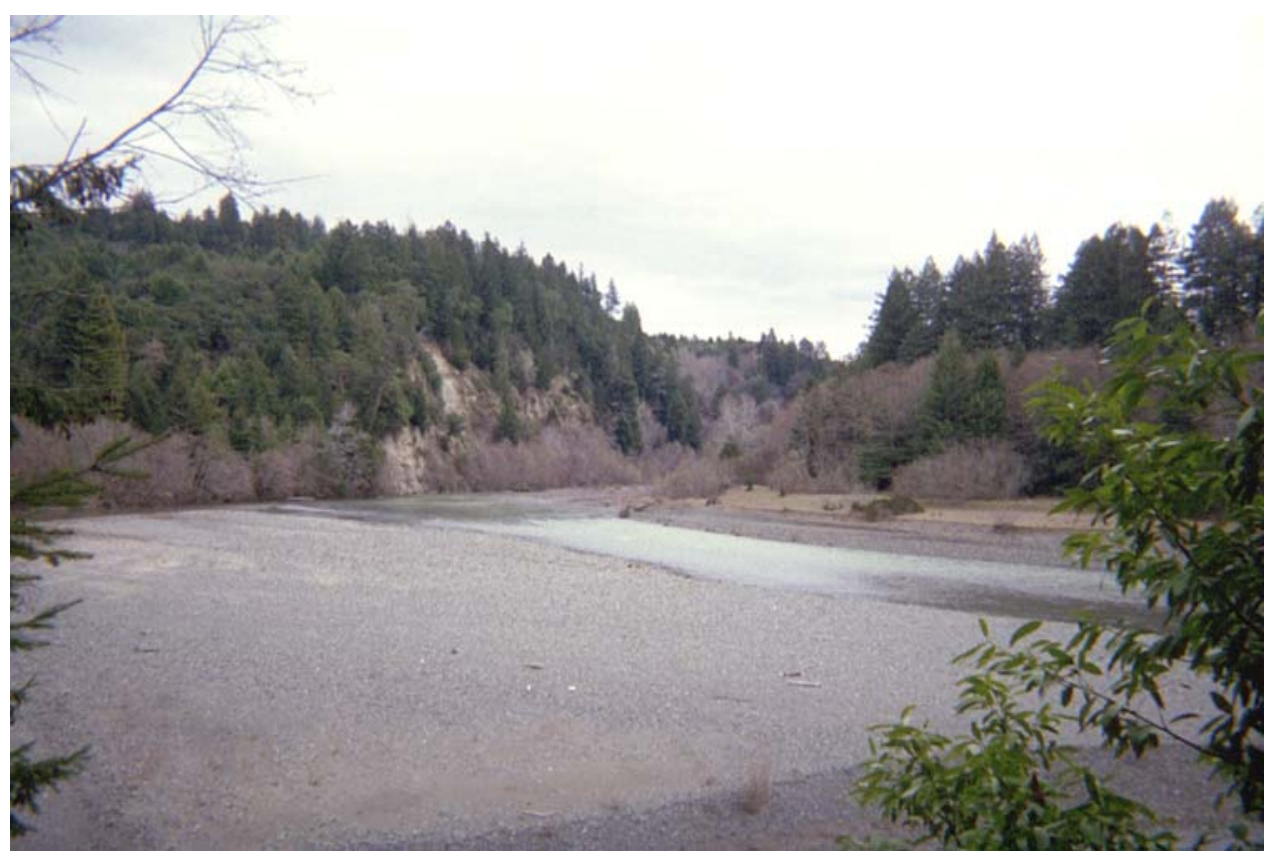

Figure D1. Mad River near Blue Lake gauge - no significant evidence of erosion 


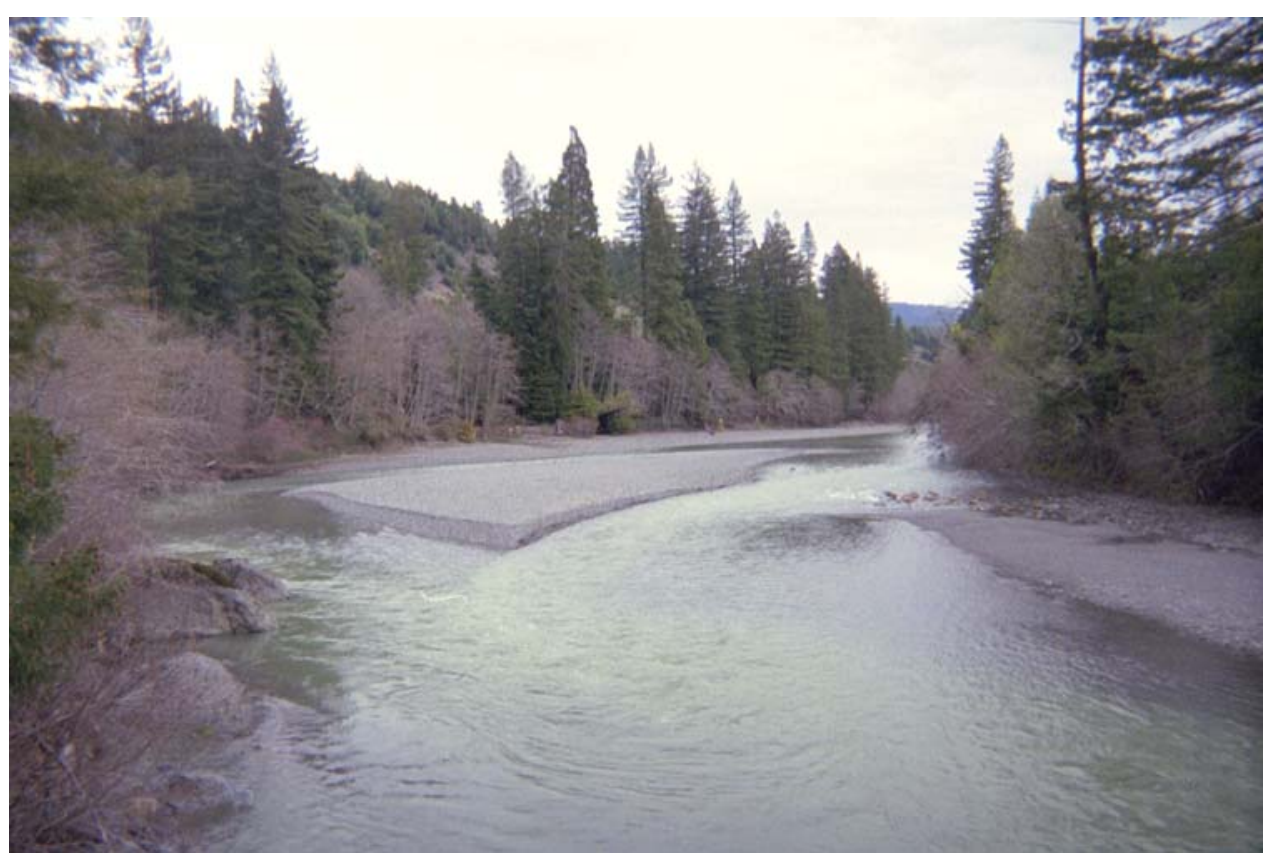

Figure D2. Mad River near Blue Lake gauge - no significant evidence of erosion

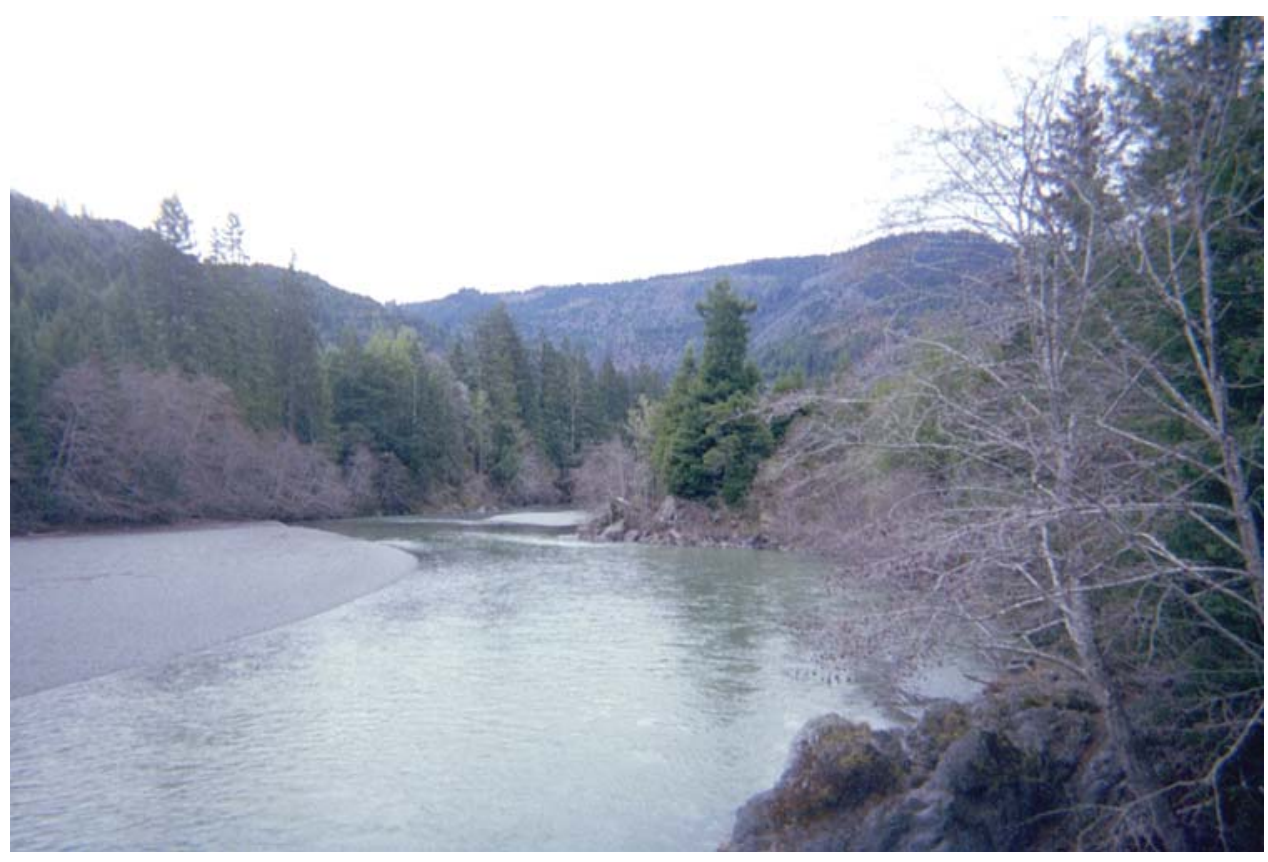

Figure D3. Mad River near Blue Lake gauge - no significant evidence of erosion 


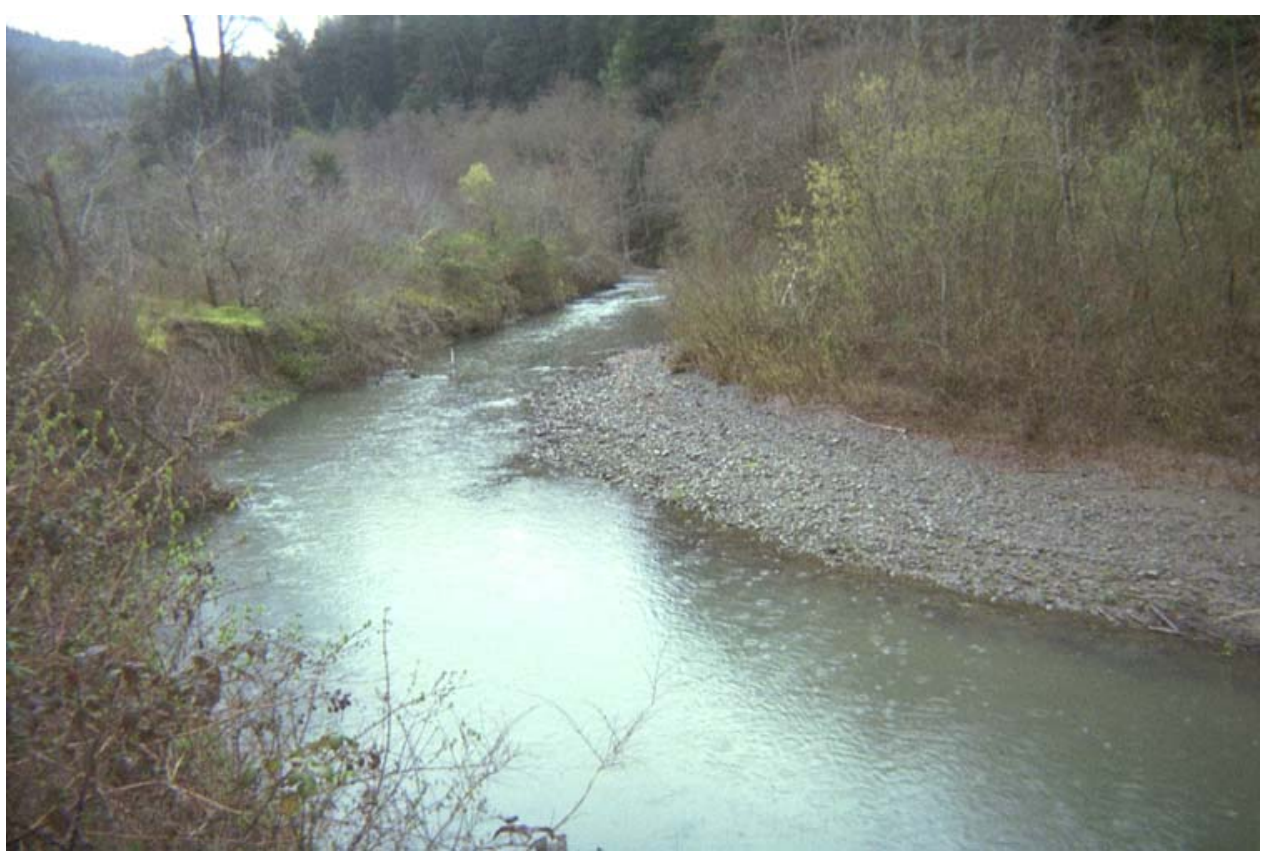

Figure D4. North Fork Mad River near Korbel at point where river bends southeast off road

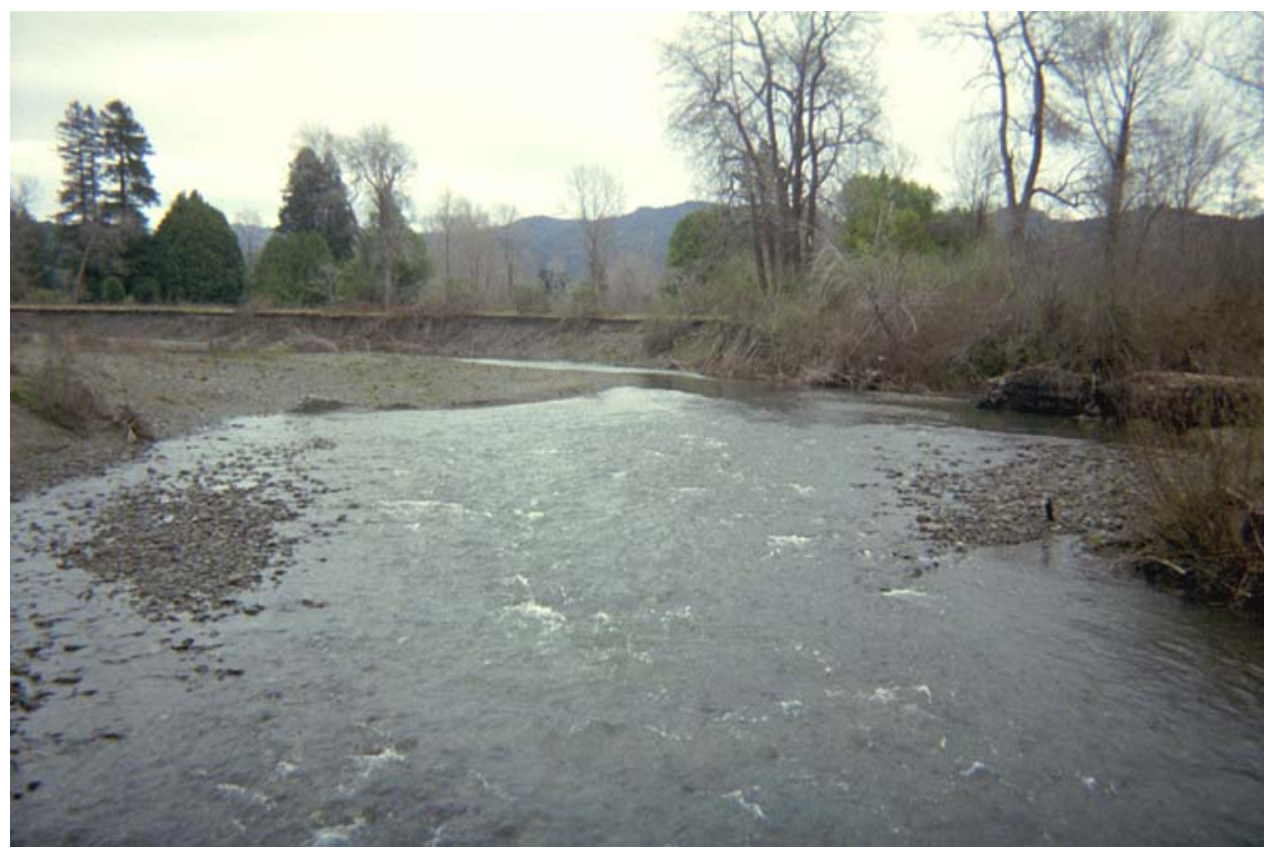

Figure D5. North Fork Mad River near main stem - severe bank erosion and possible incision 


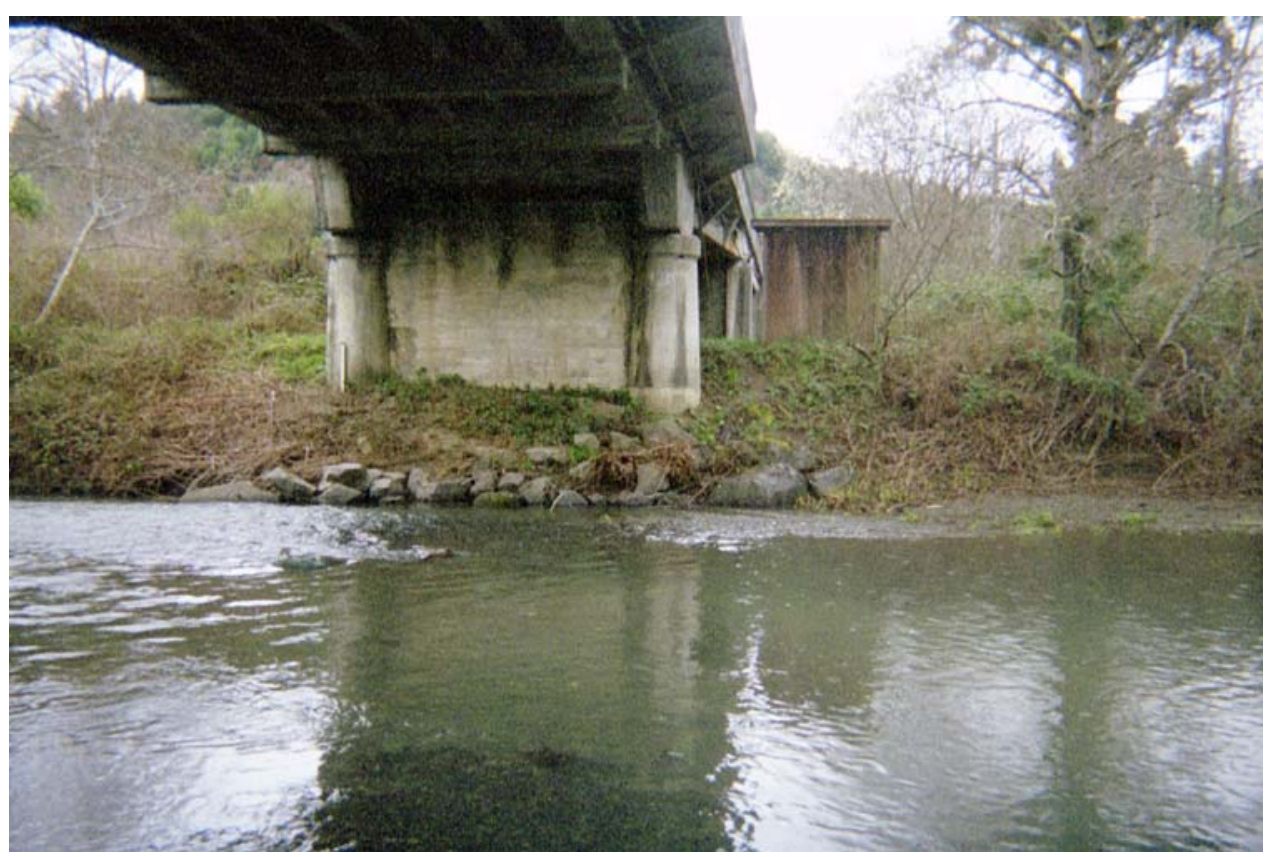

Figure D6. North Fork Mad River -1928 Blue Lake (Korbel) bridge abutment

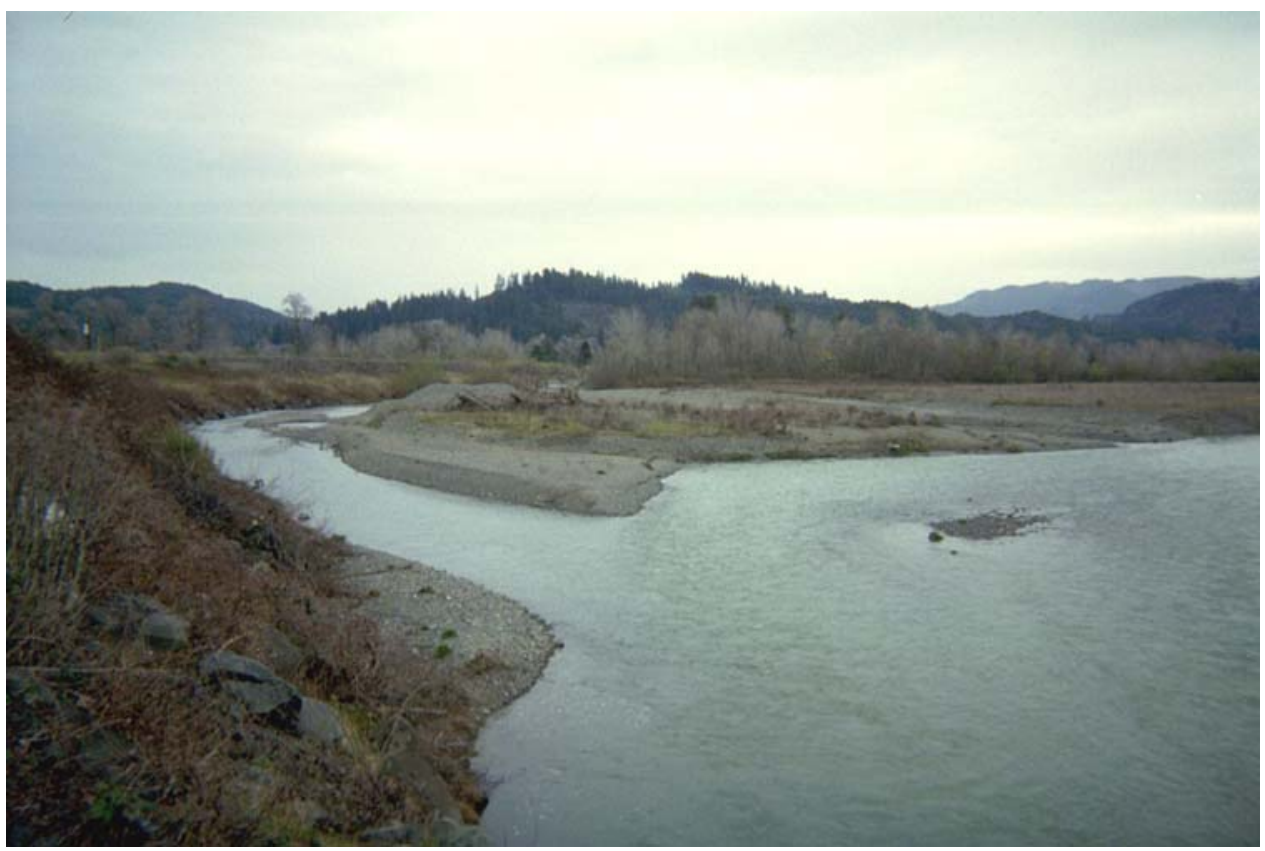

Figure D7. North Fork Mad River (right bank) - main stem confluence 


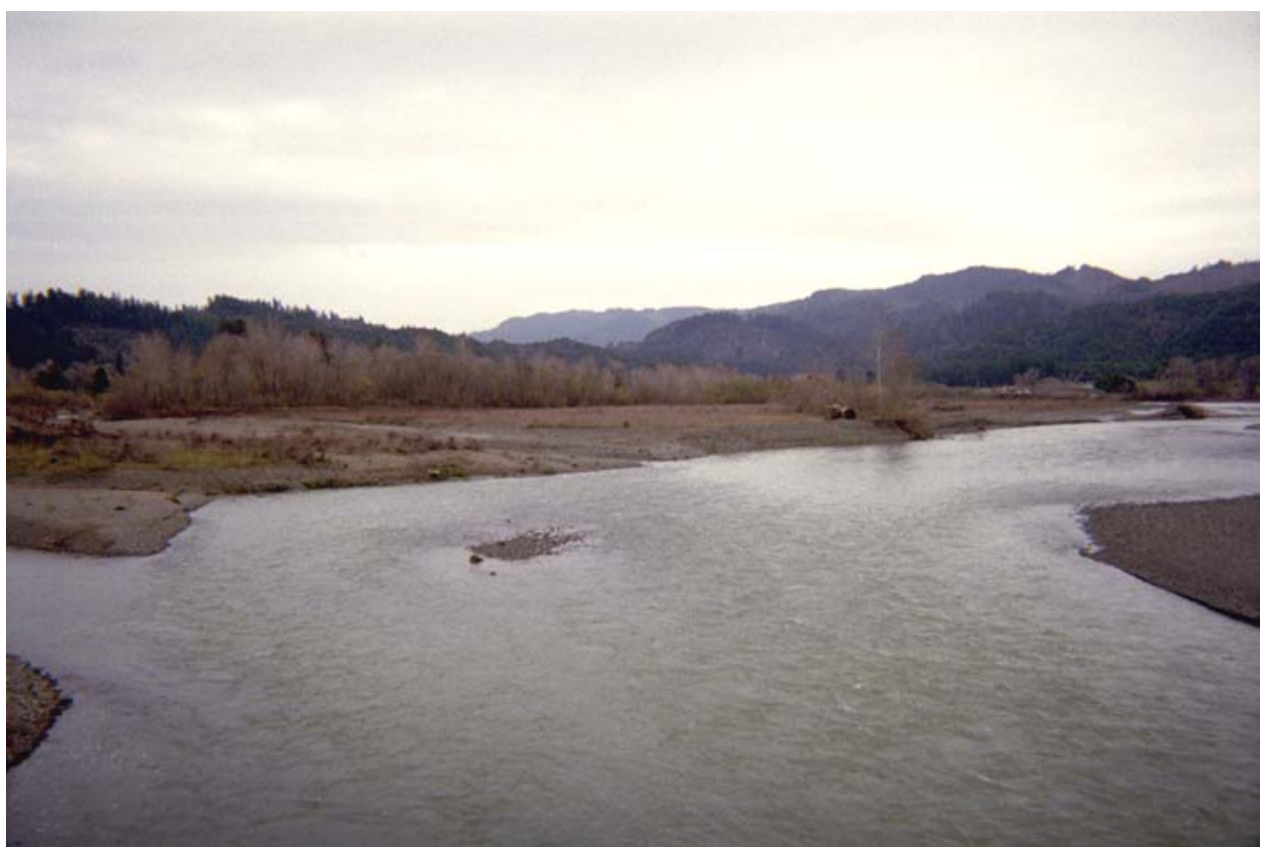

Figure D8. North Fork Mad River - main stem confluence

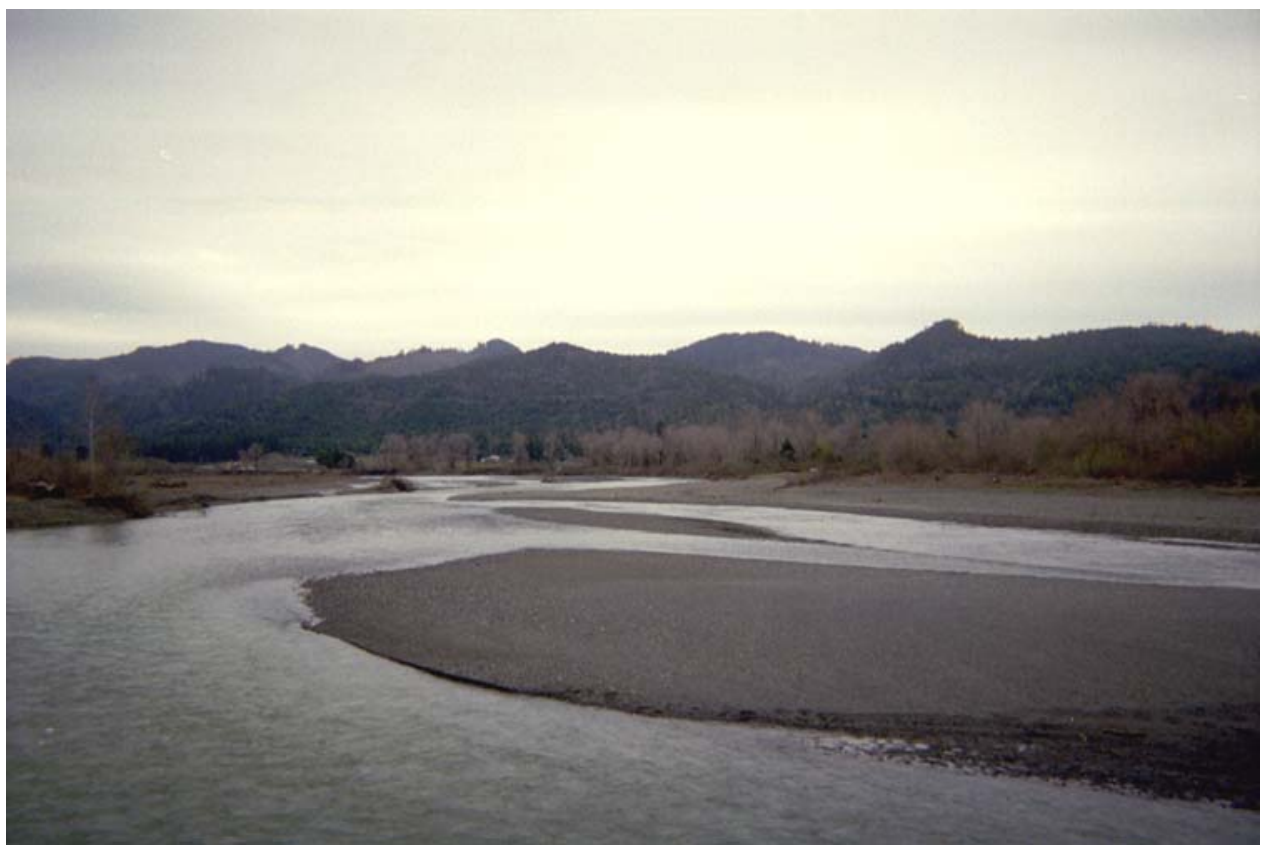

Figure D9. North Fork Mad River (left bank) - main stem confluence 


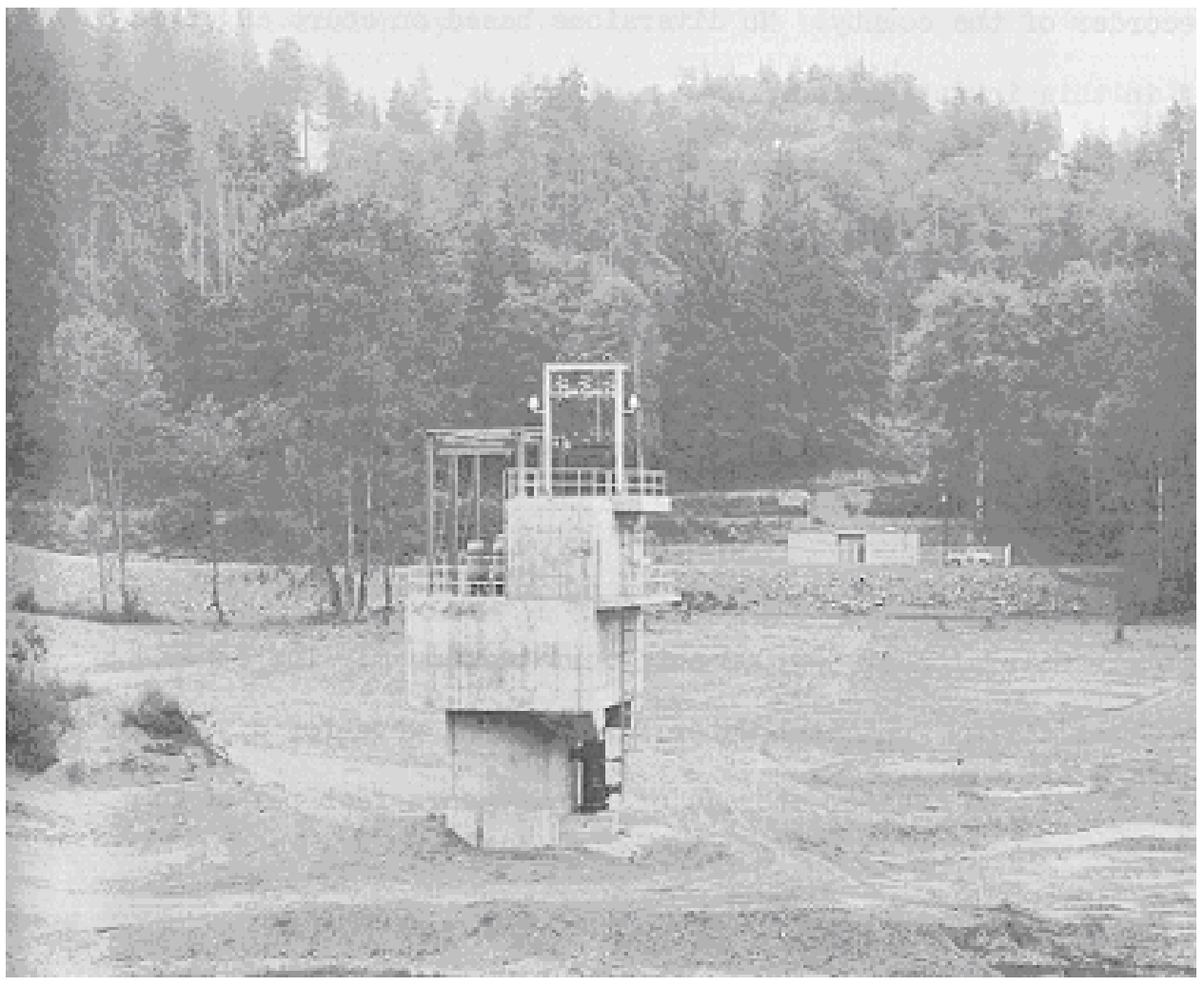

Figure D10. Raney collector near HBMWD operations building, circa 1965

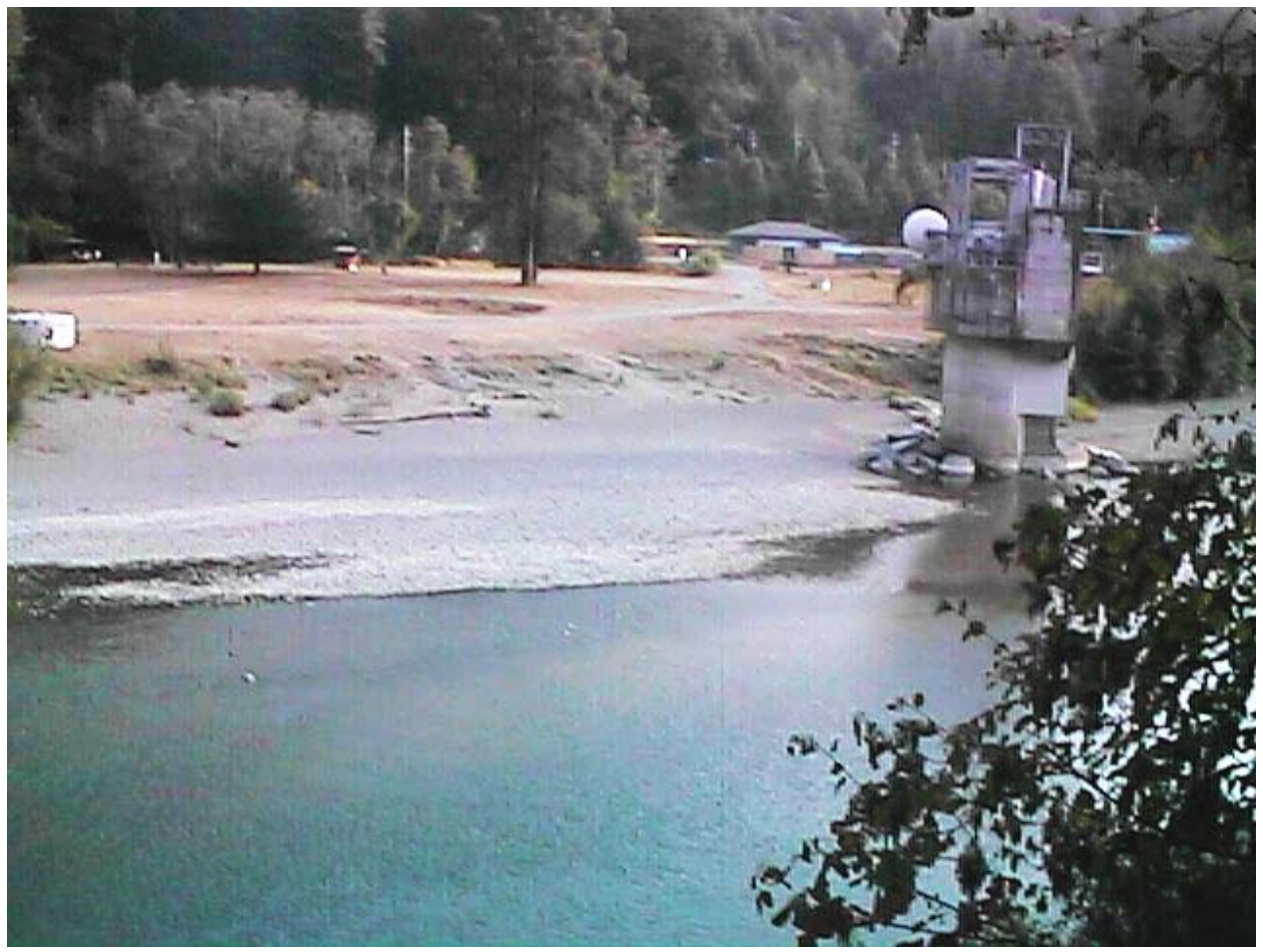

Figure D11. Raney collector near HBMWD operations building, Sept. 17, 1999 


\section{Appendix E Bed-Load Data}

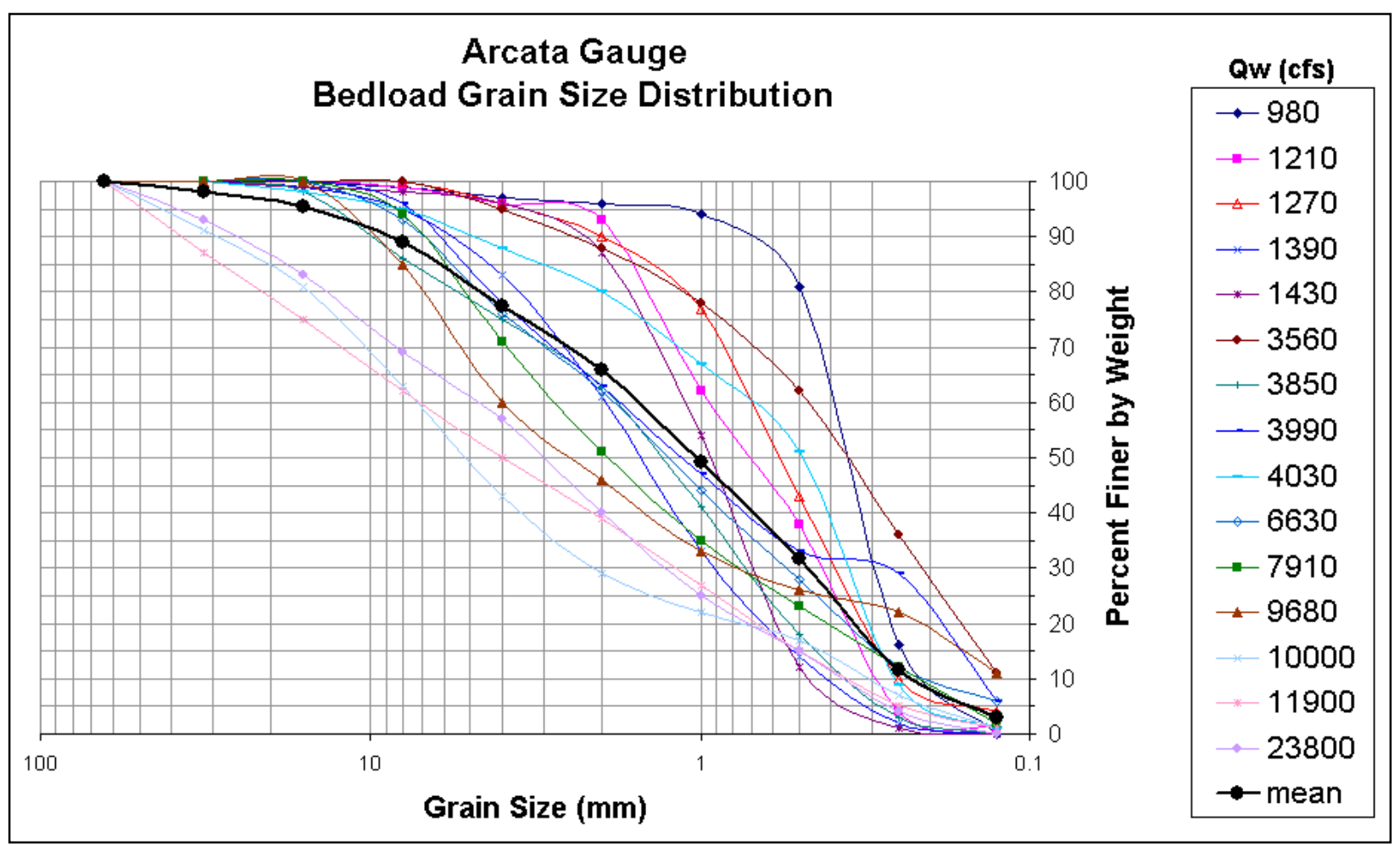

Figure E1. Arcata gauge bed-load grain-size distributions 


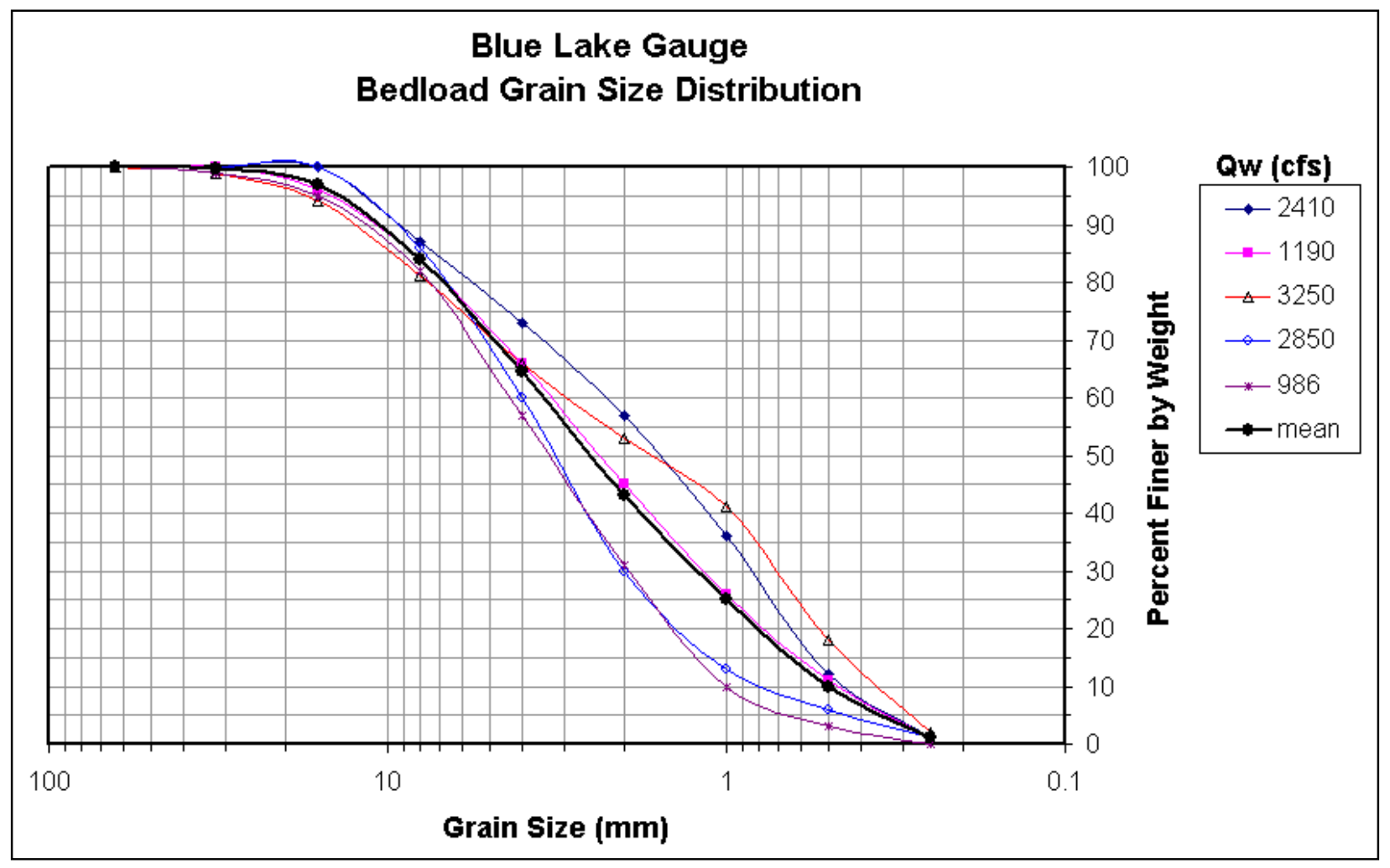

Figure E2. Blue Lake gauge bed-load grain-size distributions 


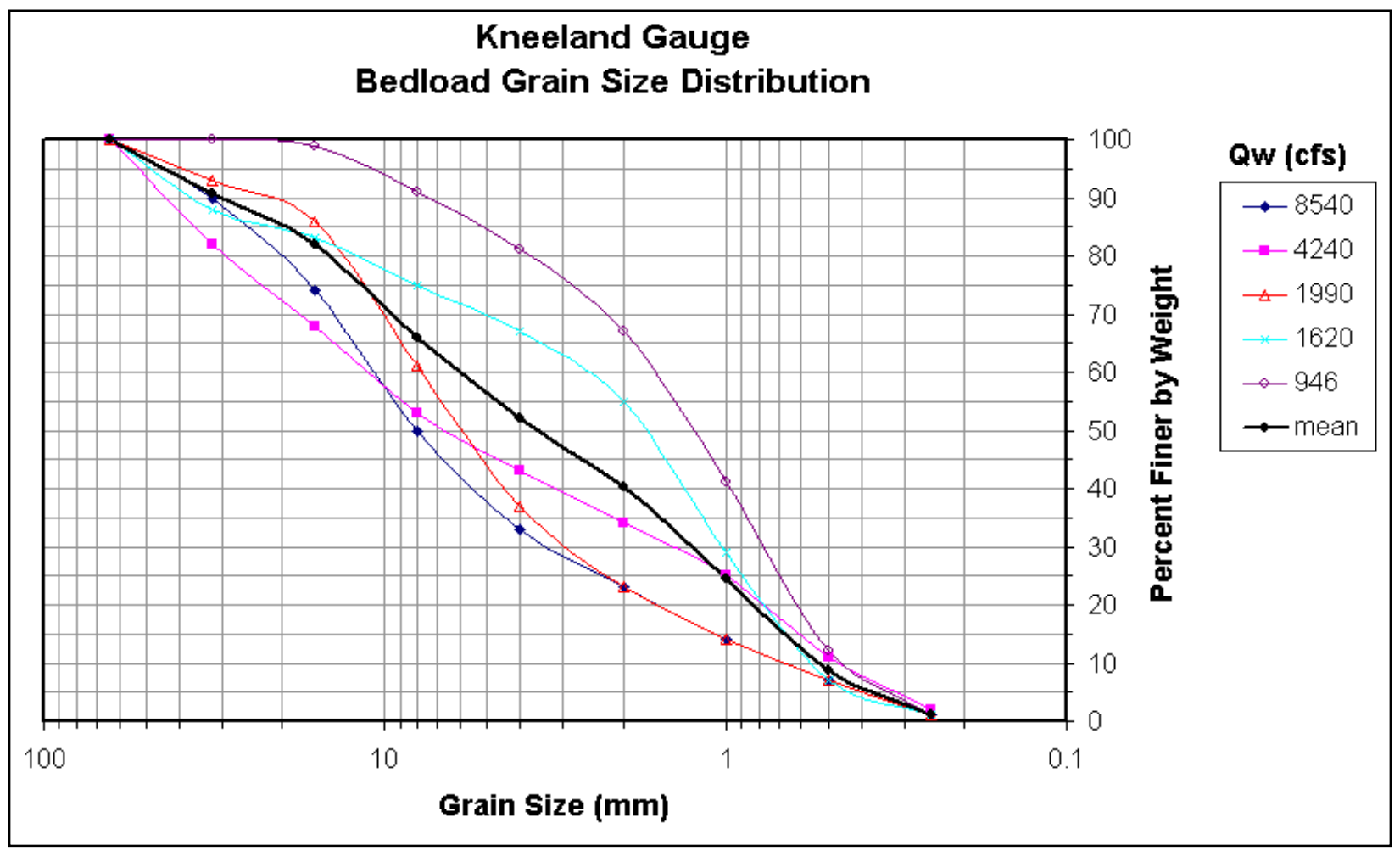

Figure E3. Kneeland gauge bed load grain-size distributions

\begin{tabular}{|c|c|c|c|c|c|c|c|c|c|c|c|}
\hline $\begin{array}{l}\text { Table E1 } \\
\text { USGS Be } \\
\text { Blue Lak }\end{array}$ & $\begin{array}{l}\text { ed-Loac } \\
\text { e, and }\end{array}$ & $\begin{array}{l}\text { d Data } \\
\text { Korbel }\end{array}$ & Collecte & US & St & am Gaı & Lo & ons & Arca & 8 & nd, \\
\hline Arcata (\#114 & 181000) & & Kneeland (\# & 1148075 & & Blue Lake ( & \#1148078 & & Korbel (\# & 1480800 & \\
\hline Date & $\begin{array}{l}\text { Qw } \\
\text { (cfs) }\end{array}$ & $\begin{array}{l}\text { Qs } \\
\text { (t/day) }\end{array}$ & Date & $\begin{array}{l}\text { Qw } \\
\text { (cfs) }\end{array}$ & \begin{tabular}{|l} 
Qs \\
(t/day)
\end{tabular} & Date & $\begin{array}{l}\text { Qw } \\
\text { (cfs) }\end{array}$ & $\begin{array}{l}\text { Qs } \\
\text { (t/day) }\end{array}$ & Date & $\begin{array}{l}\text { Qw } \\
\text { (cfs) }\end{array}$ & $\begin{array}{l}\text { Qs } \\
\text { (t/day) }\end{array}$ \\
\hline 12/28/1972 & 1,390 & 291 & $12 / 14 / 2000$ & 262 & 0 & $12 / 13 / 1972$ & 350 & 0 & $1 / 23 / 1973$ & 211 & 1.2 \\
\hline \begin{tabular}{|l|}
$1 / 21 / 1972$ \\
\end{tabular} & 23,800 & 1,870 & $1 / 18 / 1973$ & 8,540 & 3,860 & $12 / 20 / 1972$ & 2,410 & 2,680 & \begin{tabular}{|l|}
$2 / 23 / 1973$ \\
\end{tabular} & 70 & 0 \\
\hline \begin{tabular}{|l|}
$1 / 24 / 1972$ \\
\end{tabular} & 10,000 & 451 & $2 / 26 / 1973$ & 4,240 & 1,140 & $2 / 21 / 1973$ & 1,190 & 460 & & & \\
\hline 3/4/1972 & 11,900 & 990 & $3 / 20 / 1973$ & 1,990 & 512 & $2 / 28 / 1973$ & 3,250 & 988 & & & \\
\hline $4 / 25 / 1972$ & 1,210 & 34 & 4/3/1973 & 1,620 & 85 & $3 / 20 / 1973$ & 2,850 & 1,520 & & & \\
\hline \begin{tabular}{|l|}
$2 / 20 / 1973$ \\
\end{tabular} & 1,430 & 330 & $4 / 11 / 1973$ & 946 & 21 & \begin{tabular}{|l|}
$4 / 10 / 1973$ \\
\end{tabular} & 986 & 994 & & & \\
\hline 3/1/1973 & 3,850 & 753 & & & & & & & & & \\
\hline 3/20/1973 & 4,030 & 246 & & & & & & & & & \\
\hline $4 / 12 / 1973$ & 980 & 5.8 & & & & & & & & & \\
\hline $11 / 20 / 1973$ & 6,630 & 4,150 & & & & & & & & & \\
\hline \begin{tabular}{|l|}
$12 / 19 / 1973$ \\
\end{tabular} & 3,990 & 2,920 & & & & & & & & & \\
\hline \begin{tabular}{|l|}
$1 / 30 / 1974$ \\
\end{tabular} & 1,270 & 70 & & & & & & & & & \\
\hline $2 / 19 / 1974$ & 9,680 & 2,270 & & & & & & & & & \\
\hline \begin{tabular}{|l|}
$3 / 5 / 1974$ \\
\end{tabular} & 3,560 & 919 & & & & & & & & & \\
\hline $4 / 3 / 1974$ & 7,910 & 10,000 & & & & & & & & & \\
\hline \begin{tabular}{|l|}
$5 / 9 / 1974$ \\
\end{tabular} & 304 & 0 & & & & & & & & & \\
\hline
\end{tabular}




\begin{tabular}{|c|c|c|c|c|c|c|c|c|c|c|c|c|c|c|c|}
\hline \multicolumn{16}{|c|}{$\begin{array}{l}\text { Table E2 } \\
\text { Arcata Gauge Bed-Load Sieve Analysis Results }\end{array}$} \\
\hline \multicolumn{16}{|c|}{$\begin{array}{l}\text { Arcata Gauge - } 11481000 \\
\text { Mad River at Arcata - percent finer by weight values }\end{array}$} \\
\hline Date & $\begin{array}{l}4 / 12 \\
1973\end{array}$ & $\begin{array}{l}4 / 25 \\
1972\end{array}$ & $\begin{array}{l}1 / 30 \\
1974\end{array}$ & \begin{tabular}{l|l}
$12 / 28$ \\
1971
\end{tabular} & $\begin{array}{l}2 / 20 \\
1973\end{array}$ & $\begin{array}{ll}3 / 5 \\
1974\end{array}$ & $\begin{array}{l}3 / 1 \\
1973\end{array}$ & $\begin{array}{l}12 / 19 \\
1973\end{array}$ & $\begin{array}{l}3 / 20 \\
1973\end{array}$ & $\begin{array}{l}11 / 20 \\
1973\end{array}$ & $\begin{array}{l}4 / 3 \\
1974\end{array}$ & $\begin{array}{l}2 / 19 \\
1974\end{array}$ & $\begin{array}{l}1 / 24 \\
1972\end{array}$ & $\begin{array}{l}3 / 4 \\
1972\end{array}$ & $\begin{array}{l}1 / 21 \\
1972\end{array}$ \\
\hline Flow (cfs) & 980 & 1,210 & 1,270 & 1,390 & 1,430 & 3,560 & 3,850 & 3,990 & 4,030 & 6,630 & 7,910 & 9,680 & 10,000 & 11,900 & 23,800 \\
\hline $\begin{array}{l}\text { Number } \\
\text { of } \\
\text { Samples }\end{array}$ & 4 & 5 & 5 & 5 & 5 & 7 & 7 & 7 & 5 & 5 & 7 & 5 & 5 & 5 & 5 \\
\hline $\begin{array}{l}\text { Qs } \\
\text { (tons/day) }\end{array}$ & 5.8 & 34 & 70 & 291 & 330 & 919 & 753 & 2920 & 246 & 4150 & 10000 & 2270 & 451 & 990 & 1870 \\
\hline \multicolumn{16}{|c|}{ Grain size (mm) } \\
\hline 0.125 & 0 & 1 & 4 & 0 & 0 & 11 & 0 & 6 & 1 & 6 & 2 & 11 & 1 & 1 & 0 \\
\hline 0.25 & 16 & 4 & 10 & 2 & 1 & 36 & 3 & 29 & 9 & 12 & 12 & 22 & 7 & 5 & 4 \\
\hline 0.5 & 81 & 38 & 43 & 14 & 12 & 62 & 18 & 33 & 51 & 28 & 23 & 26 & 17 & 15 & 15 \\
\hline 1 & 94 & 62 & 77 & 33 & 54 & 78 & 41 & 47 & 67 & 44 & 35 & 33 & 22 & 27 & 25 \\
\hline 2 & 96 & 93 & 90 & 61 & 87 & 88 & 63 & 63 & 80 & 62 & 51 & 46 & 29 & 39 & 40 \\
\hline 4 & 97 & 96 & 96 & 83 & 96 & 95 & 75 & 78 & 88 & 76 & 71 & 60 & 43 & 50 & 57 \\
\hline 8 & 99 & 99 & 100 & 95 & 98 & 100 & 86 & 96 & 95 & 93 & 94 & 85 & 63 & 62 & 69 \\
\hline 16 & 100 & 100 & 100 & 99 & 99 & 100 & 98 & 100 & 98 & 100 & 100 & 100 & 81 & 75 & 83 \\
\hline 32 & 100 & 100 & 100 & 100 & 100 & 100 & 100 & 100 & 100 & 100 & 100 & 100 & 91 & 87 & 93 \\
\hline 64 & 100 & 100 & 100 & 100 & 100 & 100 & 100 & 100 & 100 & 100 & 100 & 100 & 100 & 100 & 100 \\
\hline
\end{tabular}

\begin{tabular}{|c|c|c|c|c|c|}
\hline \multicolumn{6}{|c|}{$\begin{array}{l}\text { Table E3 } \\
\text { Blue Lake Gauge Bed }\end{array}$} \\
\hline \multicolumn{6}{|c|}{ Blue Lake Gauge - 11480780} \\
\hline Date & 20-Dec-72 & 21-Feb-73 & 28-Feb-73 & 20-Mar-73 & 10-Apr-73 \\
\hline Flow (cfs) & 2,410 & 1,190 & 3,250 & 2,850 & 986 \\
\hline Stream Width (w, ft) & 278 & 190 & 345 & 322 & 195 \\
\hline Number of samples & 5 & 5 & 5 & 5 & 5 \\
\hline Qs (tons/day) & 2,680 & 460 & 988 & 1,520 & 994 \\
\hline Grain Size (mm) & 2,410 & 1,190 & 3,250 & 2,850 & 986 \\
\hline 0.25 & 1 & 1 & 2 & 1 & 0 \\
\hline 0.5 & 12 & 11 & 18 & 6 & 3 \\
\hline 1 & 36 & 26 & 41 & 13 & 10 \\
\hline 2 & 57 & 45 & 53 & 30 & 31 \\
\hline 4 & 73 & 66 & 66 & 60 & 57 \\
\hline 8 & 87 & 84 & 81 & 86 & 82 \\
\hline 16 & 100 & 96 & 94 & 100 & 95 \\
\hline 32 & 100 & 100 & 99 & 100 & 99 \\
\hline 64 & 100 & 100 & 100 & 100 & 100 \\
\hline
\end{tabular}




\begin{tabular}{|c|c|c|c|c|c|}
\hline \multicolumn{6}{|c|}{$\begin{array}{l}\text { Table E4 } \\
\text { Kneeland Gauge Bed }\end{array}$} \\
\hline \multicolumn{6}{|c|}{ Kneeland Gauge - 11480750} \\
\hline Date & 18-Jan-73 & 26-Feb-73 & 20-Mar-73 & 3-Apr-73 & 11-Apr-73 \\
\hline Flow (cfs) & 8,540 & 4240 & 1,990 & 1,620 & 946 \\
\hline Stream Width (w, ft) & 147 & 133 & 129 & 116 & 167 \\
\hline Number of samples & 5 & 5 & 5 & 5 & 5 \\
\hline Qs (tons/day) & 3,860 & 1,140 & 512 & 65 & 21 \\
\hline Grain Size $(\mathrm{mm})$ & 8,540 & 4,240 & 1,990 & 1,620 & 946 \\
\hline 0.25 & 1 & 2 & 1 & 1 & 1 \\
\hline 0.5 & 7 & 11 & 7 & 7 & 12 \\
\hline 1 & 14 & 25 & 14 & 29 & 41 \\
\hline 2 & 23 & 34 & 23 & 55 & 67 \\
\hline 4 & 33 & 43 & 37 & 67 & 81 \\
\hline 8 & 50 & 53 & 61 & 75 & 91 \\
\hline 16 & 74 & 68 & 86 & 83 & 99 \\
\hline 32 & 90 & 82 & 93 & 88 & 100 \\
\hline 64 & 100 & 100 & 100 & 100 & 100 \\
\hline
\end{tabular}




\section{Appendix $F$ Bed-Material Data}

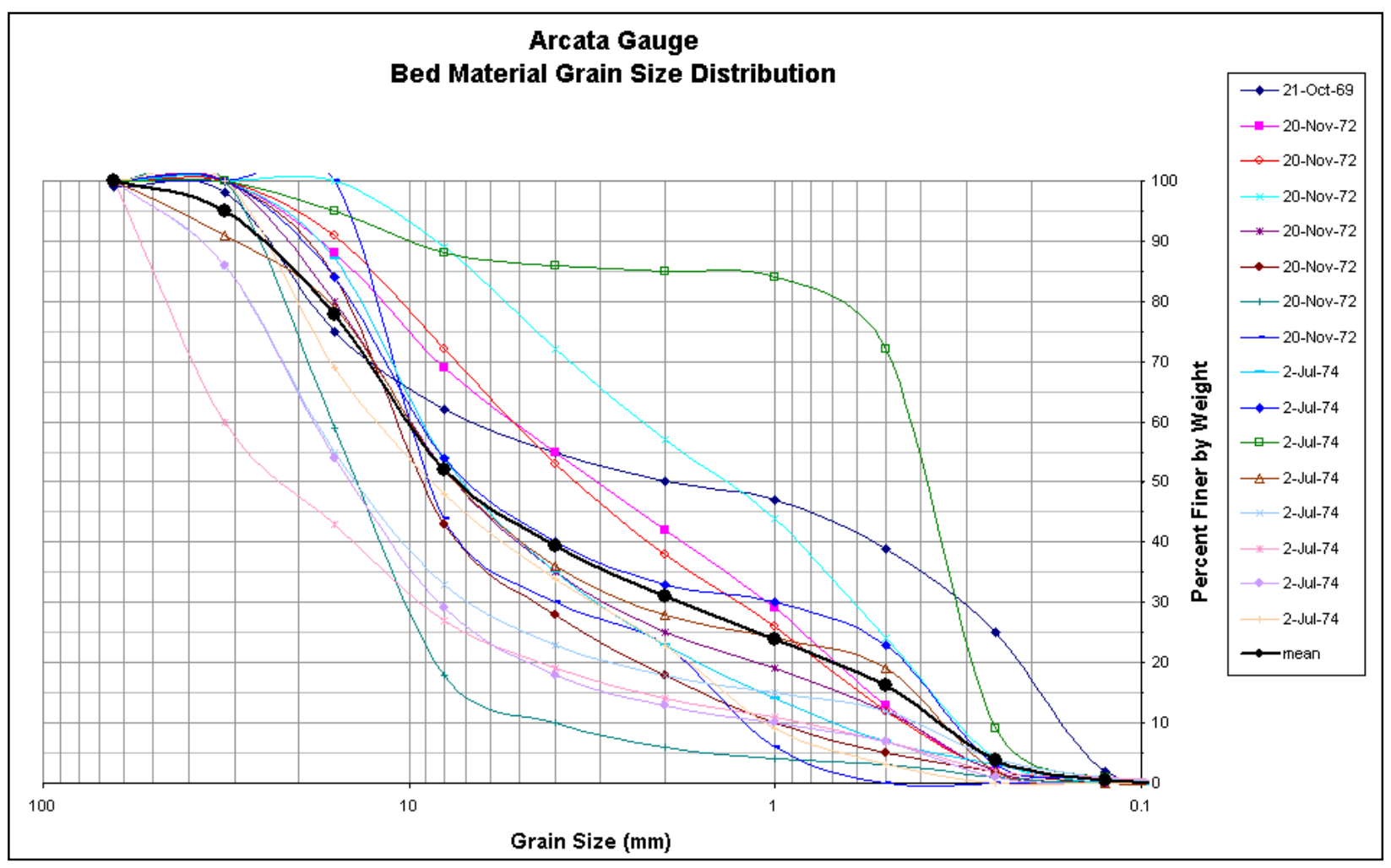

Figure F1. Arcata gauge bed-material grain-size distributions 


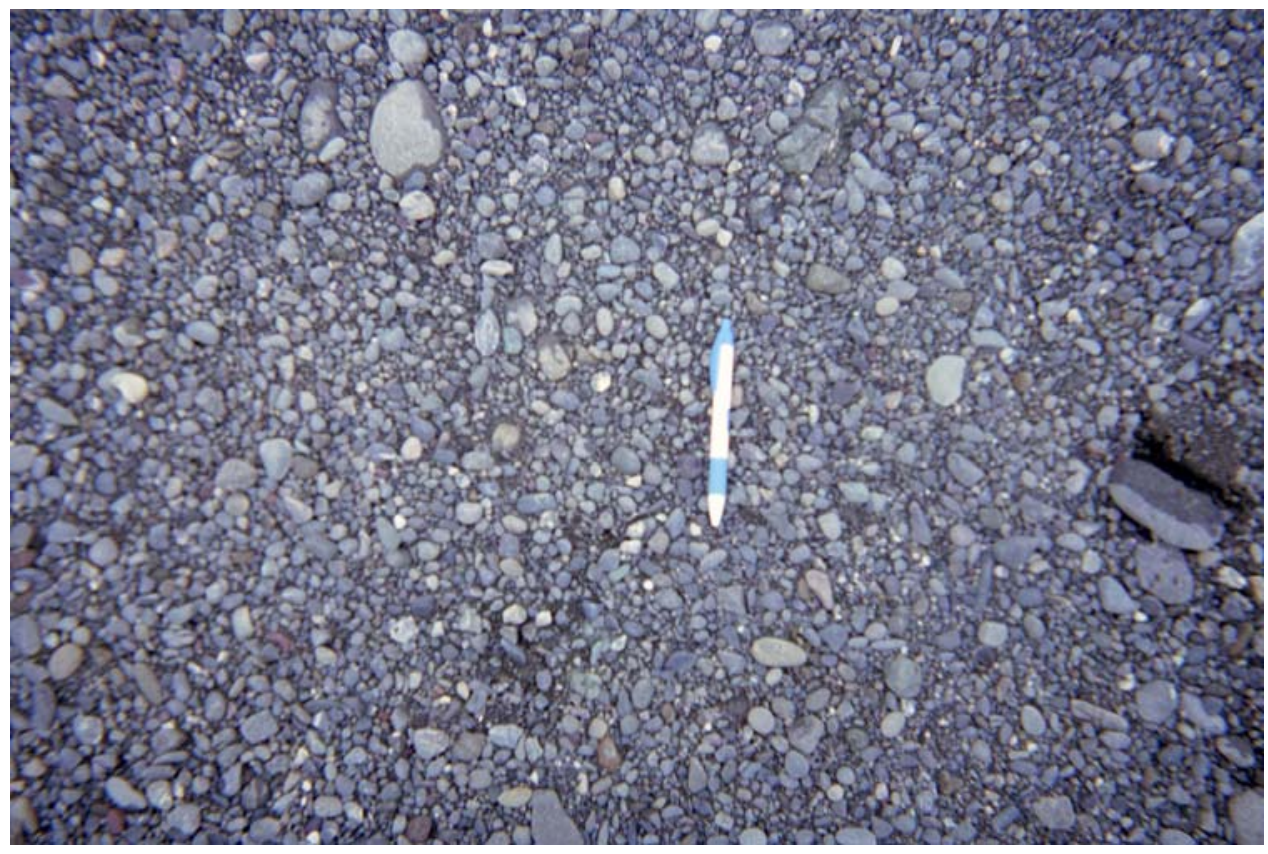

Figure F2. Bed material at surface in mining area, cross section 27 (right side)

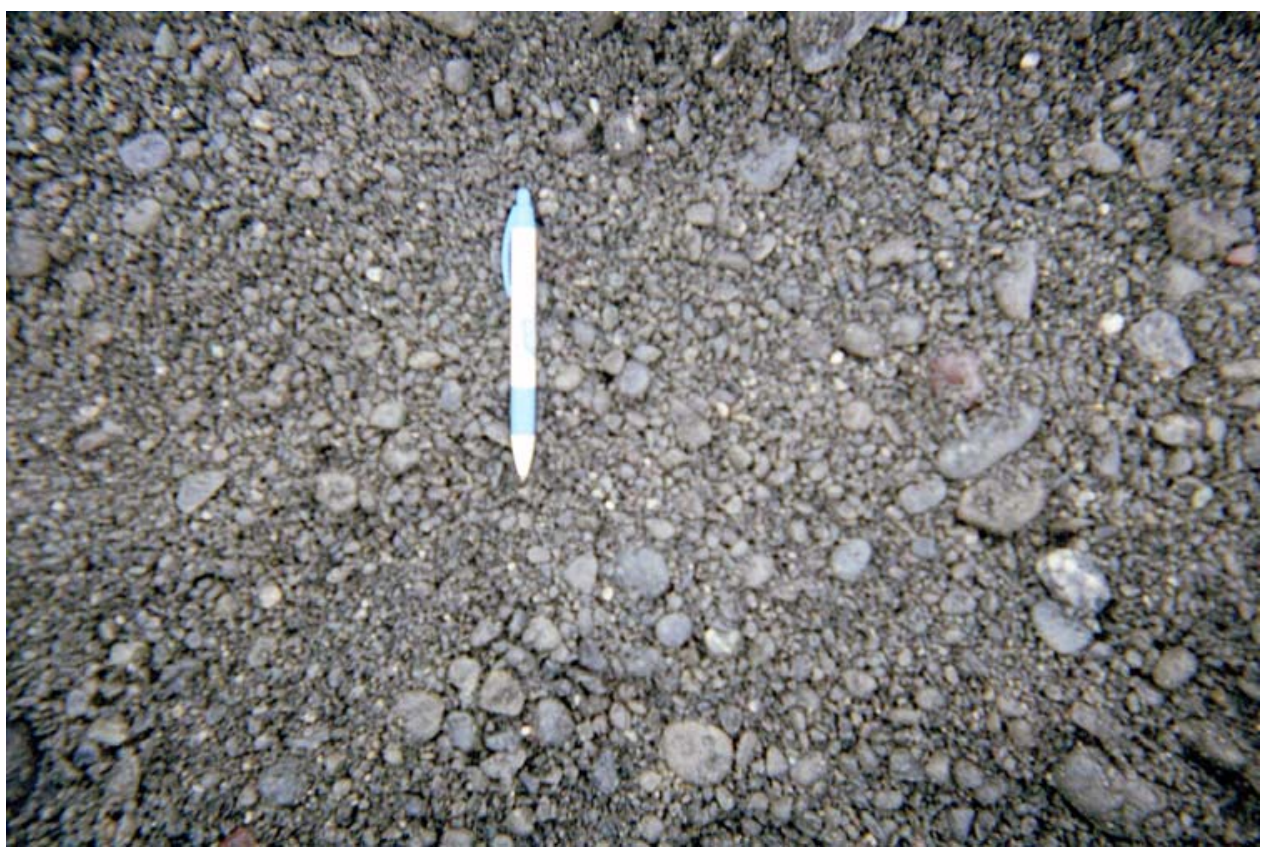

Figure F3. Bed material $1 \mathrm{ft}$ below ground surface, cross section 27 (right side) 


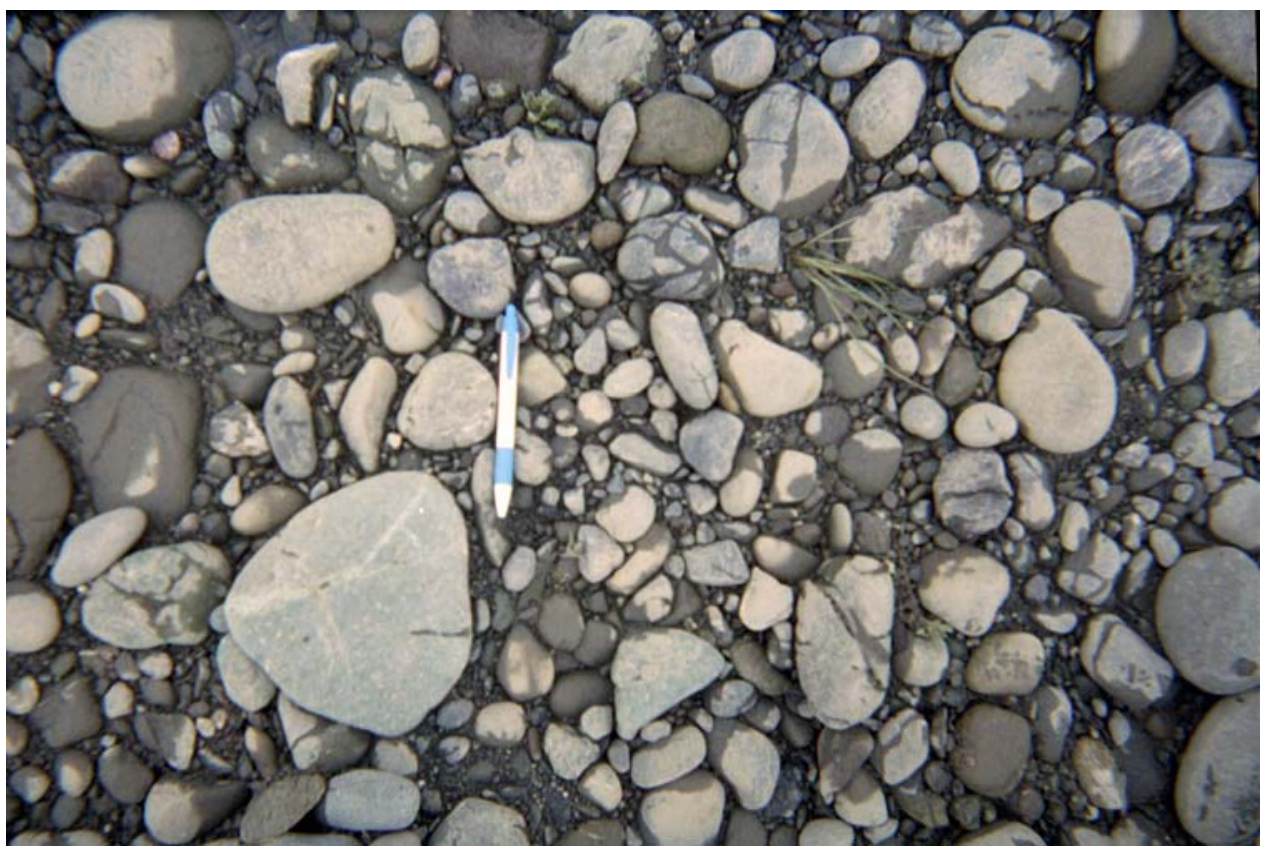

Figure F4. Bed material at surface, not in mining area, cross section 27 (right side)

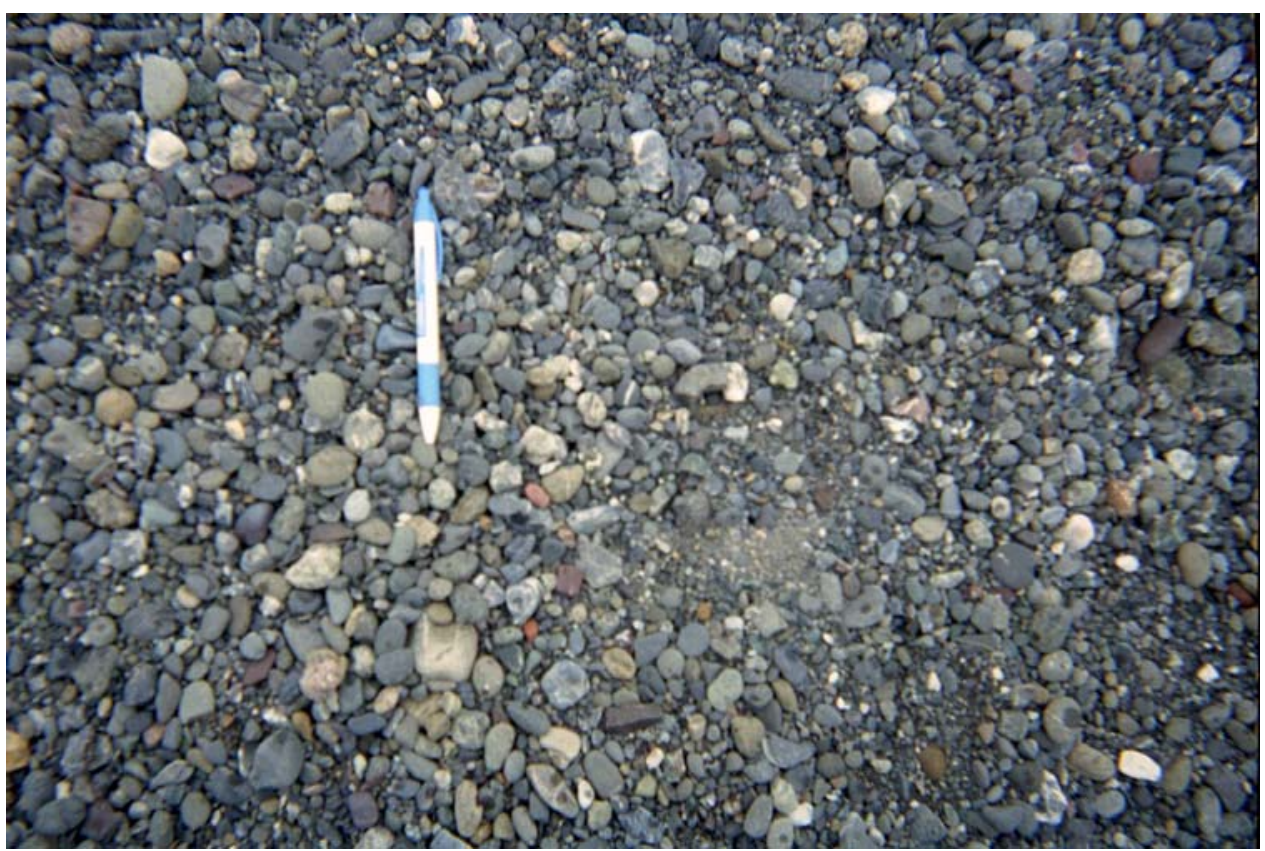

Figure F5. Bed material at surface, cross section 23 (right side) 


\begin{tabular}{|c|c|c|c|c|c|c|c|c|c|c|c|}
\hline \multicolumn{12}{|c|}{$\begin{array}{l}\text { Table F1 } \\
\text { USGS Bed-Material Data, Mad River at Arcata (collected adjacent to USGS stream } \\
\text { gauge) }\end{array}$} \\
\hline Date & \begin{tabular}{|l|} 
Sieve- \\
0.062 \\
\end{tabular} & \begin{tabular}{|l|} 
Sieve- \\
0.125 \\
\end{tabular} & \begin{tabular}{|l} 
Sieve- \\
0.25 \\
\end{tabular} & \begin{tabular}{|l|} 
Sieve- \\
0.5 \\
\end{tabular} & \begin{tabular}{|l} 
Sieve- \\
1
\end{tabular} & \begin{tabular}{|l} 
Sieve- \\
2 \\
\end{tabular} & \begin{tabular}{|l} 
Sieve- \\
4 \\
\end{tabular} & \begin{tabular}{|l|} 
Sieve- \\
8
\end{tabular} & \begin{tabular}{|l} 
Sieve- \\
16 \\
\end{tabular} & $\begin{array}{l}\text { Sieve- } \\
32\end{array}$ & $\begin{array}{l}\text { Sieve- } \\
64\end{array}$ \\
\hline $210 c t 69$ & 1 & 2 & 25 & 39 & 47 & 50 & 55 & 62 & 75 & 98 & 99 \\
\hline 20 Nov72 & 0 & 0 & 2 & 13 & 29 & 42 & 55 & 69 & 88 & 100 & 100 \\
\hline 20 Nov72 & 0 & 0 & 2 & 12 & 26 & 38 & 53 & 72 & 91 & 100 & 100 \\
\hline 20Nov72 & 0 & 0 & 4 & 24 & 44 & 57 & 72 & 89 & 100 & 100 & 100 \\
\hline 20 Nov72 & 0 & 0 & 2 & 12 & 19 & 25 & 35 & 52 & 80 & 100 & 100 \\
\hline 20 Nov72 & 0 & 0 & 2 & 5 & 10 & 18 & 28 & 43 & 84 & 100 & 100 \\
\hline 20 Nov72 & 0 & 0 & 1 & 3 & 4 & 6 & 10 & 18 & 59 & 100 & 100 \\
\hline 20 Nov 72 & 0 & 0 & 0 & 0 & 6 & 23 & 30 & 44 & 100 & 100 & 100 \\
\hline 2Jul74 & 0 & 0 & 3 & 7 & 14 & 23 & 35 & 54 & 87 & 100 & 100 \\
\hline 2Jul74 & 0 & 1 & 3 & 23 & 30 & 33 & 40 & 54 & 84 & 100 & 100 \\
\hline 2Jul74 & 0 & 1 & 9 & 72 & 84 & 85 & 86 & 88 & 95 & 100 & 100 \\
\hline 2Jul74 & 0 & 0 & 2 & 19 & 24 & 28 & 36 & 52 & 79 & 91 & 100 \\
\hline 2Jul74 & 0 & 1 & 4 & 12 & 15 & 18 & 23 & 33 & 55 & 86 & 100 \\
\hline 2Jul74 & 0 & 1 & 2 & 7 & 11 & 14 & 19 & 27 & 43 & 60 & 100 \\
\hline 2Jul74 & 0 & 0 & 1 & 7 & 10 & 13 & 18 & 29 & 54 & 86 & 100 \\
\hline 2Jul74 & 0 & 0 & 0 & 3 & 9 & 23 & 34 & 48 & 69 & 100 & 100 \\
\hline mean & 0.06 & 0.38 & 3.88 & 16.13 & 23.88 & 31 & 39.31 & 52.13 & 77.69 & 95.06 & 99.94 \\
\hline
\end{tabular}

\begin{tabular}{|c|c|c|}
\hline $\begin{array}{l}\text { Table F2 } \\
\text { Lehre B }\end{array}$ & ta, Mad & ry (near \\
\hline & 22-Oct-89 & 22-Oct-89 \\
\hline$Q$ (cfs) & 140 & 140 \\
\hline $\mathrm{D} 90(\mathrm{~mm})$ & 25.38 & 40.51 \\
\hline $\mathrm{D} 84(\mathrm{~mm})$ & 22.85 & 31.15 \\
\hline $\mathrm{D} 65(\mathrm{~mm})$ & 16.27 & 18.84 \\
\hline $\mathrm{D} 50(\mathrm{~mm})$ & 12.87 & 9.51 \\
\hline D35 (mm) & 8.59 & 5.78 \\
\hline
\end{tabular}




\section{Appendix G Historic Gravel Extraction Volumes}

The total volume ${ }^{1}$ of gravel extracted from the study area of the Mad River (between the mouth and the Blue Lake hatchery) is difficult to determine. Conversations with the State of California (Division of Mines, Office of Mine Reclamation) indicated that Mr. Randy Klein, a member of CHERT, had compiled the most accurate summary of gravel mining extraction volumes for the Mad River. After presenting this data at a public meeting in Eureka in 2002, Mr. Rob McLaughlin, of Eureka ReadyMix, stated that he thought there was additional information that was available and that was not included in the data compiled by Randy Klein. On behalf of Rob McLaughlin, Pacific Affiliates provided the additional gravel mining extraction volumes included in this appendix. ${ }^{2}$ Randy Klein reviewed this data and commented that the two differences were for gravel mined by the HBMWD and by REA. Because Randy Klein received his data for these two groups from their Director (Art Bolli, former Director of HBMWD) and owner (Bob King of REA), respectively, he stated that he felt more comfortable with his original data. Upon reviewing both sets of data, it appears that the values provided by Pacific Affiliates for gravel extracted upstream of Highway 299 by HBMWD and REA may be estimates instead of actual extraction values. Without further review, it is not possible to determine which set of extraction values is most accurate. The values provided by Randy Klein, however, have been reviewed by the State of California and were provided to him by the people who should have the best knowledge of extraction volumes by HBMWD and REA. For this study, it was most appropriate to use the extraction volumes provided by Randy Klein. It should be noted that the values provided by Pacific Affiliates do not significantly change the results of this study but would be slightly less favorable to the desires of the gravel mining industry in Humboldt County.

\footnotetext{
${ }^{1}$ All volumes are given in cubic yards.

2 Pacific Affiliates. (2002). Letter to U.S. Army Corps of Engineers describing reasons for updating the Mad River historic gravel mining extraction volumes compiled by Mr. Randy Klein.
} 
The following notes and explanation of abbreviations accompanied the data compiled and provided by Randy Klein:

- $\quad$ REA - Redwood Empire Aggregates

- $\mathrm{ERM} / \mathrm{CHR}$ - Eureka ReadyMix (later mining) and Christie Ranch (earlier mining)

- MRS\&G - Mad River Sand and Gravel

- MFC - Mercer Fraser Co.

- STC - Simpson Timber Co.

- HUMCO - Humboldt County Public Works Department

- HBMWD - Humboldt Bay Municipal Water District

- ARM - Arcata Readimix

- HOOKER - predecessor to REA (also known as ABS)

Series of the same round number indicate approximate volumes estimated by the specific data providers.

\begin{tabular}{|c|c|c|c|c|c|c|c|c|}
\hline \multicolumn{9}{|c|}{$\begin{array}{l}\text { Table G1 } \\
\text { Gravel-Extraction Volumes Upstream of Highway } 299\end{array}$} \\
\hline Year & REA & ERM/CHR & MRS\&G & MFC & STC & HUMCO & HBMWD & YearTotal \\
\hline 1971 & 0 & 30,000 & 85,000 & 1000,000 & 30,000 & 1515,000 & 0 & 260,000 \\
\hline 1972 & 0 & 30,000 & 85,000 & 100,000 & 30,000 & 15,000 & 0 & 260,000 \\
\hline 1973 & 0 & 42,620 & 85,000 & 100,000 & 30,000 & 15,000 & 0 & 272,620 \\
\hline 1974 & 0 & 35,870 & 85,000 & 100,000 & 30,000 & 15,000 & 0 & 265,870 \\
\hline 1975 & 0 & 30,000 & 85,000 & 100,000 & 30,000 & 15,000 & 0 & 260,000 \\
\hline 1976 & 0 & 80,000 & 85,000 & 100,000 & 30,000 & 15,000 & 0 & 310,000 \\
\hline 1977 & 0 & 50,000 & 87,900 & 100,000 & 30,000 & 15,000 & 0 & 282,900 \\
\hline $\begin{array}{l}1978 \\
\end{array}$ & 0 & 50,000 & 87,900 & 100,000 & 30,000 & 15,000 & 0 & 282,900 \\
\hline 1979 & 0 & 74,900 & 87,900 & 1,000 & 30,000 & 15,000 & 0 & 208,800 \\
\hline 1980 & 0 & 70,000 & 78,400 & 1,000 & 30,000 & 15,000 & 0 & 194,400 \\
\hline 1981 & 0 & 50,000 & 55,000 & 1,000 & 30,000 & 15,000 & 0 & 151,000 \\
\hline 1982 & 0 & 50,000 & 31,900 & 1,000 & 40,454 & 15,000 & 0 & 138,354 \\
\hline 1983 & 0 & 50,000 & 23,000 & 1,000 & 9,400 & 15,000 & 0 & 98,400 \\
\hline 1984 & 0 & 50,000 & 15,200 & 1,000 & 20,707 & 15,000 & 0 & 101,907 \\
\hline 1985 & 113,448 & 50,000 & 50,000 & 1,000 & 2,400 & 15,000 & 0 & 231,848 \\
\hline 1986 & 56,228 & 50,000 & 50,000 & 1,000 & 0 & 15,000 & 0 & 172,228 \\
\hline 1987 & 63,668 & 50,000 & 50,000 & 1,000 & 25,368 & 15,000 & 0 & 205,036 \\
\hline 1988 & 40,537 & 50,000 & 50,000 & 1,000 & 600 & 25,000 & 0 & 167,137 \\
\hline 1989 & 74,195 & 50,000 & 50,000 & 1,000 & 0 & 15,000 & 0 & 190,195 \\
\hline 1990 & 49,204 & 50,000 & 50,000 & 1,000 & 62,298 & 15,000 & 0 & 227,502 \\
\hline 1991 & 95,509 & 50,000 & 50,000 & 1,000 & 0 & 15,000 & 0 & 211,509 \\
\hline 1992 & 71,617 & 39,000 & 42,000 & 0 & 0 & 0 & 0 & 152,617 \\
\hline 1993 & 44,500 & 39,900 & 23,400 & 0 & 0 & 0 & 0 & 107,800 \\
\hline 1994 & 45,600 & 40,000 & 38,000 & 2,518 & 0 & 0 & 0 & 126,118 \\
\hline 1995 & 96,749 & 41,531 & 39,286 & 5,000 & 0 & 0 & 0 & 182,566 \\
\hline 1996 & 55,841 & 44,857 & 17,037 & 3,412 & 0 & 0 & 0 & 121,147 \\
\hline 1997 & 70,646 & 41,869 & 29,224 & 4,727 & 0 & 0 & 0 & 146,466 \\
\hline 1998 & 79,407 & 43,019 & 30,602 & 4,154 & 0 & 0 & 0 & 157,182 \\
\hline 1999 & 64,629 & 40,409 & 33,189 & 3,097 & 0 & 0 & 0 & 141,324 \\
\hline 2000 & 59,310 & 59,396 & 19,585 & 4,663 & 0 & 0 & 0 & 142,954 \\
\hline \multicolumn{8}{|c|}{ 1971-2000 Average } & 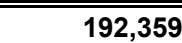 \\
\hline
\end{tabular}




\begin{tabular}{|c|c|c|c|c|}
\hline \multicolumn{5}{|c|}{$\begin{array}{l}\text { Table G2 } \\
\text { Gravel-Extraction Volumes Downstream of Highway } 299\end{array}$} \\
\hline Year & REA & ARM & HOOKER & Year Total \\
\hline 1971 & 140,385 & 50,000 & 0 & 190,385 \\
\hline 1972 & 85,000 & 50,000 & 70,000 & 205,000 \\
\hline 1973 & 31,882 & 50,000 & 36,300 & 118,182 \\
\hline 1974 & 14,413 & 72,100 & 53,200 & 139,713 \\
\hline 1975 & 21,507 & 77,100 & 63,400 & 162,007 \\
\hline 1976 & 73,016 & 48,000 & 0 & 121,016 \\
\hline 1977 & 86,625 & 18,415 & 29,400 & 134,440 \\
\hline 1978 & 49,447 & 36,013 & 66,500 & 151,960 \\
\hline 1979 & 65,908 & 30,492 & 50,000 & 146,400 \\
\hline 1980 & 58,897 & 42,998 & 44,800 & 146,695 \\
\hline 1981 & 77,627 & 34,987 & 0 & 112,614 \\
\hline 1982 & 23,389 & 16,307 & 57,300 & 96,996 \\
\hline 1983 & 50,000 & 27,826 & 0 & 77,826 \\
\hline 1984 & 78,296 & 55,616 & 0 & 133,912 \\
\hline 1985 & 17,000 & 60,780 & 0 & 77,780 \\
\hline 1986 & 28,811 & 83,147 & 0 & 111,958 \\
\hline 1987 & 17,168 & 80,101 & 0 & 97,269 \\
\hline 1988 & 36,814 & 89,302 & 0 & 126,116 \\
\hline 1989 & 10,226 & 138,863 & 0 & 149,089 \\
\hline 1990 & 35,960 & 84,941 & 0 & 120,901 \\
\hline 1991 & 0 & 56,879 & 0 & 56,879 \\
\hline 1992 & 0 & 0 & 0 & 0 \\
\hline 1993 & 0 & 14,300 & 0 & 14,300 \\
\hline 1994 & 0 & 8,780 & 0 & 8,780 \\
\hline 1995 & 0 & 43,699 & 0 & 43,699 \\
\hline 1996 & 0 & 68,370 & 0 & 68,370 \\
\hline 1997 & 0 & 64,510 & 0 & 64,510 \\
\hline 1998 & 0 & 66,170 & 0 & 66,170 \\
\hline 1999 & 0 & 33,650 & 0 & 33,650 \\
\hline 2000 & 0 & 3,580 & 0 & 3,580 \\
\hline
\end{tabular}




\begin{tabular}{|c|c|c|c|}
\hline \multicolumn{4}{|c|}{$\begin{array}{l}\text { Table G3 } \\
\text { Disputed Gravel-Extraction Volumes Upstream of Highway } 299\end{array}$} \\
\hline Year & REA & HBMWD & Year Total (including CHERT data) \\
\hline 1971 & 130,000 & 20,000 & 410,000 \\
\hline 1972 & 130,000 & 20,000 & 410,000 \\
\hline 1973 & 130,000 & 20,000 & 422,620 \\
\hline 1974 & 130,000 & 20,000 & 415,870 \\
\hline 1975 & 130,000 & 20,000 & 410,000 \\
\hline 1976 & 130,000 & & 440,000 \\
\hline 1977 & 130,000 & & 412,900 \\
\hline 1978 & 130,000 & & 412,900 \\
\hline 1979 & 130,000 & & 338,800 \\
\hline 1980 & 130,000 & & 324,400 \\
\hline 1981 & 130,000 & & 281,000 \\
\hline 1982 & 130,000 & & 268,354 \\
\hline 1983 & 130,000 & & 228,400 \\
\hline 1984 & 130,000 & & 231,907 \\
\hline 1985 & & & 231,848 \\
\hline 1986 & & & 172,228 \\
\hline 1987 & & & 205,036 \\
\hline 1988 & & & 167,137 \\
\hline 1989 & & & 190,195 \\
\hline 1990 & & & 227,502 \\
\hline 1991 & & & 211,509 \\
\hline 1992 & & & 152,617 \\
\hline 1993 & & & 107,800 \\
\hline 1994 & & & 126,118 \\
\hline 1995 & & & 182,566 \\
\hline 1996 & & & 121,147 \\
\hline 1997 & & & 146,466 \\
\hline 1998 & & & 157,182 \\
\hline 1999 & & & 141,324 \\
\hline 2000 & & & 142,954 \\
\hline \multicolumn{3}{|c|}{ 1971-2000 Average } & 256,359 \\
\hline
\end{tabular}




\begin{tabular}{|c|c|c|c|c|c|}
\hline \multicolumn{6}{|c|}{$\begin{array}{l}\text { Table G4 } \\
\text { Summary of Gravel-Mining Extraction Volumes for Entire Study } \\
\text { Area }\end{array}$} \\
\hline Year & $\begin{array}{l}\text { CHERT } \\
\text { Values for } \\
\text { Upstream of } \\
\text { Hwy } 299\end{array}$ & $\begin{array}{l}\text { CHERT Values } \\
\text { for } \\
\text { Downstream of } \\
\text { Hwy } 299\end{array}$ & $\begin{array}{l}\text { CHERT } \\
\text { Values for } \\
\text { Total in } \\
\text { Study Area }\end{array}$ & $\begin{array}{l}\text { Pacific } \\
\text { Affiliates } \\
\text { Values for } \\
\text { Upstream of } \\
\text { Hwy } 299\end{array}$ & $\begin{array}{l}\text { Pacific } \\
\text { Affiliates } \\
\text { Values for } \\
\text { Total in Study } \\
\text { Area }\end{array}$ \\
\hline 1971 & 260,000 & 190385 & 450,385 & 410,000 & 600,385 \\
\hline 1972 & 260,000 & 205000 & 465,000 & 410,000 & 615,000 \\
\hline 1973 & 272,620 & 118182 & 390,802 & 422,620 & 540,802 \\
\hline 1974 & 265,870 & 139713 & 405,583 & 415,870 & 555,583 \\
\hline 1975 & 260,000 & 162007 & 422,007 & 410,000 & 572,007 \\
\hline 1976 & 310,000 & 121016 & 431,016 & 440,000 & 561,016 \\
\hline 1977 & 282,900 & 134440 & 417,340 & 412,900 & 547,340 \\
\hline 1978 & 282,900 & 151960 & 434,860 & 412,900 & 564,860 \\
\hline 1979 & 208,800 & 146400 & 355,200 & 338,800 & 485,200 \\
\hline 1980 & 194,400 & 146695 & 341,095 & 324,400 & 471,095 \\
\hline 1981 & 151,000 & 112614 & 263,614 & 281,000 & 393,614 \\
\hline 1982 & 138,354 & 96996 & 235,350 & 268,354 & 365,350 \\
\hline 1983 & 98,400 & 77826 & 176,226 & 228,400 & 306,226 \\
\hline 1984 & 101,907 & 133912 & 235,819 & 231,907 & 365,819 \\
\hline 1985 & 231,848 & 77780 & 309,628 & 231,848 & 309,628 \\
\hline 1986 & 172,228 & 111958 & 284,186 & 172,228 & 284,186 \\
\hline 1987 & 205,036 & 97269 & 302,305 & 205,036 & 302,305 \\
\hline 1988 & 167,137 & 126116 & 293,253 & 167,137 & 293,253 \\
\hline 1989 & 190,195 & 149089 & 339,284 & 190,195 & 339,284 \\
\hline 1990 & 227,502 & 120901 & 348,403 & 227,502 & 348,403 \\
\hline 1991 & 211,509 & 56879 & 268,388 & 211,509 & 268,388 \\
\hline 1992 & 152,617 & 0 & 152,617 & 152,617 & 152,617 \\
\hline 1993 & 107,800 & 14300 & 122,100 & 107,800 & 122,100 \\
\hline 1994 & 126,118 & 8780 & 134,898 & 126,118 & 134,898 \\
\hline 1995 & 182,566 & 43699 & 226,265 & 182,566 & 226,265 \\
\hline 1996 & 121,147 & 68370 & 189,517 & 121,147 & 189,517 \\
\hline 1997 & 146,466 & 64510 & 210,976 & 146,466 & 210,976 \\
\hline 1998 & 157,182 & 66170 & 223,352 & 157,182 & 223,352 \\
\hline 1999 & 141,324 & 33650 & 174,974 & 141,324 & 174,974 \\
\hline 2000 & 142,954 & 3580 & 146,534 & 142,954 & 146,534 \\
\hline Total & $5,770,780$ & $2,980,197$ & $8,750,977$ & $7,690,780$ & $10,670,977$ \\
\hline $\begin{array}{l}\text { Annual } \\
\text { Average }\end{array}$ & 192,359 & 99,340 & 291,699 & 256,359 & 355,699 \\
\hline
\end{tabular}




\section{Appendix $\mathrm{H}$ Polygon Analysis Method and Results}

\begin{tabular}{|c|c|c|c|c|c|c|c|}
\hline \multicolumn{8}{|c|}{$\begin{array}{l}\text { Table H1 } \\
\text { Summary of Data Used in Polygon Analysis }\end{array}$} \\
\hline \multirow[b]{2}{*}{ Reach } & \multirow[b]{2}{*}{$\begin{array}{l}\text { Kondolf } \\
\text { Polygon \# }\end{array}$} & \multirow[b]{2}{*}{$\mathrm{XCs}$} & $\begin{array}{l}\text { Pac. } \\
\text { Aff. }\end{array}$ & Knuuti & \multirow{2}{*}{$\begin{array}{l}\text { Kondolf } \\
\text { Polygon Area } \\
\left(\mathrm{ft}^{2}\right)\end{array}$} & Pac. Aff. & Knuuti \\
\hline & & & \multicolumn{2}{|c|}{$\begin{array}{l}\text { Vertical Change } \\
\text { (ft) }\end{array}$} & & \multicolumn{2}{|c|}{ Volume Change $\left(\mathrm{yd}^{3}\right)$} \\
\hline \multirow{8}{*}{$\begin{array}{l}\text { Downstream of Hwy } \\
101 \text { Bridge }\end{array}$} & 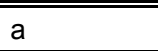 & "1,2 & 1.8 & 0.55 & $\begin{array}{l}1,100,000 \\
\end{array}$ & 73,333 & 22,407 \\
\hline & $\mathrm{b}$ & 2,3 & 1.1 & 1.1 & $1,000,000$ & 40,741 & 40,741 \\
\hline & c & 4,5 & 1.95 & 0.1 & 330,000 & 23,833 & 1,222 \\
\hline & $\mathrm{d}$ & 5,6 & 2.6 & -0.225 & $1,100,000$ & 105,926 & $-9,167$ \\
\hline & $\mathrm{e}$ & 6,7 & 1.75 & -0.875 & 780,000 & 50,556 & $-25,278$ \\
\hline & $\mathrm{f}$ & 7,8 & 2.15 & -1.5 & $1,200,000$ & 95,556 & $-66,667$ \\
\hline & $g$ & 8,9 & 2.75 & -0.85 & 350,000 & 35,648 & $-11,019$ \\
\hline & & & & & & 425,593 & $-47,759$ \\
\hline \multirow{5}{*}{$\begin{array}{l}\text { Hwy } 101 \text { Bridge to } \\
\text { Hwy } 299\end{array}$} & $\bar{~} 1$ & $11,12,13$ & 0 & 2.3 & $1,163,000$ & 0 & 999,070 \\
\hline & 2 & 12 & 10 & 2.3 & 328,515 & 121,672 & 27,985 \\
\hline & 3 & 13 & 4.6 & 4.6 & 730,000 & 124,370 & 124,370 \\
\hline & $0 X$ & 13 & 0 & 0 & 783,031 & 0 & 0 \\
\hline & 4 & 14,15 & 0 & 0 & $2,176,140$ & 0 & 0 \\
\hline \multirow{7}{*}{$\begin{array}{l}\text { Hwy } 299 \text { Bridge to } \\
\text { A\&MRR Bridge }\end{array}$} & 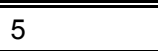 & $\begin{array}{l}16,17 \\
\end{array}$ & 0.2 & 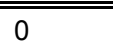 & 25257,720 & 101,909 & 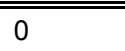 \\
\hline & 6 & 17 & 0.2 & 0 & 197,830 & 1,465 & 0 \\
\hline & $x-1$ & & 0 & 0 & 75,186 & 0 & 0 \\
\hline & 7 & 18 & 0.2 & 0 & 109,275 & 809 & 0 \\
\hline & 8 & 19 & -0.5 & -1.3 & 518,379 & $-9,600$ & $-24,959$ \\
\hline & 9 & 20 & -0.7 & -2.5 & 104,238 & $-2,702$ & $-9,652$ \\
\hline & 10 & 20,21 & -2.5 & -5.5 & 842,620 & $-78,020$ & $-171,645$ \\
\hline \multirow{6}{*}{$\begin{array}{l}\text { A\&MRR Bridge to } \\
\text { Blue Lake Bridge }\end{array}$} & 11 & 23 & -2.5 & -2.5 & 93,786 & $-8,684$ & $-8,684$ \\
\hline & 12 & 22,23 & -2.5 & -2.5 & 936,589 & $-86,721$ & $-86,721$ \\
\hline & 13 & 24 & 0 & 0 & $2,060,460$ & 0 & 0 \\
\hline & 14 & 24 & -4.5 & -7.5 & $1,765,550$ & $-294,258$ & $-490,431$ \\
\hline & 15 & 24 & -9 & -11 & 299,883 & $-99,961$ & $-122,175$ \\
\hline & 16 & 25 & -2 & -5 & $2,416,423$ & $-178,994$ & $-447,486$ \\
\hline & & & & & & & (Conti \\
\hline
\end{tabular}




\begin{tabular}{|c|c|c|c|c|c|c|c|}
\hline \multicolumn{8}{|c|}{ Table H1 (Concluded) } \\
\hline & $x-2$ & & 0 & 0 & 49,912 & 0 & 0 \\
\hline & 17 & 25 & -5 & -5.3 & $1,267,203$ & $-234,667$ & $-248,747$ \\
\hline & 18 & 26 & -9 & -8 & 720,568 & $-240,189$ & $-213,502$ \\
\hline & 19 & 25,26 & -4.5 & -4.5 & 328,568 & $-54,761$ & $-54,761$ \\
\hline & $x-3$ & & 0 & 0 & 290,658 & 0 & 0 \\
\hline & 20 & 26 & -4.5 & -12.1 & 321,410 & $-53,568$ & $-144,039$ \\
\hline & 21 & 26 & -5 & -5 & 530,521 & $-98,245$ & $-98,245$ \\
\hline & $x-4$ & & 0 & 0 & 530,532 & 0 & 0 \\
\hline & 22 & 27 & -1.5 & -5.25 & $1,672,518$ & $-92,918$ & $-325,212$ \\
\hline & 23 & 27 & 0 & 0 & 125,000 & 0 & 0 \\
\hline & 24 & 27,28 & -10 & -9.9 & $1,105,992$ & $-409,627$ & $-405,530$ \\
\hline & 25 & 27,28 & 0 & 0 & 252,500 & 0 & 0 \\
\hline & 26 & 28,29 & 0 & -2.5 & 635,512 & 0 & $-58,844$ \\
\hline \multirow{3}{*}{$\begin{array}{l}\text { Upstream from Blue } \\
\text { Lake Bridge }\end{array}$} & 27 & 30 & -8.5 & -8.5 & $1,000,000$ & $-314,815$ & $-314,815$ \\
\hline & 28 & 30 & 3.5 & 3.5 & $1,820,000$ & 235,926 & 235,926 \\
\hline & & & & & & $-1,771,579$ & $-2,738,095$ \\
\hline
\end{tabular}




\section{Appendix I NMFS - Partial List of Basic Biological Concerns ${ }^{1}$}

\section{Partial List of (Anadromous Salmonid) Habitat Attributes as They Pertain to Main Stem River Reaches Subject to Gravel Mining}

- Maintenance or restoration of pool habitat with sufficient depth to provide rearing and holding areas. Concern is that continued mining within a reach promotes lateral channel migration and decreased pool frequency and quality (increased w/d). Pool quality here is defined as depth, cover, velocity, thermal stratification, and substrate composition.

- Maintenance or restoration of in-stream and near-stream vegetation and organic debris to provide cover. Concern is that mining directly removes vegetation and increased lateral channel migration "removes" low-flow channel contact with terrace edges. These edges are where complex habitats are most likely to exist.

- Maintenance or restoration of course textured riffles to provide food, turbulent water cover and rearing habitat (particularly for juvenile steelhead).

- Maintenance or restoration of bed stability to protect redds (concern is that mined reaches may possess relatively finer textured bed and be more mobile during lesser peak flows versus unmined reaches).

- Avoidance of fine sediment pulses from mined surfaces that inundate redds.

- Maintenance and restoration of channel geomorphic complexity that provides high-water refuge: alcoves, bar-roughness features, live vegetation and organic debris.

- Migration/stranding on skimmed bars - improperly shaped skimmings may lure fish onto these surfaces and strand them as flows recede.

- Food/substrate relationship and the potential impacts of chronic fining due to mining activities.

\footnotetext{
${ }^{1}$ Draft list of initial concerns, prepared February 12, 2001.
} 


\section{Appendix $\mathbf{J}$ Response to Comments}

Due to the concerns of various interested parties, a draft copy of this report was sent to several individuals and groups for comment in April 2003. Those individuals and groups included the San Francisco District for the Corps of Engineers, the National Marine Fisheries Service in Arcata, CHERT (Randy Klein and Professor Andre Lehre), the gravel operators (Paul Kraus), and the gravel operators' consultant (Professor Matt Kondolf). We received formal, written comments back from NMFS (Brian Cluer) and the gravel operators (Paul Kraus and Bill Davis, Esq.) and informal comments from others. We also received verbal comments on the draft report at a public meeting held in Arcata, California on Wednesday, July 23, 2003.

With the exception of a few questions from the gravel operators (Paul Kraus), all comments have been answered with modifications to the text in the body of this report. We felt the following questions from the gravel operators would be more clearly answered individually in this appendix.

Question (Kraus): The annual average extraction volume removed downstream of the Highway 299 Bridge during the 1971-2000 study period is calculated as 99,349 cubic yards (Table 4, Appendix G). This volume is equal to the entire sediment budget for the upstream study area stated in Section 6.0. Bed elevation change within the reach downstream of the Highway 299 Bridge was negligible during the period of assessment. In fact, sediment storage for the reach between the Highway 101 and 299 Bridge crossings is shown as a positive value (Table 6, Page 36). There is no bankloss contribution within this reach and no secondary sources of sediment input. Why were these conditions not evaluated in the Assessment with respect to condition of the Lower Mad River? The lack of degradation within the reach between Highway 101 and Highway 299 is not consistent with the trend shown upstream and places into question your calculation of average annual sustainable gravel yield and study reach output volume.

Utilizing the reported volumes in Appendix G, average annual extraction volume downstream of the Highway 299 Bridge appears equal to the entire sediment budget for the Lower Mad River listed in Section 6.0, or roughly 100,000 cubic yards. However, during the period from 1971-2000, 7,690,371 cubic yards of aggregate was extracted from the study reach upstream of the Highway 299 Bridge. Subtracting the volumetric polygon analysis figure of 
2,989,520 cubic yards for degradation (Table 6, Page 36) during the 1971-2000 period leaves a balance of 4,700,850 cubic yards that could have been extracted while maintaining channel equilibrium. Dividing this balance by the 30 -year study period provides an annual average volume of 156,700 cubic yards. Adding the 156,700 cubic yards from the study area to the 100,000 cubic yards downstream of the Highway 299 Bridge produces a total extraction volume for the Lower Mad River of approx. 257,000 cubic yards, while maintaining channel equilibrium. This volume is in relative agreement with the 2001 Kondolf Assessment. Is this simplistic approach to a sediment budget calculation not valid?

Using the same calculation, but utilizing the end area degradation value of 3,981,389 cubic yards (Table 4, Page 23), produces a balance of 123,630 cubic yards per year for the study area. When added to the 100,000 cubic yards of annual extraction downstream of the Highway 299 Bridge, yields an annual extraction volume for the Lower Mad River of 223,630 cubic yards.

We know the volume of aggregate extracted $( \pm)$ for the period of 1971 to 2000. We know the volume of degradation $( \pm$ ) for the period of 1971-2000. Therefore, the balance $( \pm)$ can be assumed to be extracted from the river without causing degradation.

The average annual sustainable yield estimate provided in the Assessment suggests that all extraction upstream of Highway 299, or nearly 8,000,000 cubic yards should not have been removed. If this were the case and only 50 percent of this material remained in storage $(4,000,000$ cubic yards) in the reach above Highway 299, the entire active channel area of 23,804,333 square feet (Lehre. 1993 PEIR, Appendix F, Section 3, Page 22) would have aggraded 4.5 feet, if this volume was spread evenly across the area.

Response: While Table 6 shows a positive value for sediment storage between the Hwy 101 and 299 bridges, the text in the report explains why that reach was assumed to have no significant change from 1971-2000. In summary, we were not comfortable with the locations of all the cross sections in this area and thus did not feel the data supported a statement saying the river in this area had aggraded, degraded or widened. Additionally, we had no data to calculate how much sediment had passed through this reach at the location of the Hwy 101 Bridge, or had been stored within the reach, and could thus not reach conclusions in this area. Degradation in the river upstream of the Hwy 299 Bridge (significant degradation becomes readily apparent beginning approximately 1,200 meters upstream from the bridge) is not inconsistent with a possible lack of degradation between the Hwy 101 and 299 bridges. This is explained in Section 3.3.3 but may be more easily understood when one considers that the channel slope in this lower reach is less than that above the Hwy 299 Bridge. The fact that the river bed elevation near the Hwy 101 bridge is near the MHHW tidal datum, and that this lower portion of the river is tidally influenced, provides additional rationale for expecting less (or no) bed degradation in this area since 1971.

Due to the uncertainty associated with the annual gravel extraction volumes and the cross section analysis (using either the average-end-area method or the polygon method) we did not feel it was appropriate to calculate a sediment 
budget using only this data and these methods. We felt it was better to calculate sediment transport via other means, as described in this report, and to use the extraction volumes and cross section data to check or verify those calculations.

We added Sections 3.7.1, 3.7.2, and 3.7.3 to the report to explain the effects of three regions of the river (mouth to Hwy 101 bridge, between Hwy 101 and 299 bridges, and Hwy 299 bridge to fish hatchery) on the overall sediment budget for the lower Mad River. Without knowing how much bed load or bed material load passes the Hwy 101 Bridge, it is not possible to accurately determine the sediment storage within the reach between the Hwy 101 and 299 bridges.

The interpretation that "the average annual sustainable yield estimate . . . suggests that all extraction upstream of Highway 299 . . . should not have been removed" is incorrect. Table 7 clearly shows the sustainable yield for this area to be between 101,000 tons/year and 157,000 tons/year (73,000 - 114,000 cy/year).

Question (Kraus): In Table 7 on Page 39, a tons-per-year value for beddegradation and bank loss is provided. What portion of the bank loss volume is considered as wash load? Table 7 contains nine columns of volume calculations. The first five columns of data are bedload sediment related figures. Column six, Volume of Bed Degradation and Bank Erosion contain a washload component in the bank erosion value. Would the consideration of a washload component affect the values in columns 7-9? I am not sure how this might affect the values, but is a thought that occurred during review.

CHERT 1997, estimated that gravel contribution to the Mad River from bank erosion was only about 50 percent of the gross bank erosion due to sand and silt that would become washload.

Response: We did not calculate what percentage of the combined bed degradation and bank loss is due to bank loss, but it is likely to be fairly small due to the fact that we focused our examination of bank loss on the area close to the ordinary high water line. Bank material in this area appeared to be mostly sandy gravel, similar to what is present in nearby bed material, but this was based only on visual examination and not on a sieve analysis.

Question (Kraus): In numerous instances, the 1971 cross sections are adjusted to fit the 2000 cross sections, en lieu of recovering monuments on the cross section lines during the 2000 surveys. These corrections were made assuming errors in the 1971 surveys. Some of these adjustments were significant and all adjustments made to lines upstream of cross section 18 would cause increase in the calculation of degradation within the study reach. Can these adjustments be substantiated? In assessing the polygon analysis volume, the vertical adjustments to the historic survey are the fundamental difference between Professor Kondolf's analysis and your assessment (see attached EXCEL spreadsheet).

As an example, at cross section 29, located along the downstream side of the Hatchery Road Bridge, the 1971 cross section was adjusted vertically1.9 feet. This vertical adjustment increases the elevation of the 1971 cross section in 
relation to the 2000 cross section and results in a perception of degradation at this location. When the 1999 surveys were conducted, the 1955 and 1982-' 83 bridge plans were obtained from the County of Humboldt Engineering Department. Upon comparison of the historic plans, and through discussion with Engineering Department staff, it was found that when the bridge was reconstructed in the mid1980 's, both the bridge approaches and surrounding levee areas were recontoured (built-up) and repaved. This was noted on our cross section plots. Since there were no remaining monuments at the bridge location from the 1971 survey, or anywhere else on cross section 29 , and that the topography surrounding the bridge had obviously changed, there was no justifiable reason to move the cross section, or determine the 1971 cross section to be in error.

Vertical adjustment of the cross sections obviously affects the outcome of the end area and polygon calculations. If all adjustments made to the 1971 cross sections result in an increase in the 1971 cross section elevations, as is the case for cross sections 19-30, a significant difference in the outcome of the end area and polygon analysis results. This needs to be stated in the document.

The 2000 R.B. Davis surveys suggest that the 1971 endpoints and cross sections were in error by as much as 1.9 feet, with no pattern to the vertical adjustment. If this was the degree of accuracy of the 1971 surveys, how can one assume that any other point on the cross section lines were surveyed to a greater tolerance than the endpoints or found monuments? Are the remaining points on the cross section more or less accurate than the endpoints? These factors should be considered prior to adjusting the 1971 surveys.

Response: This question was received from Paul Kraus, on behalf of the gravel operators, in a letter dated May 13, 2003. A July 18, 2003 e-mail from Bill Davis, Esq., on behalf of the gravel operators, stated that the gravel operators no longer consider this a concern. Despite that, we made changes to the body of the report to clarify issues associated with the cross section surveys. We stand by the adjustments made to the 1971 USACE cross sections by R.B. Davis, Inc. and ourselves.

Question (Kraus): In Section 3.8 it is noted that a remarkable similarity exists between the Blue Lake bedload rating curve value and the Browlie equation. However, in Section 4.2.5 it is stated that of the rating curves, the Blue Lake curve is "quite suspect." With these conflicting statements presented, what is the utility of the comparison made in Section 3.8? These statements cause internal and ultimately external conflict, as some readers will only see the words "remarkable similarity" and others will only see the words "quite suspect."

Response: We do not feel these two statements are in conflict with one another. However, we modified the wording in these two sections to decrease the potential for confusion. 


\section{REPORT DOCUMENTATION PAGE}

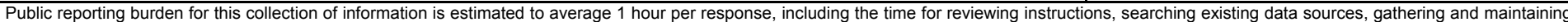

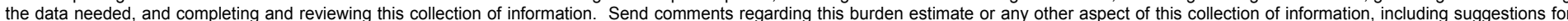

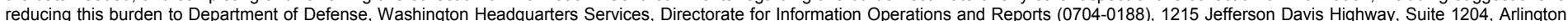

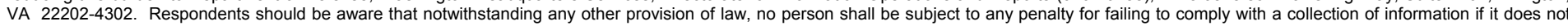
display a currently valid OMB control number. PLEASE DO NOT RETURN YOUR FORM TO THE ABOVE ADDRESS.

\begin{tabular}{l|c}
$\begin{array}{l}\text { 1. REPORT DATE (DD-MM-YYYY) } \\
\text { September } 2003\end{array}$ & $\begin{array}{c}\text { 2. REPORT TYPE } \\
\text { Final report }\end{array}$ \\
\hline
\end{tabular}

\section{TITLE AND SUBTITLE}

Assessment of Changes in Channel Morphology and Bed Elevation in Mad River,

California, 1971-2000

3. DATES COVERED (From - To)

5a. CONTRACT NUMBER

5b. GRANT NUMBER

5c. PROGRAM ELEMENT NUMBER

\section{AUTHOR(S)}

5d. PROJECT NUMBER

Kevin Knuuti, Dinah McComas

5e. TASK NUMBER

5f. WORK UNIT NUMBER

\section{PERFORMING ORGANIZATION NAME(S) AND ADDRESS(ES)}

8. PERFORMING ORGANIZATION REPORT NUMBER

U.S. Army Engineer Research and Development Center

Coastal and Hydraulics Laboratory

ERDC/CHL TR-03-16

3909 Halls Ferry Road

Vicksburg, MS 39180-6199

\section{SPONSORING / MONITORING AGENCY NAME(S) AND ADDRESS(ES)}

10. SPONSOR/MONITOR'S ACRONYM(S)

U.S. Army Engineer District, San Francisco

333 Market Street

San Francisco, CA 94105

11. SPONSOR/MONITOR'S REPORT NUMBER(S)

\section{DISTRIBUTION / AVAILABILITY STATEMENT}

Approved for public release; distribution is unlimited.

\section{SUPPLEMENTARY NOTES}

\section{ABSTRACT}

The U.S. Army Corps of Engineers currently regulates gravel-mining activities in Humboldt County, CA, under the authority described in Sec. 404 of the Clean Water Act. In order to better understand the effects gravel mining has had on the Mad River, the U.S. Army Engineer District, San Francisco, initiated this study to examine changes in channel morphology and bed elevation between 1971 and 2000 .

This study focused on existing cross section data and historic aerial photography from a variety of sources, and river sediment (bed-load and bed-material) data collected by the USGS. It also used new cross-section data collected in 2000 and gravel extraction records. This information was used to quantify geomorphic changes in the river, to establish a sediment budget, and to determine a sustainable yield for gravel extraction based on maintaining the river in an equilibrium condition.

\begin{tabular}{|c|c|c|c|c|c|}
\hline $\begin{array}{l}\text { 15. SUBJECT TERMS } \\
\text { Fluvial } \\
\text { Geomorphology }\end{array}$ & \multicolumn{2}{|c|}{$\begin{array}{l}\text { Gravel-bed } \\
\text { Gravel mining } \\
\text { Humboldt County }\end{array}$} & \multicolumn{2}{|c|}{$\begin{array}{l}\text { Mad River } \\
\text { River } \\
\text { Sediment budget }\end{array}$} & $\begin{array}{l}\text { Sediment transport } \\
\text { Stable channel }\end{array}$ \\
\hline \multicolumn{3}{|c|}{ 16. SECURITY CLASSIFICATION OF: } & $\begin{array}{l}\text { 17. LIMITATION } \\
\text { OF ABSTRACT }\end{array}$ & $\begin{array}{l}\text { 18. NUMBER } \\
\text { OF PAGES }\end{array}$ & $\begin{array}{l}\text { 19a. NAME OF RESPONSIBLE } \\
\text { PERSON }\end{array}$ \\
\hline $\begin{array}{l}\text { a. REPORT } \\
\text { UNCLASSIFIED }\end{array}$ & $\begin{array}{l}\text { b. ABSTRACT } \\
\text { UNCLASSIFIED }\end{array}$ & $\begin{array}{l}\text { c. THIS PAGE } \\
\text { UNCLASSIFIED }\end{array}$ & & 164 & $\begin{array}{l}\text { 19b. TELEPHONE NUMBER (include } \\
\text { area code) }\end{array}$ \\
\hline
\end{tabular}

